\title{
Uganda: Poverty Reduction Strategy Paper
}

Poverty Reduction Strategy Papers (PRSPs) are prepared by member countries in broad consultation with stakeholders and development partners, including the staffs of the World Bank and the IMF. Updated every three years with annual progress reports, they describe the country's macroeconomic, structural, and social policies in support of growth and poverty reduction, as well as associated external financing needs and major sources of financing. This country document for Uganda, dated May, 2005, is being made available on the IMF website by agreement with the member country as a service to users of the IMF website.

To assist the IMF in evaluating the publication policy, reader comments are invited and may be sent by e-mail to publicationpolicy@imf.org.

Copies of this report are available to the public from

International Monetary Fund • Publication Services

$70019^{\text {th }}$ Street, N.W. • Washington, D.C. 20431

Telephone: (202) 623-7430 • Telefax: (202) 623-7201

E-mail: publications@imf.org • Internet: http://www.imf.org

Price: $\$ 15.00$ a copy

International Monetary Fund

Washington, D.C. 



\section{Poverty Eradication Action Plan (2004/5-2007/8)}

Ministry of Finance, Planning and Economic Development P.O. Box 8147

Kampala

Website: www.finance.go.ug 
Ministry of Finance, Planning and Economic Development P.O. Box 8147

Kampala

Website: www.finance.go.ug

(C) 2004 


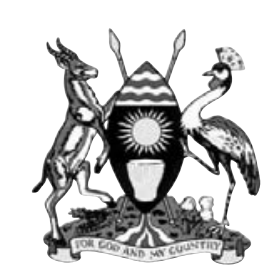

THE REPUBLIC OF UGANDA

\section{FOREWORD}

Over the last 19 years, Government has implemented policies geared towards eradicating poverty among our people. These policies have led to a substantial reduction in poverty levels from $56 \%$ in 1992 to $38 \%$ in 2003. More needs to be done to ensure that all Ugandans move and stay out of poverty. In 1997 the Poverty Eradication Action Plan (PEAP), a framework for addressing the key poverty challenges, was developed and launched. During the process of implementation, new challenges arose which led to the first revision of the PEAP in 2000.

In the current revision, Government has taken stock of the achievements so far attained and the remaining challenges. The challenges include the following: (a) to consolidate national security, deal with the consequences of con ict, and improve regional equity; (b)to restore sustainable growth in the incomes of the poor; (c) to build strong social and economic infrastructure; (d) to enhance human development; and (e) to use public resources more efficiently. Over the next three years, Government will focus its attention on addressing these challenges.

In addition, government will concentrate on areas that will have a major impact on Uganda's economic transformation. For example, Uganda needs to expand agricultural output through increasing farm productivity and household incomes. Government also needs to strengthen the export sector to be able to access international markets.

I am pleased to note that the PEAP has become an important vehicle for policy coherence. This has been manifested through the wide consultative process that has involved many stakeholders including, development partners and civil society.

I wish to express my appreciation to all those who worked tirelessly to produce this document.

Finally, I urge all the citizens of Uganda and development practitioners to use this policy document in steering our efforts to eradicate poverty.

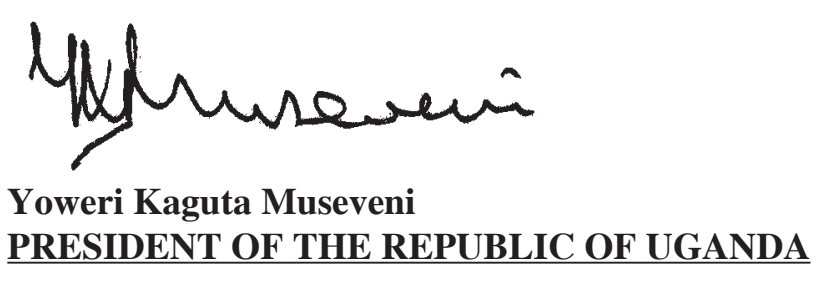




\section{Contents}

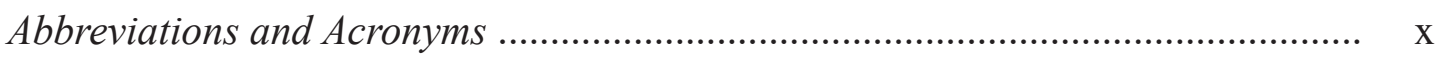

Executive Summary $\quad$...................................................................................... $\mathrm{xv}$

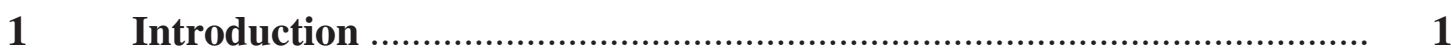

1.1 The Poverty Eradication Action Plan ............................................... 1

$1.2 \quad$ Government's strategy for poverty eradication .............................. 2

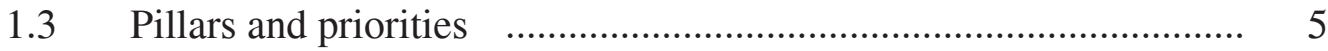

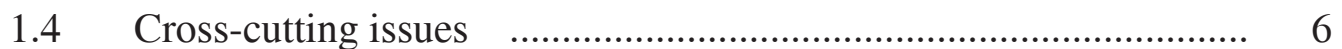

1.5 Roles of the state, the private sector and other partners .................. 8

1.6 The PEAP and international initiatives ...................................... 10

$1.7 \quad$ Structure of the PEAP …............................................................. 10

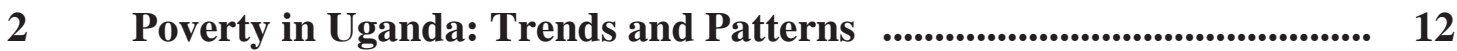

$2.1 \quad$ Income, poverty and inequality .............................................. 12

$2.2 \quad$ Who are the poor? ..................................................................... 18

2.3 Structural transformation and poverty reduction ........................... 21

2.4 Human development outcomes ................................................. 26

2.5 Access to public services and infrastructure …............................ 28

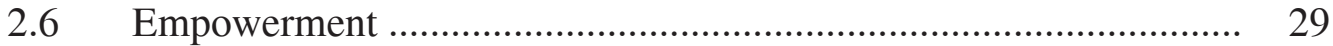

$2.7 \quad$ Policy implications ............................................................ 30

$3 \quad$ Economic Management ........................................................................................ 31

3.1 Uganda's growth performance …............................................. 31

3.2 Macroeconomic Management ..................................................... 34

3.3 Tax Policy ........................................................................... 43

3.4 Financial Sector …................................................................ 45

3.5 Investment \& Trade Policy ...................................................... 47

$4 \quad$ Enhancing production, competitiveness and incomes ............................ 51

4.1 Government's strategy for increasing production, competitiveness and incomes ...................................................... 51

4.2 Boosting production, incomes and competitiveness .................... 53 
4.3 Public expenditure priorities for production, competitiveness and incomes .................................................................... 92

$5 \quad$ Security, Con ict Resolution and Disaster Management ........................ 99

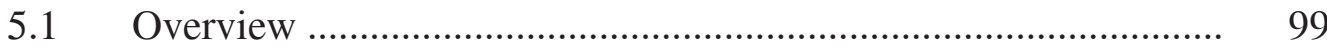

5.2 Security and Defence ............................................................. 99

5.3 Con ict-resolution ................................................................ 102

5.4 Disaster Preparedness and Management ....................................... 105

5.5 Planning for the aftermath of disaster and insecurity ................... 111

5.6 Public expenditure implications for security, con ict-resolution and defence …............................................................... 114

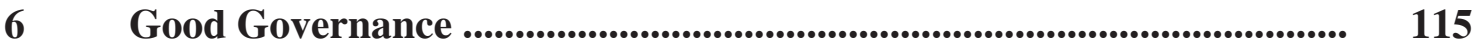

6.1 Democracy, Human Rights and Political governance ................... 115

6.2 Justice, Law and Order ............................................................ 121

6.3 Managing the public sector ....................................................... 127

6.4 Public expenditure priorities for governance ............................... 143

$7 \quad$ Human Development .............................................................................. 147

7.1 Introduction ......................................................................... 147

7.2 Education and Skills Development .............................................. 153

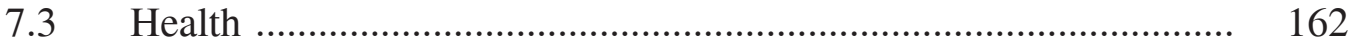

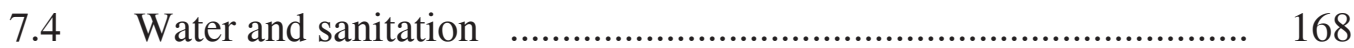

7.5 Social Development Sector ...................................................... 173

7.6 Public expenditure priorities for human development .................. 180

$8 \quad$ Public expenditure to implement the PEAP ......................................... 185

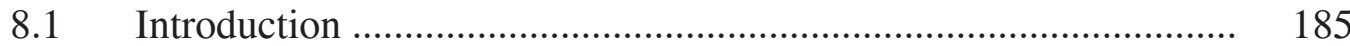

8.2 Public expenditure and poverty eradication spending:

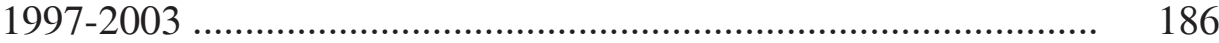

8.3 Criteria for public expenditure allocation ...................................... 190

8.4 Funding PEAP expenditure priorities ......................................... 192

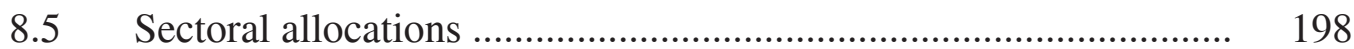

8.6 Strengthening Budgeting at the Sector Level ............................... 201

8.7 Rationalising public sector structures ......................................... 206 
8.8 Donor support for public expenditure ....................................... 211

8.9 Conclusion ................................................................... 212

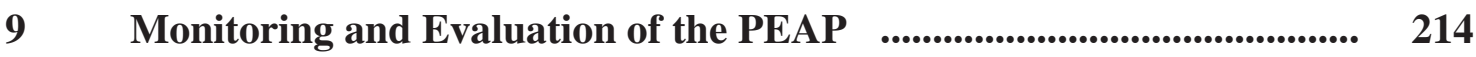

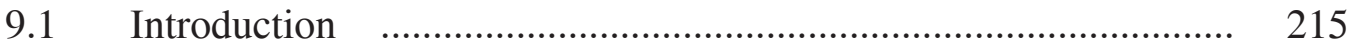

9.2 Challenges for monitoring and evaluation ................................. 216

9.3 Government's strategy for addressing the current weaknesses in the M\&E Framework ............................................................... 217

9.4 Prospects for the Millennium Development Goals ....................... 222

PEAP Results and Policy Matrix ................................................................... 224

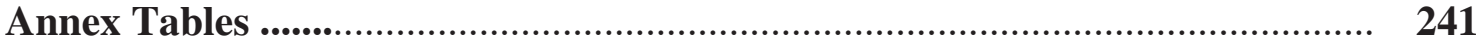

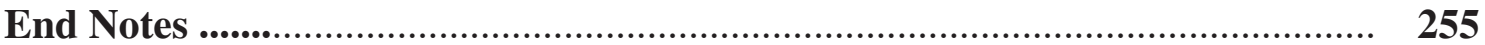




\section{List of Tables}

Table 2.1: Proportion of people below the poverty line, $\%$................................... 13

Table 2.2: Proportion of people below the poverty line by occupational group, \% .. 13

Table 2.3: Poverty headcount for male and female-headed households .................. 19

Table 2.4: Main activities of household head and poverty status ........................... 22

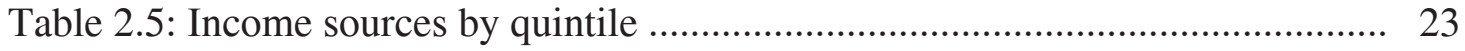

Table 2.6: Visible underemployment, $\%$ of labour force ....................................... 24

Table 2.7: Trend in Literacy Rates for the Population Aged 10 Years and above

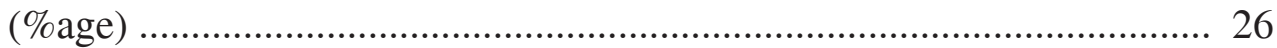

Table 3.1: Key LTEF Indicators ................................................................... 36

Table 5.1: Impact of rebel activities on northern populations during 2001

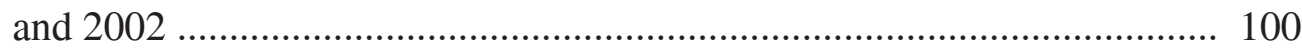

Table 5.2: Total number of IDPs by district by $10^{\text {th }}$ October 2003 ......................... 106

Table 6.1: Selected key democratisation events in Uganda ................................... 116

Table 6.6: Public service employees by category ................................................ 139

Table 7.1: Key indicators of access and quality in primary education ..................... 155

Table 7.2: Percentage of pupils achieving the required minimum proficiency .......... 156

Table 7.3: Trends in Enrolment in Secondary Schools in Uganda ........................... 158

Table 7 4: Health sector PEAP performance indicators ........................................... 165

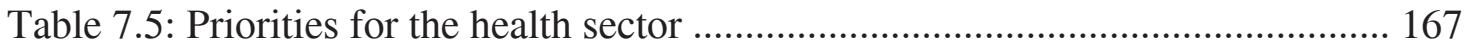

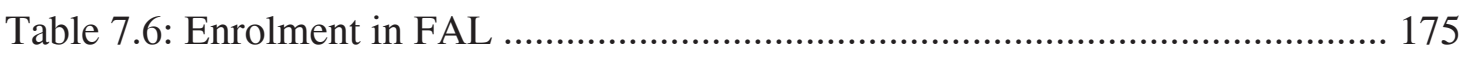

Table 7.7: Water supply: resource needs and LTEF projections ............................. 183

Table 8.1: Public expenditure in Uganda .......................................................... 186

Table 8.2: Supplementaries by sector, 2002/03 ..................................................... 189

Table 8.3: Provisional Sector Shares, 2003/04 and 2013/14: Shs billions ............... 199

Table 8.4 Human resource expenditures in the development budget of core ministries ( 2003/4) .................................................................... 209

Table 8.5: The wage bill in 2003/4 _.................................................................. 210

Table A 2.1: Average assets owned by households: dollar value .......................... 240

Table A 2.2: Open unemployment, $\%$ of labour force ...................................... 240 
Table A 2.3: Proportion of households with access to services at a community level

Table A 2.4: Community projects implemented in last three years, and whether they met the needs of the community in households' opinions

Table A 4.1: The business environment in Uganda ............................................ 243

Table A 4.2: Delays in procedures and constraints to business .......................... 244

Table A 4.5: Forms of land con icts in registered and unregistered land ........... 245

Table A 4.6: Household perceptions of benefits of systematic demarcation

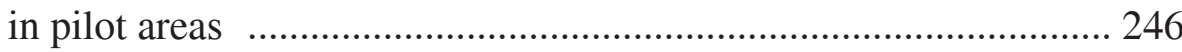

Table A 4.7: Improvement in the condition of roads 1988-2003 ..................... 247

Table A 5.1: Major disasters in Uganda and their impact during 1966-2003 ....... 247

Table A 6.1: Death rates in prisons ................................................................... 248

Table A 6.2: Transparency International Corruption Perception Index for Uganda 1998-2003 …............................................................ 250

Table A 6.3: Reported Percentage Levels of Bribery in Selected Institutions ..... 250

Table A 6.4: Institutional respondents' ranking of integrity of various institutions

Table A 6.5: Investigations carried out by the IG from the years 2001 and 2002

Table A 7.1: Enrolment numbers by grade level, 1998-2002

Table A 7.2: Enrolment in public sector BTVET institutions 1999/2000 2003/2004

Table A 7.3: Summary of PEAP Matrix Macro Indicators 


\section{List of Figures}

Figure 2.1: Infant, Under-5, and Maternal Mortality ........................................ 27

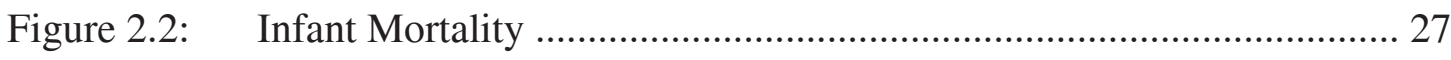

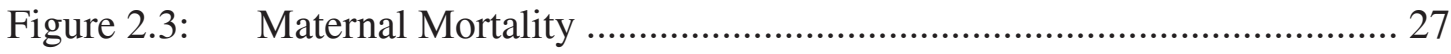

Figure 7.1: $\quad$ Percentage of rural people served with inproved water sources

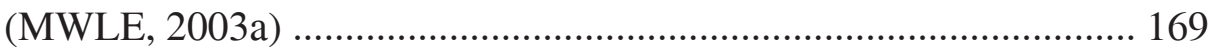

Figure 7.2: Percentage of urban people served with improved water sources...... 170

Diagram 9.1: The National Integrated Monitoring \& Evaluation Framework ........ 220

\section{List of Charts}

Chart 3.1: $\quad$ Real GDP Growth at Market Prices 1990/91 - 2002/03 .................. 31

Chart 3.2: $\quad$ Sectoral GDP growth rates 1990/91-2002/03 …............................. 32

Chart 3.3: $\quad$ Sectoral Shares of GDP 1990/91 - 2002/03 .................................. 32

Chart 3.4: Annual headline in ation 1990/91 - 2002/03 ............................... 35

Chart 3.5: Real private investment 1990/91 - 2002/03

(constant $1997 / 98$ prices) ........................................................... 35

Chart 3.6: Government expenditure, revenue and fiscal deficit, 1998/99-

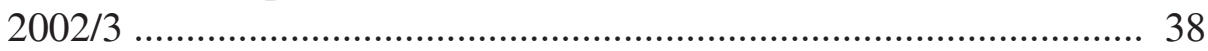

Chart 3.7: $\quad$ Bank loans to Private Sector and Government as a \% Deposits end June 1995- end June 2003 ........................................................ 40

Chart 3.8: $\quad$ Investment as a \% of GDP 1990/91 - 2002/03 ............................. 48

Chart A 4.1: The potential effect of global warming on coffee production in Uganda 


\section{Abbreviations and Acronyms}

\begin{tabular}{|c|c|}
\hline ABEK & Alternative Basic Education in Karamoja \\
\hline ADF & Allied Democratic Forces \\
\hline AGOA & African Growth and Opportunities Act of USA \\
\hline APRM & African Peer Review Mechanism \\
\hline ART & Anti Retroviral Therapies \\
\hline ARVs & Anti-retrovirals \\
\hline BEUPA & Basic Education for Urban Poor Areas \\
\hline BMU & Beach Management Units \\
\hline BOG & Board of Governors \\
\hline BOU & Bank of Uganda \\
\hline BTVET & Business Technical Vocational Educational and Training \\
\hline CAA & Civil Aviation Authority \\
\hline CADER & Centre for Arbitration and Dispute Resolution \\
\hline CAOs & Chief Administrative Officers \\
\hline CDM & Clean Development Mechanism \\
\hline CDWs & Community Development Workers \\
\hline CDWCG & Community Development Workers Conditional Grant \\
\hline CJRP & Commercial Justice Reform Programme \\
\hline COMESA & Common Market for Eastern and Southern Africa \\
\hline COPE & Complimentary Opportunities for Primary Education \\
\hline CPR & Contraceptive Prevalence Rate \\
\hline CRC & Constitutional Review Commission \\
\hline CSOs & Civil Society Organisations \\
\hline DANIDA & Danish International Development Agency \\
\hline DFID & Department for International Development \\
\hline DFS & District Forestry Service \\
\hline DPP & Director of Public Prosecutions \\
\hline DRC & Democratic Republic of Congo \\
\hline DRIS & District Resource Information System \\
\hline DWD & Department for Water Development \\
\hline DWSCCs & District Water and Sanitation Coordination Committees \\
\hline EAC & East African Community \\
\hline EACU & East African Customs Union \\
\hline EBA & Everything But Arms \\
\hline
\end{tabular}




\begin{tabular}{|c|c|}
\hline EMIS & Education Management Information Systems \\
\hline EMOC & Emergency Maternal and Obstetric Services \\
\hline ENR & Environment \& Natural Resource \\
\hline EPRC & Economic Policy Research Centre \\
\hline ERRP & Emergency Relief and Rehabilitation Programme \\
\hline ERT & Energy for Rural Transformation \\
\hline ESIP & Education Strategic Investment Plan \\
\hline ESSP2 & Second Education Sector Strategic Plan \\
\hline FAL & Functional Adult Literacy \\
\hline FDS & Fiscal Decentralization Strategy \\
\hline FIA & Financial Institutions Act \\
\hline FIAS & Foreign Investment Advisory Service \\
\hline FSSP & Fisheries Sector Strategic Plan \\
\hline $\mathbf{F Y}$ & Financial Year \\
\hline GDP & Gross Domestic Product \\
\hline GIS & Geographical Information Systems \\
\hline GOU & Government of Uganda \\
\hline GTZ & German Technical Corporation \\
\hline HIPC & Highly Indebted Poor Country \\
\hline HMIS & Health Management Information Systems \\
\hline HPPG & Harmonised Participatory Planning Guidelines \\
\hline HSSP & Health Sector Strategic Plan \\
\hline ICT & Information Communication \& Technology \\
\hline IDP & Internally Displaced Persons \\
\hline IFMS & Integrated Financial Management System \\
\hline IFPRI & International Food Policy Research Institute \\
\hline ILO & International Labour Organisation \\
\hline ITMs & Insecticide Treated Materials \\
\hline JLOS & Justice, Law and Order Sector \\
\hline LASPs & Legal Aid Service Providers \\
\hline $\mathbf{L C}$ & Local Council \\
\hline LG & Local Government \\
\hline LGDP & Local Government Development Programme \\
\hline LGFC & Local Government Finance Commission \\
\hline
\end{tabular}

$\begin{array}{ll}\text { LGFIAS } & \text { Local Government Financial Information Analysis System } \\ \text { LOGICS } & \text { Local Government Information and Communication System } \\ \text { LRA } & \text { Lord's Resistance Army }\end{array}$


LTEF Long Term Expenditure Framework

M\&E Monitoring and Evaluation

MAAIF Ministry of Agriculture, Animal Industry \& Fisheries

MAPS Marketing \& Agro-processing Strategy

MDGs Millennium Development Goals

MDI Micro Deposit Taking Institutions Act

MEMD Ministry of Energy \& Mineral Development

MFIs Micro Finance Institutions

MFPED Ministry of Finance, Planning \& Economic Development

MGLSD Ministry of Gender, Labour \& Social Development

MIS Management Information Systems

MJCA Ministry of Justice \& Constitutional Affairs

MoES Ministry of Education \& Sports

MOFA Ministry of Foreign Affairs

MoH Ministry of Health

MOLG Ministry of Local Government

MOU Memorandum of Understanding

MP Member of Parliament

MSMES Micro, Small \& Medium Scale Enterprises

MTCS Medium Term Competitiveness Strategy

MTEF Medium Term Expenditure Framework

MTTI Ministry of Tourism, Trade \& Industry

MWHC Ministry of Works, Housing \& Communications

MWLE Ministry of Water, Lands \& Environment

NAADS National Agricultural Advisory Services

NARO National Agricultural Research Organisation

NARS National Agricultural Research System

NBFIs Non Bank Financial Institutions

NCC National Coordination Committee

NEMA National Environment Management Authority

NEPAD New Partnership for Africa's Development

NFA National Forestry Authority

NFP National Fisheries Policy or National Forest Plan

NFP National Focal Point

NGO Non Governmental Organisation

NHP National Health Policy 


\begin{tabular}{|c|c|}
\hline NPV & Net Present Value \\
\hline NRC & National Resistance Council \\
\hline NRI & Natural Resource Institute \\
\hline NRM & National Resistance Movement \\
\hline NSCG & Non-Sectoral Conditional Grant \\
\hline NSDS & National Service Delivery Survey \\
\hline NSF & National Strategic Framework \\
\hline NSSF & National Social Security Fund \\
\hline NUMU & Northern Uganda Management Unit \\
\hline NURPII & Northern Uganda Reconstruction Programme (II) \\
\hline NUSAF & Northern Uganda Social Action Fund \\
\hline NWC & National Women's Council \\
\hline NWSC & National Water and Sewerage Corporation \\
\hline NYC & National Youth Council \\
\hline OAU & Organisation of African Unity \\
\hline OPD & Out Patient Department \\
\hline OPM & Office of the Prime Minister \\
\hline P.V.R.I.S & Photographic Voter and Identification System \\
\hline PA & Protected Areas \\
\hline PAF & Poverty Action Fund \\
\hline PAPSCA & Programme for the Alleviation of Poverty and Social Costs of Adjustment \\
\hline PEAP & Poverty Eradication Action Plan \\
\hline PMA & Plan for Modernisation of Agriculture \\
\hline PMES & Poverty Monitoring and Evaluation Strategy \\
\hline PPA & Participatory Poverty Assessment \\
\hline PPA2 & Second Participatory Poverty Assessment \\
\hline PPDA & Public Procurement and Disposal of Public Assets Authority \\
\hline PPP & Public Private Partnership \\
\hline PTA & Parent Teachers Associations \\
\hline PTCs & Primary Teacher Training Colleges \\
\hline PWDs & Persons With Disability \\
\hline RDCs & Resident District Commissioners \\
\hline RSDP & Road Sector Development Plan \\
\hline RUWASA & Rural Water \& Sanitation \\
\hline SDIP & Social Development Sector Strategic Plan \\
\hline SDS & Social Development Sector \\
\hline
\end{tabular}




\begin{tabular}{|c|c|}
\hline SEP & Strategic Exports Programme \\
\hline SRI & Social Returns on Investment \\
\hline STDs & Sexually Transmitted Diseases \\
\hline SWAP & Sector Wide Approach \\
\hline SWG & Sector Working Group \\
\hline TB & Treasury Bills \\
\hline TDMS & Teacher Development and Management System \\
\hline UBoS & Uganda Bureau of Statistics \\
\hline $\mathbf{U C C}$ & Uganda Communications Commission \\
\hline UCDA & Uganda Coffee Development Authority \\
\hline UDN & Uganda Debt Network \\
\hline UEB & Uganda Electricity Board \\
\hline UEGCL & Uganda Electricity Generation Company Limited \\
\hline UEPB & Uganda Export Promotion Board \\
\hline UHRC & Uganda Human Rights Commission \\
\hline UIA & Uganda Investment Authority \\
\hline UIRI & Uganda Industrial Research Institute \\
\hline UMHCP & Ugandan Minimum Health Care Package \\
\hline UNBS & Uganda National Bureau of Standards \\
\hline UNCDF & United Nations Capital Development Fund \\
\hline UNCST & Uganda National Council of Science \& Technology \\
\hline UNHCR & United Nations High Commission for Refugees \\
\hline UNICEF & United Nations International Children Education Fund \\
\hline UNRFII & Uganda National Rescue Front II \\
\hline UPE & Universal Primary Education \\
\hline UPPAP & Uganda Participatory Poverty Assessment Process \\
\hline URA & Uganda Revenue Authority \\
\hline UVQF & Uganda Vocational Qualifications Framework \\
\hline UWA & Uganda Wildlife Authority \\
\hline UWEC & Uganda Wildlife Education Centre \\
\hline VAT & Value Added Tax \\
\hline WES & Water Environment and Sanitation \\
\hline WFP & World Food Programme \\
\hline WRM & Water Resources Management \\
\hline WSS & Water and Sanitation Services \\
\hline WTO & World Trade Organisation \\
\hline
\end{tabular}




\section{Executive Summary}

\section{Introduction}

The PEAP provides an over-arching framework to guide public action to eradicate poverty. It has been prepared through a consultative process involving central and local Government, Parliament, Donors and Civil Society. In order to achieve middle-income status, Uganda needs to industrialise by enhancing its competitiveness. Industrialisation in Uganda will depend on using the resource base and hence on equipping farmers to understand the technical and quality requirements of commercial production. Government will therefore ensure the provision of public goods to support both agriculture and industry. In order to reverse the recent marked increase in inequality, Government will aim to increase the ability of the poorer households to participate in economic growth through self-employment inside and outside agriculture and wage employment.

Four core challenges for the PEAP are (a) the restoration of security, dealing with the consequences of con ict and improving regional equity (b) restoring sustainable growth in the incomes of the poor (c) human development (d) using public resources transparently and efficiently to eradicate poverty. The PEAP is grouped under five 'pillars': (1) Economic management, (2) Production, competitiveness and incomes (3) Security, con ict-resolution and disaster-management (4) Good governance and (5) Human development.

\section{Poverty in Uganda: trends and patterns}

During the 1990s, income poverty fell dramatically. However, since 2000, income poverty has risen, with the proportion of people below the poverty line rising from $34 \%$ in 2000 to $38 \%$ in 2003 . This has been accompanied by a marked increase in inequality, which has been rising since 1997. The Gini coefficient, which measures inequality, rose from 0.35 in $1997 / 8$ to 0.43 in 2003.

The reasons for the recent patterns include a slowdown in agricultural growth during the last three years, declines in farmers' prices re ecting world market conditions, insecurity, high population growth rate and morbidity related to HIV/AIDS. Regional and gender inequalities are wide, with the East suffering a marked decline in living standards in the last three years.

As Uganda's economy develops, the ways in which people earn incomes will change. Households are moving out of relying solely or mainly on crop farming into nonagricultural enterprises. Wage employment is expanding more slowly. It remains critical to increase agricultural incomes, because returns to activities other than agriculture will decline in rural areas unless agricultural incomes increase.

If Uganda achieves $6 \%$ annual growth in real GDP, inequality will be reduced to the levels observed in 2000 , and if population growth falls to $2.4 \%$, the poverty headcount is projected to fall to $18 \%$ in $2013 / 4$.

In regard to human development, recent years have seen major improvements in education and literacy. Child health outcomes, however, did not improve in the 1990s, and HIV/ AIDS remains the leading cause of death within the most productive age ranges of 15- 
49. Child nutrition, together with infant and maternal mortality indicators deteriorated between 1995 and 2000, and HIV/AIDS prevalence rates stagnated between 6\% and 7\%. Notably, even if prevalence continued to fall, morbidity is unlikely to drop for at least another 5 years. Co-ordinated multi-sectoral action is required to reverse these trends, and mitigate the impact of HIV/AIDS. The health reforms of the last few years have shown encouraging signs of improvements, but data is not yet available to confirm this.

Access to public services has improved, but the poor are less well served than other groups. Government therefore needs to target its services more effectively to ensure that they reach the poorest households.

\section{Pillar 1: Economic management}

Uganda has experienced strong economic growth averaging 6.5\% per annum since 1991/ 92. At the same time, the structure of the economy has been changing, as the share of agriculture fell from $51 \%$ in $1991 / 2$ to $39 \%$ in 2002/3. Government aims to boost growth from $6.5 \%$ to $7 \%$ over the medium term by the following measures:

- $\quad$ Removal of bureaucratic barriers to investment

- Improvement in transport infrastructure and utility services

- Modernisation/commercialisation of agriculture, with emphasis on valueaddition

- $\quad$ Actions to improve rural access to finance and to strengthen SME development.

- Actions to enhance environmental sustainability

- $\quad$ Security in Northern Uganda

- $\quad$ Continued focus on HIV prevalence reduction and impact mitigation

Per capita growth will depend on population growth. Per capita growth will be accelerated if Uganda enters the demographic transition by achieving smaller family sizes.

The objectives of macroeconomic management are in ation control and private sector-led growth. During the last decade, Government has brought in ation under control, and real private investment has risen by three times between 1991/2 to 2002/3, and as a share of GDP from $9 \%$ to $15 \%$. However, the public sector deficit has risen from $6 \%$ in $1997 / 8$ to over $12 \%$ in 2001/2. This has appreciated the exchange rate and led to a major expansion of net issuance of securities by Government, pushing interest rates up.

Government therefore intends to reduce the deficit to $6.5 \%$ of GDP by 2009/10 and keep its share constant thereafter. This target is compatible with a rise in private sector investment to $21 \%$ of GDP and in exports from 12.6 to $16.1 \%$ of GDP by 2013/4. In ation is to be kept to $5 \%$ by controlling monetary growth.

Government's strategy of deficit reduction is motivated by a number of macroeconomic considerations: 
- The cost and volume of private sector borrowing. The deficit has increased the cost of private sector borrowing, which peaked at 34\% in 2001, and reduced the resources Commercial Banks have available for private sector lending.

- Domestic interest costs. The deficit is causing high domestic interest costs, which have increased by a factor of ten in six years and now account for $8 \%$ of expenditure.

- Upward pressures on the exchange rate. The deficit tends to cause real exchange rate appreciation. Sales of foreign exchange have increased tenfold during the period 1998/99 to $2002 / 3$. These sales have tended to appreciate the real exchange rate and have partially offset the terms of trade shock, reducing shilling earnings for exporters.

- Budget security. Domestic revenues were funding $79 \%$ of GOU expenditures in $1997 / 8$, but this fell to $60 \%$ in $2001 / 2$. This increases the exposure of Government to unexpected cuts in aid.

- External debt sustainability: The ratio of NPV to exports has risen to 305\% compared to the level achieved at the time of the HIPC debt relief of $150 \%$.

- Domestic debt sustainability: The domestic debt was 1\% of GDP in late 1990s but is $10 \%$ now. $95 \%$ of securities have maturity of 1 year or less.

- Political economy, excessive reliance on donor funds reduces domestic accountability.

In view of these macroeconomic consequences of an excessive deficit, Government will from now on focus on enhancing the quality rather than the quantity of public expenditure, so that the deficit reduces gradually over time. At the same time, it will work with its development partners to improve the modalities of external support, placing particular emphasis on budget support grants.

The share of revenue in GDP in Uganda is relatively low, at 12.1\% 2002/3. Revenue generation is hampered by the large size of informal sector, the unreliability of data, and unequal income distribution. URA is being reformed to improve its effectiveness. Hard choices are needed on how to increase revenue, especially in view of the negative effects of the Customs Union on revenue. Excise duty and VAT increases will be needed during the PEAP period, in order to finance the priority public expenditures needed to reduce poverty.

Financial sector development will need to focus on commercial banks, as there is a limited sector of Non-Bank Financial Institutions. So the priority is to reduce commercial bank holdings of Government securities, which were larger than their loans to the private sector by mid-2003, in order to free up funds for private sector lending. Financial deepening will be pursued by the expected increase in the savings rate (re ecting rising incomes) and mobilisation of deposits. Government will also establish a credit reference bureau, and promote microfinance institutions, now that their legal status has been defined. The pensions sector will be reformed; this will help private investment, because the NSSF has invested mainly in property and Government securities, rather than acting as a source of long-term finance.

Investment and trade are being promoted by the environment of macroeconomic stability and liberal trade policy. Because exports are only profitable if they re ect comparative or competitive advantage, Government allows international trade to re ect market signals. 
Hence Uganda does not tax exports and the exchange rate is market determined (though it suffers some upwards pressure from the deficit); Government will continue to avoid domestic protection and firm-specific interventions. The diversification of exports will be pursued by negotiating trade barrier reductions (including tariff and non-tariff barriers).

\section{Pillar 2: Enhancing production, competitiveness and incomes}

In order to restore growth in rural incomes, agriculture remains a critical sector, because it continues to provide the majority of employment, because low agricultural incomes form a constraint on the expansion of non-agricultural rural production, and because agriculture is responsive to public goods such as research, extension and support to marketing. To address the recent increases in inequality, Government's strategy will focus on agriculture, promote better security in the North, and take actions to empower women and strengthen women's land rights, and promote the involvement of men in HIV prevention and care. To promote competitiveness, Government will aim at increasing the ability of firms to innovate and adapt to new technologies, thus increasing the ability of the private sector to profitably increase market share.

Actions to promote production, competitiveness and incomes are guided by the policy frameworks of PMA, MTCS and SEP.

\section{Agriculture}

There is evidence of high returns to expenditure on research and extension. Agricultural research will be promoted through a demand-led system under NARS, to be guided by the National Agricultural Research Bill. Advisory services will be publicly funded, but provided by private contractors contracted by farmers groups. Major challenges include rolling out NAADS within available resources, and ensuring that enterprise selection is guided by good economic analysis and close links with marketing strategy. Livestock play an increasingly important role in the rural economy: Government will develop a strategic approach focusing on the impact of livestock on the livelihoods of the poor as a whole. Disease control will be an important aspect of this; with this in mind, it will be important to ensure that veterinary services are affordable for the poorest rural households. Strategic Export: interventions will be reviewed and made more pro-poor, with stronger private sector focus and involvement.

\section{Transport infrastructure}

Major improvements in road conditions have been achieved. Government is creating a National Roads Authority to implement the Road Sector Development Plan. Prioritisation within the RSDP (rate of return above $12 \%$ ) will be guided by poverty consideration for particular projects. There is a need to increase funding for maintenance and find cheaper technology. Community roads have been historically neglected and will receive increased attention. On railways, Government will finalise the joint concessioning of the operations and explore private sector incentives for rehabilitation of lines and regional links. On air transport, there is a need for further investment at Entebbe Airport. The financing modality will be reviewed. 


\section{Energy}

Studies have shown that Uganda will have a peak demand of between 411 and 649 MW by 2010. The current level of about $317 \mathrm{MW}$ is therefore inadequate. In the short run, finance has been secured for two extra turbines of 40MW at Kiira power station. In the longer term, two sites with big electricity generation potential have been identified at Bujagali falls (250 MW) and Karuma falls (200 MW). Investment will be led by the private sector. Commercially viable tariffs will be established. However, the provision of infrastructure for rural electrification will be subsidised to reduce costs for rural users. The rural electrification fund is supporting the extension of electricity in rural areas, aiming at covering $10 \%$ of households by 2012 .

\section{Mining}

Government has licensed companies for petroleum exploration and established New Mineral Policy and Mining Law. The aim of the policy will be to encourage investment mining, including formal and artisanal mining, to Uganda while maximising the benefits to the country.

\section{Tourism}

Government will continue to support the promotion of Uganda as a tourist destination including cultural and domestic tourism.

Science, technology and industrialisation

Government will create incentives including Innovation Awards for technological development, and will implement the industrialisation policy to promote technical transformation.

\section{Financial services}

The microfinance sector has grown fast in recent years. However, this growth has been concentrated in peri-urban areas and has tended not to finance agriculture. Under the Microfinance Outreach Programme, Government plans to fund capacity-building and matching grants to encourage expansion in more remote areas and products for agriculture.

\section{Medium, small-scale and micro-enterprises}

MSMEs provide about $12 \%$ of employment in rural areas and $40 \%$ in urban areas. Government will develop a cost effective way of delivering services to them, particularly for business development skills, and will review the method of taxation used for this subsector. Bureaucratic obstacles to their operations will be reduced by the systematic and consultative scrutiny of proposed new regulations and review of existing ones.

\section{Environment}

There are serious signs of declining soil fertility and deforestation in Uganda. To meet these challenges, Government will develop a sector-wide approach for the ENR sector. 
Land reform offers large potential benefits in clarifying land rights and strengthening the rights of the poor, especially for women. Government will focus on improving the land registry in the short run and strengthening the land rights of the poor through systematic demarcation in the long run. Urban land reform should also help the market for urban housing to work better. While the provision of housing is mainly a private sector responsibility, Government will regulate to ensure minimum standards and avoid overcrowding.

There is an urgent need to reduce deforestation, since distances walked to fetch fuelwood are increasing and the age of the tree stock is rising, causing negative impacts on women's time and soil fertility, and posing serious threat to the livelihoods of some poor forest residents. The National Forest Authority will encourage private participation in forestry while protecting Central forest reserves. District and community forests need more support. The district forest services will be supported to promote pilot community forest initiatives.

The fisheries subsector is an important area of growth. The newly established Fisheries Agency will oversee the provision of services to the sector. Local beach management units are being established to ensure sustainable management at the community level.

Government will also proceed with ongoing programmes to protect wetlands and wildlife, and will aim to strengthen the meteorological service, so that it can provide farmers with usable and accurate information to improve production decisions in agriculture.

\section{Labour market and productivity of workers:}

Government will take actions to enhance the productivity of workers, including the reform of vocational education, and continue to monitor working conditions. The system of occupational health insurance will be reviewed to ensure that it does not impose an excessive burden on businesses while providing effective protection to workers. Labourintensive methods of work will be encouraged in the public sector where feasible and cost-effective

\section{Pillar 3: Security, con ict-resolution and disaster management}

Uganda has suffered from insecurity of various kinds including rebel insurgency and, cattle rustling. The country suffers from various forms of natural disaster in addition to the large number of internally displaced persons.

Government will continue to use security forces to protect the security of the population. The army will be equipped and transformed as guided by the Defence Review, based on an analysis of future security threats, and phasing the reforms according to resources. Vigilante forces will be regularised, and the roles of the army and other institutions normalised as peace is restored.

The search for peaceful methods of con ict-resolution will continue; Government will cooperate with CSOs, faith-based groups and traditional leaders. Diplomatic ties with countries will be strengthened to assist with con ict-resolution.

The process of amnesty will be supported. Hitherto, only a proportion of reporters have been resettled. Government will establish clear and consistent expectations of the support to be received by reporters. 
Disarmament has made progress, and will be pursued in the context of regional actions for small arms control, since some groups fear that they could be attacked by groups in neighbouring countries if disarmament is imposed without international cooperation. A national Focal Point for small arms control has been established. Government will support peace-building initiatives in Karamoja.

Government will strengthen disaster preparedness, using the successful experience of the El Nino rains in 2002, where the population was effectively protected. Central Government will promote awareness of the risks and recommend actions to local governments.

The most severe disaster requiring response is internal displacement. While humanitarian aid is treated off-budget, Government will continue to coordinate the response. Government will consider allocating funds more exibly to distressed districts and will involve IDPs actively in planning and monitoring conditions in the camps, ensuring adequate attention to sanitation in particular.

Refugees numbered over 200,000 in mid-2003. The management of the issue will be mainstreamed into district planning. Government will continue to implement the policy on self-reliance of refugees.

There are a number of initiatives that are intended to assist areas recovering from disaster and insecurity, Government will streamline these initiatives. Regional plans will be mainstreamed within sector strategies. The Northern Uganda Social Action Fund will provide funds for communities to dedicate to projects they identify.

\section{Pillar 4: Good Governance}

\section{Democratisation}

The Constitutional Review Commission delivered its report to Government. A White Paper has accordingly been prepared and is now before Parliament. While the system of Government that has prevailed since 1986 has enabled considerable progress with democratisation, it is now expected that future elections will be held under the multi-party system. Government will seek a national consensus in good time. Enabling laws will be strengthened to discourage malpractices and enacted in good time. Parliament's role in the budget process has been strengthened; the executive branch is now obliged to share budget proposals with Parliament well in advance.

Government is committed to maintaining high standards of human rights. The Human Rights Commission reports regularly both on positive achievements and challenges; Government will act to prevent any violations identified by UHRC from continuing.

\section{Justice, law and order}

Crime has a harmful impact on poverty because it reduces investment. Similarly, incarceration involves costs to households and the state. In addition to normal crimes, Uganda faces some new challenges including money laundering and terrorism.

Government will continue to proceed with the reforms of criminal and commercial justice. Access to justice will be improved by recruiting police and judicial officers. Efficiency and effectiveness will be strengthened by a number of initiatives. The mandate 
of local courts (which are popular, though they need training) will be strengthened; to this end, a Local council courts bill has been prepared. Community service will be rolled out nationally, since there is evidence that it produces lower levels of recidivism than incarceration and also has lower fiscal and human costs. The chain linked initiatives will be extended to reduce case backlog. Prison farms will be strengthened. In the commercial justice: dispute resolution is being promoted.

\section{Managing the public sector}

There are signs of improvement in public accountability, but perceptions about corruption remain a concern. Better monitoring and financial controls are being introduced including the Integrated Financial Management System, procurement reforms, and the publication of transfers to local governments. There has been an improvement in compliance with reporting requirements, under the Local Government Development Programme. Legislative reform will be pursued covering areas including money laundering and access to information. In investigating and acting against corruption, Government will act on the findings of Commissions of Inquiry. At a local level, cooperation with CSOs and the public will be promoted. Government will also expand public information strategies in all sectors.

Decentralisation has achieved major improvement in getting funds to their destination, but slower progress towards autonomy. Fiscal decentralisation will lead to a simplification in transfers to districts. Consideration is being given to streamlining LGDP and PMA, both of which offer more exible sources of funds for investment projects at a local level.

Local revenue generation needs review, since graduated tax has been found administratively difficult and is regressive in effect though not in design. Market dues are tendered out at inadequate prices for the tenders and impose problems for small businesses. Property taxes offer a promising avenue for strengthening local revenue generation in a more equitable way. A Local Government Rating Bill has been developed. Government will work with local authorities through LGFC to improve methods of revenue collection.

There are major challenges to human resource management in the public sector, including the gap in pay between public and private sectors and between the public sector and autonomous agencies; excessive use of consultancy in some sectors; inadequate supervision; staff absenteeism; inadequate projection of the impact of the HIV/AIDS epidemics on human resources requirements; weak management of the payroll and of training; and arrears in pension and terminal gratuities.

Public sector reform will strengthen performance management through implementing ROM, enhance capacity in the context of sector strategies, address the pay reform strategy focusing on job evaluation targets of technical cadres and preserving purchasing power of public salaries, and strengthening efficiency and cost control.

\section{Pillar 5: Human development}

A healthy and well-educated population is both a necessary condition for development and one of the central objectives of development. During the first two PEAPs, Government has invested in a massive expansion of primary education. To confront the challenges of child and maternal health, Government has prepared an Infant and Maternal Health strategy 
focusing on improving the quality of health care and treatment of malaria, sanitation, community mobilisation, and family planning. Water supply has improved substantially during the 1990s; balancing private and public sector roles in urban and rural areas will be critical. Human resources planning needs to be strengthened.

Inter-sectoral issues in this area include nutrition, sanitation, AIDS and fertility. Nutritional indicators remain poor; factors include low incomes, unequal bargaining power in the household, heavy burdens on women's time, and poor health. Government is developing a Food and Nutrition Bill and will mainstream actions on nutrition into sector plans. Sanitation needs to be addressed by public campaigns to promote hygiene, to be operated by the existing administrative structures supported by the health, water and education sectors.

There has been progress in reducing the prevalence of AIDS, but there are recent signs of some reduction in awareness, especially among young people who are the most at risk. Some of the highest recorded levels of AIDS prevalence are in Gulu, re ecting the insecurity and poorer public information in the North. Government is introducing free treatment for AIDS. Counselling and monitoring of the treatment will be critical. On fertility, Government will promote public discussion of the issue. More public understanding of the implications of high family size and a high dependency ratio is needed.

\section{Education}

Investment in education contributes to the accumulation of human capital, which is essential for higher incomes and sustained income growth. Education has good economic returns in Uganda, especially for primary education. Education is also linked to children's survival, and secondary education is associated with smaller family size. In order to maximise the impact of public expenditure, Government will focus its resources on those who would not otherwise access education, particularly in secondary and tertiary education, where universal access is not yet achievable. The education sector therefore faces the twin challenges of delivering primary education and strengthening the performance of higher levels of education.

Primary education has been continuing to expand (with net enrolment in household survey data steady at about $86 \%$ since 1997). The gender gap in most levels of primary education has been eliminated. However, while the provision of inputs has increased, the retention of children in education remains a serious challenge, partly because of the costs borne by households, and the achieved proficiency of students shows no clear trend. Absenteeism and drop out rates of girls is frequently associated with inadequate hygiene and sanitary facilities at schools. Quality of education remains an important challenge.

Government will take measures to improve the efficiency of primary education, including multi-grade teaching, double-shift teaching, and incentives for teachers in hard-to reach areas. Quality will be improved by teacher training, implementing the use of mother tongue in lower grades, and increasing the relevance of the curriculum. Access will be improved by the continued provision of schools and classroom facilities, training teachers in special needs education, and provision of basic education in emergency situations. A school feeding programme is being developed to target children in selected areas. The effectiveness of this intervention in improving retention and educational performance will be monitored. 
Transition to post primary education has increased from 35\% in 1997 to $50 \%$ in 2002. Secondary education has expanded because of the liberalisation of private sector participation. However, access to secondary education remains very unequal. Government is therefore seeking to improve the targeting of secondary education by supporting private community secondary schools, introducing student bursaries, and increasing efficiency by double-shift teaching and increasing the teacher-student ratio above 30 . Vocational education needs to be well matched with the economy's needs. A more exible framework will be developed allowing for modular courses. The Education Sector Plan envisages that vocational education will become an alternative to academic education in the last two years of the secondary level, rather than an alternative to the early years of secondary education.

Tertiary education is to be strengthened with an expansion in student numbers, the introduction of bursaries for poorer students, including orphans, the operationalisation of a loan scheme, and improvement in curriculum and facilities.

\section{Health}

The health sector is slowly recovering from the decline in social services experienced during the 1970s and 1980s. The Health Sector Strategic Plan is being implemented in a phased manner, re ecting resource constraints. Priorities include hygiene and sanitation; immunisation; malaria control; information, education and communication; reproductive health and HIV/AIDS. Under the HSSP Government has upgraded infrastructure, abolished user fees in public facilities, provided subsidies to the not-for-profit sector, and upgraded training and enhanced drug availability. As a result, the usage of the public health system has expanded dramatically, though the impact on health outcomes is not yet known. Government will continue to implement these reforms and will prioritise preventive care under the new (HSSP II) Cross-Cutting Cluster: Health Promotion, Prevention and Community Health Initiatives. Elements of this CCC include health education and promotion, environmental health, control of diarrhoeal diseases, school health and community health, internally displaced populations and extension work from other sectors. In addition, insecticide treated nets, vaccination, family planning messages, and IEC messages.

\section{Water supply}

Government has developed sector investment plans for urban and rural water supply. Government has assumed responsibility for most of the costs of rural water supply. The percentage of people served with access to improved water sources has improved from about $20 \%$ at the start of the 1990 s to around $60 \%$ today. Government is allocating funds to enable every district to reach the same level of coverage in 2015. Although access to safe drinking water is improving, this is being undermined because the quality of water that is eventually swallowed is frequently reduced because of inadequate domestic hygiene in maintaining the safe water chain. The supply of urban water is managed on a commercial basis by private contractors, under a lease arrangement, but Government will support supply to peri-urban areas as needed. Modalities for financing investment in large towns will be explored, as agreed in the performance contract established between Government and NWSC. 


\section{Social development}

In social development, Government is revitalising the community development function. Management and monitoring will be strengthened. Functional adult literacy has been rolled out nationally in recent years and will be strengthened further. Government will strengthen social protection for vulnerable groups using community-based approaches, and will strengthen the analysis of gender in sectoral ministries. In addition, community development officers will be expected to actively engage in hygiene promotion and sanitation at the rural household level.

\section{Public expenditure to implement the PEAP}

Since 1997- expenditure has risen fast. Achievements include the development of sector programmes, expansions in service-delivery, and some improvements in efficiency. Challenges include weak implementation capacity, lack of discipline, the development of high cost capital projects, pro igacy in some autonomous agencies, and imperfect targeting of services to the poor.

Government has developed precise criteria for public expenditure. Returns to different areas of expenditure will be compared by rigorous quantitative methods. In prioritising expenditures for the PEAP, Government will be guided by the following strategy:

1. Ensure that service delivery is maintained and pension obligations are met

2. Continue with infrastructural programmes, but phase them over the LTEF period

\section{Increase expenditures on previously under-funded priority areas}

A list is provided in the document. In the short term, particular urgency is attached to funding agricultural advisory services, district and community forests: preventive health care and pension arrears.

4. Restrain growth in other areas

5. Cut back on areas of waste

6. Account for possible increases in unit costs

This PEAP presents provisional shares that may be achieved during the lifetime of the Long-Term Expenditure Framework (LTEF), re ecting these general principles.

Government will strengthen the role of sector-wide approaches and sector working groups in the budget process. Sectors will be responsible for drawing up medium and longterm expenditure plans that re ect the sector's priorities. Project aid will be integrated into the MTEF; sectors will be responsible for ensuring that projects do not crowd out higher-priority expenditures. Sectors should aim to reverse imbalance between capital and recurrent expenditures: address equity, and contract out services where appropriate. Strategies that address cross-cutting issues will be integrated within sectoral ceilings, rather than being funded separately. 
Public sector structures need to be rationalised. The structure and purpose of commissions and autonomous agencies and the structure of Government will be reviewed: Human resource expenditures will be integrated, reducing waste.

Government continues to urge donors to provide support as general budget support. Donors have a right to contribute to the debate about resource allocation, but this should be exercised through participation in the many fora which take place during the budget process, rather than by using projects to in uence resource allocation to favoured sectors.

\section{Monitoring and Evaluation of the PEAP}

The major challenges to $M \& E$ include weak coordination arrangements, parallel M\&E efforts, poor public management culture, gaps in information, and underused information. Government has developed the National Integrated Monitoring and Evaluation Strategy to address these problems.

Under this strategy, monitoring is to be to be implemented through censuses and surveys, administrative data, PPAs, beneficiary assessments, and research studies. The PEAP Results and Policy Matrix will be used to guide monitoring.

NIMES will report to Cabinet through a National Coordination Committee and Technical Implementation Committee. The NIMES secretariat is located in OPM.

The prospects for achieving the Millennium Development Goals are mostly good. However, resources may be insufficient to achieve the target for maternal mortality, and education targets are constrained by the factors that in uence drop-out, which are hard to precisely quantify. 


\section{Introduction}

\subsection{The Poverty Eradication Action Plan}

The Poverty Eradication Action Plan is Uganda's national planning framework. The PEAP was first drafted in 1997 and was revised in 2000. This is the second revision of the PEAP. Revisions are intended to keep the PEAP current in the light of changing circumstances and emerging priorities.

The purpose of the PEAP is to provide an overarching framework to guide public action to eradicate poverty, defined as low incomes: limited human development: and powerlessness. The PEAP provides a framework within which sectors develop detailed plans.

\section{Overall framework}

The PEAP aims at contributing towards transforming Uganda into a middle-income country. Such a process of transformation will involve industrialisation based on private investment in competitive enterprises. Middle-income countries invariably have a higher share of industry in GDP, both because they have a higher capital stock and because they have higher domestic demand for manufactured output.

It is now recognised that the best way to industrialise is usually not to protect domestic industry, but to enhance competitiveness. Protection leads to the establishment of uncompetitive industries and also, in low-income countries, tends to increase inequality. Uganda is therefore aiming at a path of economic development that will expand the country's ability to compete in international markets

Because of the country's geographical position and strong (though vulnerable) natural resource base, one of the main forms of industrialisation will be value-addition by processing agricultural products. For this to happen, the country's farmers need to understand the technical and quality requirements of commercial production. The incomes generated as a result will represent a crucial infusion into rural areas, where most poor people in Uganda live.

While manufactured exports will depend on agricultural inputs, manufacturing for the domestic market will depend on the demand for manufactured goods, and this in turn depends on rural incomes. For both these reasons, manufacturing growth will depend on agricultural development, even though the rate of manufacturing growth is likely to continue to be faster than that of agricultural growth, corresponding to patterns observed elsewhere.

Government's strategy in the short run is therefore aimed at strengthening both agriculture and manufacturing. For agriculture, critical interventions include infrastructure (especially rural roads), information and support to farmers' marketing. For manufacturing, Government will strengthen infrastructure (especially electric power), improve governance (since corruption has been identified as a constraint for manufacturing), boost the education of the workforce, improve the financial system, and establish a regulatory regime that ensures a level playing field. 
As Chapter 2 notes, there has been a marked increase in inequality in the last few years. Government aims to tackle this by increasing the ability of the poorer households to participate in economic growth. There are three main channels. First, many of the poorest households depend heavily on their own agricultural production thus the need to improve quality and enable them to enter the market, while strengthening their property rights. Secondly, non-agricultural self-employment has been increasingly important as a route out of poverty as well as wage employment.

The process of economic development will both cause and depend on social and human development. As economic development occurs, the health, educational level and empowerment of the population will improve. Government recognises the importance of community empowerment at all stages of development, and is committed to involving communities more fully in the provision of services and the identification of new economic opportunities.

\subsection{Government's strategy for poverty eradication}

During the implementation of the PEAP 2000 a number of core challenges have emerged that are the basis for the overall strategy for the PEAP 2004.

\section{Core Challenges and Priority Action for the PEAP}

Since 2000 there have been major developments in the delivery of social services and continued economic growth. However, this growth has been highly unequal and as a result, poverty has increased. The growth has also been accompanied by environmental degradation. Also, information now available shows that there was less improvement in human development indicators in the 1990s than had previously been thought (except for the achievement with AIDS). Insecurity has persisted, causing changes in the regional pattern of poverty.

This set of circumstances implies the following core priorities for action in this PEAP.

- $\quad$ Restoring security, dealing with the consequences of con ict, and improving regional equity

Over the PEAP period, Government will endeavour to end armed con ict in all parts of the country, to enable Internally Displaced Persons (including formerly abducted children) to return home or to find new livelihoods (according to their preference), and to start to repair the damage done by the war to the economies of the North and North-East.

- $\quad$ Restoring sustainable growth in the incomes of the poor

During the period 2000-2003, income poverty increased, and inequality has been increasing markedly since 1997 . Government will aim to achieve increases in per capita consumption and halt or reverse the increasing trend in inequality, so that per capita incomes and consumption as well as savings of the poor rise. This growth must take a form that maintains and protects the environment and natural resource assets on which the poor depend.

- Human development: addressing quality and drop-out in UPE and planning for post-primary education, cutting mortality and increasing people's control over the size of their families 
Uganda has achieved major increases in the volume of primary education, but quality and drop-out remain concerns. There will be an increased demand for post-primary education in the coming years. AIDS prevalence has fallen dramatically, but has recently levelled out. Progress in reducing child and infant mortality and promoting family planning has been disappointing.

Government will endeavour to improve the quality of primary education and reduce dropout, to expand post-primary education, and reduce infant and child mortality. Government will ensure that family planning services are accessible to all those who need them and that all households are aware of their responsibility of protecting themselves from HIV/ AIDS and to make sure that they can support their children.

- $\quad$ Using public resources transparently and efficiently to eradicate poverty

Government enjoyed a major expansion of resources during the late 1990s and early 2000s, as a result of increased donor in ows. This expansion was not accompanied by an increase in domestic revenues, and hence increased the deficit. In order to control the deficit, Government resources will expand more slowly over the PEAP period, unless the expansion is funded by domestic revenues. Hence the focus has to be on improving the efficiency with which resources are used. Government will endeavour to reduce corruption and increase accountability in the use of resources: to improve the allocation of public resources by giving high priority to the actions identified in the PEAP and reducing the proliferation of uncoordinated initiatives. Streamlining the structures within the public sector itself will be a major challenge.

\section{The Process of Revising the PEAP}

The Government of Uganda embarked on the process of revising the PEAP in November 2002 with the development of the 2003 Poverty Status Report (PSR 2003). The PSR 2003 brought together all available evidence on the progress we have made in the implementation of the PEAP and the outstanding key challenges that we see in the revision process. During 2003 and 2004, three major stakeholder workshops were held, bringing together over 1000 stakeholders from central government, local government, the civil society and private sector in each workshop.

The first workshop was used to launch the revision process and explain the PEAP Revision Guide to all the stakeholders. After the first workshop, different groups held independent consultations. Government Sector Working Groups developed sector PEAP revision papers, which have been synthesised in the draft PEAP itself. Civil society and the private sector ran consultative processes led by the Uganda NGO forum and the Private Sector Foundation respectively. A working group on cross cutting issues integrated issues of gender, HIV/AIDS and environment into the whole PEAP revision process. The second workshop reviewed the draft sector papers, and the third workshop reviewed the first draft of the PEAP itself. Two workshops were held by Parliament during the preparation of the PEAP and their input is re ected in the document.

Several research initiatives and studies have been used in the revision process. The latest National Census data (2002) and the Uganda National Household Survey (2002/03) provided the quantitative research evidence that was used in the revision of the PEAP. 
Qualitative data on poverty was provided by the findings of the 2 nd participatory poverty assessment process, conducted in 12 districts in 60 sites in all regions of Uganda ${ }^{1}$. All these data sources gave statistical as well as qualitative research evidence that has been sharpening Government's overall strategy for poverty eradication. This consultative process has therefore been one of learning and sharing information, which are key ingredients in any country's poverty eradication strategy.

\section{What is New in the PEAP}

a) More focus on linking public expenditure to the PEAP priorities: PEAP 2004 provides a clear link between the PEAP priorities and public expenditure. A new chapter that focuses on issues of public expenditure and the PEAP implementation has been added.

b) Making the PEAP more functional: The new naming of the pillars in this PEAP is based on the functions that will be implemented under each pillar. In this way the PEAP 2004 is now a document that allows sectors to relate to various parts of the PEAP in the implementation process.

c) Developing a PEAP Results and Policy Matrix: A PEAP Results and Policy Matrix has also been developed making the monitoring and evaluation of the PEAP much more clearer.

d) Balance between Social and Productive Sector Spending: This PEAP has also created a balance between the productive and social sectors. The PEAP 2000 did emphasize investment in the social sector and we have been able to see significant improvements. However, we have also observed slow growth in the productive sector and therefore this PEAP emphasizes a strategy that is linked to both sectors.

e) Prioritizing Ending Insecurity: A new pillar on security and con ict resolution has been introduced as a direct recognition that security of all Ugandans needs to be treated as a national priority and in a holistic manner so that we can cater for interventions both in con ict areas and also post con ict areas.

f) Cross cutting Issues: The PEAP 2004 has also paid attention to several cross cutting issues that affect people's livelihoods and have an impact on the PEAP. The environment sector working group, HIV/AIDS sector working group and gender sector working group organized their own consultations and contributed evidence that has been used in the PEAP revision process. It is now clear that removing constraints caused by HIV/AIDS, Environment and above all gender inequalities is key to achieving Uganda's poverty eradication goals.

g) Process of Consultation: The process of consultation in the revision of the PEAP is probably the most detailed since the PEAP 1997 was developed. The PEAP 2004 is based on consultations with very many stakeholders. We have consulted local governments who conducted their own consultation in their respective local governments, sectors have prepared Sector PEAP Review Papers, the Civil Society Organizations sent in contributions, the private sector organized consultations among themselves and many of development partners sent in comments on the various drafts of the revised PEAP. The PEAP 2004 therefore represents the aspiration of very many Ugandan stakeholders at all the different levels. 


\subsection{Pillars and priorities}

This PEAP is presented under five 'Pillars' or components. Each sector of Government is grouped as far as possible under one pillar. It is, of course, recognised that many sectors contribute to the objectives of other pillars as well.

The priorities identified here are derived from the core challenges listed above.

\section{Economic management}

Key priorities in economic management are:

- The maintenance of macroeconomic stability

- $\quad$ Fiscal consolidation

- $\quad$ Boosting private investment

\section{Production, competitiveness and incomes}

Key priorities in this area are:

- The modernisation of agriculture

- $\quad$ Preservation of the natural resource base, particularly soil and forests

- Infrastructure including roads, electricity and railways; better maintenance, costreduction and private sector participation will be key to achieving improvements in the context of fiscal consolidation.

- $\quad$ Enhancing private sector skills and business development.

\section{Security, con ict-resolution and disaster-management}

The key priorities in this area are:

- $\quad$ Ending rebel insurgency, by peaceful means if possible

- $\quad$ Ending cattle-rustling

- Dealing with internal displacement and abduction, which are major sources of distress in contemporary Uganda

\section{Governance}

The key priorities are:

- Human rights and democratisation

- The development of a better legal system

- Transparency, accountability and the elimination of corruption 


\section{Human development}

Key priorities are:

- $\quad$ Primary and secondary education: with a clear focus on quality and the ultimate objective of learning, and with better targeting of public expenditure on secondary education at those who could not otherwise afford it.

- Improving health outcomes: this will be the joint achievement of several sectors

- Increasing people's ability to plan the size of their families

- $\quad$ Community empowerment including adult literacy

The identification of an area as a priority does not necessarily mean that spending on this area will increase. The chapter on public expenditure examines the relations between the existing and projected resource envelope and Government's plans in various sectors, and uses this analysis to see which areas are currently underfunded.

\subsection{Cross-cutting issues}

As part of the PEAP process, a working group was formed: to focus on cross-cutting issues, in particular gender, environment and HIV/AIDS. Other cross-cutting issues include: employment, population, social protection, income distribution and regional equity.

Gender issues arise under all pillars. In particular, the importance of addressing intra-household relations for agricultural productivity is emphasised. Discriminatory legislation is to be reviewed and reformed. The pattern of usage of services by gender is examined in various sectors. The shortage of fuelwood and its effect on women's time use is strongly emphasised, as is the need for coordination between forestry and energy policy in addressing it. Women's land rights need to be strengthened. Domestic violence is recognised as a problem and actions are being taken to reduce it.

As part of the PEAP process, more analytical work has been done on the economic importance of environment and natural resources in Uganda. Problems of soil degradation, deforestation, depletion of wildlife resources and encroachment on wetlands give examples where public action is needed. In the case of soil degradation and forestry, both technical and participatory evidence show the problems have in the past been underestimated. Relevant actions are considered in chapter 4 . The lack of a sectoral apporach to environment and natural resources has been a constraint and will be addressed.

With $H I V / A I D S$ prevalence apparently plateauing at $6 \%$ of the adult population, more needs to be done to reduce it and to treat victims of the disease. Actions for prevention and treatment are mainly covered in Chapter 7. Implications for human resource management are covered in the various sectors, although not all sectors have human resources management systems of enough sophistication to take HIV/AIDS fully into account.

Employment: is an important concern throughout the new PEAP. New data from the Labour Force survey, discussed in Chapter 2, give good quantitative estimates of unemployment. While open unemployment is a relatively rare phenomenon, visible 
underemployment is highly prevalent. Wage employment has not been growing as fast as was hoped, so that the share of wage-earners in the population has been increasing slowly. Chapter 2 sets out the implications of structural transformation for the demand for labour in wage employment and self-employment, and Chapter 3 translates this into implications for economic management. All the actions in Chapter 4 are likely to in uence employment, and the specific area of employment policy is also discussed, with a particular focus on working conditions and wages. There appears to be scope for more use of labour-intensive techniques in public investment, which is not being fully exploited at the moment. Pension reform and a more exible approach to occupational health and safety can also help to reduce the costs of employing people.

It is sometimes suggested that economic demand should be increased in order to raise levels of employment. At the macroeconomic level, this would be likely to exacerbate shortages of skills. Over the last three years wages for the better-off have increased sharply, widening the gap with others. Visible underemployment is not a sign that there is a large pool of people looking for full-time work, but that there are many people who would like to augment their current incomes with some extra wage-earning opportunities in their locality. What is appropriate in this case is not a global increase in demand but an increase in locally targeted employment opportunities.

Population growth: is a major issue for poverty reduction. New analytical work has been conducted for this PEAP on the effects of population growth for incomes, motivated by the discovery in the 2002 Census that population growth was higher than had previously been observed. The results of this analysis strongly suggest that the very large families that have been observed over the years in Uganda are now becoming an impediment to the speed of economic growth and social and structural transformation. There is evidence that many people, particularly women, would like smaller families. Chapters 2, 3 and 7 examine the implications of large families and how family planning service can be made more accessible and attractive to the population.

Social protection: is receiving more attention. Chapter 2 discusses a number of the identified disadvantaged groups in Uganda. Social protection is further discussed in Chapter 7.

Income distribution: is an absolutely central concern of the PEAP, particularly because income inequality has been increasing since 1997. All sectors preparing PEAP papers were asked to discuss who their beneficiaries were, in order to generate more creative thinking about how the poor can be reached by public services. The prioritisation of public actions continues to focus on the poverty impact. In this PEAP, poverty impact is raised as a policy issue in a number of places where existing policy may need to be refocused.

Regional equity: One particularly dramatic source of inequality in Uganda is the poor economic performance of the North, caused largely by the insecurity suffered by its population. Chapter 2 discusses the phenomenon of regional inequality, and Chapter 5 , on security, con ict-resolution, and disaster-management, is centrally concerned with the North and parts of the East. It is intended that the problems of the North should mainly be addressed by mainstreaming this concern throughout the sectors' actions, but there are a number of outstanding policy issues in this area discussed particularly in Chapters 5,6 and 8 . 
In the last three years, there has been a marked increase in poverty in Eastern Uganda. One reason for this is distress migration from the con ict-affected areas of the North. However, this does not appear to be adequate to explain all the change; Chapter 2 provides more discussion.

\subsection{Roles of the state, the private sector and other partners}

\section{The Role of Government}

The state is responsible for ensuring a basic framework of legality, rights and freedom and intervening in the economy to promote economic efficiency, equity and growth. Interventions are appropriate for three main reasons:

- $\quad$ Promoting the right incentives to encourage private production

- $\quad$ Ensuring that public goods are supplied

- $\quad$ Reducing inequality. (This is particularly relevant in a context where income inequality has been increasing sharply)

One of the objectives of the PEAP is to develop consensus on how to interpret these principles in Uganda. All sectors were asked to analyse the public sector's role in their submissions for the PEAP revision. Likewise, the PMA and the MTCS provide frameworks for the public sector's role in supporting economic production. This PEAP re-emphasises the importance of some public goods, such as agricultural extension, while exploring the option of public funding for private provision in a number of areas.

Government is committed to serving all citizens of Uganda irrespective of ethnic background, sex, or religious beliefs. This fundamental commitment will underlie all Government policies in the PEAP.

\section{Legislature and executive}

Most of the actions included in the PEAP are implemented by the executive arm of Government. The fundamental commitments, however, are guided by the vision of Government as re ected in the promises made to the electorate. Parliament has a fundamental role both in passing legislation that bears on poverty-eradication, and in scrutinising the executive. The Public Finance and Accountability Act sets up an improved framework for this scrutiny.

\section{Autonomous and semi-autonomous agencies}

There are a large number of autonomous and semi-autonomous agencies within the public sector. Some of these have essential public roles including policy formulation, independent monitoring, service delivery, and the procurement of services. These are expected to pursue the interests of the population as a whole in the same away as central Government. Others are expected to operate on an essentially commercial basis though subject to regulation.

The roles of these agencies are subject to review. There are concerns about the efficiency of some of these agencies, the very substantial gap between remuneration in them and in the public service, and the amount of revenue that is effectively hypothecated by 
being assigned to these agencies. There is also some concern that social and commercial missions have been blurred in some cases, leading to a reduction in the efficiency of investment.

\section{The Private Sector (national and international)}

It is the private sector, including the many small-scale farming households, that is responsible for the majority of productive investment. In general, the motivation for investment is expected to be commercial, and Government will therefore seek to ensure that the incentives in the economy encourage the kinds of investment that will generate pro-poor growth. In some cases, the commercial private sector supports public goods for altruistic, cultural or prestige reasons. For instance, commercial sponsorship of sport is an important international phenomenon. The private sector has contributed significantly to the priorities identified in this PEAP.

Over time, it is hoped that producer organisations will be strengthened. Services such as information about marketing opportunities, which benefit an industry as a whole, can be usefully provided by such organisations. Producers' organisations in grain trading and horticulture already play an important role, and Government will collaborate with such organisations in promoting private sector development.

\section{Civil Society}

It is essential to the concept of civil society that its actions are not planned or dictated by Government. However, Government enjoys productive partnerships with civil society in a number of areas and there are four general roles that civil society organisations play:

- Advocacy, particularly for the interests of groups who might otherwise be neglected;

- Voluntarily financed service delivery in sectors not covered by Government programmes;

- Publicly financed service delivery, subcontracted by Government;

- Support to con ict resolution; and

- Independent research on key policy issues

Civil society has made a substantial input into the policies proposed in this PEAP, and even to the structure of the document.

\section{Donors}

Donors continue to play a critical part in financing public expenditure in Uganda. In accordance with the partnership principles spelt out in Volume 3 of the previous PEAP, the donors are encouraged to support Government programmes through budget support rather than through projects. With the introduction of sectoral ceilings for the development budget including donor projects, both sectoral ministries and donors need to understand that each additional project will have an opportunity cost for the sector in terms of exible resources for the sector's priorities. This is being done to ensure that project funds are subject to the same process of prioritisation as more exible resources.

Some donors provide support direct to NGOs and to some districts outside the central government budget. The amounts are not currently integrated into the national resource 
envelope, but information is collected on them. The amounts are not large enough currently to have substantial macroeconomic effects.

Government has developed partnership principles, discussed in chapter 8, to guide interactions with donors.

\subsection{The PEAP and international initiatives}

Since 2000, the World Bank and IMF have asked their developing-country clients to prepare Poverty Reduction Strategy Papers (PRSPs), partly inspired by the example of Uganda's first PEAP. The PRSPs have become central documents for guiding recipientdonor relations. In Uganda's case, the PEAP is the country's PRSP and Comprehensive Development Framework.

Government also signs a wide range of agreements with donors. It has not always been easy to ensure that all the commitments in these agreements are mutually consistent, let alone consistent with the country's own priorities. Increasingly, however, all donor agreements make reference to the PEAP. Ideally, all budget support agreements should be based on the actions specified in the PEAP without imposing additional conditions. In practice, some instruments such as IMF programmes and the World Bank's Poverty Reduction Support Credit often involve commitments which go into more detail than the PEAP. Government will cooperate with donors in ensuring that any such commitments are compatible with the PEAP and that donor instruments progressively converge on the contents of the PEAP.

Government is also participating in a number of regional initiatives including the East African Community and the New Partnership for Africa's Development (NEPAD). As the PEAP process evolves, the links between these processes will be fully articulated.

Government is a signatory to a number of international treaties specifying obligations such as the International Convention for the Rights of the Child. Since the United Nations Conference on Development and Environment (UNCED), 1992, Uganda has been an active participant in global environmental policy process including ratification of Major Multilateral Environment Agreements (MEAs).

The most high-profile of these international initiatives is the Millennium Development Goals (MDGs), under which a number of targets have been set that both developing countries and development partners are committed to achieving by 2015 . The country remains committed to achieving these targets and the PEAP Results and Policy Matrix re ects the priority given to them. In general, the MDGs are fully consistent with Uganda's national priorities. However, the relative speed at which any particular target is approached will re ect the particular constraints and trade-offs that the country faces. 


\subsection{Structure of the PEAP}

Chapter 2 sets out the existing state of knowledge about poverty in Uganda, and the implications for poverty eradication strategy. Chapters 3 to 7 set out the actions planned under five pillars:

- $\quad$ Economic management

- $\quad$ Enhancing production, competitiveness and incomes

- $\quad$ Security, con ict resolution and disaster management

- $\quad$ Good governance

- Human development

These are different from the 4 pillars of the previous PEAP. The restructuring of the pillars is intended to emphasise the importance of the con ict-related issues and to group actions in a way that mirrors the institutional structure of Government, as well as being more logical. For instance, the new grouping allows the road subsector and the education sector to be treated as a whole rather than divided across pillars.

Chapter 8 discusses the expenditure plans for implementing the PEAP. Finally, Chapter 9 sets out the monitoring framework for the PEAP and presents the policy matrix that will guide the implementation of the PEAP. 


\section{Poverty in Uganda: Trends and Patterns}

This chapter provides an overview of recent developments in poverty in Uganda and patterns across different groups. It covers three main aspects of poverty: low incomes, limited human development, and limited empowerment. However, particular emphasis is placed on income poverty, because there is good recent evidence for changes in this dimension. Further discussion on the other dimensions of poverty can be found in the chapters on the relevant pillars.

\subsection{Income, poverty and inequality}

\section{Box 2.1:}

\section{How is income poverty measured?}

Using a national survey on household expenditure (which has been conducted in most years since 1992), statisticians calculate the real household expenditure per adult equivalent. This measure includes home-produced food as well as goods purchased from the market, and adjusts household size for the number of people of different ages, to give an accurate re ection of the relation between the household's total expenditure and its members' consumption needs. It also corrects for in ation. Households whose real expenditure per adult equivalent falls below a given level (the poverty line) are considered poor. The poverty line used in Uganda is an absolute, not a relative one; it measures the level of expenditure needed to secure basic food consumption needs (taking into account regional variations in food prices) and a corresponding level of non-food consumption. Poverty can be measured by the headcount - the proportion of people below the poverty line - or by the poverty gap and depth of poverty, which also take into account the distance below the poverty line.

\section{Trends in income poverty and inequality}

During the 1990s, income poverty fell dramatically. The proportion of Ugandans whose expenditures fell below the poverty line (the poverty headcount) fell from 56\% in 1992 to $44 \%$ in $1997 / 8$ and even faster to $34 \%$ in 2000 . These changes were driven mainly by increases in average income, rather than by redistribution. Inequality was basically steady from 1992 to 1997 , but increased thereafter; the Gini coefficient ${ }^{2}$ was between 0.37 and 0.35 until 1997, but rose to 0.39 in 2000 . Since 2000 , the trends have been less encouraging. Income poverty increased from 34\% to 38\% between 2000 and 2003, and inequality as measured by the Gini coefficient rose markedly from 0.39 to 0.43 . 
Table 2.1: Proportion of people below the poverty line $\%^{3}$ and inequality coefficient

\begin{tabular}{|c|c|c|c|c|c|c|c|}
\hline & 1992 & $1993 / 4$ & $1994 / 5$ & 1996 & $1997 / 8$ & $1999 / 2000$ & $2002 / 3$ \\
\hline National & 55.7 & 51.2 & 50.2 & 49.1 & 44.4 & 33.8 & 37.7 \\
\hline Rural & 59.7 & 55.6 & 54.3 & 53.7 & 48.7 & 37.4 & 41.1 \\
\hline Urban & 27.8 & 21 & 21.5 & 19.8 & 16.7 & 9.6 & 12.2 \\
\hline Central & 46 & & & & 28 & 19.7 & 22.3 \\
\hline Western & 53 & & & & 43 & 26.2 & 31.4 \\
\hline Eastern & 59 & & & & 54 & 35.0 & 46.0 \\
\hline Northern & 72 & & & & 60 & 63.7 & 63.6 \\
\hline \multicolumn{8}{|c|}{ Gini coefficients } \\
\hline National & .36 & .35 & .36 & .37 & .35 & .39 & .43 \\
\hline
\end{tabular}

Table 2.2: Proportion of people below the poverty line by occupational group, $\%{ }^{4}$

\begin{tabular}{|c|c|c|c|c|}
\hline & 1992 & 1996 & $1999 / 2000$ & $2002 / 3$ \\
\hline \multicolumn{5}{|c|}{ Occupation of household head } \\
\hline Food crop & 64 & 62 & 45 & \\
\hline Cash crop & 63 & 46 & 34 & \\
\hline Crop farmers & & & 39 & 50 \\
\hline Noncrop agriculture & 55 & 40 & 42 & 34 \\
\hline Manufacturing & 44 & 34 & 23 & 28 \\
\hline Construction & 37 & 35 & 20 & 23 \\
\hline Trade & 26 & 21 & 13 & 17 \\
\hline $\begin{array}{l}\text { Government } \\
\text { services }\end{array}$ & 37 & 32 & 15 & 13 \\
\hline Not working & 59 & 60 & 43 & 38 \\
\hline
\end{tabular}


There has been extensive discussion of the relation of these findings to participatory evidence $^{5}$. While the participatory data show less perceived improvement, this arises partly because the period of comparison was different. While most Ugandan households in 2000 were economically better off than they had been in 1992, they were not necessarily better off than they or their parents had been in the 1960s or early1970s, because of the decline in incomes during the 1970s and early 1980s.

The results in Table 2.1 have a number of implications for poverty in the period 2000-2003:

- Poverty rose in almost all regions of the country, with a particularly sharp rise in the East. However, the North (in which poverty fell slightly, although it must be noted that the sample excludes the insecure areas of Pader, Kitgum and Gulu) remains the poorest region in the country.

- The regional shares of population changed markedly, with an increase in the share of the East and a reduction in the share of the North. This partly re ects the movement of some displaced persons to the East because of insecurity.

- Inequality increased markedly, with the Gini coefficient rising from 0.39 to 0.43 .

- The sectoral shares of household heads changed dramatically, with a major shift out of crop agriculture. This may be partly due to a change in the sample, although the share of households owning land is constant across the two surveys. This is accompanied by a large drop in consumption of home-produced food, while consumption of purchased food increased.

- The increase in poverty is particularly marked for households in crop agriculture, although other sectors such as trade and hotels also show large increases. By contrast, workers in government services experienced reductions in poverty.

The evolution of durable assets and welfare indicators shows a more encouraging pattern, with some improvements. The proportion of households with metal roofing and with radios rose over the period, as did the proportion of households eating meat or fish. Seven per cent of households now use a mobile phone, and as many as 35\% of households in Kampala. Communications among urban households have thus been successfully transformed by the adoption of new technology in a liberalised environment. ${ }^{6}$ Recent research shows that more than $40 \%$ of the households who had livestock or a bicycle at the end of the 1990s reported that they had not had the corresponding asset in $1992^{7}$.

Households' access to land is likely to be squeezed by population growth and land scarcity. The rate of urbanisation has been gradual rather than dramatic, and the proportion of households with agricultural land appears to have changed little between 2000 and $2003^{8}$. Hence an increased number of households are using the country's limited resources of land. There are also some signs that land inequality is growing. The Village Census conducted for UPPAP found that the richer households had accumulated land and other assets over the 1990s much more than other households. ${ }^{9}$

While the role of depressed producer prices gives reason to think that the increase in poverty is likely to be a temporary phenomenon, a more disturbing fact is the increase in inequality that has been evident over the last six years. This is particularly disappointing in the context of increased public expenditure. Inequality has increased not only because of different growth in different sectors but also because of increased dispersion within particular sectors. In particular, wages became more unequal both in the public and the private sectors ${ }^{10}$. For this reason, while short-term shocks provide part of the explanation for what happened, there are more underlying structural concerns that need to be confronted. 


\section{Explaining the trends in poverty and inequality}

\section{Why poverty fell between 1992 and 2000}

The poverty reduction of the 1990s was achieved by a very high rate of consumption growth $(5.3 \%$ annually per capita both in the household surveys and in the national accounts). This re ected very fast rates of GDP growth in the early and mid-1990s (19927), which slowed somewhat from 1997 to $2000^{11}$. This growth included all sectors of the economy.

Between 1992 and 1997, a critical factor in consumption growth was the increased prices that producers received for their crops. Because agricultural marketing was liberalised, farmers were able to benefit from the increase in the world price of coffee. The unit export price for Ugandan coffee tripled from $0.82 \mathrm{US} \$ / \mathrm{kg}$ in $1992 / 93$ to a peak of $2.55 \mathrm{US} \$ / \mathrm{kg}$ in 1994/95. Hence the most dramatic poverty reductions were found among cash crop farmers.

After 1997, GDP growth slowed and the terms of trade deteriorated somewhat. The poverty reduction appears to accelerate, because consumption growth in the household surveys accelerated in this period ${ }^{12}$. In particular, food crop farmers benefited. However, inequality began to rise and poverty in the North increased. Two factors are particularly important in explaining these patterns. First, agricultural growth was healthy during these years. International evidence (discussed below) shows that rural income has a particularly close relation with poverty reduction, and this is particularly likely to be true in an economy as heavily rural as Uganda's. Moreover, non-agricultural rural growth is dependent on agricultural income growth. Secondly, public expenditure was increasing sharply. The evidence is that the immediate effect of public expenditure is to increase incomes at the upper end of the distribution, because Government workers are generally better off than the average. While the services delivered will increase incomes in other parts of the distribution, this takes time to be seen. Hence the pattern that emerged was rapidly rising consumption, but increasing inequality at the same time.

\section{Why poverty and inequality have risen since 2000}

Recent research sheds some more light on the changes in poverty. First, per capita expenditures fell most dramatically in the second quintile. This corresponds with an increase in poverty in crop farming households and households with small non-agricultural enterprises, driven by falls in producer prices. Secondly, most inequality in Uganda is within, rather than between, regional or occupational groups. However, the changes in inequality in the 1990s and early 2000s are explained by changes in underlying factors such as education and community services.

The increase in poverty since 2000 , and the marked increase in inequality since 1997 , are of concern to policymakers. The pattern is a result of a number of factors:

- Slower growth in agriculture

The exceptionally fast economic growth of the mid-1990s led to very fast poverty reduction. After strong growth in 1998-9, agricultural growth during 2000-2003 was disappointing except in the livestock sector. This has contributed significantly to the increase in poverty. The slowdown in agriculture relative to other sectors that was 
observed in 2000-2003 will have tended to increase inequality in this period, both because the poor are concentrated in agriculture, and because the share of labour in the incomes of other sectors may be quite small.

It is too early to say whether the slowdown in 2000-3 is a temporary uctuation or re ects a more structural set of problems. However, there is no doubt that soil fertility is widely reported to be decreasing and technology does not seem to be responding fast enough. Moreover, between 1985 and 2020, Uganda will have lost 14 percent of its agricultural labour force because of AIDS. It follows that Uganda's agricultural potential remains underexploited. Hence it is an urgent priority to accelerate agricultural development.

- Declines in farmers' prices

Uganda's terms of trade have been declining since the coffee boom in 1994. During the last three years, there have been very dramatic falls in the price of several export crops. Overall, the terms of trade declined by about $10 \%$ between 2000 and 2003 . While the devaluation partially shielded cash crop producers from this, it also produced an increase in the price of tradeable goods relative to the price of food. Hence those farmers who depend on selling food saw drop in the real price they were receiving. The ratio of food crop prices to other consumer good prices in the CPI fell by $19 \%$ between 2000 and $2003 .{ }^{13}$. Moreover, within the export sector, the prices of fish products and tourism did better than the prices of coffee and cotton, which are grown more widely in the rural economy.

The effect of terms of trade on poverty and inequality are likely to be temporary, as the terms of trade are expected to recover.

- Income diversification and population movement in a context of agricultural slowdown and insecurity

Households throughout Uganda are diversifying into a wider range of activities. For the particular household, this is usually income-enhancing ${ }^{14}$. But as new people enter a sector, prices for the output of that sector will fall, and incomes per capita within that sector will fall if the outputs of the sector face inelastic demand. The evidence in Uganda is that people have moved into sectors of production that serve local markets. As a result, prices and incomes per capita in the non-agricultural rural sector appear to have fallen.

This finding has a very important policy implication. People with a non-agricultural enterprise are usually better off. But if everyone starts up such an enterprise, then there will be excess supply and prices will fall, unless agricultural incomes rise simultaneously. Hence raising agricultural incomes is crucial for poverty reduction.

- Insecurity

Even if the level of insecurity is constant, this can generate increasing inequality because its effect is to restrict investment and hence growth, not merely to reduce the current level of income (see Annex Table A.1 and the discussion below). Some areas, such as the East, have experienced an increase in insecurity-related poverty, partly because there has been distress migration into the East from disturbed parts of the North, including the relocation of some camps for IDPs. However, the proportion of households in the sample in the East who report that they migrated to escape insecurity is low, so the observed deterioration in the East may mainly re ect other factors. 
- Fertility and mortality

Another structural factor tending to increase inequality and poverty is the high rate of fertility. Poor households tend to have more children and therefore their assets are subject to greater subdivision across generations. On average, a Ugandan woman who lives through the childbearing years has 6.9 children, and this is higher for the poorest families. A high fertility rate, even if constant, tends to cause increased inequality among households over time, as high fertility is associated with relative poverty and households with high fertility have top subdivide their assets at a higher rate than households with lower fertility.

Similar effects may come from AIDS related mortality and polygamy. Some studies have found AIDS susceptibility to be correlated with poverty. Moreover, the illness, or death of a productive adult is likely to lead to loss of income as well as often absorbing expenditures for health care and funerals, further impoverishing affected households. In the case of polygamy, this is thought to be associated with low educational levels and hence with poverty. Often polygamy has the effect that instead of investing in physical assets or children's education, the household invests in extra married women and in due course more children. In the next generation, the increased size of the husband's family means that there are less assets for each child to inherit.

- The uses of public expenditure

A high proportion of the increased public expenditures over the period went into social services. These certainly improved access to health care over the period and enabled the continued implementation of UPE. They also reduced the costs of health care to the poor, an effect which may not be fully captured in the CPI used for the calculation of real expenditures. But it did not directly increase the incomes of the poor, and the income benefits to public servants mostly went to people above the poverty line. Some of the increases went into salaries, public administration and defence. None of these has a dramatic direct impact on poverty, except in the case where increased defence expenditure leads to improved security. Finally, there were increases in agricultural spending (especially under the Strategic Exports Programme); these may not yet have borne fruit, partly because of time lags for investments such as coffee trees to mature, and partly because of efficiency issues. Also, data on public services (table 2.6 below) suggest that the interventions in production, such as extension and demonstration gardens, did not yet successfully target the poorest.

The increase in education has had a significant impact. However, this impact has been mainly experienced by the better-off households. This may be because the impact of UPE on adults' education comes with a lag. For this reason, it is hoped that the long-run impact of UPE will be to spread economic opportunities more widely and hence reduce inequality.

\section{- Asset distribution}

There are signs that the distribution of assets as well as incomes became more unequal during the late 1990s and early 2000s. In general, this re ects the underlying causes of increased inequality. However, recent land reforms may lead to increases in the rents paid by kibanja holders on mailo land, which have previously been controlled at a very 
low level. There is some risk that this could lead to an increase in inequality, re ecting a transfer of income from kibanja holders to mailo owners. It will be important to monitor the effects of this change.

- Social and cultural factors

Recent research indicates that high alcohol consumption is perceived by women as a serious and increasing problem ${ }^{15}$. The reasons for this problem include the availability of a wider range of drinks and the effects of past con ict and trauma on some of the population. A high share of alcoholic drinks in expenditure and in consumption is associated with poverty ${ }^{16}$ and domestic violence ${ }^{17}$.

\subsection{Who are the poor?}

The characteristics of the poor have been widely surveyed in past publications. For this PEAP, there are four particular concerns: regional inequalities; gender; occupational structure; and other disadvantaged groups.

\section{Regional inequalities}

While most parts of the country shared in the benefits of growth between 1992 and 2000, the North was left behind. The proportion of people in the North below the poverty line fell from $72 \%$ in 1992 to $60 \%$ in $1997 / 8$, but rose again to $66 \%$ in 2000 . This pattern is observed even though the most insecure areas were omitted from the sample. Between 2000 and 2003, the North remained relatively poor; also, the second-poorest region, the East, suffered a significant deterioration, partly because of distress migration. If real consumption had grown during the period 1992-2003 in the North at the same rate as the rest of the country, real consumption would now be $38 \%$ higher in the North and aggregate national consumption would be about $3.3 \%$ higher.

The major reason for the increasing regional gap is insecurity. Households that are physically insecure cannot make economic investments. While the dollar values of household assets increased sharply between 1992 and 1999 in the West and Central regions, this was not observed in the East and West. Households in the North, who started with smaller asset values, were unable to increase their investments in land or no land assets (see Annex Table A 2.1). This may be mainly because of the low prices of assets $\mathrm{n}$ the North, since livestock holdings are fairly similar, although holdings of land (often communally owned) and modern consumer goods are lower in the North ${ }^{18}$.

While other factors including poor prices for cash crops and the specific problems faced by pastoralist communities contributed to the relative poverty of the North, there is no doubt that security is the most important factor.

There is also a wide gap between urban and rural areas, even when the higher prices for some consumer goods in urban areas are taken into account ${ }^{19}$. Human development indicators are also mostly much better among urban households. Urban poverty also often re ects migration from rural areas and therefore can be addressed partly by making conditions in rural areas better. Nevertheless, there are some particular problems faced by the urban poor including the shortage of decent housing and sanitation. 


\section{Gender inequalities}

It is too simple to say that women are poorer than men. However, there are specific groups of women who are particularly likely to be poor, and there are some dimensions of poverty in which women are generally at a disadvantage.

Table 2.3: Poverty headcount for male and female-headed households ${ }^{20}$

\begin{tabular}{|c|c|c|c|c|c|c|c|c|c|c|}
\hline & \multicolumn{4}{|c|}{ male-headed } & \multicolumn{4}{c|}{ female-headed } \\
\hline & single & married & divorced & widowed & all & single & married & divorced & widowed & all \\
\hline 1992 & 45 & 57 & 48 & 49 & 56 & 40 & 53 & 55 & 63 & 56 \\
\hline 1999 & 18 & 33 & 20 & 26 & 33 & 18 & 45 & 29 & 40 & 39 \\
\hline 2003 & 17 & 39 & 34 & 40 & 38 & 13 & 43 & 35 & 43 & 39 \\
\hline
\end{tabular}

Women-headed households were found to be poorer than MHH in 1999, but not 1992 or 2003. However, households headed by female widows are consistently poorer than others, and households headed by married women (probably mostly married to polygamous or absent husbands) are poorer than other households in both the later two surveys.

If the delayed age at first intercourse for both has certainly added to the decrease in HIV prevalence, women remain more affected by HIV/AIDS than men. In addition to biological susceptibility, there is the problem of unequal power relationships, when women cannot control their sexuality. The impact of the HIV/AIDS epidemics is also more heavy for women who often have to care for the sick and the dependant.

Women's land rights are limited in Uganda both by the inequitable legal structure ${ }^{21}$ and by traditional practice. Data show that female-headed households have less land than male-headed households, even when corrected for household size, if the head is married, divorced or single. Widows have quite high land holdings per adult equivalent, but they tend to lose these assets over time as their male children grow up. However, the lack of a gap in income poverty suggests that women-headed households are able to compensate for their lack of land.

Women participate less in the labour market than men, and women's wages have been found to be significantly lower than men's. In 2003, $51 \%$ of currently employed women had wages of 40,000 per month or below, compared to $44 \%$ of currently employed men ${ }^{22}$. This may be at least partly due to the difference in average educational status, or it may re ect labour market institutions that discriminate against women.

It has often been found that women work longer hours than men, when domestic tasks are considered. Recent work on the household ${ }^{23}$ data finds men have slightly longer working hours than women on economic activities. However, women almost certainly work much longer hours on domestic activities than men. As a result, women are overburdened, as the second round of UPPAP ${ }^{24}$ found.

Male-headed households spend more on alcohol, especially on local brews other than beer; for instance, households headed by divorced men devote more than $6 \%$ of their expenditures to alcohol ${ }^{25}$. By comparison, female-headed households spend more on school fees ${ }^{26}$. 


\section{Poverty by occupational group}

The largest group of poor households in Uganda have consistently been those in agriculture. The poorest occupational group in Uganda consists of households who specialise mainly or solely in crop production. Participatory evidence in the second UPPAP study has shed particular light on pastoralists, fishermen and their families, and estate workers.

\section{Inequality within the group}

Although inequalities between regions and between occupational groups and demographic groups are important, recent studies show that most inequality is explained by differentials within regions and within groups. For instance, the sex of the household head explains virtually none of the observed inequality; the rural-urban gap explains $20 \%$ of inequality; differences between regions explain 13\%; and the economic activity of the head of households explains 15\%. Even education, the most powerful determinant of inequality, explains only $25 \% .{ }^{27}$ It is likely that inequalities in physical and financial assets are an important proximate determinant of inequality.

\section{Other disadvantaged groups}

There are a number of specifically disadvantaged groups who need attention.

\section{Orphans and other vulnerable children}

About 14\% of children below 18 have lost at least one parent, and 3\% have lost both. For children aged 6-17, as many as $20 \%$ have lost at least one parent mostly as a result of HIV and con ict. Most orphans are cared for by surviving parents or by other relatives. Data on the relative conditions of orphans is scarce. Household survey data suggest higher rats of poverty for male but not female orphans than the national average. Orphans are more likely to have to work than other children, though their schooling does not appear to suffer as a result ${ }^{28}$. However, the care of orphans continues to pose a major challenge to households, communities and Government in Uganda. In particular, orphans are likely to suffer emotional and psychological vulnerability in addition to any material deprivation.

Government's strategy for orphans and other vulnerable children has identified other vulnerable groups of children as: those who are living on their own including the estimated 10,000 street children living in the municipalities of Uganda; those who are abused, neglected or abandoned; children in need of legal protection and alternative family care; children in hard to reach areas; children with disability related vulnerabilities and children inside households where they are facing significant physical, mental, social and emotional harm.

\section{The elderly}

In some cases, the elderly are relatively vulnerable. In particular, as noted above, female widows are relatively likely to be poor. Some studies find that the elderly (those over 60) are less likely to be poor than the average; others find the contrary. More analysis of this group is needed ${ }^{29}$.

\section{The disabled}

There are varying estimates of the number of disabled persons in Uganda. The National union of disabled persons estimates the proportion disabled at $10.4 \%$ of the population. The proportion of people unable to work for the last twelve months was estimated at $0.5 \%$ in the 1999/2000 Household Survey ${ }^{30}$. 
Disabled people suffer relative income poverty in addition to the reduction in their quality of life caused by their disability, the social stigma sometimes experienced, and more limited access to services. In 2000, $46 \%$ of persons with disability were poor (using the narrow definition as those who were economically inactive during the last 12 months because of disability), compared to $34 \%$ of people in general.

More information is needed on the extent to which disabled people are able to meet their specific needs such as access to equipment, and the extent to which specific disabilities are currently preventing economic participation or reducing people's productivity.

The chronically ill

Data on the relative poverty of those who are chronically ill is limited.

The displaced

One of the most serious forms of poverty in Uganda is the living conditions of people in camps. While rigorous data are scarce, some studies have shown alarmingly high rates of malnutrition in the camps. This group is not always easy to identify within the household surveys, although a pointer is that poverty was high in the 2003 survey among people now resident in the East who had recently moved from other districts. Improved monitoring of the living conditions of people in camps is a high priority research need.

\section{Chronic poverty and vulnerability}

Vulnerability in some societies takes the form of temporary income shocks due to climatic factors. These can be translated into chronic impoverishment if households are unable to insure themselves against the shocks without selling vital assets and do not receive outside assistance.

In Uganda's case, much vulnerability takes the form of the disruption of the household membership, often due to the illness or death of a member. This makes a permanent change in the household's ability to raise income. Households headed by female widows are particularly vulnerable to asset depletion and impoverishment.

\subsection{Structural transformation and poverty reduction}

\section{Incomes and economic transformation}

In order to become a middle-income country, the structure of Uganda's economy must change. Currently, most households derive much of their income from subsistence agriculture, but many households are moving into production for the market and selfemployment outside agriculture. 
Table 2.4: Main activities of household head and poverty status ${ }^{31}$

\begin{tabular}{|l|c|c|c|c|}
\hline $\begin{array}{l}\text { Activity status of household } \\
\text { head }\end{array}$ & \multicolumn{2}{|c|}{ Population share } & \multicolumn{2}{c|}{$\begin{array}{c}\text { Proportion under } \\
\text { poverty line }\end{array}$} \\
\hline & $\mathbf{1 9 9 9 / 2 0 0 0}$ & $\mathbf{2 0 0 2 / 3}$ & $\mathbf{1 9 9 9 / 2 0 0 0}$ & $\mathbf{2 0 0 2 / 3}$ \\
\hline $\begin{array}{l}\text { Self-employment in } \\
\text { agriculture }\end{array}$ & 70.8 & 57.7 & 39.1 & 48.8 \\
\hline $\begin{array}{l}\text { Self-employment outside } \\
\text { agriculture }\end{array}$ & 12.0 & 25.2 & 17.0 & 20.6 \\
\hline Government employment & 5.1 & 4.8 & 13.7 & 15.5 \\
\hline Private employment & 7.1 & 6.7 & 17.3 & 21.0 \\
\hline Not working & 4.9 & 5.6 & 42.3 & 39.4 \\
\hline
\end{tabular}

The structure of the labour force is changing (table 2.4). Between 2000 and 2003, the proportion of households whose head is mainly employed in agriculture fell from $71 \%$ to $58 \%$, and there is a corresponding increase in the proportion of those who are self-employed outside agriculture from $12 \%$ to $25 \%$. Farmers' incomes fell during the period, so that the proportion of farming households in poverty rose from $39 \%$ to $49 \%$. This was accompanied by an increase in poverty among those in non-agricultural selfemployment (17\% to $21 \%$ ). Nevertheless, for the individual household non-agricultural self-employment is still a way out of poverty; poverty is much lower among those with non-agricultural self-employment $(21 \%)$ than among those who depend on agriculture $(49 \%)$.

Although data are highly sensitive to definitions, the pattern of incomes in urban and rural areas is shown in Table 2.5. 
Table 2.5: Income sources by quintile ${ }^{32}$

\begin{tabular}{|c|c|c|c|c|c|c|}
\hline & \multicolumn{6}{|c|}{ Mean share of income source in total income $(\%)$} \\
\hline & $\begin{array}{c}\text { crop } \\
\text { farming }\end{array}$ & $\begin{array}{l}\text { no crop } \\
\text { farming }\end{array}$ & $\begin{array}{c}\text { non } \\
\text { agricultural } \\
\text { entreprises }\end{array}$ & property & $\begin{array}{c}\text { other } \\
\text { sources }\end{array}$ & $\begin{array}{c}\text { Wage } \\
\text { employment }\end{array}$ \\
\hline $\begin{array}{l}\text { 1997: } \\
\text { 1st expenditure } \\
\text { quintile (poorest 20\%) }\end{array}$ & 60.3 & 0.3 & 8.5 & 5.1 & 14.4 & 10.7 \\
\hline Lower middle & 58.0 & 0.6 & 9.7 & 6.2 & 13.2 & 12.3 \\
\hline Middle & 56.9 & 1.0 & 11.6 & 5.3 & 12.6 & 12.6 \\
\hline Upper middle & 51.3 & 1.3 & 16.8 & 5.1 & 12.9 & 14.4 \\
\hline Richest & 32.4 & 3.1 & 23.8 & 4.7 & 12.9 & 23.1 \\
\hline Total & 51.9 & 1.3 & 14.1 & 5.3 & 12.8 & 14.6 \\
\hline $\begin{array}{l}\text { 1999/2000: } \\
\text { 1st expenditure } \\
\text { quintile (poorest) }\end{array}$ & 42.5 & 4.9 & 12.4 & 7.1 & 24.7 & 8.4 \\
\hline Lower middle & 51.8 & 3.8 & 11.1 & 5.9 & 18.5 & 8.9 \\
\hline Middle & 50.5 & 3.3 & 12.3 & 6.7 & 16.5 & 10.7 \\
\hline Upper middle & 45.8 & 3.9 & 15.2 & 7.2 & 15.4 & 12.5 \\
\hline Richest & 28.2 & 4.0 & 23.3 & 9.2 & 14.4 & 20.9 \\
\hline Total & 43.8 & 4.0 & 14.9 & 7.2 & 17.9 & 12.3 \\
\hline
\end{tabular}

\section{Self-employment inside and outside agriculture}

Self-employment within agriculture remains the largest single income source, although its share has fallen over time. In 1997, its average share in incomes was over 50\%; this remained the case for the poorest $40 \%$ of households in 1999-2000. Non-agricultural enterprises provide an average share of about $15 \%$ of incomes, but are more important for the richest households. Together, these two sources provide the bulk of incomes at all income levels.

To boost incomes from self-employment, it is essential to accelerate growth in smallholder agriculture. The maximum benefit to farmers will come from exported agriculture, because production for the domestic market tends to drive prices down and hence passes the gains on to urban consumers. 


\section{Wage employment}

The data in Table 2.5 show that the average share of wages in income remains quite small at about $12 \%$ and that it is more important for the better-off households. Wage employment has not been growing very fast and inequality among wages is increasing. ${ }^{33}$ A substantial proportion of this employment is in the public sector, and comparative studies have found that employment opportunities for secondary and tertiary graduates are more concentrated in the public sector in Uganda than in other African countries ${ }^{34}$. The proportion of households headed by a wage-earner actually fell between 2000 and 2003. Within the wage sector, wage inequality increased markedly. The acceleration of private investment during the period 2000-2003 does not yet appear to have led to major increases in the share of wage employment in household activities ${ }^{35}$.

\section{Unemployment}

Open unemployment is relatively rare, and is found mainly in urban areas, particularly among the most highly educated and amongst women (Annex Table 2.2).

Underemployment (working on economic activities less than 40 hours a week) is widespread, affecting $65 \%$ of adults, including $75 \%$ of women and $55 \%$ of men. This re ects the burden on women's time from 'non-economic' activities such as childcare and fetching fuel wood and water. Women cannot devote 40 hours a week to 'economic' 36 activities because they are so heavily committed to these 'non-economic' activities.

Visible underemployment (working on economic activities less than 40 hours a week despite being available for work) is the best way of capturing the dimensions of underutilised labour. This is higher among men than women, and higher in rural areas than urban areas (table 2.6). The lower rate of underemployment among women re ects the 'non-economic' burdens on their time.

Table 2.6: Visible underemployment, $\%$ of labour force f $^{37}$

\begin{tabular}{|l|c|l|c|c|c|c|c|c|c|}
\hline Age group & Rural & urban & total & & & & & & \\
\hline & male & Female & total & male & female & total & male & female & total \\
\hline $\mathbf{1 0 - 1 9}$ & 12 & 12 & 12 & 8 & 5 & 6 & 12 & 11 & 12 \\
\hline $\mathbf{2 0 - 2 9}$ & 24 & 17 & 20 & 8 & 9 & 8 & 18 & 15 & 16 \\
\hline $\mathbf{3 0 - 3 9}$ & 19 & 15 & 17 & 11 & 12 & 12 & 18 & 15 & 16 \\
\hline $\mathbf{4 0 - 4 9}$ & 18 & 13 & 15 & 7 & 11 & 9 & 16 & 13 & 15 \\
\hline $\mathbf{5 0 +}$ & 12 & 6 & 9 & 7 & 8 & 8 & 11 & 6 & 9 \\
\hline Total & 18 & 14 & 16 & 9 & 9 & 9 & 16 & 13 & 15 \\
\hline
\end{tabular}




\section{Sectoral growth and household incomes}

In the medium run, poverty reduction depends on expanding incomes from smallholder agriculture, for two reasons. First, the incomes of the poor depend directly on agriculture. Secondly, farmers spend part of the incomes generated from crop sales, on nonagricultural goods and services. Most self-employed non-agricultural producers sell their products locally ${ }^{38}$ and therefore depend on the demand generated by the incomes raised from agriculture. Therefore, when agricultural incomes fall - as they did between 2000 and 2003 - people in non-agricultural self-employment experience difficulties. There is international evidence ${ }^{39}$ that in low-income, agricultural economies, poverty responds much more to rural than to urban growth, and that agricultural growth is needed in order to generate broader rural growth. This concern is particularly important because of the increased inequality in incomes that has been evident since 1997. Expansion in incomes from smallholder agriculture is the best way of reversing this trend.

In the long run, an increasing proportion of incomes will be raised from wage employment. While wage employment provides only a small proportion of incomes for the poor at the moment, its importance will increase in the future. To boost wage employment, labourintensive activities in the formal sector need to grow. This depends on profitable private investment.

Uganda's strategy for poverty reduction therefore combines increased agricultural incomes from smallholder farming with increased opportunities for wage employment coming from the growth of formal enterprises in agriculture, industry and services.

\section{Production and economic transformation}

Corresponding to the shift in labour force is a shift in the structure of the economy. Over time, two major shifts are expected; towards industry, and towards exports. For nine comparator countries that reached an income level which would be achieved by Uganda in twenty years' time with a good growth performance, the average proportion of manufacturing to GDP when they reached this level was $21.9 \%$ and the average proportion of exports to GDP was 24.5\%. The equivalent ratios in Uganda in 2001/2 were $9.7 \%$ and $11.8 \%{ }^{40}$. As noted in Chapter 3 , the share of industry has increased significantly over the last twelve years in Uganda.

In Uganda's case, the natural resource endowment and location of the country means that industry is most likely to be internationally competitive if it adds value to agricultural output (and other natural resource based activities such as forestry). Agro-processing is therefore an important sector within industry that is expected to expand over the next several years. This process has started in a number of areas; for instance, there has been a marked expansion in processing and exports of commodities such as coffee, fish and cut owers.

\section{Prospects for the reduction of income poverty}

The LTEF allows a forward projection of poverty. If population grows at 3.6\%over the next fifteen years, income distribution is constant ${ }^{41}$, and GDP grows at about $6 \%$ over the period, then the proportion of people below the poverty line is projected to fall to $28 \%$ by 2013/4. Clearly, faster poverty eradication is desirable and can be achieved in three ways: 
- Higher GDP growth. Given a population growth rate of 3.4\%, an increase in economic growth from 5 to $7 \%$ represents more than a doubling of per capita growth and an even more dramatic impact on the rate of poverty reduction.

- Reductions in inequality. If the Gini coefficient were to fall to 0.39 over the next ten years, reversing the increases in inequality observed over the last three years, then with $6 \%$ real growth the poverty headcount would fall to $23 \%$.

- If, in addition to the above assumptions, population growth falls to $2.4 \%$, then poverty is projected to fall to $18 \%$.

A $6 \%$ real rate of growth is considered realistic based on the macroeconomic projections; the reduction in inequality and in population growth, while ambitious, are possible if growth in the regions and sectors where the poor are located is promoted. Hence an ambitious, but reasonable target for the proportion in poverty by $2013 / 4$ is $18 \%$.

\subsection{Human development outcomes}

Improvement in education and functional adult literacy have borne fruit in literacy rates. While there was no observable change by the expiry of the $1^{\text {st }}$ PEAP in 2000 , the national average literacy level rose from $65 \%$ in $1999 / 00$ to $70 \%$ in $2002 / 3$, mainly because of improvement in rural areas. Women have benefited more from the improvement than men. These developments are the shared achievement of the education and social development sectors through the UPE and FAL programmes.

Table 2.7: Trend in Literacy Rates for the Population Aged 10 Years and above (\%age)

\begin{tabular}{|l|c|c|c|c|c|c|c|c|c|}
\hline \multicolumn{9}{|c}{1997} & $\mathbf{1 9 9 9 / 0 0}$ \\
\hline & Male & Female & Total & Male & Female & Total & Male & Female & Total \\
\hline National & 74 & 57 & $\mathbf{6 5}$ & 74 & 57 & $\mathbf{6 5}$ & 77 & 63 & $\mathbf{7 0}$ \\
\hline Urban & 89 & 79 & $\mathbf{8 3}$ & 92 & 82 & $\mathbf{8 6}$ & 90 & 84 & $\mathbf{8 7}$ \\
\hline Rural & 70 & 49 & $\mathbf{5 9}$ & 72 & 54 & $\mathbf{6 2}$ & 74 & 60 & $\mathbf{6 7}$ \\
\hline Kampala & - & - & - & - & - & - & 94 & 91 & $\mathbf{9 2}$ \\
\hline Central & 81 & 74 & $\mathbf{7 7}$ & 81 & 74 & $\mathbf{7 7}$ & 82 & 74 & $\mathbf{7 9}$ \\
\hline Eastern & 72 & 52 & $\mathbf{6 2}$ & 72 & 52 & $\mathbf{6 2}$ & 72 & 54 & $\mathbf{6 3}$ \\
\hline Northern & 72 & 38 & $\mathbf{5 5}$ & 64 & 33 & $\mathbf{4 7}$ & 72 & 42 & $\mathbf{5 6}$ \\
\hline Western & 70 & 51 & $\mathbf{6 0}$ & 74 & 61 & $\mathbf{6 7}$ & 79 & 69 & $\mathbf{7 4}$ \\
\hline
\end{tabular}

Source: UNHS 2002/03

Health outcomes show a more mixed performance. As discussed in Chapter 2, evidence from the 2000 DHS indicates that there were no significant improvements in child and maternal health outcomes during the 1990s (Figures $2.1-2.3$ ). Throughout the 1990s, almost one in ten Ugandan children died before their first birthday. Improvements in incomes, water supply and access to health services appear to have been counteracted by increasingly dangerous malaria, the knock-on effects of adult illness on future generation's social capitals as a result of the AIDS epidemic, and deterioration in sanitary practices. 
In the second PEAP, major improvements have been made in the delivery of health services (discussed under the health sector). There is as yet no evidence on trends in infant and child mortality in the early 2000s, but it is hoped that the improvements in services will have started to improve the outcomes. Similarly, much less progress has been made than was hoped in reducing maternal mortality. As a result, Government missed its targets for infant and maternal mortality (see Fig. 7.2 and 7.3).

\section{Figure 2.1: Infant, Under-5, and Maternal Mortality}

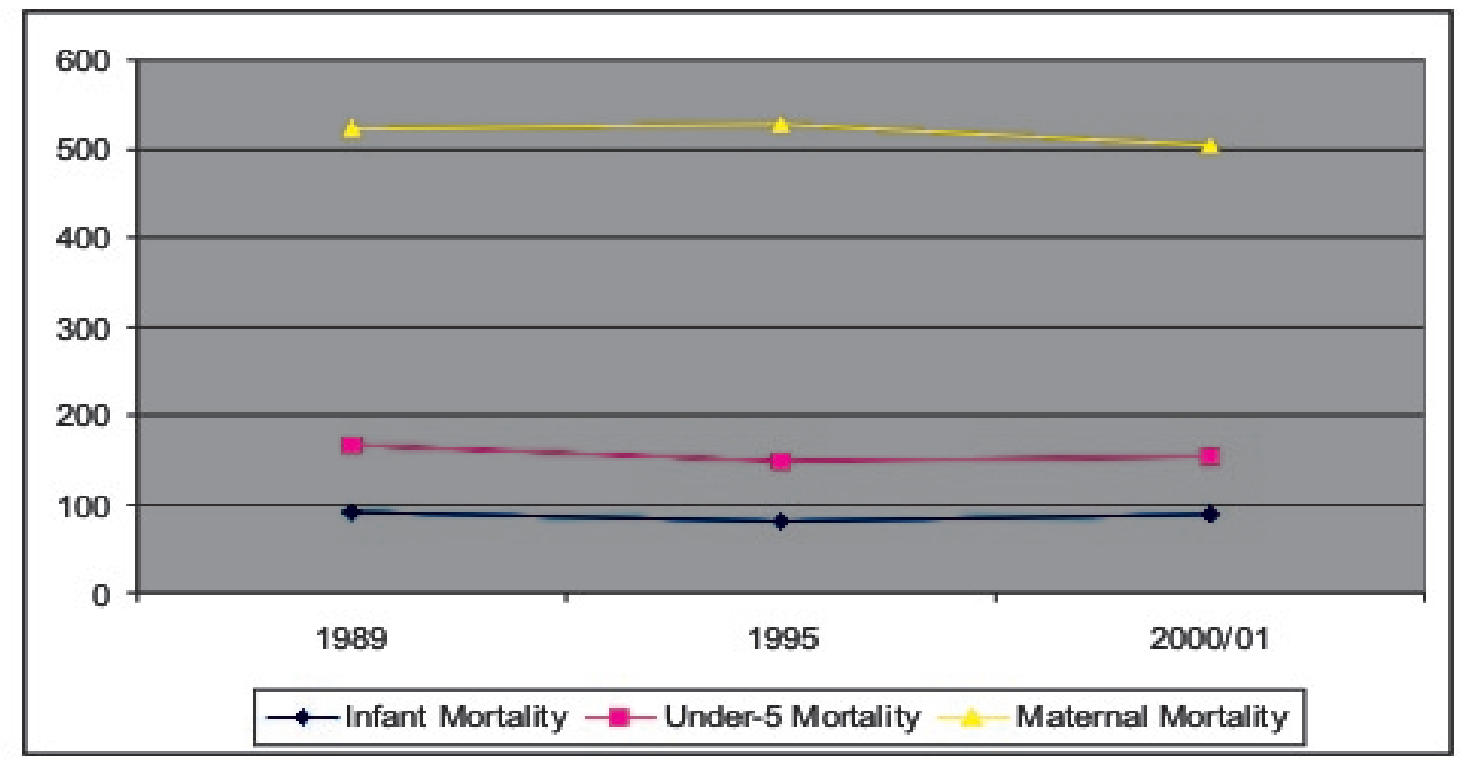

Source: UDHS (1995, 2000/01)

Note: infant and under-five mortality are per 1000, maternal mortality per 100,000.

Figure 2.2: Infant Mortality

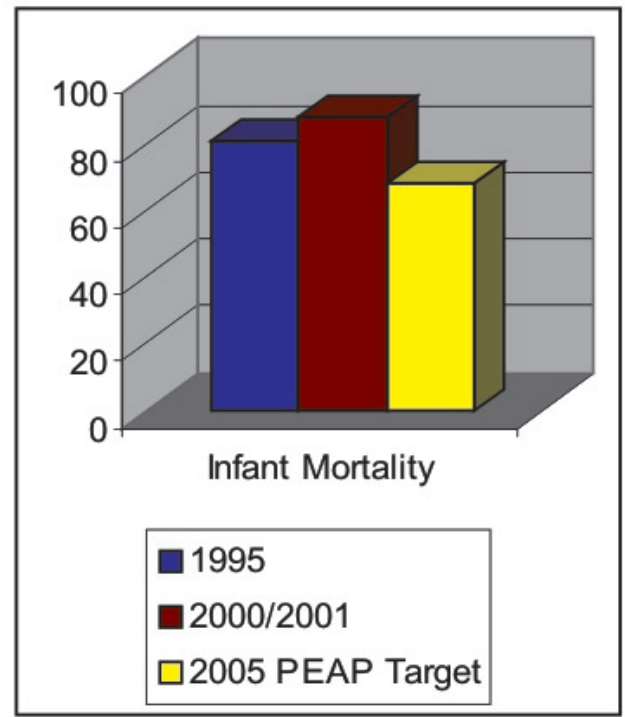

Source: UDHS (1995, 2000/01)
Figure 2.3: Maternal Mortality

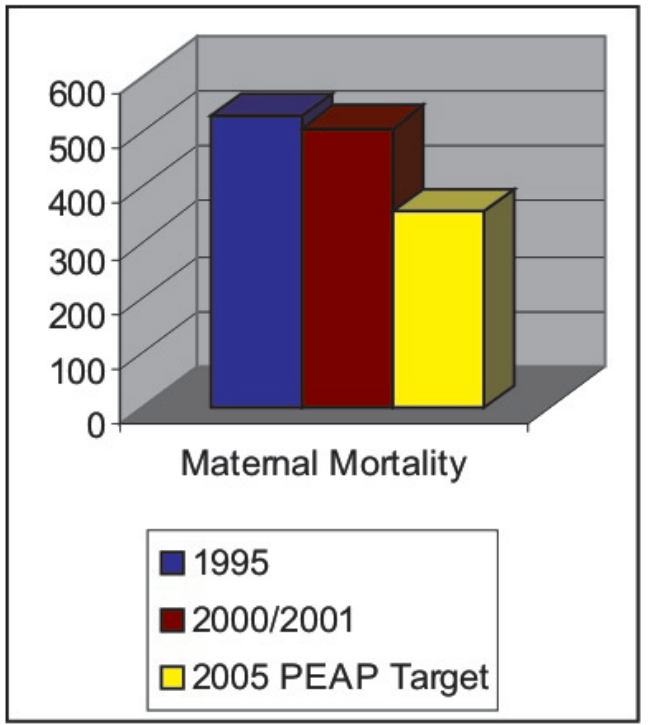

Source: UDHS (1995, 2000/01) 
There are significant regional differentials in child and infant mortality, with much worse outcomes in the North.

In 2001, 39\% of children under five years were stunted, compared to 38\% in 1995. Poor nutrition is a result of low incomes, limited information about health and nutrition, unequal bargaining power within the household, the heavy burdens on women's time, and the high incidence of disease.

In the case of HIV/AIDS, the last three years have seen some fall in the prevalence rate from $6.8 \%$ to $6.2 \%{ }^{42}$, though the number of people getting sick as a result of infection over the last 5 years or more will remain high for some time to come and will need to be factored in to all strategies described in this PEAP. The continuing insecurity and consequent population movements in parts of the country expose some groups to higher risk, and make a continued vigorous prevention and impact mitigation efforts particularly important.

The 2002 Census showed that Uganda's population was growing faster than had been thought. Between 1991 and 2002, the population grew at 3.4\% per year, compared to rates between 2 and 3\% in the 1970s and 1980s. The increase may partially re ect population movement and increased security, but the high rate of growth is mainly due to large family size. The total fertility rate (the number of women born on average to a woman who lives through the childbearing age) is very high, at 6.9, and has changed little in recent years.

Uganda's high fertility rate presents a challenge to poverty reduction in its own right. Larger families are more likely to be poor, to fall into poverty, and children in them are at much greater risk of dying young.

Water supply improved significantly over the 1990s. However, the delivery of water to the rural population remains a major challenge. During the second PEAP, public spending on rural water supply increased, but costs also increased. Safe water coverage had mildly improved from a rural coverage of $49.8 \%$ in 2000 to $54.9 \%$ in 2002 while urban coverage rose from $54 \%$ in 2000 to an estimated $60 \%-65 \%$ in 2003 . While this may not yet have led to improved health outcomes, it has reduced the time women and girls have to spend fetching water. Strengthening the complementary inputs to water supply, such as public information about sanitation, will enhance the health benefits of water supply.

\subsection{Access to public services and infrastructure}

The last three years have seen very significant improvements in the access to public services and infrastructure. But the poor have much less access to services and infrastructure than the better-off. Annex Table A 2.3 shows the pattern of access to service by income quintile.

It can be seen that access to almost all services have improved over the last three years. In particular, there are marked improvements in access to schools, public health facilities and telephones. All quintiles of the population benefited. However, there are also marked differentials in access by quintile; this is particularly striking for telephones, where only $11.2 \%$ of the poorest quintile have access within $2 \mathrm{~km}$. compared to $53 \%$ of the top quintile, for electricity, and for secondary schools. 
Annex Table A 2.4 shows that most communities have seen projects implemented in most sectors. However, projects in a number of sectors are rated more highly by betteroff households than by the poor. For instance, about $30 \%$ of communities had had new agricultural techniques introduced. In these communities, $77 \%$ of the people in the top quintile felt that this initiative met the community's needs, compared to only $49 \%$ in the bottom quintile.

\subsection{Empowerment}

Empowerment in Uganda's context is understood as all those processes where women and men take control and ownership of their lives. There are three core elements of empowennent:

The first one is agency or the ability to define one's goals and act upon them. However, evidence from participatory studies shows that although the affirmative action policy that government is pursuing is showing some positive results, participation by women in local governance still needs to be strengthened.

The second core element of empowerment is gender awareness. In order to be able to act on ones goals, one must be aware of the forces and structures working to one's disadvantage e.g. value systems, nonns, legal frameworks, discriminatory practices. Recent participatory research has concluded that lack of control over productive resources by women remains one of the root causes of poverty. Women explained that they lack control over land, the crops their labour produces from it, livestock and other productive resources. Yet they are responsible for meeting family needs. It is clear that although women are subordinated in a number of different power structures based on e.g. class, geographical location, ethnicity all of these are gendered and unless there is awareness of these structures women will not be able to change them. Ultimately, the empowennent processes should lead to protest against all structures that subordinate women.

The third component of empowerment is self-esteem and self-confidence. Living in societies where vulnerable groups are subordinated and subject to different kinds of oppression often leads to a naturalisation of the prevailing power relations to the extent that the powerless see their own powerlessness as natural or justified. Gaining strength from shared experiences and a common will to change is therefore important for all groups of people. In Uganda local community members have described vulnerability as powerlessness to mitigate negative household and individual shocks. Government recognizes that vulnerability varies with gender, age, ethnicity, occupation and social status.

The steps taken by Government through various social policies and programmes for disadvantaged groups like, women, widows, the youth, the elderly, neglected children and orphans, people with disabilities, the displaced and refugees are central to poverty reduction initiatives over the PEAP period.

It is difficult to monitor changes in empowerment. However, the political process of democratisation (discussed further in Chapter 6) has certainly led to a large increase in political participation, with particular attention given to representatives of women, youth and the disabled. Much anecdotal evidence and quantitative evidence shows that women have 
entered more than before into economic activities outside the household, and although this has imposed a burden on their time, it has also conferred greater economic independence and empowerment ${ }^{43}$. However, women remain disempowered by the unequal ownership of assets, by the widespread practice of bride price, and by the occurrence of domestic violence. Ending these forms of inequality represents a major challenge. Displaced people also represent an important, relatively disempowered group.

\subsection{Policy implications}

In light of the above analysis and the core challenges highlighted in Chapter 1, the following are the key policy implications:

- A reduction in poverty will require reversing the recent reduction in incomes and moderating the increase in inequality

- The sector where the poor are most heavily involved is self-employment in agriculture. Hence removing the constraints to this sector and increasing opportunities in the nonfarm sectors is high priority. This will also create demand for non-agricultural goods and services.

- Insecurity has been a major contributor to poverty and inequality over the last fifteen years and the most af icted areas have not been able to share in the benefits of economic growth. Hence achieving an end to con ict and the rue of law and order is critical for poverty-reduction.

- The disappointing performance in child health in recent years requires a range of actions, some of which are already being taken.

- Enhance policy and institutional co-ordination for improved programme implementation. 


\section{Economic Management}

\subsection{Uganda's growth performance}

\section{GDP Growth}

Uganda has experienced strong economic growth over the past decade. Real GDP growth at market prices has averaged 6.5\% per annum since 1990/1991. Recently, concerns have been raised that growth has slowed slightly over the past five years, as the average growth rate between $1998 / 99$ and 2002/03 was $6.1 \%$ per annum, as compared to $6.8 \%$ between 1990/91 and 1997/98. In fact, the higher average growth rate between 1990/91 and 1997/ 98 was boosted by three years of exceptionally strong growth in the early 1990s, which was driven by the economic reforms implemented in the first half of the 1990s and the coffee price boom.

\section{Chart 3.1: Real GDP Growth at Market Prices 1990/91 - 2002/03}

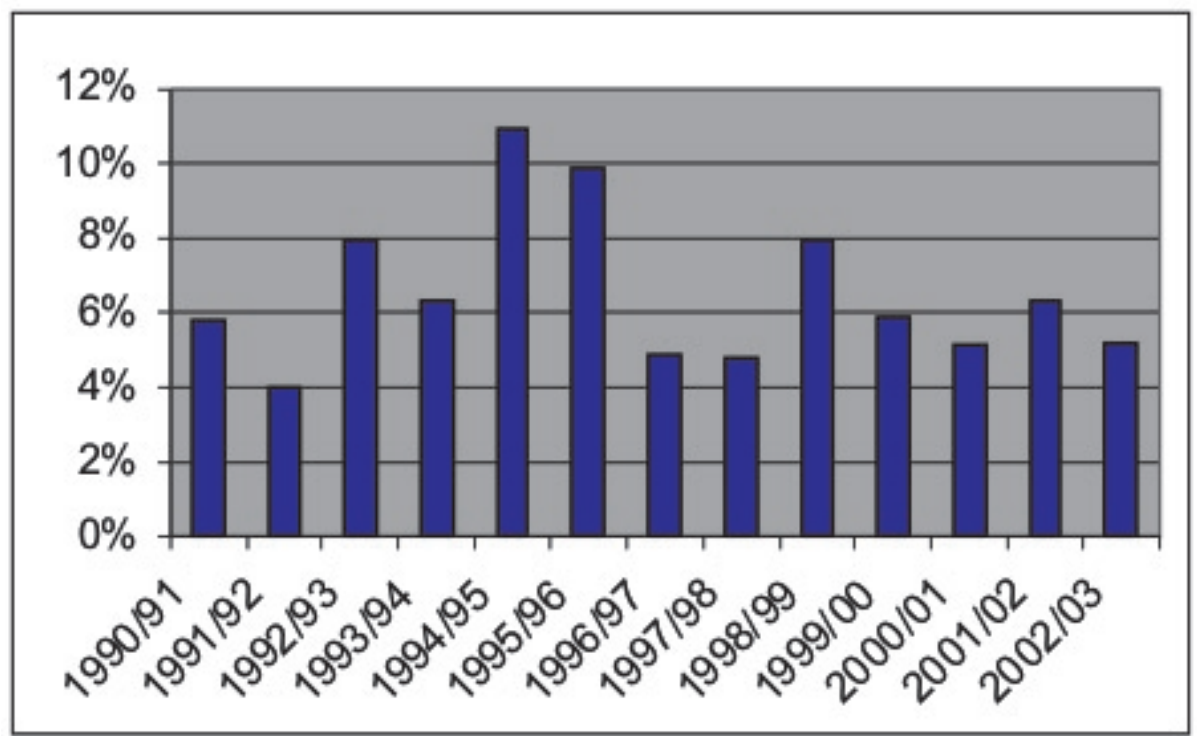

The determinants of growth in Uganda during the 1990s have been identified as improved security, the restoration of macroeconomic stability, the removal of economic distortions and an improvement in the terms of trade, as a result of the mid-nineties coffee price boom. ${ }^{1} \quad$ Growth in total factor productivity, meaning the efficiency with capital and labour are used, made a significant contribution to GDP growth during the 1990s, re ecting the scale of rehabilitation of production processes after the restoration of peace to most of the country.

On a sectoral basis, industrial production saw the highest rate of growth, averaging $10.4 \%$ per annum between 1990/91 and 2002/03 as a whole, although it slowed slightly to an average of $7.7 \%$ per annum in the last five years. Services grew by an average of $7.5 \%$ per annum between $1990 / 91$ and 2002/03, and by $6.9 \%$ per annum over the past five years. Agriculture had the slowest growth rate amongst the major sectors, averaging $3.8 \%$ per annum between 1990/91 and 2002/03, although growth was slightly higher in the last five years, at $4.4 \%$ per annum. 
Chart 3.2: Sectoral GDP growth rates 1990/91-2002/03

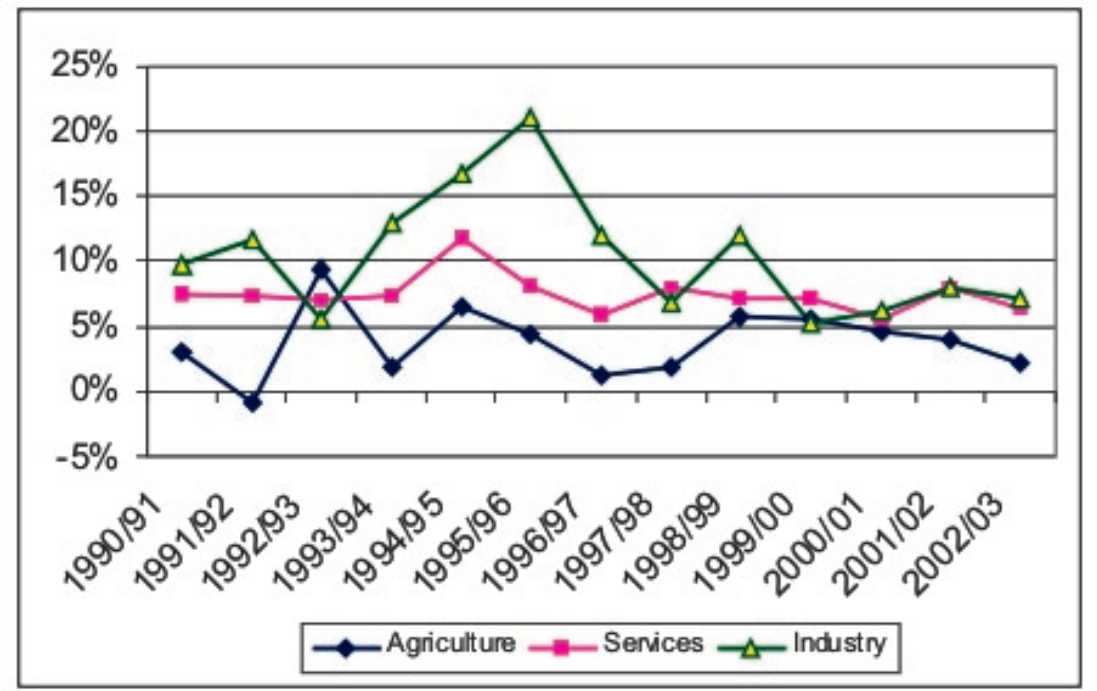

Source: MoFPED

\section{Structural Transformation}

Production has been shifting slowly towards services and industry, as growth in those sectors has outpaced agricultural growth. Agriculture accounted for 38.7\% of GDP in $2002 / 03$, as compared to $51.1 \%$ in $1991 / 92$, as subsistence agriculture declined by 10 percentage points of GDP over the period. Services increased as a share of GDP from $36.6 \%$ in $1990 / 91$ to $41.8 \%$ in $2002 / 03$, and industrial production rose from $12.4 \%$ to $19.5 \%$ over the same period.

\section{Chart 3.3: Sectoral Shares of GDP 1990/91 - 2002/03}

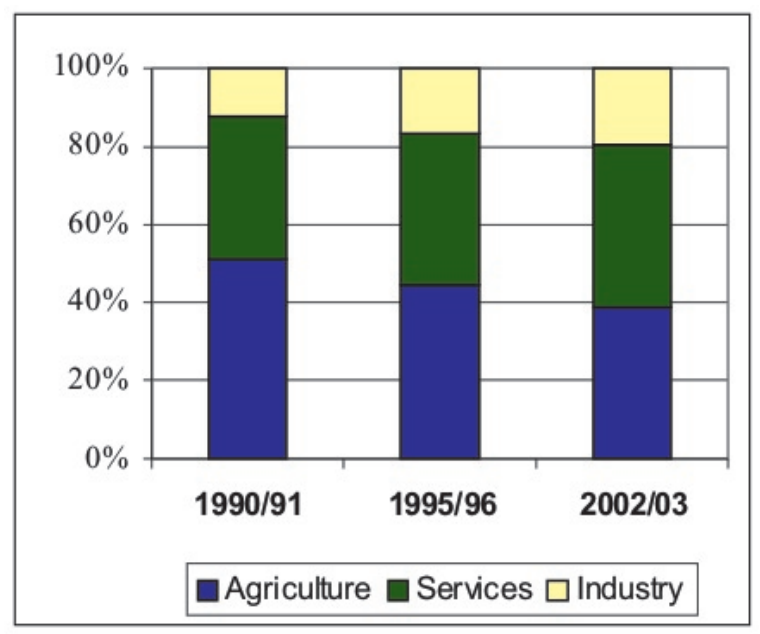

Source: MoFPED

These shifts constitute the beginning of the process of structural transformation in the economy, whereby production slowly moves away from subsistence-based agricultural to a mix of commercial agriculture, services and industry as a result of shifts in demand and labour patterns in the economy. Agricultural commercialisation is expected to lead 
to increased demand for non-agricultural goods and services, and increased agricultural productivity is expected to free up labour for use in other sectors of the economy, leading to a slow shift in the pattern of production over time.

However, given Uganda's natural competitive advantage of fertile land and a good climate, it is not expected that Uganda will move away from agricultural production altogether, but that it will orientate its agricultural output towards regional and international export markets. Increasing the share of exports within agricultural production is important because increased supplies of basic food crops to the domestic market will depress farm gate prices, transferring part of the benefits of production to urban consumers. Consequently, Government's agricultural strategy is focusing on the production and processing of agricultural exports, both traditional exports such as coffee and cotton and non-traditional exports such as horticulture, vanilla and honey.

Increasing agricultural commercialisation and export production is particularly important for poverty reduction given the dependence of the majority of the poor on agriculture as their main source of income. This dependence of the workforce on agriculture is illustrated by the 2003 Labour Force Survey, which shows that in spite of the twelve percentage point decline in agricultural production as a percentage of GDP between 1990/91 and 2002/03, agriculture in Uganda remains very labour intensive. Sixty-nine percent of the labour force was employed in agriculture-related activities in 2003, as compared to $23 \%$ in services and $8 \%$ in industry ${ }^{2}$.

To achieve its objectives of agricultural commercialisation and export production, however, Government cannot rely on Uganda's natural comparative advantage of fertile soils and a good climate alone. It has to safeguard the environment by ensuring longterm environmental sustainability. Research conducted for this PEAP suggests that farming practises which contribute to soil nutrient depletion pose a significant threat to land productivity in Uganda ${ }^{3}$. Population pressures also diminish land productivity. In a study sample, $95 \%$ of farmers were found to be taking out more nutrients from the soil than they were putting back. Actions to address environmental sustainability are discussed in detail in the following chapter.

\section{Per Capita growth}

Although Uganda's overall GDP growth averaged 6.5\% per annum between 1990/91 and 2002/03, the rate of per capita GDP growth was much slower on account of Uganda's high rate of population growth. GDP per capita grew by $2.7 \%$ per annum over the period as the population grew by $3.4 \%$ a year. Uganda has the third highest population growth rate in the world, with the average Ugandan woman giving birth to almost seven children in her lifetime. A reduction in the rate of population growth would have a positive impact on the level of per capita GDP growth, and on per capita incomes, particularly in the ten to fifteen year phase when the labour force would be large relative to the total population as the birth rate slowed. This PEAP commits the Government of Uganda to extend the national coverage and effectiveness of family planning services, to allow women to meet their 'unmet needs' for family planning, as identified in the most recent Demographic Health Survey ${ }^{4}$. Further actions to reduce family size and to increase female participation in income-generating activities are discussed in Chapter 4 and 7. 


\section{Future Growth Prospects}

Uganda's objective remains strong, private sector-led growth which can contribute to economic development and poverty reduction. This PEAP, like the previous ones has set a real GDP growth target of $7 \%$ per annum as one of the conditions for achieving the required poverty reduction. The actions needed to boost growth from the average rate of $6.1 \%$ seen over the past five years to $7 \%$ are as follows:

- Removal of administrative barriers to investment

- Improvement in transport infrastructure and utility services

- Modernisation/commercialisation of agriculture, with emphasis on valueaddition

- Actions to improve rural access to finance and to strengthen SME development.

- Actions to enhance environmental sustainability

- Security in Northern Uganda

- Actions to enhance gender equality

Policies to achieve the above objectives are discussed in detail in subsequent chapters.

The East African Customs Union is also expected to boost production in the medium to long term, as domestic producers benefit from duty free imports from within the Union, and produce for a larger internal market.

In addition, agricultural commercialisation, environmental sustainability and measures to reduce family size will also be important factors in reducing income inequality. Poverty estimates based on existing levels of inequality, a population growth of $3.6 \%$ per annum and real GDP growth of $6 \%$ per annum, estimate that $26 \%$ of the population will be living in poverty in 2017. If this PEAP meets its objectives of reducing inequality and raising GDP growth to $7 \%$ per annum, poverty can be expected to fall below this level. For example, a fall in the rate of population growth to $2.8 \%$ per annum would reduce poverty to $21 \%$ by 2017 , even if annual real GDP growth remained at $6 \%$.

\subsection{Macroeconomic Management}

A sound economic framework which is conducive to private sector investment is vital to Uganda's growth strategy. In the absence of a sound economic environment, other interventions to boost growth will hold little value. Uganda's economic policy framework emphasises in ation control, strong growth in private investment, fiscal consolidation and increased revenue generation as its main objectives.

\section{Objectives of Macroeconomic Management}

The central objectives of Uganda's macroeconomic management are in ation control and private sector-led growth. Government's fiscal policies are subordinated to these objectives, meaning that Government expenditure should be restricted to a level that is compatible with them by controlling its fiscal deficit. Too high a fiscal deficit, even when funded by donor in ows, can generate in ation or crowd out the private sector by appreciating the exchange rate, driving up interest rates or limiting the funds available to commercial banks for private sector lending. 


\section{Uganda's macroeconomic performance}

Uganda brought in ation under control in 1992/93, mainly as a result of exercising tight control over Government expenditure. ${ }^{5}$ Annual average headline in ation has averaged just $4.8 \%$ per annum over the past decade as a result of the Government's sound macroeconomic policies.

\section{Chart 3.4: Annual headline in ation 1990/91 - 2002/03}

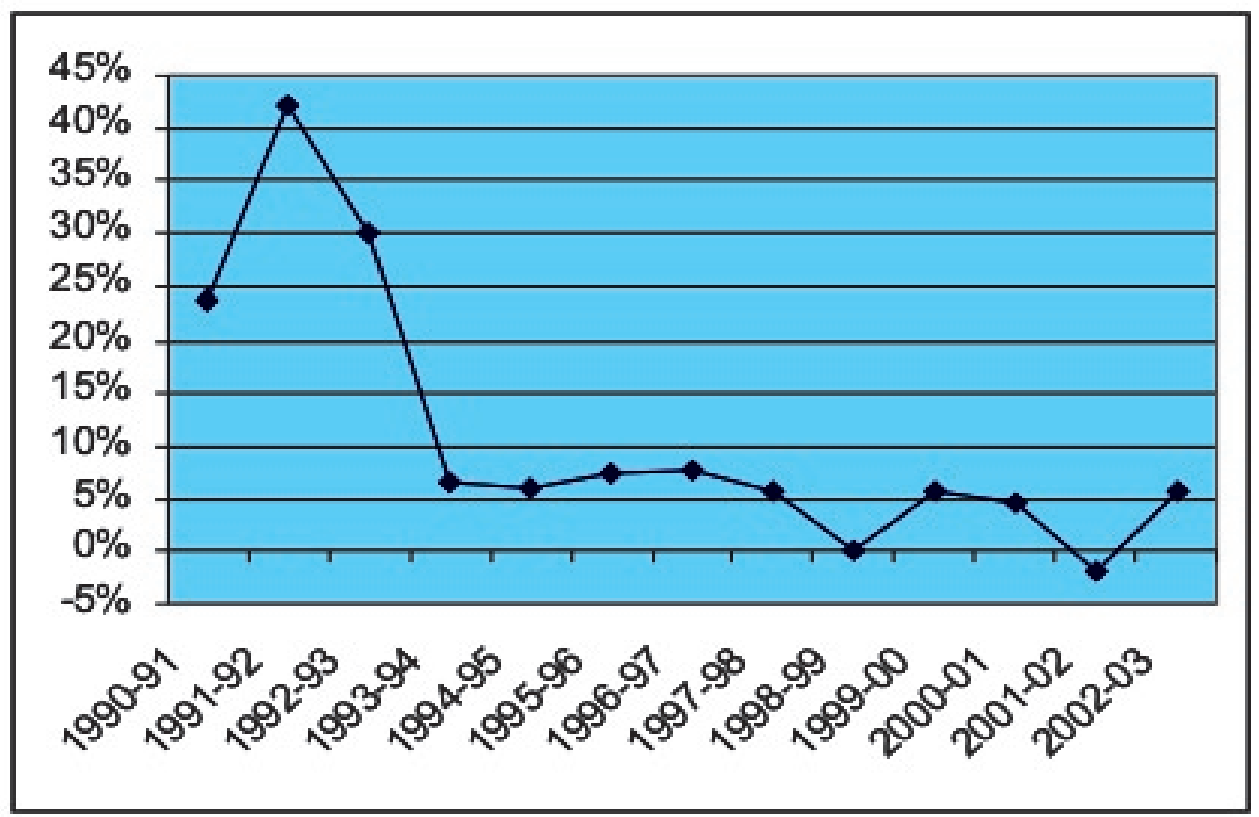

Once in ation had been brought under control and key markets, such as the foreign exchange and financial markets, were liberalised in the first half of the 1990s, private investment began to expand rapidly. In real terms, private investment in 2002/03 was three times higher than it had been in 1991/02. As a percentage of GDP, private investment rose from $9.1 \%$ of GDP in 1990/91 to 15.6\% of GDP in 2002/03.

\section{Chart 3.5: Real private investment 1990/91 - 2002/03 (constant 1997/98 prices)}

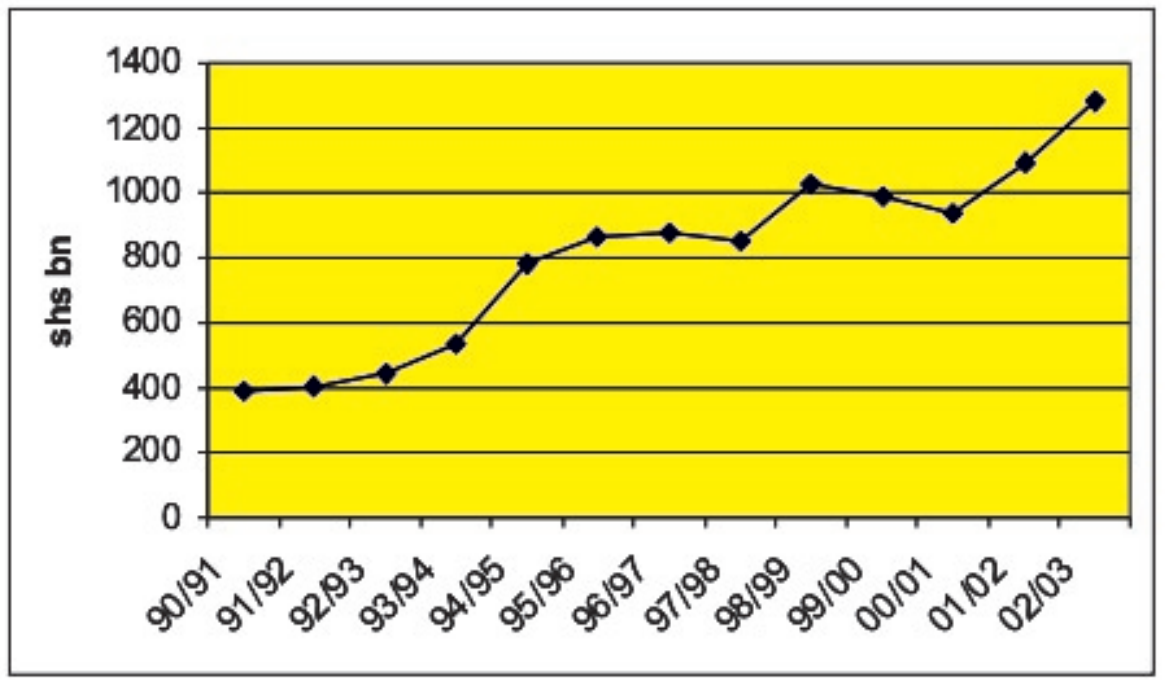


However, since 1997/98, the Government's fiscal deficit excluding grants ${ }^{6}$ has risen substantially, as a result of an increase in donor aid in ows to finance Government expenditure. Between 1997/98 and 2001/02 the fiscal deficit doubled as a percentage of GDP, from just over $6 \%$ in $1997 / 98$ to $12.4 \%$ in $2001 / 02$. It fell back slightly in 2002/03, but remained in double figures, at $11.2 \%$ of GDP.

Although the increase in the donor-funded fiscal deficit has enabled Government to increase expenditure more rapidly than the growth in domestic revenues alone would allow, it has led to an increase in the net issuance of Government securities and sales of foreign exchange by the Bank of Uganda, in order to control in ation at $5 \%$. Government's net issuance of securities has risen by $500 \%$ over the past five years, whilst Bank of Uganda's foreign exchange sales have risen by $1000 \%$. The increased sale of Government securities has tended to drive up interest rates and to reduce Commercial Bank's extension of private sector credit as they increase their TB holdings, whilst the increased sale of foreign exchange to the domestic market has appreciated the level of the real exchange rate.

\section{Long-term macroeconomic policy objectives and indicators}

The Government is committed to maintaining in ation at 5\%. It is also committed to reducing its fiscal deficit excluding grants, to enable further scope for private sector development. The Long Term Expenditure Framework (LTEF) ${ }^{7}$ prepared for this PEAP revision shows that reducing the fiscal deficit to $6.5 \%$ of GDP by $2009 / 10$, and keeping it constant thereafter, is compatible with a rise in private sector investment to $22 \%$ of GDP by $2013 / 14$, and a rise in exports from $12.6 \%$ of GDP to $15.4 \%$ of GDP.

Uganda's macroeconomic indicators for the next ten years as projected in the LTEF are summarised below.

Table 3.1: Key LTEF Indicators

\begin{tabular}{|l|c|c|c|}
\hline & $\mathbf{2 0 0 2 / 0 3}$ & $\mathbf{2 0 1 3} / \mathbf{1 4}$ & Period Av. \\
\hline Annual In ation & $5.7 \%$ & $3.5 \%$ & $3.8 \%$ \\
\hline Annual GDP growth & $5.2 \%$ & $6.5 \%$ & $6.0 \%$ \\
\hline Real Exchange Rate depreciation & $3.0 \%$ & $2.0 \%$ & $2.4 \%$ \\
\hline Private Investment (\% GDP) & $15.6 \%$ & $22.4 \%$ & - \\
\hline Domestic Savings (\% GDP) & $6.6 \%$ & $13.6 \%$ & - \\
\hline Private sector credit (\% GDP) & $7.1 \%$ & $17.5 \%$ & - \\
\hline Exports (\% GDP) & $12.3 \%$ & $15.4 \%$ & - \\
\hline Exports (\$m) & 774 & 1699 & - \\
\hline Trade Deficit (\% GDP) & $-14.0 \%$ & $-15.0 \%$ & - \\
\hline
\end{tabular}




\begin{tabular}{|l|c|c|c|}
\hline NPV Debt/Exports & $305 \%$ & $187 \%$ & - \\
\hline Domestic Revenue (\% GDP) & $12.1 \%$ & $15.8 \%$ & - \\
\hline Fiscal Deficit (\% GDP) & $-11.2 \%$ & $-6.5 \%$ & - \\
\hline Donor Aid (\% GDP) & $12.1 \%$ & $8.5 \%$ & - \\
\hline Govt Expenditure (\% GDP) & $23.4 \%$ & $22.5 \%$ & $22.3 \%$ \\
\hline
\end{tabular}

Source: MoFPED

The objective of the LTEF, which was prepared for this PEAP, has been to produce 10 year projections of the budgetary resources available to the Central Government for expenditure which are consistent with a coherent, comprehensive and realistic set of projections for the main macroeconomic variables, and with Government's macroeconomic targets, such as the target for in ation. The expenditure levels derived from the LTEF are used as a basis for the sectoral costings given in Chapter 8 .

\section{In ation control}

High and unpredictable rates of in ation discourage private investment and savings as their value is eroded by price increases. The erosion of the value of savings by higher prices particularly affects the poor, who have few savings in the first place. Low levels of savings and investment and high prices in turn reduce the real growth rate of the economy, and high in ation acts as an incentive for subsistence production instead of commercial production.

Government has therefore established a policy target of keeping the annual underlying in ation rate to a maximum of $5 \% .^{8}$ The main policy instrument for achieving this target is monetary policy, which aims to control the growth of broad money in line with estimated money demand. Monetary policy cannot be subordinated to fiscal policy. If the Government's domestic borrowing requirement is too large, either the money supply must expand at a faster rate than that of money demand, which will fuel in ation, or private sector credit will have to be squeezed through monetary policy actions to restrain the growth of the money supply.

Raising the in ation target from the current level 5\%, either in an attempt to generate economic growth or to accommodate a more expansionary fiscal policy, is not a viable policy option. Uganda's consistent record of maintaining low rates of in ation sends a powerful signal to private investors about the credibility of macroeconomic policy; the in ation rate is the most visible signal available to the private sector to judge the quality of macroeconomic management. Allowing the in ation rate to rise would undermine the credibility of Government's macroeconomic policy which has been painstakingly built up over the last 10 years. 
Box 3.1: Inflation versus Growth

- The Government is committed to keeping in ation at 5\% per annum or less.

- In ation in Uganda has averaged 4.8\% per annum since 1993/94.

- Low in ation has contributed to high levels of GDP growth in Uganda, averaging $6.3 \%$ per annum since 1993/94.

- International evidence does not imply higher growth if in ation is above 5\%, and once in ation rises above $10 \%$, growth declines.

- Raising the in ation target would undermine the credibility of Government's macroeconomic policies.

- Higher in ation is associated with higher price volatility, which undermines investment opportunities.

- A higher in ation target is more likely to reduce growth in Uganda than increase it.

Adopting a higher in ation target would also make in ation control more difficult, because the in ation rate becomes more volatile as in ation rises. It would erode the private sector's expectations of low in ation, which in turn would affect how future prices are determined. For example, higher expected in ation would lead workers to demand larger wage increases to compensate for the expected erosion of the real value of their wages.

\section{Deficit Reduction}

A central objective of Government's macroeconomic strategy is to reduce the overall fiscal deficit, excluding grants. ${ }^{9}$ The fiscal deficit widened sharply, by six percentage points of GDP, between the mid 1990s and 2001/02, when it peaked at $12.4 \%$ of GDP. The increase in the fiscal deficit was mainly attributable to an expansion of Government expenditure, which was not matched by increased domestic revenues. Between 1995/96 and 2001/02, Government expenditure rose by seven percentage points of GDP, to $24.6 \%$ of GDP, whereas domestic revenue increased by less than two percentage points of GDP, to $12.2 \%$ of GDP.

Chart 3.6: Government expenditure, revenue and fiscal deficit, 1998/99-2002/3

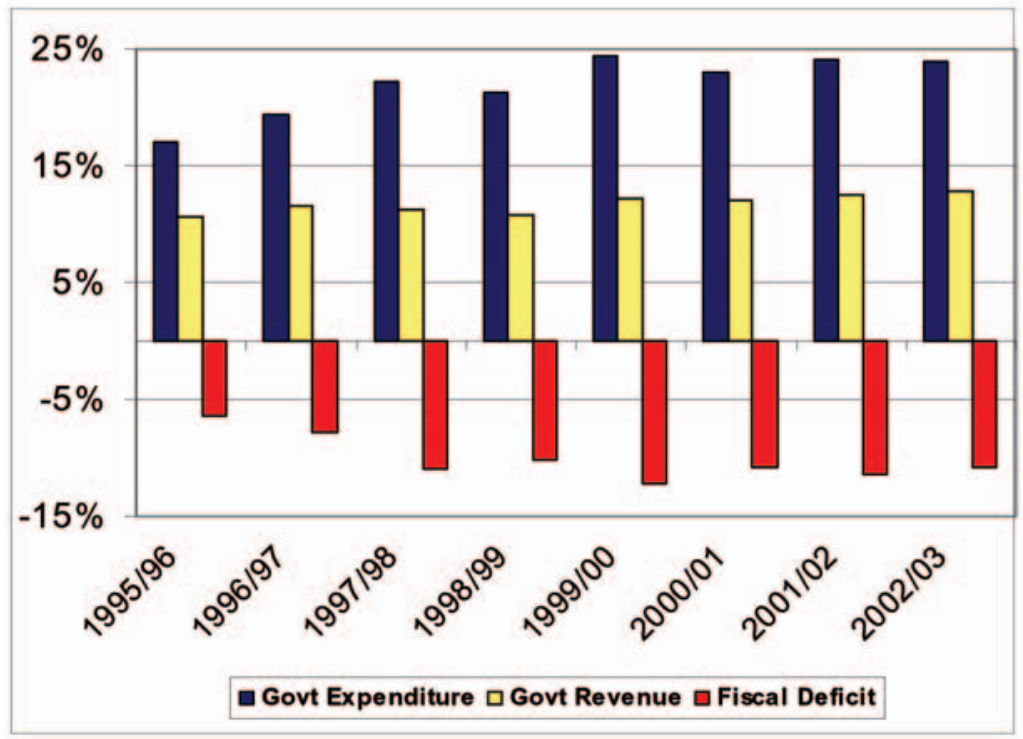

Source: Macro Department 
The expansion in Government expenditure was mainly funded by an increase in donor aid ows. The primary purpose of the aid ows was to help fund key Government priorities in social services provision, such as Universal Primary Education and Primary Health Care. These programmes have undoubtedly benefited from increased resources, as will be outlined in Chapter 7, but the rapid increase in the Government budget at the same time diminished the need to scale back expenditure in non-priority areas such as public administration, leading to wastage, corruption and poor value for money in some areas of the budget. In addition, it is now becoming evident that even some of the money being channelled into key poverty-eradicating programmes is not being well spent, resulting, for example, in poorly constructed classrooms, and poorly built and maintained rural feeder roads.

These problems have signalled the need for Government to focus on the quality rather than the quantity of expenditure over the medium term. Key actions in this area include strengthened budget prioritisation, clearer focus on value for money, strengthened procurement, and actions to reduce corruption. They are discussed in greater detail in Chapters 6, 8 and 9.

These budget implementation problems arising from the scale of Government expenditure, poor accountability and absorptive capacity constraints have coincided with macroeconomic problems arising from the size of the fiscal deficit, which could potentially jeopardise future private sector development and fiscal sustainability, unless tackled immediately. Recognising these budgetary and economic problems, Government has begun to implement a strategy to scale back the fiscal deficit, and as a result the overall deficit excluding grants reduced to $11.2 \%$ of GDP in 2002/03. Government aims to reduce the fiscal deficit to around $6.5 \%$ of GDP by the end of the decade by restraining the growth of Government expenditures to less than the growth of domestic revenues. At the same time, Government will also endeavour to raise domestic revenues to around $16 \%$ of GDP by the end of the decade.

Box 3.2: The Fiscal Deficit

- The commonly used measure for the fiscal deficit in Uganda is the fiscal deficit excluding donor grants - i.e. domestic revenue minus total government expenditure

- Uganda's fiscal deficit rose from 6.5\% of GDP in 1995/96 to 12.4\% of GDP in 2001/02 as donor aid financed increases in Government expenditure.

- The rapid increase in the fiscal deficit has generated concerns about its potential impact on the economy, particularly raising interest rates, crowding out private sector credit and appreciating the real exchange rate.

- The increase in the fiscal deficit has had a direct impact on the Government budget, as it has caused domestic interest costs to increase by $1000 \%$ in six years, as Bank of Uganda has sold domestic securities to contain its in ationary impact.

- Government's target is to reduce the fiscal deficit to $6.5 \%$ of GDP by 2009/10.

There are several sound macroeconomic reasons for Government's fiscal deficit reduction strategy: 
- Cost of private sector borrowing

The increase in the fiscal deficit has led to an increase in the net issuance of Government securities to control in ation. As a result, the stock of Government securities has increased by more than $500 \%$ in five years, and interest rates have become sharply higher and more volatile. The average interest rate on a 364 day Treasury Bill was $17 \%$ in $2002 / 03$, as compared to $9 \%$ in 1998/99, and the rate reached a peak of $34 \%$ in January 2001. Because an increase in Treasury Bill rates drives up Commercial Bank lending rates to the private sector, the increase in the fiscal deficit has sharply increased the cost of borrowing for the private sector, placing a constraint on private sector investment.

- Volume of private sector borrowing

The increase in the fiscal deficit has also been observed to have negative consequences for the volume of private sector credit extended by Commercial Banks. The rapid increase in the net issuance of Government securities to control in ation, as noted above, has led to a rapid increase in net Government borrowing ${ }^{10}$ from the commercial banks, and this has inevitably squeezed the resources available for bank lending to the private sector.

\section{Chart 3.7: Bank loans to Private Sector and Government as a \% Deposits end June 1995- end June 2003}

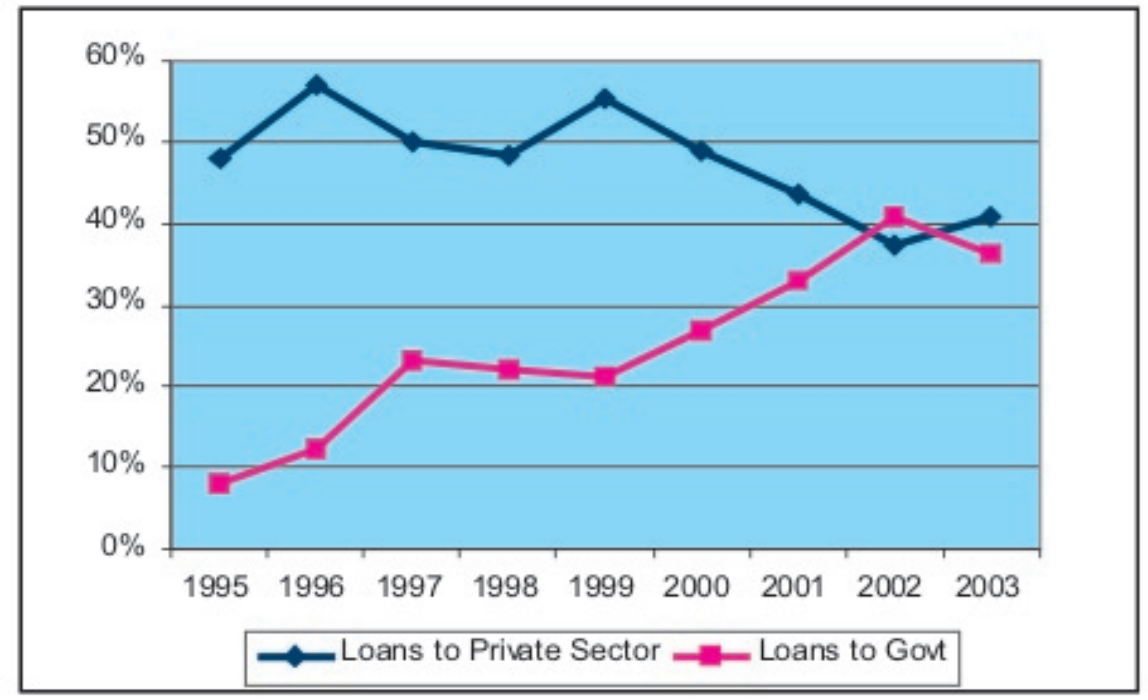

Source: MoFPED

- High domestic interest costs

The increase in both the stock of Treasury Bills and Treasury Bill interest rates has also led to a significant increase in Government's interest costs. As of 2003/04, Government interest costs have increased by $1000 \%$ in six years, from shs 21 bn in 1998/99 to shs $190 \mathrm{bn}$ this financial year. Government's domestic interest costs now account for more than $8 \%$ of Government of Uganda expenditure. A reduction in the fiscal deficit will lead to a gradual decline in the burden of interest payments on the GoU budget. The LTEF projects that interest payments should amount to just $3 \%$ of the Government budget by $2013 / 14$ if the deficit is scaled back to $6.5 \%$ of GDP. 
- Exchange rate

Bank of Uganda's sales of foreign exchange have risen ten fold as donor in ows and the fiscal deficit have increased, from $\$ 25 \mathrm{~m}$, equivalent to $2 \%$ of private sector foreign exchange sales, in $1998 / 99$, to $\$ 247 \mathrm{~m}$, equivalent to $16 \%$ of private sector foreign exchange sales, in 2002/03. The increase in aid ows and Bank of Uganda's foreign exchange sales coincided with the fall in Uganda's terms of trade, as the price of coffee and other major export commodities fell in the late-1990s. Consequently, the impact of the fall in the terms of trade on the exchange rate was partially offset, adversely affecting the shilling incomes of exporters. More broadly, a recent study suggests that Uganda's exchange rate has been overvalued since the late 1990s, and attributes considerable proportion of this overvaluation to the behaviour of aid ows ${ }^{11}$. Going forward, the Government believes that fiscal deficit reduction will help alleviate upward pressures on the exchange rate generated by aid ows, thus stimulating export-led growth.

\section{- Budget security}

The Government's dependency on donor aid has increased the vulnerability of the budget to a sudden cut-back in donor aid. In 1997/98 domestic revenues were sufficient to fund $79 \%$ of GOU expenditures plus external debt repayments, but this had fallen to only $60 \%$ in 2001/02, when the fiscal deficit peaked. ${ }^{12}$ The reduction in the fiscal deficit in 2002/ 03 brought about a small improvement in the share of GOU expenditures and external debt repayments which could be funded from domestic revenues, to $66 \%$. Despite the improvement in 2002/03, the Government budget remains vulnerable to any substantial cutback in donor aid. While a temporary loss in donor aid could be absorbed through a limited rundown of the BOU's foreign exchange reserves, a cutback in aid which lasted for much more than one year, given Uganda's current level of dependence on donor aid, would force Government to make severe budget cuts.

- External Debt Sustainability

Uganda's current dependence on donor funds also has implications for the sustainability of its external debt burden, as external loans currently account for approximately $40 \%$ of donor in ows in any given year. Uganda was the first country to qualify for the Highly Indebted Poor Countries (HIPC) debt relief initiative in 1998, and on its exit from the Enhanced HIPC Completion Point in April 2000, it was pledged debt relief amounting to $\$ 1$ billion in Net Present Value (NPV) terms from multilateral and bilateral creditors. This debt relief was intended to ensure that Uganda's future debt burden remained at a sustainable level, defined as the ratio of the debt stock in NPV terms not exceeding $150 \%$ of export earnings. Uganda has borrowed $\$ 1.5 \mathrm{bn}$ from multilateral donors since the HIPC Completion point, and although these loans have been on highly concessional terms, their impact on the debt stock, combined with lower export growth as a result of the fall in coffee prices and low prevailing world market interest rates, has been to raise Uganda's NPV of debt to exports ratio to $305 \%$, which is more than double the HIPC threshold. Uganda's policy of gradual deficit reduction will enable it to bring its debt stock back down to manageable levels. 
- Domestic Debt Sustainability

Uganda's stock of domestic debt has risen from less than 1\% of GDP in the mid 1990s to $10 \%$ of GDP this financial year. The rapid increase in Uganda's domestic debt burden is directly associated with the increase in the fiscal deficit, as Bank of Uganda has increased its net issuance of Government securities to mop up the domestic liquidity arising from donorfunded Government expenditure, so that annual in ation remains on target, at 5\% or less. Although Government has recently introduced long-term bonds to the domestic securities market to extend the yield curve, $95 \%$ of Government securities nonetheless have a maturity of one year or less. This means that if the budget were to be subject to an aid shock which reduced Government's injection of liquidity into the domestic market, monetary and fiscal policy management would be placed under significant pressure, as a large number of Government securities would require redemption within a short time period.

\section{- Political Economy}

Excessive aid dependency inevitably impinges on the sovereignty of the aid recipient and constrains its economic and budgetary choices, which is not consistent with the development of a healthy and equal relationship between aid recipients and the donors, based on mutual respect. Reducing dependence on aid is crucial for the development of democracy and the accountability of government.

Government's fiscal deficit reduction strategy means that in future it will focus on the quality rather than the quantity of its donor support. Budget support grants are Government's preferred modality of donor aid, since they directly fund GoU's expenditure priorities, as guided by the PEAP, and do not contribute to Uganda's external debt burden. By contrast, project support loans are Government's least preferred form of donor support, since they do not directly fund the GoU budget, and they add to Uganda's external debt burden. Government's policy therefore is to encourage donors to shift to budget support, particularly budget support grants, and to be more selective about the projects it accepts as it gradually reduces its fiscal deficit. Plans to integrate donor projects within sector ceilings to improve budget prioritisation are discussed in Chapter 8 . Furthermore, Government does not intend to accept any tied aid over the PEAP period, even if given as a grant, as aid which restricts Government's procurement choices does not offer value for money.

\subsection{Tax Policy}

As outlined above, Uganda is faced with the challenge of achieving ambitious targets in poverty reduction over the PEAP period whilst scaling backing its fiscal deficit. While donor support has so far helped the government to fund half of its budget, the pressing need now is to enhance the country's capacity to mobilize domestic resources to fund public services. This makes a well designed tax policy a crucial element of Uganda's strategy to support economic growth and reduce poverty.

A sound tax policy framework comprises a tax system capable of financing the desired levels of government spending in the most efficient and equitable way possible. In particular, the tax system is expected to: 
(a) Raise enough domestic revenue to finance expenditure without recourse to excessive public sector borrowings or excessive recourse to donor grants that might make the budget vulnerable to unexpected fiscal shocks;

(b) Raise revenue in ways that are efficient and equitable; it is important to note that the economic, rather than political, incidence of taxes should be the basis for assessing both equity and efficiency;

(c) Enable taxes to be collected cost-effectively in a manner which minimizes opportunities for corruption, and

(d) To do so in ways that do not deviate substantially from international best practice.

Uganda has one of the lowest revenue to GDP ratios in Sub-Saharan Africa (12.1\% as of 2002/03), re ecting the dominance in the economy on a primary sector that provides a small tax base. Within the East Africa region, Kenya has a revenue-to-GDP ratio of 26 percent, while Tanzania's is similar to that of Uganda. In the mid 1990s, the government adopted an ambitious growth target for the revenue ratio of one percentage point per year; which was considered achievable because the tax base was very low, and there were policy options available to generate revenue growth. Moreover, the very rapid growth in the economy's formal sector (and, in particular, in the sales of highly taxed goods such as beer, cigarettes, sodas and fuels) provided a strong stimulus to revenue growth.

In 1997/98, government made a downward revision to the target for growth of the revenue-to GDP ratio from $1 \%$ to $0.5 \%$ per year, because the options for generating new revenues had become more limited, with the major tax reforms to income tax and VAT having already been implemented. The constraints to revenue growth remain as difficult now as they were for the past years, while demands for tax rate reductions are even more intense. The largest risk is the continued pressure to give investment incentives which would undermine revenue mobilization, combined with limited latitude in tax handles to boost revenue mobilization. The risk of frequent policy reversals is also damaging, because policy instability is of itself likely to impose high economic costs, as potential investors approach each change with growing scepticism.

\section{Revenue Generation Constraints}

The main elements that hamper domestically-generated revenue mobilisation are:

1. The large size of the informal sector: The economy is characterized by a large share of agriculture in total output and employment; by large informal sector activities and occupations; by many small establishments; by a low share of wages in total national income, with many workers paid in cash, 'off the books'; and by a small share of total consumer spending in large modern establishments that keep accurate records of sales and inventories. These characteristics of the economy reduce the possibility of efficiency gains from such taxes as personal income tax and Value Added Tax (VAT), and undermine the possibility of achieving high growth of domestic revenues

2. Lack of reliable data: Revenue collection is also hampered by the absence of reliable data, which severely restricts the government's ability to assess tax policy. 
The paucity of data has many sources, including the taxpayers' limitations in keeping proper accounts; the large role played by informal activities; the limited reporting requirements; the low capacity in many private economic establishments, as well as financial constraints.

3. Uneven income distribution: Income distribution in Uganda is highly uneven with a rising Gini coefficient which implies that for tax revenue collections to generate high revenue, the top deciles have to be taxed significantly more proportionally than the lower deciles

The existing challenges in tax administration are currently being tackled by the Uganda Revenue Authority, including significant weaknesses in customs administration, particularly in areas such as duty drawback and customs valuation, and problems in VAT administration, particularly compliance and the operation of VAT refunds. A recent report has highlighted the key challenges in this area ${ }^{13}$, and the Government is working with the URA to tackle them. Improving tax administration will deliver efficiency gains for Government in revenue collections, as well as improving the operating environment for the private sector.

However, improvements in tax administration alone are unlikely to deliver sufficient revenue growth to maintain Government expenditure at 22\%-23\% of GDP as the fiscal deficit reduces. The Government therefore faces hard choices as to how to raise additional revenue, particularly in the light of the need to retain a competitive tax system which stimulates private sector development. Over the past decade, Uganda has been pursuing an aggressive policy of reducing taxes to remove distortions, to reduce protection, to improve competitiveness, to improve incentives for export activity, to facilitate tax administration and to promote taxpayer compliance. Any significant reversal aimed at either mobilising further revenue or protecting domestic, or firm-specific, production would send negative signals to investors and raise serious doubts about the credibility and stability of government's economic policies. They would also make tax administration and tax compliance more difficult.

In addition, as of 2004, Uganda with its other partners in East African Community (EAC) will finalize a Protocol establishing a Customs Union. This will have implications in terms of revenue and trading arrangements. The negative revenue effects of the Customs Union, which include trade liberalization within the EAC and the likely abolition of import commission, might impede revenue growth in the medium term.

Given the likely revenue shortfall arising from the East African Customs Union, and given the need to maintain an internationally competitive tax regime, Government will have to make upward adjustments to domestic consumption taxes over the PEAP period if it is to maintain expenditure at $22 \%-23 \%$ of GDP whilst reducing the fiscal deficit. Failure to do so will result in lower overall Government expenditure, which could compromise service delivery and the Government's ability to meet PEAP targets. 


\subsection{Financial Sector}

\section{Financial Sector Development}

As explained in previous sections, Uganda's long term economic strategy is to promote private sector-led economic growth. If the private sector is to achieve rapid growth it requires finance for fixed investment and working capital. Uganda's financial markets are both shallow - they are small in relation to GDP - and poorly developed, being dominated by commercial banks. Commercial bank lending to the private sector plays a key role in supporting the growth of the private sector in Uganda, because there are so few alternative sources of finance. The main alternative sources of domestic finance for the private sector are non bank financial institutions (NBFIs), such as leasing companies and a housing finance company, and the Stock Exchange, but the NBFIs are small relative to the commercial banks, and only well established companies with a track record of profits can raise funds by issuing securities on the Stock Exchange.

Box 3.3: Why Government does not fix Commercial Bank lending rates

- Commercial bank lending rates to the private sector are market-determined.

- Private sector lending rates are always higher than interest rates on Treasury Bills, due to the higher risk associated with lending to the private sector compared to Government.

- The more Treasury Bills the Government offers, the higher their interest rates will be, driving up private sector lending rates too.

- If Government sells fewer Treasury Bills, TB interest rates will fall, Commercial Banks will have more credit available to offer to the private sector, placing downward pressure on lending rates.

- $\quad$ Fixing lending rates at a rate other than the market rate will reduce Commercial Bank lending to the private sector, as either the rates will be too high for the private sector, or (more likely) too low to be commercially viable for the banks.

- A reduction in Government's issuance of Treasury Bills is a more effective way to reduce the cost of borrowing than fixing interest rates.

- Government's fiscal deficit reduction strategy will entail a reduction in TB issuances over the medium term.

Growth in bank lending to the private sector must be consistent with maintaining the maximum growth rate of the money supply which is needed to deliver low in ation. Given the constraints imposed by the imperative to control monetary expansion, bank lending to the private sector can only grow quickly if the growth of other, competing, demands on commercial bank resources are restrained. The most important competitor of the private sector for commercial bank resources is Government, mainly through the Treasury Bills, which are issued by the BOU to sterilise base money created by fiscal operations. At endJune 2003, Government securities comprised 29\% of commercial banks' total assets and loans to the private sector comprised $26 \%$ of total assets. Therefore, the most effective strategy for promoting more rapid growth of bank lending to the private sector, without jeopardizing the control of money supply and in ation, is for Government to reduce its demands for funds from the commercial banks, by reducing its fiscal deficit. 


\section{Financial Deepening}

Financial deepening refers to the increase in the holding of financial assets by economic agents relative to GDP. It enhances financial intermediation, which is the process of channelling financial resources from surplus economic agents into the productive investment opportunities of agents with financial deficits, which in turn promotes economic growth. Financial depth as measured by M3 as a percentage of GDP has grown steadily over the past thirteen years, from $8 \%$ in $1990 / 91$ to $20 \%$ in $2002 / 03$. It is expected to continue to rise over the medium term, as the economy becomes increasingly monetised, and domestic savings rates increase. The LTEF projection is for financial depth to increase to $29 \%$ of GDP by $2013 / 14$.

Gross domestic savings grew rapidly in the early 1990s, from 2\% of GDP in 1990/91 to $8.8 \%$ of GDP in 1994/95, as macroeconomic stability was restored and in ation was brought down to single digits. Since then, the level has uctuated, and gross domestic savings in 2002/03 amounted to $6.6 \%$ of GDP. Savings are expected to grow substantially over the medium term, to $13.6 \%$ of GDP by $2013 / 14$, as GDP growth is expected to outpace the average growth in consumption, and as the reduction in the fiscal deficit raises public savings.

The mobilization of savings into deposits in the banking system, thereby increasing financial depth, will be enhanced by financial product development. Currently, the main financial assets available in the financial sector apart from bank deposits are corporate bonds and equities, of which there are few, and government treasury bills. However, a government long-term bond has been introduced recently, and further areas of possible product development include mortgage and insurance products and mutual funds.

In addition, the Financial Institutions Act (FIA 2004) was assented to by the President in March 2004 and is now law. Among other provisions, the FIA 2004 provides for the setting up of a Credit Reference Bureau through which information about borrowers will be made available to financial institutions, in order to reduce the risk of creating non-performing loans. This is expected to boost credit extension to the private sector to support economic growth. However, besides the newly enacted Financial Institutions law, there is need to revise the laws that govern financial sector innovations and operations in order to address elements such as electronic financial products and services, and leasing operations.

\section{Micro Finance \& the Formal Financial Sector}

As mentioned earlier, financial deepening enhances financial intermediation. However, while financial institutions' coverage of the urban areas is relatively sufficient, outreach to the rural areas specifically by formal institutions is still limited. As much as efforts are underway to encourage rural outreach by the formal banks, the socio-economic and cultural setups in the rural areas do not favour the formal banking system. To this extent, the Micro Finance Institutions law was enacted by Parliament in April 2003 to allow soundly managed and well-capitalized Micro Finance Institutions (MFIs) to intermediate resources in the rural areas. The defined legal status of these MFIs now puts them into a position that should forge links with the formal banking system. 
With the legal status of the micro finance deposit taking institutions now clearly defined, it is expected that the formal banking sector will increase their transactions with these institutions. These are expected to act as retail institutions for both deposit taking and credit extension to rural agents, since they have a relatively better information base on agents in the rural areas than the formal banks. The role of the banks will be to wholesale both deposit taking and credit extension to the MFIs. Such a linkage should further increase the provision of financial services to the rural areas.

\section{Pension Sector Reform}

Government's plan to reform the pension sector will liberate a major source of longterm capital for the domestic financial market. Social Security, pension and provident funds represent the most important sources of long-term capital in most economies. Defined contribution schemes such as the National Social Security Fund (NSSF) should, therefore, play an important role in the financial sector because they hold a large amount of fixed liabilities (individuals' pension contributions) and have a huge potential in creating long-term assets (as they invest the contributions to ensure real returns for future pensioners). Unfortunately, the NSSF has not been successful in fulfilling these roles, and has to a large extent undermined the potential for capital accumulation and financial sector deepening. Although it has an asset base of approximately shs $250 \mathrm{bn}$, which is equivalent to $10 \%$ of the total assets of commercial banks, the NSSF has to date invested almost all its liabilities in short-term Government securities and property, thus depriving the private sector of vital source of long-term investment funds.

The Government is committed to reforming the pension sub-sector in order to introduce competition in pension provision. This should in turn increase the efficiency with which pension funds are invested, bringing greater long-term capital to the financial market, and raising the level of private sector investment. The Government will also ensure appropriate regulation of the sub-sector.

\subsection{Investment \& Trade Policy}

Private sector investment more than tripled in real terms between 1990/91 and 2002/03, as a result of the stable and conducive policy environment created by the Government of Uganda during the 1990s. This growth resulted in private investment almost doubling as a percentage of GDP, from $9.1 \%$ of GDP in 1990/91 to $15.6 \%$ in 2002/03. Total investment amounted in 2002/03 to $20.3 \%$ of GDP, as compared to $15.3 \%$ in 1990/91. 


\section{Chart 3.8: Investment as a \% of GDP 1990/91 - 2002/03}

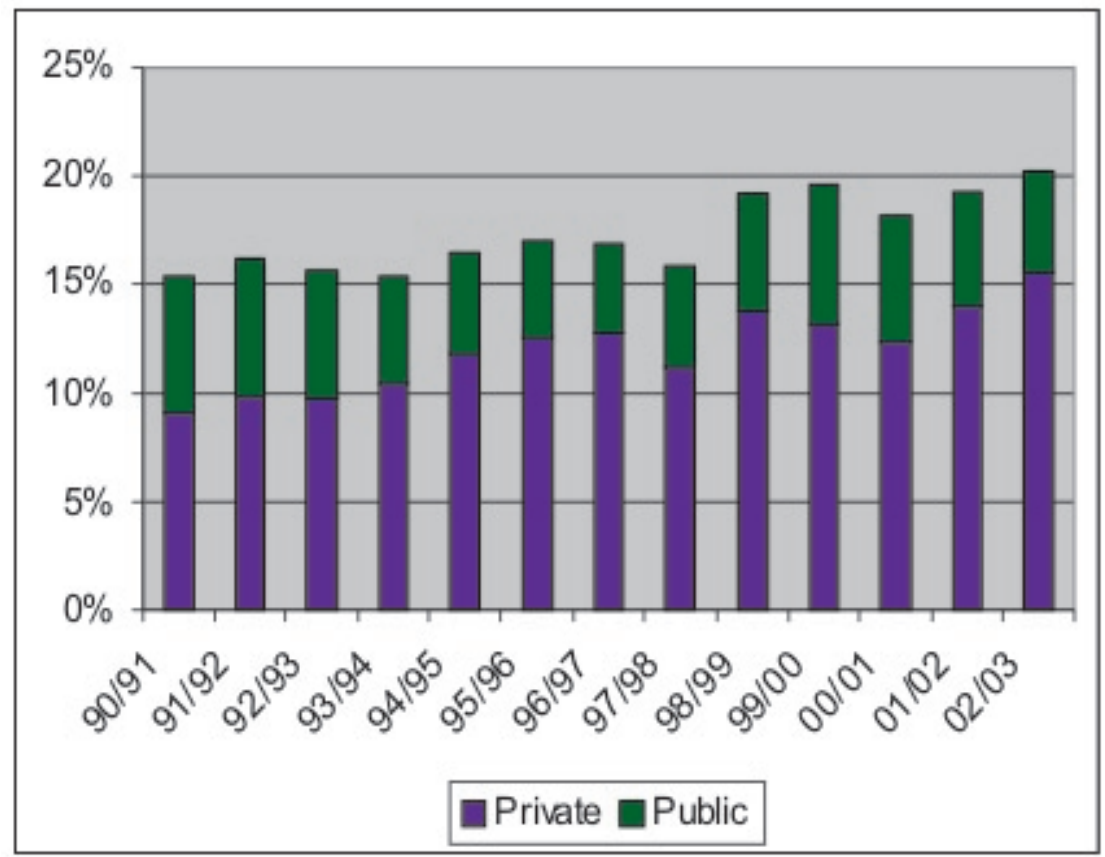

Source: MoFPED

However, private investment needs to continue to grow in real terms if Uganda is to meet its objective of rapid and sustained GDP growth over the medium term. As explained earlier in this section, Uganda has already reaped most of the growth gains arising from the economic reforms implemented during the 1990s, and recent research ${ }^{14}$ has suggested that sustained higher growth over the next five years can only be achieved with much higher investment rates, with investment having to jump to $27 \%$ of GDP. The LTEF projects that total investment will rise to $28 \%$ of GDP by $2013 / 14$, while private sector investment will rise to $22 \%$ of GDP, an increase of seven percentage points as compared to the current level. Achieving this will require private investment to grow by an average of $7.7 \%$ per annum in real terms.

What policies are required for investment to grow to $28 \%$ of GDP by 2013/14? First, Government will maintain its existing policies of macroeconomic stability and deficit reduction to minimise economic risks to investment, and to ensure that Government does not crowd out the private sector, either by driving up prices of non-tradable investment goods relative to output prices, or by crowding out private sector credit. Second, it will maintain its current trade policy, which is broadly liberal. Economic growth in Uganda is particularly dependent on the expansion of profitable exports because exports are not constrained by domestic demand, and in most cases Uganda has a small share of the world market and can therefore expand exports fast without driving prices down much.

\section{Comparative Advantage of the Economy}

Exports are only profitable if they re ect the comparative or competitive ${ }^{15}$ advantage of the economy. In Uganda's case, these advantages are largely in agriculture and agro processing. Labour in Uganda is not cheap as in India or China ${ }^{16}$, and high transport costs (partially re ecting the geographical positions of the country) make it unlikely 
that Uganda can quickly become competitive in the assembly of goods from imported components. Manufacturing in Uganda is likely to focus mainly on production for the domestic market, and to some degree the regional market, except where it is processing products based on natural resources in Uganda - agriculture, forestry and fisheries. Uganda may also be able to develop a comparative advantage in some services, but will face stiff international competition in this area.

The Government trade policy supports the export sector by minimising domestic and international barriers to trade. Government does not levy taxes on exports ${ }^{17}$, and export procedures in the country have been simplified. The exchange rate is market determined, thus ensuring it re ects supply and demand for foreign exchange and does not distort price incentives. However, it is important to understand that having a market determined exchange rate will not of itself deliver an exchange rate that is competitive for exports. Even when market determined, the exchange rate may be overvalued relative to trade fundamentals if the economy experiences strong in ows of foreign exchange from sources other than exports, as has been discussed above.

In addition to having a market-determined exchange rate, there are no restrictions on capital account transactions, and it is not government's policy to protect domestic industry. Domestic protection sti es export-led growth because it induces producers to focus on the local market, and the firms/farms make little or no efforts to develop capacity to compete in export markets. This in turn causes a welfare loss for the domestic consumer, who inevitably faces higher prices for the goods he/she is buying, and for the economy as a whole, as demand in the domestic market is limited, therefore limiting production.

Box 3.4: The Cost of Domestic Protection

- It is sometimes argued that Government should boost domestic production by placing high taxes on imports or banning them altogether

- 'Protecting' domestic industries from imports may create jobs in the industries involved, but the benefit of these jobs to the economy will be offset by the welfare loss to all other consumers

- Protected domestic industries produce high costs goods (there is no competition with imports to drive prices down) which domestic consumers are forced to buy as a result of the lack of alternatives

- The cost of protection is often borne disproportionately by the poor - e.g. higher prices for clothes if mivumba imports are taxed/banned, higher prices for sugar if sugar imports are taxed/banned

- Domestic protection undermines export growth \& economic growth, because protected industries have no incentive to be competitive in terms of world markets (they are producing for a captive domestic market), and domestic demand is limited, limiting production

In addition, Government does not intend to pursue a policy of firm-specific interventions. Firm specific interventions are undesirable because they are widely perceived to be inequitable (thus eroding the certainty of the investment climate and increasing its risks), inefficient (Government is less well equipped than the private sector to 'pick winners') and create a climate for lobbying rather than entrepreneurship ${ }^{18}$. Government's policy is to create a level playing field for all investors, whereby private incentives are not distorted by public policy, to minimise economic cost and risk, to reduce barriers to production and to address market failures through sector-wide interventions. These latter policies will be covered in greater detail in the section on Production, Competitiveness and Incomes. 


\section{Export Diversification}

Uganda's exports are vulnerable to uctuations and/or downward trends in international commodity prices, and still face both tariff and non tariff barriers abroad which inhibit their growth, particularly in the value-added end of the market. For example, the country's exports face tariff escalation from its trading partners (increase in the level of tariffs with the level of processing), which discourages value-addition to our products. The non-tariff barriers it faces are mainly sanitary and phytosanitary (SPS) measures imposed by developed countries such as the European Retailers Good Agricultural Practices (EUREPGAP). Under these measures, Uganda is required to establish a residue monitoring system and monitor the chemical content of its products, which increases transaction costs.

As will be discussed in the section on production, competitiveness and incomes, Uganda's strategy on export diversification and value addition is primarily intended to boost agricultural output and productivity, thus boosting economic growth and poverty reduction, but it is also in part designed to mitigate the effects of uctuations in global commodity prices on export performance. Uganda lost $\$ 700 \mathrm{~m}$ in coffee earnings between 1998/99 and 2002/03 as a result of a decline in coffee export prices, which fell by more than $60 \%$ over the period. Reducing the economy's dependency on any single commodity, and shifting production to the value-added end of the market is designed to reduce this vulnerability, and will be complemented by market-based insurance schemes for farmers to hedge against short-term price volatilities during a production season, which are currently being piloted in Uganda.

However, the country will not be able to benefit in full from its strategy of value-addition unless Government works to reduce the tariff and non-tariff barriers placed on Ugandan exports by its trading partners. Government is to strengthen its capacity to engage in multilateral, regional and bilateral trade negotiations to help reduce market access problems to both trade in goods and services through negotiations. Formalization and facilitation of the Inter-Institutional Trade Committee are the major activities planned in order to strengthen the country's trade negotiation capacity. Government also intends to strengthen its institutional ability to respond to export challenges, through the institutionalisation of quality management in industry, enforcement of standards, quality assurance and procurement of market information. These initiatives will be covered in greater detail in the section on production, competitiveness and incomes. 


\title{
4 Enhancing production, competitiveness and incomes
}

\author{
4.1 Government's strategy for increasing production, competitiveness and \\ incomes
}

This chapter discusses Government's strategy for fighting poverty through increasing production, competitiveness of Uganda's products and household incomes. Production is used here in a broad sense, including agriculture, industry and services. As discussed in Chapter 3, agriculture grew more slowly than the other sectors at 3.8\% per annum between 1990/91 and 2002/03, while industry grew at $10.5 \%$ per annum and services grew at $7.5 \%$ per annum. These sectoral performances have implications for poverty reduction, depending on the share of population employed in each sector. Agriculture employs $69 \%$ of the population, and services employ $23 \%$, whereas industry employs $8 \%$. Thus, although the share of services in GDP is now higher than that of agriculture, services employ only a third as many people as agriculture. About $86 \%$ of the population lives in rural areas and $77 \%$ of the active labour force in rural areas is employed in agriculture. Agriculture is by far the largest employer of Ugandans in rural areas, despite a declining share in GDP. Moreover, $96 \%$ of those below the poverty line live in rural areas. Hence agricultural growth is critical for poverty reduction and rural development.

In addition to its role as employer, there are two other reasons why agriculture is a critical focus of the PEAP. First, the non-agricultural goods and services produced in rural areas are mostly sold locally. Their production cannot expand sustainably unless the demand generated by agricultural incomes also expands. The recent tendency of returns in the non-agricultural sector to decline while people moved into the sector illustrates that demand may be becoming saturated in some areas. Secondly, agriculture is particularly dependent on public goods including research, extension and support to marketing. The slow technological progress in smallholder agriculture in Uganda illustrates this point.

Growth of agriculture thus generates spill-over benefits to the non-agricultural sector in rural areas and beyond, through the consumption of non-farm products. Linkages with manufacturing and service sectors then spread the benefits of growth in agricultural incomes to the rest of the economy. An important aspect of this process is the increase in value-addition through the processing of agricultural products.

In order to reduce poverty as fast as possible, not only the level of incomes but their distribution across income groups matters. As discussed in Chapter 2, income inequality in Uganda has increased sharply between 1997 and 2003, with the Gini coefficient rising from 0.37 to 0.43 . While various aspects of all the PEAP pillars are intended to address this, there are three areas that particularly need attention.

- First, an intensified focus on agricultural production should reduce inequality. While it is inevitable that agricultural growth will be slower than that of the other sectors, Government will aim to accelerate agricultural growth by better provision of public goods including research, extension and support to marketing. 
Government strategy will therefore focus on increasing agricultural production and incomes, especially for poor rural households. In order for households to escape poverty, they must produce and sell. Studies in Uganda ${ }^{3}$ show that constraints on smallholder agriculture include: information, organisation of marketing, infrastructure, access to assets, physical depletion of assets, and finance.

- Secondly, poverty in Uganda has a regional pattern. Historical factors and the civil war that has continued for more than fifteen years have kept northern Uganda as the poorest region in the country. The East has recently experienced a significant increase in income poverty, as discussed in Chapter 2. The situation in northern Uganda requires special attention. Ending the war, resettling IDPs and enabling them to become productive citizens and rebuild their livelihoods is critical.

- Thirdly, women do not always share in the benefits of production, even though they may have done most of the work. For example, women in Arua district, in the early 1990s were much less enthusiastic than men about tobacco growing because of the men's control of income. ${ }^{4}$ Similarly a woman in Mbale said 'I cannot put in more effort in cultivation because the harvest can as well be used to marry a third wife' ${ }^{5}$. In one study in West Africa ${ }^{6}$ the disincentive effect was found to reduce output by $10-15 \%$. If the size of these effects in Uganda is similar, the benefit of changing these incentives could amount to a one-off increase of about $5 \%$ of GDP.

Among the actions that will contribute to reducing gender inequality are: community actions to organise women's groups and empower women: support to ensuring female participation in all public service, especially extension services (most of NAADS group members are women) and education: and improving women's land rights. If women had full ownership of the land they farmed, they would be in a better position to retain control of the incomes. An amendment to the Land Act introducing the requirement that spouses consent to disposal of land on which they subsist has recently been passed.

Government will undertake measures to provide an environment within which Ugandan enterprises can be more competitive. This means improving the provision of infrastructure (roads, rail, electricity etc) and reducing the unnecessary regulatory burdens faced by entrepreneurs. Government will also provide a stable macroeconomic environment, improve commercial justice and increase access to financial services.

Competitiveness will be achieved by increasing the ability of Ugandan enterprises to be profitable and increase their share of the market, both domestic and external, and by satisfying the needs of the consumers. Key to this, will be the firms levels of productivity and their ability to both innovate and adapt to new technologies. Thus by improving the competitiveness of Uganda's private sector we improve the ability of firms to respond to the demands of the marketplace. Indicators of increased private sector competitiveness would be re ected by increased export earnings and investment levels and an improvement in the international image of Uganda's business environment. 
In order to boost production, incomes and competitiveness, supply and demand constraints must be addressed. Government will address these constraints through three main policy frameworks, the Plan for the Modernisation of Agriculture (PMA), the Medium-Term Competitiveness Strategy (MTCS) and the Strategic Export Programme (SEP).

\subsection{Boosting production, incomes and competitiveness}

The expansion of production and incomes in rural areas is addressed by a large number of interventions, which are grouped under the Plan for the Modernisation of Agriculture. This Plan focuses on agricultural modernisation and commercialisation by a multisectoral approach to addressing the constraints facing agriculture-based livelihoods. The PMA was developed to focus public intervention on those areas where a clear public sector role was identified, to avoid duplication, and to ensure that the needs of poor smallscale farmers were fully addressed.

Supply-side interventions in the PMA include research and technology development, advisory services, rural financial services, rural infrastructure and sustainable natural resource use and management. The implementation of the PMA is reviewed by an annual joint review process; the third joint review, held in August 2003, found that progress in implementing institutional reforms was good, but that the most of the PMA pillars are not yet visible on the ground. Responsibility for the direct implementation of the PMA components lies within the mandates of relevant ministries and other public agencies, while co-ordination is undertaken by the PMA Steering Committee, the PMA technical committee and the PMA Secretariat.

\section{Agricultural research and technology development}

Research $^{7}$ on returns to public expenditure (discussed in more detail in Chapter 8) has shown that the impact of spending on agricultural research and extension on income poverty is higher in Uganda than that of spending on roads, education or health. Government is developing a national agricultural research system (NARS) that will be more decentralised, efficient, effective and responsive to the needs of the poor than the existing set-up. A National Agricultural Research Policy has been produced that seeks to promote the delivery of high quality and efficient agricultural research services by enhancing the participation and co-ordination of both public and private sector service providers. Farmers, particularly poor women and men, are to be empowered to demand and control agricultural research processes and services.

It is expected that a new National Agricultural Research Act will be enacted during the 2004/05 financial year and implementation of a revised programme of agricultural research will then begin in earnest. The components of the new NARS are: (i) establishment and operation of a National Agricultural Research Council; (ii) core funding for NARO and a rationalised network of public agricultural research institutes; (iii) support to demandarticulation structures; and (iv) national \& zonal competitive agricultural technology research funds. 


\section{Priority actions for agricultural research}

Government will enact the NARS bill and implement the provisions in the bill including:

- Completing a functional analysis of NARO

- Implementing the agricultural research competitive grants system

- Establishing the NARS apex institutions

- Increasing the involvement of the private sector and other stakeholders in the provision of research services, incorporating socio-economic and poverty concerns.

\section{Agricultural advisory services}

Information is an important constraint in smallholder agricultural production and it can be effectively addressed by public action. The National Agricultural Advisory Services programme began implementation in 2001. It seeks to increase the proportion of marketoriented production by empowering farmers to demand and control agricultural advisory and information services. Implementation of the programme will be consolidated and reviewed in depth during 2004/05. Assuming that the assessment is favourable its implementation will be stepped-up to cover the remaining Districts over the subsequent four-year period. As NAADS expands into the sub-Counties of each District, the existing District agricultural extension staff will be replaced by contracted services. Extension staff are being assisted to become service providers in the private sector if they wish to do so.

Under the NAADS approach, extension services are delivered by private providers who are awarded short-term contracts to promote specific enterprises. There is a coordinator at subcountry level who works with the LC3 and the local community to identify priorities and manage the allocation of contracts. By the end of 2003/04, the Programme will cover a total of 21 Districts (up from 6 in 2001/02 and 16 in 2002/03) located in all regions of the country .

The Programme is working principally with the economically-active poor - those with limited physical and financial assets, skills and knowledge - rather than with the destitute or large-scale farmers. The districts covered include both better-off and worseoff districts. A poverty and gender strategy has recently been completed, providing clear guidelines to be used from now on by staff working under the Programme, in both its design and implementation.

One important challenge is how to ensure that the selection of enterprises is based on good social and economic analysis. It is essential for the success of NAADS that products can be marketed at prices that make them profitable for farmers. This requires realistic technical assessments of productive potential as well as a sound assessment of future market conditions for the product. Some useful work has been done by organisations including EPRC $^{8}$ and IFPRI ${ }^{9}$ NAADS, FEWSNET, IITA and NRI in this area.

Another challenge for NAADS is to balance support for crops grown for subsistence and those for the market. Women may have a better chance of sharing in the benefits of subsistence production than marketed production. However, significant increases in productivity in most 'subsistence' crops are likely to lead either to production of a surplus for the market, or a shift in labour to other activities. NAADS will therefore focus 
mainly on crops that can be developed into marketable ventures. There is a risk, because NAADS alone cannot guarantee a market for any product. Recently, for instance, the price of vanilla, which is one of the enterprises supported by NAADS, fell sharply. Close links between NAADS and the Marketing and Agro-Processing Strategy are needed to minimise these risks. Likewise, links with NARS are important to ensure that where new inputs are recommended they are approved for release and multiplication by NARS.

\section{Priority actions for agricultural extension}

Government will:

- Review the NAADS roll-out roadmap, and harmonise and realign with the existing resources and on-going extension projects/programmes

- Deepen the targeting of the poor

- Integrate advice on the needs of commercial producers

- Integrate environmental concerns, especially soil fertility, into the advice given by NAADS

- Finalise the strategy for linkages between NAADS and NARS.

\section{Livestock}

Recent work has shown the importance of livestock in household incomes, indicating that the poor tend to lack livestock. Better-off households had four times as much livestock as the poorest households. Livestock ownership is more widespread than commonly believed - involving the majority of farmers in most parts of the country, beyond areas normally associated with livestock (the "Cattle Corridor"). At the same time, the majority of livestock-keepers do not hold animals in order to provide direct income but, rather, for other reasons, including investment of savings, social and cultural reasons. The importance of small stock species - poultry and goats, in particular - to poorer households in rural areas is only now being recognised. The share of noncrop agriculture in households incomes rose from 1.3\% to 4\% between 1997 and 2000.

Government will therefore develop an over-arching policy and strategy for the livestock sub-sector that explicitly recognises the main national policy objective of poverty reduction. The current focus on maximising livestock production alone needs to be replaced by one that recognises the multiple contributions that livestock make to livelihoods. This will require a greater understanding of who are the clients of livestock development efforts/services and what their priorities are. Lack of such understanding is the reason why there has been only limited uptake of 'improved' livestock technologies, which have been largely inappropriate to meeting the needs of livestock keepers in general and pastoralists, in particular. Hence pastoralists and their farming systems will be a key component in the new policy.

This policy will need to include disease control. Fast response to disease outbreaks including the control of animal movement is critical to minimising their costs, particularly for those producers who are aiming at the export market. Likewise, the affordability of veterinary services for the poorest livestock keepers is a concern. If preventive veterinary measures are unaffordable, this causes problems for them and other producers. 


\section{Priority actions for livestock}

- Government will develop a strategy for the livestock sector, covering disease control, and addressing the needs of pastoralists.

- In the meantime, Government will undertake necessary actions to control the spread of livestock diseases.

\section{Strategic Exports Programme}

In September 2001 Government launched the Strategic Exports Programme (SEP) aimed at increasing competitiveness through stimulating value addition investments in selected sectors of the economy and removing bottlenecks that impede the private sector's ability to take advantage of emerging trade opportunities under various initiatives including AGOA and EBA. The selected sectors include coffee, cotton, tea, fish, livestock, horticulture, Irish potatoes, and information and communication technology (ICT). So far, interventions under the programme have included the distribution of coffee and tea seedlings and cotton seeds to farmers; the importation of improved breeds of livestock (Boer goats and boran bulls); the supply of fish fry to farmers with fish ponds; the importation of processing equipment for the cotton and coffee sectors; and training for farmers involved in the production of tea, livestock and horticultural products.

A review of the programme has recommended the need to rationalise some of the activities under the programme with those already under the PMA (including NAADS and MAPS); supporting identification of interventions with analytical work along the entire market chain and minimising the production bias in the current activities; greater private sector involvement in the selection, funding and implementation of the interventions. Commodity sector associations such as the Uganda Fish Processors and Exporters Association (UFPEA) and the Uganda Flower Exporters Association (UFEA) can play an important role in the achievement of SEP objectives. Future emphasis will be put on supporting such associations so that they can play a leading role in identifying constraints and implementing the agreed interventions.

In order to enhance the integration of production, value addition and market access, a countrywide Zonal Initiative has been developed. The Agricultural Zoning Initiative will contribute to the realisation of the objectives of SEP and the NAADS enterprise development component by ensuring the selection of zonal commodity enterprises based on factors that go beyond agro-ecological conditions. Critical to the selection of enterprises will be additional factors such as profitability, value addition, export potential, availability of service providers and infrastructure. Commodity/sector clusters will be created to ensure that selected sectors will be supported on a sustainable basis. This will ensure that farmers will produce products that can be marketed, in quantities and standards that meet the requirements of the market. The development of the National Export Strategy will provide the framework within which SEP and the Zonal Production Initiative will be implemented. 


\section{Priority actions for strategic exports}

Government will:

- Harmonise some of the current SEP activities within the PMA and MTCS programmes and activities, coordinated by the MTCS Secretariat.

- Implement SEP and the Agricultural Zoning Initiative in a manner that focuses activities along the commodity value chain.

- Encourage private sector leadership (through commodity associations and clusters) in the identification and implementation of interventions.

\section{Agricultural policy framework}

It is often assumed that large-scale commercial farming is more productive than smallholder farming. This is not always true; in Uganda, as in other countries, farm size is negatively associated with output per hectare and total factor productivity. However, there are a number of areas where estate production can play an important role in agricultural development: For instance, in crops such as horticulture, the formal commercial sector uses land very intensively, such as horticulture, where it is reported that 120 workers are employed per hectare. For some crops, profitable smallholder production depends on the availability of processing facilities, but the private sector will not invest in these facilities without a nucleus estate. Tea is a good example.

The decision whether a particular area of land should be used for large-scale production or small-scale farming is a matter of private initiative, and Government's role is mainly regulatory. Government will seek to ensure that large-scale investors in farming face a conducive business environment; for instance, improved functioning of the land market should make it possible for people to buy large areas of land for commercial production, conditional on land use policy at the district level, while also ensuring that existing property rights are not disturbed.

Two other areas that require policy attention are urban agriculture and biotechnology. Policy and legislation relating to farming in the country's rapidly-growing urban centres need to be drawn up if the livelihoods of those practising them - often amongst the poorest strata of society - are to be made more secure. National bio-technology and biosafety policies are needed to provide guidance both to producers and to consumers.

\section{Transport infrastructure}

Improving transport infrastructure (roads, railway, air, waterways) is important in boosting production, incomes and competitiveness because it links producers to consumers. Poor or inadequate road infrastructure is partly responsible for low production and productivity of some parts of the country. Producers should have reliable road networks to quickly transport their produce to markets, many of which are perishable in nature (milk and vegetables are examples). A good road network also facilitates market integration by linking surplus to deficit areas, as well as linking producers to input markets. Government is committed to expanding and maintaining a good road network. The railway network has virtually collapsed, save for the Kampala-Malaba route, yet it is a cheaper way of moving bulky agricultural products. Air transport is vital for perishable, high-value products such as fresh cut owers and fish exports. 
Recent research on the Ugandan experience shows that Government spending on rural roads has had a substantial effect on rural poverty reduction. The impact of low grade feeder roads was shown to be larger than that of higher grade murram and tarmac roads. The large impact of lower grade roads was mainly through improved agricultural productivity, whereas the impact of higher grade roads was mainly through improved non-farm employment opportunities. Government will also seek opportunities for other methods of reducing transport costs including the provision of an oil pipeline to Kenya and measures to encourage competition in the haulage industry.

\section{Roads}

Road transport is the dominant mode of transport in the country, accounting for over $92 \%$ of the volume of freight and human movement. The country's road infrastructure comprises $10,500 \mathrm{~km}$ of national roads, $27,500 \mathrm{~km}$ of district roads, $2,800 \mathrm{~km}$ of urban roads and about $30,000 \mathrm{~km}$ of community access roads. The national roads are developed and maintained by the Ministry of Works, Housing and Communications (MWHC); district roads are maintained by District Governments; urban local governments are responsible for urban roads, while community access roads are the responsibility of the Sub-county (LCIII).

Over the last 15 years, Government with the assistance of development partners has invested heavily in developing and rehabilitating road infrastructure, particularly national and district roads. Considerable improvements have been registered, with the proportion of national roads in a fair condition improving from 6 percent to 75 percent and district roads from 15 percent to 67 percent between 1988 and 2003 respectively. However, most community access roads and urban roads are still in a poor condition. Rural areas are poorly served with roads, with only 10 percent of community access roads reported to be in good/fair condition in 2003. This means that the road network serving the poor cannot bring the poverty reducing effects that infrastructure is expected to bring.

Investments in roads are guided by the 10-year road sector development plan (RSDP), which was started in 1996 for national roads and updated in 2002 to include district and urban roads. The road-sector development plan essentially includes only projects with at least $12 \%$ rate of return. A Road Agency Formation Unit has been established as a transitional arrangement and has taken charge of the implementation of the RSDP. MWHC retains the mandate for planning, while the Coordination unit within MFPED translates the RSDP into an expenditure programme and oversees the performance of the works carried out.

Government's objective is to achieve a level of expenditure sufficient to keep the whole network in good condition once it has been rehabilitated. In accordance with Road Sector Development Plan, Government committed itself in 2001 to achieving this equilibrium level by 2009. However, since 2002 maintenance expenditure has been rising at a lower rate than is needed. The achievement of the proposed equilibrium expenditure level at US\$ 54 million (excluding VAT) per year will be postponed about 10 years, unless maintenance spending is increased. By then, there could be a backlog of $20-25 \%$ of the total planned expenditure. Government will therefore prioritise maintenance expenditure within the roads sector. 
Government will create a National Road Authority during FY 2004/5 to take responsibility for construction maintenance of the national road network. During 2005/6, MWHC will be restructured to focus on policy, standards and regulation, and strategic planning.

Within the investment projects included in the RSDP, it is necessary to prioritise. Government will continue to rely on the poverty benefits of particular projects in selecting projects to be prioritised within the RSDP. Government will also explore the potential for private sector involvement especially in the form of area-wide long-term maintenance contracts on a performance basis and in the form of Public-Private Partnerships (PPPs) especially for ring roads or bypasses in greater urban areas and especially in Kampala, at an alternative bridge crossing on the River Nile at Jinja and at adjacent road sections to/from certain large factories and farms.

District, urban and community access roads are a protected area on the state budget, financed via PAF funds. The investments are guided by the Ten Year District Roads Investment Programme (TYDRIP) whose implementation will start in 2004/05.

Using existing technologies, for district roads in urban and rural areas, the present level of funding is only sufficient to maintain approximately $70 \%$ of the district road network in a fair/good condition. However, MWHC is examining technological options for low-cost construction and maintenance of low-traffic roads.

Another deficiency has been a historical neglect of community roads and footpaths. Rehabilitation of such infrastructure is a possible use of LGDP funds and the PMA nonsectoral conditional grant. Maintenance is the responsibility of the local authorities, and will need higher priority to ensure that all households can continue to benefit from the improvements in the transport network as a whole.

\section{Priority actions for roads}

Government will:

- Continue to invest in road rehabilitation and maintenance in accordance with the RSDP

- Ensure that adequate funds are available for maintenance. The sector will have responsibility for allocating funds between rehabilitation and maintenance within its overall ceiling.

- Enforce the axle load restrictions

- Develop a price index for construction to enable the unit cost of construction to be monitored more accurately.

- Establish the National Road Authority in 2004/05 financial year.

For district, urban and community access roads (ducar-roads) Government will:

- Continue to provide financial resources for ducar-roads including urban infrastructure improvement. 
- Give priority to those rural roads which could unlock areas with potentially high agricultural surplus and also enable the rural populace to access basic social services as well as product and input markets.

- Strengthen local capacity for road management with a focus on labour intensive work methods to provide employment and income.

- Examine the scope for enhancing support to community roads; this may be an appropriate area for spending under the Local Government Development Programme (LGDP) and the Non-Sectoral Conditional Grant (NSCG)

- Through the White Paper specify a long-term strategy for the sub-sector and how it is to be implemented

Regarding private sector participation, Government will:

- Support pilot activities to be launched in FY 2005/06 for area wide long-term maintenance contracts on a performance basis.

- Develop a strategy to increase private sector participation in management, investment and maintenance of projects within the transport sector as well as strengthening the national construction industry.

\section{Railways}

The Uganda Railways Corporation was formed in 1977 after the collapse of the East African Community. It inherited the assets of the former East African Railways Corporation, which were old and largely dilapidated. Railways provide bulk haulage capacity for Uganda's export and imports. Railways currently handle between 30 and 40 percent of Uganda's bulk cargo to and from the ports of Mombasa and Dar-es Salaam, handling exports of coffee and imports of general goods. There are only two operational lines, Kampala-Malaba and the Tororo-Soroti line commissioned in July 2004, out of five lines. The Northern line and Busoga loop were closed due to uneconomic operations while the western line was closed due to dilapidation and very high operational costs.

The major problems with railways include dilapidated infrastructure and rolling stock, poor quality of services, and a rather limited national market for bulk transport. It has been estimated that if the Kampala-Malaba line and the marine wagon services on Lake Victoria were in a good condition, and being managed efficiently, the cost of transportation by rail would be at least twenty per cent lower than by road. Further, to provide a larger market for Uganda Railways Corporation and more cost effective transit transports the Ugandan railway network may be connected to DRC, Rwanda and Southern Sudan. Government negotiations for a joint concession for Kenya and Uganda Railways are in progress. Joint concession may make it more attractive to private investors.

\section{Priority actions for railways}

Governement will:

- Finalise negotiations for the concessioning of the railway system in Uganda in a joint operation with Kenya. 
- Consider how to improve private sector incentives to invest in the rehabilitation of operational lines, in the re-opening of closed lines and in connecting the Ugandan Railways network including the marine wagon service on Lake Victoria with that of the neighbouring countries.

\section{Air transport}

Air transport infrastructure in the country is managed by the Civil Aviation Authority, funded out of airport landing fees. The infrastructure consists of an international airport at Entebbe, which is a key outlet for high-value agricultural exports and an inlet for tourism, and 16 other main upcountry aerodromes and airstrips, five of which are near national game parks and are therefore important for tourism. Over the period 1991-2002 international passenger traffic grew at an average annual rate of $12 \%$, while cargo exports have grown by $32 \%$ on average. If this trend continues, the export cargo passing through Entebbe International Airport will have doubled in three years.

Despite the removal of the monopoly of Entebbe Handling Services, airport handling remains inefficient. The navigational and security equipment at the airport needs upgrading, and the basic infrastructure needs upgrading including a new runway, taxi way, lighting systems and apron. Upcountry airstrips need funding for infrastructure development. The East African Civil Aviation School in Soroti, under the CAA, provides training courses for airport support staff needs rehabilitation. The public sector role in this training needs review; private financing may be appropriate, since the training has a welldefined private return and private airlines can sponsor potential pilots.

\section{Priority actions for air transport}

Government will:

- Consider the best way of funding necessary infrastructure at Entebbe including a new runway, taxi way, lighting system and apron

- Upgrade the navigational system at Entebbe Airport

- Consider whether East African Civil Aviation School in Soroti should be supported with public funds.

\section{Water transport}

The principal water transport is on Lake Victoria, Lake Kyoga and Lake Albert and the river Nile. Water transport was formerly widespread in Uganda up to the early 1960's when steamers operated passenger services on the larger lakes and the navigable sections of the River Nile. Since then, water transport has declined and most of the infrastructure is now dilapidated. The Ministry operates six ferry services as a continuation of the national roads across rivers and lakes where it would be uneconomical to build bridges. These ferry services are important for linking parts of the country to the capital, regional centres and communities, but the ferries are in poor condition and most of them need replacement. There is an increasing demand for more ferries to serve several important towns across Lake Kyoga. 
Major challenges include insufficient or absent navigational aids, poor water landing site infrastructure and poor enforcement of water transport regulations. Also, poor adjacent infrastructure (feeder roads and/or ferry connections) may in some cases act as a barrier to the continued development of lake fisheries. There are possibilities of enhanced private sector participation; for instance, the provision of ferries need not be a uniquely public sector role.

\section{Priority actions for water transport}

The Government will:

- Continue to provide ferries on existing ferry connections, landing sites and navigation aids as needed and economically feasible.

- Strengthen the regulation of all regular water transport services.

- Promote private sector participation in regular water transport services.

\section{Communications}

Communications are important in generating marketing opportunities and productive linkages. Since the reform of 1996, Uganda Communications Commission (UCC) has acted as an independent regulator of the sub-sector and the Uganda Post and Telecommunication Corporation has been split into Uganda Post Ltd (UPL), Uganda Telecom Ltd (UTL) and Post Bank (U) Ltd. The major development in the sector has been the huge growth of mobile phones, led by the private sector. $35 \%$ of households in Kampala, and $7 \%$ nationally have mobile phones, though the proportion in the North is just $2 \%$. There are now far more mobile connections than land lines. Total tele-density has improved from 0.28 to 2.5 with over 600,000 and 59,000 subscribers in the mobile and fixed networks respectively.

While the private sector is doing a very good job of satisfying the demand for mobile phone services for those who can afford them, there is a need for some intervention to support rural communications. This is being handled by imposing requirements on private providers to support some extension of their coverage to underserved areas, and in addition by spending managed by UCC, which raises a levy of $1 \%$ on the gross revenues of telecommunications and postal service providers. This is used to support communications in rural areas. 55 of 56 districts now have network coverage or a point of telecommunications presence. UCC plans to competitively tender the provision of ICT infrastructure in un-served areas to private sector operators on the basis of minimum subsidy bids. Public phones are being provided in sub-counties that are not currently served.

With the liberalisation of postal services, there are now 13 private courier service operators, and a number of postal services have been introduced. The national operator is obliged to provide a post office in all the districts by 2004, to establish at least an agency in every town of 2500 people, and to service academic institutions.

\section{Priority actions for communications}

- The restructuring and privatisation of Uganda Postal Services will be achieved by the end of FY 2004/05. This will include some subsidy for socially needed but unprofitable services. 
- The UCC will continue to support communications in rural areas.

- All ministries and government agencies' ICT requirements will be mainstreamed in their budgets.

\section{Water for production}

Water for production covers water for crops, livestock, wildlife, aquaculture and rural industry. Government has developed a strategy on water for production for the period 2004-15 which clarifies roles for public and private sector. The major public sector roles in most sub sectors are information and capacity-building. However, there is some role for investment in irrigation and a considerable role in water for livestock.

\section{Water for livestock and wildlife}

There are about 765 tanks and 316 valley dams. Of these sources, over $80 \%$ are publicly owned. However, $65 \%$ are not functional. The volume of water that can be provided by the functional systems is about 6 million cubic metres, which would sustain the population of livestock for just 21 days. By 2005, the amount of water needed to sustain the expected livestock population for 3 months (which is the period needed to secure the population against the effect of drought) will be as high as 36 million cubic metres. However, the economic returns to this investment may not be adequate to justify it.

Improved water sources for livestock are needed. However, experience with public investment in valley dams shows that both project implementation and use of the dams can be problematic if communities are not actively involved in designing, as well as managing, the projects. As noted in Box 4.2, inappropriately sited valley dams can cause social problems and may not meet the needs of pastoralists who need to migrate seasonally to find grazing lands. Hence the approach taken will involve local consultation.

The most appropriate way to prioritise the actions within this sub sector appears to be allowing communities to allocate investment funds to valley dams where the community is convinced this is a priority. The framework under the Fiscal Decentralisation Strategy providing increased exibility to local governments in allocating funds, combined with funds under LGDP, would provide an appropriate mechanism for this. This will honour Government's commitment to make valley dams available while allowing communities to allocate the funds to more profitable investments if they prefer.

As noted below, resources within the water sector are already highly stretched and in the absence of evidence of economic returns there is an inadequate case for reallocating funds from other sectors to cover valley dams.

\section{Water for aquaculture}

Most of the potential for aquaculture will be met by large-scale private investment. There is a role for small-scale fishponds at the village level. Where economically profitable, this may be promoted as an enterprise by NAADS. 


\section{Water for crops}

The extent of public sector involvement in irrigation will depend on the returns to this investment relative to other uses of public funds. Whereas irrigation forms a very large proportion of the total development budget in some parts of South Asia, this is less appropriate in the context of higher rainfall, more diverse agricultural systems, and lower population densities found in Uganda. The economically viable irrigation potential of Uganda is estimated at about 90,000 ha. The area currently irrigated formally is about 7,600 ha., and about 6,800 ha. is partially irrigated on a commercial sugar estate. About 53,000 ha. is irrigated informally, mainly by farmers growing rice in swamps. There is considerable interest in irrigation, but limited information both on the part of farmers and extension staff.

Public actions in this sector will focus mainly on rehabilitating existing Government schemes and transferring them to farmers' management, and promoting small-scale irrigation technologies.

\section{Water for rural industries}

Government will aim to simplify access to permits, and to integrate the needs of industry in water supply plans in small urban settlements.

\section{Priority actions for water for production}

Government will:

- Implement the water for production strategy

- Make investments based on likely returns, taking into account local livelihoods and preferences

\section{Energy}

\section{Overview}

Energy supply is critical to enhancing production, competitiveness and incomes. Electric power is essential to the development of modern manufacturing and services. It also plays an important role in rural development, supporting activities such as wet coffee processing, fish landing sites for preservation, mining areas, and lime production. The availability of power also has benefits in reducing drudgery, especially for women and girls (for instance by reducing the need to collect fuel wood) and in enabling clinics to function and educational study to progress.

Only 3\% of Ugandan households in rural areas and $8 \%$ in urban areas have access to grid electricity; the rest rely on biomass for energy sources. Uganda's per capita electricity consumption is one of the lowest in the world at $62 \mathrm{kWh} /$ year, compared to 300 in India, 580 in China, and 11,000 in USA (1996 data). Those who have access to electricity experience regular shedding and/or outages that necessitate the installation of generators, with implications for the pricing of their products and the level of investment.

The 2002 National Energy Policy focuses on improving the effectiveness of energy sector management, attraction of capital to increase energy access, and making energy affordable. 


\section{Electricity}

Uganda has large energy resources; the hydroelectric power potential of Uganda is estimated at over 2,000 MW, mainly along the River Nile, whereas current exploitation is about $317 \mathrm{MW}$, of which $300 \mathrm{MW}$ is on the River Nile (Nalubale and Kira power stations) and generated by UEGCL. Kilembe Mines Ltd., Kasese Cobalt Company Ltd and others generate a total of $17 \mathrm{MW}$. However, power outages remain a serious constraint for economic growth.

Producers of energy are large enterprises, which may have considerable market power. Hence regulation is essential and in some cases public subsidy may be appropriate, but this need not imply public ownership. The Electricity Act, 1999 set reforms in motion by enabling private participation in the sector including rural electrification; establishing the Electricity Regulation Authority; and permitting the privatisation of the state owned Uganda Electricity Board (UEB). UEB was unbundled into three independent enterprises namely: the Uganda Electricity Generation Company Ltd (UEGCL), which owns the Kiira and Nalubale power stations (operated by Eskom under a concession agreement), Uganda Electricity Transmission Company Ltd (UETCL), which owns and operates the transmission infrastructure operating above $33 \mathrm{kv}$ and Uganda Electricity Distribution Company Ltd (UEDCL), which owns and operates the grid -connected electricity supply infrastructure at $33 \mathrm{kv}$ and below.

It is estimated that Uganda will have a peak demand of between 411 and 649 MW by 2010. The current level of about $317 \mathrm{MW}$ is inadequate. In the short run, finance has been secured for two extra turbines of 40MW at Kiira power station. In the longer term, two sites with big electricity generation potential have been identified at Bujagali falls (250 MW) and Karuma falls (200 MW). Investment will be led by the private sector.

The viability of a private-sector led strategy will depend on the charging of commercially viable tariffs. Given the existing pattern of electricity use in Uganda, providing a subsidy to domestic consumers is unjustifiably inequitable. The Rural Electrification Fund will 'buy down' tariffs by availing cheaper money for investment. While it is important for business rates to come down, this can best be done by improvements in managerial efficiency and negotiation of favourable terms for the export of electricity to other countries. In addition, an awareness campaign for electricity saving will be implemented, as will energy audits which seek to reduce inefficient use of electricity. About $18 \%$ of the biggest 50 electricity consumers have participated in the audit. By 2006 it is hoped to get to $40 \%$. The estimated impact of these measures is a reduction in load shedding from an average of 38 hours per customer each month to 25 hours by 2006 .

\section{Rural electrification}

Recent survey evidence shows that there are significant returns to rural electrification in reducing poverty. The presence of electricity in a village increases households' consumption by about $10 \%$. Government's strategy limits the costs by subsidising the investment rather than financing it outright. The benefits come mainly in the form of increased employment and agricultural marketing opportunities in rural areas, though the extended hours of work and the increased access to social services also offer benefits. 
The Energy for Rural Transformation (ERT) program has been developed to widen the access of rural areas to energy supplies to $10 \%$ by 2012 , through grid extension, independent power producers and solar or renewable energy. A rural electrification fund, supported by Government as well as a 5\% levy from transmission bulk purchases from generation companies, provides subsidies to private suppliers, based on the criteria of:

- Financial and economic soundness of project

- Sound environmental impact statement

- Positive social return

- Equitable electricity distribution

The proportion of rural household using electricity for lighting rose from 1\% in 1999/ 2000 to $3 \%$ in 2002/3. After an initial delay, the revised target is to increase the proportion of rural households with electricity to $10 \%$ by 2012 .

\section{Other energy sources}

As noted above, the majority of households' everyday energy needs are met by fuel wood and charcoal. Although electricity is crucial for economic transformation, the lives of most poor people are currently affected by their access to more traditional energy sources and the evidence suggests that this is deteriorating, as distances walked to collect fuel wood are increasing. It is likely that this is increasing the burden on women's time, with negative effects on their economic and domestic activities as well as the quality of their lives. Cooperation is therefore needed between the forestry sub sector in the Environment and Natural Resources sector and the energy sub sector in the Economic Services sector to develop effective strategies to meet domestic energy needs.

\section{Priority actions and prospects in energy}

- Generating capacity will be increased by attracting private investors

- The rural electrification strategy will be implemented.

- Government will monitor unit costs and socio-economic returns to rural electrification

- MEMD will cooperate with other sectors in promoting technologies that allow the use of fuel wood to be reduced.

\section{Mining}

Uganda's mineral endowment includes gold, tin, wolfram, cobalt, copper, iron and petroleum. It represents an important, though so far unquantified, national asset. The challenge is to exploit this asset in the way that will provide the best returns for Uganda. These returns include taxes and royalties on the resource and the earnings of artisanal miners from the sale of the resource, as well as employment opportunities and infrastructure. To this end, a framework is needed that encourages private exploration while ensuring that the country gets a good return.

In the 1950s, mining accounted for one-third of the country's export earnings, and provided formal employment for over 15,000 people. The sector later declined until the 1990s. The value of declared mineral production rose from virtually nothing in 1990 to 
US \$40.8 million in 2000 of which US \$13.2 million consisted of industrial minerals and construction materials, and US \$27.6 million of metallic minerals.

Currently, most mining is carried out by artisanal and small-scale miners whose activities represent an important source of direct and indirect income for a relatively large rural population. It is estimated that 50,000 to 100,000 people are involved in mining activities depending on the agricultural season. A sustainable management of minerals Project has been put in place with initial support from development partners. It aims at supporting geodata collection, dissemination of information and provision of extension services to key artisan miners.

The establishment of an enabling environment that is internationally competitive for attracting investment is a prerequisite for developing the mineral resources of any country. The interventions include the provision of adequate and modern geological information, modernizing the legal and regulatory framework for the mining sector, increasing capacity of government sectoral institutions, and adequate infrastructure.

To address these challenges, Government has formulated the Mineral Policy in 2001 and enacted the new Mining Law in May 2003. This allows benefits of mining to be share with local communities. A countrywide Mineral Sector Development Programme has bee developed, which will address technical and social issues of the sector including the improvement of conditions for small-scale mining, the development of Geological Infrastructure, capacity building and mining related environment management systems.

Mining royalties are set in the Mining Act, and can be waived in a particular case. Petroleum royalties are negotiated on a case-by-case basis at the time when prospecting licenses are issued. Also, mining companies pay a distinct rate of corporate income tax, which is levied on a sliding scale. The principle is to maximise benefits to Uganda - including both the income stream and the employment and spin-off benefits - while providing an attractive investment opportunity for the private sector.

\section{Priority actions and future prospects in mining}

Government will:

- Put in place Mining Regulations to operationalize the new mining law.

- Improve the information it provides to investors and artisanal miners, and establish an environmental and social impact management framework for mining activities.

\section{Tourism}

Tourism has been an area of high growth for the economy in recent years. The number of tourists visiting the country increased from 189,348 in 1999 to 254,000 in 2002 (this included a sharp increase in tourists from Africa, while tourists from Europe and America have grown more slowly). Foreign exchange earnings from the tourism industry rose from US\$ 102 million in 1999 to \$185million in 2002.. Standards have been agreed among the EAC countries. The tourism industry has used a number of cheap and simple methods to market Uganda as a high quality tourist destination, such as the use of the www.visituganda.com website and participation in trade fairs and public relations campaigns. 
Direct poverty-reduction benefits of tourism come from employment generated $(60 \%$ of employees are female), and the creation of markets for handicrafts and agricultural products. Partnerships between public and private sectors are critical to the development of the tourism sub-sector. The development of the sub-sector will also depend on improved infrastructure and security. Training (which maybe privately provided) is needed especially for tourism planning and development, business skills and marketing.

\section{Priority actions for tourism}

Government will:

- Continue to support increased promotion of Uganda as a tourist destination abroad

- Promote diversification of tourism products including agro-tourism, cultural routes, community tourism, etc

- Support training of staff in the industry.

- Support the provision of business development services for tourism, in cooperation with the private sector.

\section{Science, Technology and Industrialisation}

One of the key factors hindering Uganda's competitiveness is the export of low value and unprocessed products. Efforts to add value to Uganda's leading exports such as coffee, cotton, fish and livestock products through processing and other innovative marketing approaches such as branding, export of organic products and others hold the key to increased export earnings. Unfortunately, available processing technologies tend to be not most suited for Uganda's production systems. Coffee roasting plants, milk powder processing factories and textile mills are beyond the reach of the average entrepreneur. Uganda's production systems are based on small holdings. This demands that value addition facilities are based on cooperatives or farmer associations or based on a lead firm that provide appropriate scale of value addition facilities and applies economies of scale in product marketing.

Government will intensify efforts in promoting innovations from scientists so that they can transform science in appropriate technologies that can be applied in the production of products and services that compete in the global market. This demands putting in place a system of incentives that reward hard-working scientists that produce innovations that have practical relevance to Uganda's situation. There is also need for institutional reforms and strengthening in the area of assessment and importation of technologies and their modification to suit the Uganda situation. This may involve providing facilities for the incubation of industries, piloting and prototyping technologies. Uganda's Industrial Research Institute (UIRI) recently became a statutory body. However, it needs to be restructured and resourced to be able to play the new mandate. This applies to other institutions that support science and technology development and export promotion including the Uganda Council of Science and Technology (UNCST), Uganda Export Promotion Board (UEPB) and the Uganda National Bureau of Standards (UNBS). 


\section{Priorities for Action}

Government will prioritise the following over the medium term:

- Establish a system of incentives including Innovation Awards to scientists that generate innovations of promise in addressing Uganda's development needs,

- Strengthen the institutional capacities for incubation centres, technology prototypes and piloting for commercialisation building on the mandate of UIRI.

- Implementing the industrialisation policy.

- Provide a set of interventions, within the framework of the MTCS and the PMA, that promote enterprises based on scientific innovations and add value to Uganda's exports. These will be transparent and, as discussed in Chapter 3, will not involve firm-specific incentives.

\section{Access to Microfinance}

Credit services for the poor have been found to make positive impact on household income. Some borrow for investment, leading to increase in income, and others for consumption smoothing in periods of hardship, thus maintaining their consumption levels without running down productive assets. To promote economic development, there is a need for both short-tem and long-term financing for both the formal and informal sectors. For the informal sector, the fast-expanding microfinance industry is very effective at financing investments with quick and high returns. Micro, Small and Medium Scale Enterprises (MSMEs) tend to be more attractive to MFIs because most of them have quick returns and owners can begin to pay back the loans in a relatively short time. The micro finance industry has hitherto been less effective at financing agricultural activities, whether for marketing or seasonal credit or loans for small agricultural investments. Government is therefore exploring an initiative with the International Fund for Agricultural Development (IFAD) and other development partners to promote better access to agricultural credit for smallholders, as well as promoting the expansion to rural areas of microfinance services through the Microfinance Outreach Plan.

As noted in Chapter 3, Government has undertaken legislative reform to enable advanced microfinance institutions to accept deposits within a prudential environment, and has also legislated for the establishment of a Credit Reference Bureau. Commercial law reform, should make it easier and quicker to resolve disputes between creditors and debtors. The development of Business Development Services should also improve the functioning of financial markets.

Microfinance has grown considerably in recent years in Uganda. A survey, by the Ministry of Finance, Planning and Economic Development (MFPED) in 2002, of over 1,000 Microfinance Institutions (MFIs) revealed that MFIs had just under 1 million members, and a total loan portfolio of Shs 86.5billion; the average loan size was Shs 262,533. The majority of loans are to non-agricultural enterprises in urban or peri-urban areas. Microfinance institutions have been supported by a variety of donors and NGOs. Mapping of micro-finance institutions has revealed informal institutions even in areas not reached by formally constituted MFIs. 
Microfinance institutions fill an important gap in the financial market. International experience shows that many good institutions need support for a sustained period of time before becoming self-sustaining, and that public resources devoted to microfinance have in some countries had higher returns in terms of poverty reduction than those devoted to other public interventions.

Government is seeking to encourage the microfinance institutions to move into less served areas and activities, in particular agriculture. Under the Microfinance Outreach Plan, Government will provide capacity building and matching grants that will provide incentives for service delivery in rural areas. The grants are designed to favour delivery of innovative products in relatively remote areas. The plan is intended to promote an average growth of $25 \%$ over the entire period on the client base, so that there should be 1.3 million clients and 9 million indirect beneficiaries by 2006, of which $60 \%$ should be in rural areas. It will be important to monitor the extent to which microfinance institutions are able to meet the needs of agriculture so that, where necessary, changes in strategies can be made to better serve borrowers in the sector.

As discussed in Chapter 3, Government will promote the development and application of innovative financial products for the private sector including leasing. The pension sector will be reformed to provide a basis for availing medium- and long-term financing to the private sector. In addition, the Development Finance Department (DFD) and Uganda Development Bank will be restructured to make them appropriate institutions for providing term finance to the private sector.

\section{Priority actions for credit services}

Government will:

- Continue to implement the Microfinance Outreach Plan to ensure increased coverage - reaching out to more poor people in rural areas.

- Develop and monitor mechanisms through which MFIs can meet the needs of smallscale agriculture.

- Continue to review how the financial needs of medium-scale enterprises can be met, with the preferred approach being increased use of commercial banks to access development financing.

- Support capacity building and business skills development, especially for MSMEs.

\section{Micro, Small and Medium Scale Enterprises}

\section{Skills enhancement and business services}

As discussed in Chapter 2, recent studies ${ }^{10}$ have shown that rural households whose main source of income was non-farm activities are better-off than households whose main source of income was agricultural production. For rural areas, where poverty is most prevalent, the main non-farm activities are MSMEs (micro-, small- and mediumscale enterprises) covering a variety of activities or sectors including general retail trade, agro-processing and other services including the food and drink industry (restaurants and bars), transportation and construction. These account for about 12 percent of employment in rural areas, but over 40 percent in urban areas. Therefore, growth of MSMEs is an important way of fighting poverty, both in rural and urban areas. 
MSMEs are an important part of Uganda's economy. They include about 800,000 formal and informal enterprises comprised of retailers, processors, repair shops, hoteliers and transporters. The latter are mainly informal, employing about 90 percent of the total nonfarm economically active population estimated at about 1.5 million people.

Studies have shown that MSMEs are constrained by a number of factors including lack of entrepreneurial skills, lack of access to and cost of business development services, poor access to market information on product standards, and a poor regulatory environment. In order to improve the performance of MSMEs, they have to be coordinated to be able to access public services in a cost effective manner. Coordination and cooperation may take the form of farmer associations, cooperatives or clusters. In addition regional and national entities could be formed to enhance coordination for specific sectors or the entire SME sub-sector.

In marketing, the MSMEs constitute an important part of the supply chain as input suppliers to the medium and large firms which in turn serve final markets both domestically and internationally. A cluster strategy has been developed to enhance the growth of this supply chain. This industry cluster approach visualizes the growth of MSMEs through increased research and development facilities, provided by government, allowing them to be more independent of government support and in a better position to attract funding from the financial sector. The growth of clusters will also allow Uganda to develop a workforce with diverse areas of expertise directly enhancing international competitiveness and income levels.

The various efforts of government, development partners and private sector need to be coordinated and monitored to reduce duplication and ensure value for money. Most of the existing programmes are concentrated around Kampala. Thus many upcountry MSMEs lack the services that are most critical to their ability to grow, make profits and compete. Under the MTCS framework, the MTCS Secretariat will play this coordination and monitoring role.

Government is also considering the establishment of a funding mechanism whereby the provision of business services by the private sector would be subsidised. This re ects the conviction that inadequate entrepreneurial and managerial skills represent an important constraint on the private sector.

\section{Taxation, registration and licensing of MSMEs}

Growth and expansion of the MSMEs will depend on the economic environment created by the Government, both at central and local level. It is the role of Government to ensure that businesses operate in an environment conducive for growth, with subsequent benefits of increased employment. A recent study on rural taxation ${ }^{11}$ showed that the current taxation system is not conducive for small rural and urban business to prosper. Local governments' concern with revenue generation leads to negative effects on the growth of MSMEs. Local taxes on small businesses are highly regressive, cutting into profit margins by as much as $50 \%$ for the smallest businesses. The study further found that revenue collected from these businesses is not used to provide services relevant to their growth. Therefore, local governments need to streamline local taxation in a manner that 
encourages rather than curtail growth of MSMEs. Such measures could include reviewing the rates and levels of taxes levied on existing SMEs or even offering tax holidays, of say a year, for start-up businesses. Other measures could include taxing only businesses above a certain threshold of annual income.

Similarly, the regulatory environment including business registration and licensing requirements are critical to the growth of MSMEs. A pilot project in Entebbe Municipality reduced the time spent by businesses in obtaining licenses by $90 \%$, reduced compliance costs by $75 \%$ and increased revenue collection by $40 \%$.

Such costs are not always taken into account when creating new regulations. In order to ensure that firms are not excessively burdened, Government is committed to ensuring that principles of regulatory best practice are adopted. Regulatory best practice essentially means having in place:

- Sensible, practical laws and policies that support enterprise growth and competitiveness while at the same time protecting essential public interests:

- A systematic process for analysing and consulting on new policies and regulatory proposals that have significant economic, social or environmental consequences, before they are introduced..

- A system to monitor the legal framework to ensure that it is delivering increasingly positive returns to business, and that laws once passed are continuing to work well.

\section{Priority actions for MSMEs}

To boost growth of MSMEs, Government will:

- Continue to enhance linkages and information ow between the government and MSMES, particularly with regards to new trading regulations and any changes to international standard requirements.

- Develop a systematic approach to this sub-sector, to avoid an excessive proliferation of uncoordinated initiatives.

- Work with local governments to streamline taxation systems of MSMEs in both rural and urban areas.

- Strengthen the monitoring and coordination mechanism for the MSMEs through the MTCS Secretariat.

- Improve the investment climate by creating a conducive regulatory framework, enhancing the efficiency of the registration and trade related services.

- Provide entrepreneurial skills and business development services in partnership with the private sector.

- Create an enabling environment for MSMES to develope.

\section{Environment and Natural Resource Use and Management}

Uganda's economic growth and its sustainability will depend on how well the environment and natural resources are managed and used. However, Uganda's recent rapid economic growth has put significant stress on its ENR base resulting in environmental degradation. Consequently the quality and quantity of resources on which sustainable economic growth and poverty reduction depends, is declining. 
Recent estimates of the cost of natural resource degradation in Uganda suggest that the cost of natural resource degradation is as high as $17 \%$ of gross national income per year, of which $6 \%$ consists of forest degradation and $11 \%$ soil degradation ${ }^{12}$. Although the estimate is highly approximate ${ }^{13}$, it is confirmed by However, the finding receives dramatic confirmation from households' own experience. In UPPAP 2 communities in all 12 districts reported that the distance travelled to collect fuel wood was increasing. Declining soil fertility was reported in 11 out of 12 districts ${ }^{14}$. The average age of the tree stock and the distance travelled to fetch water is rising, suggesting that the existing use of forests is unsustainable and that the negative consequences are being felt by poor people, especially women. Water resources need to be well managed and protected from degradation for obvious reasons, including water for direct animal and human use, as well as being a habitat for capture fisheries and aquaculture. The land rights of the poor need strengthening and protecting.

Many of the resources managed by the ENR Sector, such as wildlife, forest reserves, natural water bodies, and wetlands, are held by Government in trust for the people of Uganda under article 237 of the Constitution. It is of particular importance that Government honours this trust and resists any interference by vested interests. Examples of actions in this area include: improved wetlands management, control of illegal timber harvesting and trade, control on the use of illegal fishing gear and enforcement of environmental impact assessment regulations. A more harmonised approach to managing this responsibility is also required.

The overall guiding framework for environmental management is the National Environment Management Policy of 1994 and the National Environment Statute of 1995. The NES (1995) established the National Environment Management Authority to monitor, supervise and enforce regulations, standards and guidelines and to coordinate all matters on the environment in Uganda. The main role of NEMA is to ensure that all government plans, policies and programs address relevant environmental concerns and promote sustainable development and prudent use of natural resources. Capacity-building in local governments and sectors levels is needed, because the implementation of environmental management rests with them. Also, the National Environment Statute (1995) and the subsequent laws developed to safeguard the environment are only framework laws which need regulations, standards and guidelines to operationalise them.

The benefits of a sector-wide approach to planning have now become evident throughout Government. However, this approach is yet to take root in the ENR sector.

\section{Priority actions for Environmental Natural Resource Use and Management}

Government will:

- Develop a strategy for the ENR sector.

- Ensure adequate funding for the recurrent costs of NEMA as project support is phased out. The costing will be based on the needs of NEMA in the context of the environmental sector rather than on previous expenditure levels.

- Build capacity for environmental management at sectoral and district level.

- Develop regulations to implement the National Environment Statute of 1995. 
- Define boundaries of the ENR sector and work towards closer collaboration, a single investment plan, and a single budget vote planned and allocated by the ENR SWG. In the medium term the administrative set-up of ENR, now divided over several Ministries, will be brought in line with the sector make-up.

\section{Water Resources Management}

Water as a resource is Uganda's backbone for socio-economic development. At first site Uganda seem to be endowed with freshwater resources but this vary in time and space. A number of strategies including legal and policy framework have been developed to address various water resources demands, development, conservation and management without jeopardizing the needs of the future generation. The legal and institutional framework provide enabling environment upon which support upgraded planning and prioritization capacities of decision makers at all levels. As the vast majority of the Ugandan population is dependent on land and water resources for their livelihoods through rudimentary land use practices that are detrimental to the general environment, the water quantity, quality and their sources stand threatened (MWLE, 2003d). In ood and drought prone areas it can impact directly on household income of some of the poorest and most vulnerable people. It also enables more rational management of key natural resources, thus positively impacting on the quality of life and economic prospects of future generations.

Through water Resource protection and effective water shed management, water resources management ensures availability in quantity of the resource and minimization of source pollution so that the rural community gets water for domestic use at low cost. Decentralization of Water Resources Management (WRM) activities aims to improve efficiency and effectiveness, and foster integration of WRM with other activities at all levels of service provision. The expected outputs of the WRM decentralization programme include the sensitized local governments and all stakeholders on WRM issues with increased involvement of local government structures in WRM (MWLE, 2003f). Through regular and consistent monitoring of the nation's water resources, data generated has been used in the planning and design of water related projects.

\section{Priority ActionsWater Resource Management}

Government will:

- Finalise the WRM reform study and develop an action plan for the short, medium and long term strategy for the Water Resources Management.

\section{Land}

In 1998, Uganda passed a Land Act and since then has been implementing a Land Sector Reform programme. The overall guiding framework of this sub-sector is contained in the Land Sector Strategic Plan (2001-2010). The focus of the plan is the protection of land rights of the poor, improved access to land and tenure security. Central government land institutions are comprised of Physical Planning, Lands and Surveys, Land Registration and Valuation and Uganda Land Commission. 
Findings from the Village Census (2001) reveal that the size of land held by the poor is diminishing, land is increasingly concentrated in the hands of the few and that the middle and poorest categories have seen landownership decrease significantly since 1993. Recent evidence shows that a more equal distribution of land would be likely to increase productivity, because small farms are more productive per unit of land than larger farms. The land reform process has the following potential benefits:

- Improved security for existing tenants.

- Greater freedom of action for existing occupants. People who 'borrow' land often have limited use rights ${ }^{15}$

- Reduction of disputes. Land disputes are a serious drain on the resources of poor households. So far, the evidence suggests that disputes have increased in recent years $^{16}$, but where systematic titling has been applied disputes are generally reduced (see Annex Table A 4.5).

- Increased ability to use land as collateral

- Greater transparency of titling process. ${ }^{17}$

- Improved availability of land to purchase. Investors report some difficulty acquiring land; this relates to difficulties in the functioning of the land registry ${ }^{18}$.

- Improved balance of rights within the household (strengthened rights for women in particular), with potentially powerful impacts on incentives and productivity ${ }^{19}$. Orphans would be able to inherit land formally from their deceased parents.

- Enhanced opportunities for orphans to inherit land formally from their deceased parents.

- More equal distribution, with equity and efficiency benefits. In UPPAP2 (2001/02), shortage of land was the second most frequently cited cause of poverty after health.

The distribution of benefits perceived by households from one particular aspect of land reform, pilot projects in systematic titling, are shown in Table 4.6.

\section{Priority actions for the land subsector}

- Policy and legal reform. In addition to the legal reforms already achieved, there is a strong case for strengthening women's land rights and for enhancing districts' ability to raise land taxes.

- A Land use policy is being finalised, which will link land reform to poverty reduction strategies, covering the strengthening of women's rights, improved access to land for the poor, and the framework for urban and peri-urban land rights and management.

- Land information: Currently the state of information about land is unsatisfactory. Important improvements include:

o A cadastral update (important for revenue raising),

o Improved facilitation of the land registry

o A geodetic network, and the systematic production of certified general and thematic maps.

o Systematic demarcation. Under this approach, titling is undertaken for a given area of land at a community level, rather than by a land office on receipts of individual applications. This ensures that different local stakeholders are able 
to participate in the process and reduces the risks of rural households being effectively expropriated.

o Government land inventory

o Public information campaigns

o Operation of the Land Fund. Immediate priorities are the rehabilitation of the environment through resettlement of persons, the purchase and redistribution of land to the inhabitants of Kibaale district, facilitating land readjustment in mailo areas to enhance productivity, and piloting loans on small scale to identify sustainable approaches ${ }^{20}$. Potentially, a Land Fund can assist with resettlement and could provide a powerful means of reducing the poverty of the landless. However, costs and transparency are issues.

A Poverty and Social Impact Assessment is to be undertaken to establish more clearly the magnitude of the benefits, so that expenditure needs can be assessed and prioritised.

\section{Housing}

The national housing stock is estimated at 4.2 million units of which less than $20 \%$ are of permanent construction materials. About $50 \%$ are semi permanent and the remaining $30 \%$ are grass-thatched huts. In urban areas, over $60 \%$ of residents in urban areas stay in slums, characterised by poor sanitation, high disease incidence and frequent epidemics. The increase in the number of IDPs further aggravates the housing problem.

The overwhelming majority of housing in Uganda is provided by the private sector (including individual households) and it would be unaffordable to change this. National Housing and Construction Corporation, which was a Government parastatal charged with the function of provision of housing, is now in the advanced stages of privatisation. Nor can Government afford to extend its commitments further by extensive subsidy of private housing.

Hence the main task of public policy will be to make the housing market work better. Regulation is justified to ensure minimum standards and prevent the negative externalities associated with extreme overcrowding and lack of sanitation. However, if standards were made excessively high the poor would not be able to afford legally acceptable housing and would therefore be forced back into illegal slums.

The malfunctioning of the urban land market impedes the functioning of the housing markets. People who do not have well-defined legal title to their properties are discouraged from investing in them. The improvement of living conditions for the urban poor is therefore one of the potential benefits of an effective land sector reform.

\section{Priority actions for Housing}

Government will:

- Complete divestiture of National Housing and Construction Corporation

- Enact the building control bill during 2004 
- Establish the need for local public infrastructure in low-income urban areas in order to improve the lives of slum dwellers

- Capitalise and privatise Housing Finance Company of Uganda

\section{Forestry}

Forests provide an annual economic value \$360m (6\% GDP) of which only $\$ 112 \mathrm{~m}$ is captured in the official statistics. The sub-sector employs 100,000 people directly and 750,000 subsistence workers. Forests cover $24 \%$ of the total land area, of which $70 \%$ is on private and customary land. Forests on private land are mainly in the form of scattered trees, forest patches and agro-forestry crops. Trees (through fuel wood and charcoal) provide $90 \%$ of energy demands (18m tonnes per annum) and are expected still to be contributing $75 \%$ in 2015 . Forests also provide a number of ecological services: biodiversity, climate regulation, soil and water conservation, and nutrient recycling. These are important for agricultural performance and people's livelihoods.

Recent work ${ }^{21}$ has shed light on the role that forests play in the lives of the poor. Evidence from Masindi shows that the people living near forests raise as much as $18 \%$ of their incomes from the forest. Richer households raise about as much in absolute terms as poorer households, so that in proportional terms poorer households are much more dependent on the forests than richer households.

It is becoming increasingly clear that Uganda's forests are being seriously degraded. Encroachment due to open access and unclear land ownership, conversion for other uses, unsustainable harvesting, urbanisation, industrialisation and institutional failure are to blame. For example, the average distance travelled to collect firewood has risen markedly from $0.06 \mathrm{~km}$ in 1992 to $0.73 \mathrm{~km}$ in $2000^{22}$. Also, the average age of the tree stock is increasing, with signs of an acute shortage in five years' time, when prices are expected to rise and movement into natural forests is feared.

There is great potential for increases in wage employment and production for export. Forest products like firewood, timber and poles form important inputs into other economic industries such as construction, tobacco, and lime and brick making. Non-timber and other forest products also reduce livelihood vulnerabilities. Hence Government is encouraging the private sector to invest in forests with a view to increasing the resource base and increasing access.

While increasing wage employment, it is also desirable to reduce the subsistence burden of fetching firewood, which falls heavily on adult women in rural areas. This requires a strengthening of the management of community forest institutions.

Under the National Forest Plan (2002), which states the "need to capitalise on economic, social and environmental opportunities without undermining the resource base", Government has created a semi-autonomous National Forestry Authority (NFA), to be funded by revenues from royalties and sales of forest produce from the Central Forest Reserves (CFR), which comprise $30 \%$ of all forests in Uganda, for which NFA will be responsible. 
The NFP also provides for a decentralisation of responsibilities to Districts for the remaining 70\% of Uganda's forests and woodlands (comprising of Local Forest Reserves (LFR) and private and customary forests). This will be carried out through the District Forestry Service (DFS).

The DFS will play a fundamental role in the promotion, registration and advisory of formal Community Forests. Communal Land Associated, which are provided for in the Land Act of 1998, will be able to register ownership of a forest. Certificate of Customary Ownership, as its members can better demonstrate customary ownership of the land than other associations.

Through FID, MWLE will be responsible for additional policy formulation, development of national guidelines and training manuals, publicity and advocacy, and for monitoring the implementation of the activities carried out by the DFS. During the next three years, there is a need to allocate and transfer resources to the district level to support the DFS to fulfil its mandate.

\section{Priority actions for Forestry}

Government will:

- Enhance implementation of the National Forest Plan

- Promote private sector investment in privately owned forests, through provision of information and technical advice on the management of forests; providing permits to grow trees in central forests reserves with secure land and tree tenure; reviewing tax and other disincentives; through the continued operation of the Saw log Grant Scheme and establishing a Tree Fund in accordance with the National Forestry and Tree Planting Act.

- Promote the establishment of community woodlots through the launch of the DFS for extension and advisory services to private and community members interested in tree planting, and for promotion of tree planting.

- Further develop the National Tree Seed Centre; establish a framework for decentralised seed production. The establishment of a National Tree Fund, may help communities access necessary resources.

- Investigate the possibility of benefiting from commercial markets for ecological services such as carbon trading in global markets, in line with the Kyoto Protocol.

\section{Fisheries}

Over the last decade, fish have become one of Uganda's major export commodities. Recent estimates indicate that in the FY2001/2002 capture fisheries, including marketing, had an annual economic value of $\$ 301 \mathrm{~m}$ (whereas currently $\$ 130 \mathrm{~m}$ is attributed to fish in the national accounts), equivalent to around 6\% of GDP. Of these earnings, about $70 \%$ come from sales of fish at the shore whereas the remaining $30 \%$ constitute value addition by traders, transporters and processors.

Fish exports have grown from US $\$ 1.4$ million in 1990 to US\$87.5 million in $2002{ }^{23}$ Current projections suggest that fish export earnings will reach US $\$ 90$ million during $2003 / 4{ }^{24}$. The sub-sector is estimated to employ 300,000 people, with $1.2 \mathrm{~m}$ people 
dependent on fisheries as their main source of household income. Fish also contributes to the nation's food security through providing 17 million people annually with a high quality sources of dietary protein.

Whilst the contribution of fisheries to the economy is significant, illegal and harmful fishing and trading practices threaten the sustainability of the resource base. These illegalities have largely resulted from poor management. Past management was centrally driven and did not adequately include local people in decision-making; the services provided by extension officers were not positively appreciated by fishing communities. Fish landing sites remain poorly served by infrastructure (including electricity) and public services.

The fisheries sub sector also faces some social problems; for instance, the circumstances of fishermen often expose them to a high risk of HIV infection, with devastating consequences for some fishing communities, and the theft of fish nets represents a constraint on investment ${ }^{25}$.

Government, through the Department of Fisheries Resources (DFR), is addressing these concerns through the National Fisheries Policy, (2003), which promotes a participatory approach involving fisheries stakeholders working with government to manage fisheries resources. The Policy will be implemented through the 2003 draft Fisheries Sector Strategic Plan (FSSP).

A key feature of the new fisheries co-management approach is the formation of legally empowered community Beach Management Units (BMUs) at fish landing sites for fisheries planning and management. BMUs explicitly involve women, young people and the poor in decision-making structures and processes to ensure their interests are included in the management and sustainable use of the resources, thereby reducing the vulnerability of poorer stakeholders within fisheries communities. BMUs will work closely with government in enforcing regulations to reduce harmful and illegal fisheries activities on water and land. In addition, BMUs form the foundation of lake management organisations, which have a broader remit than fisheries alone, taking a more integrated approach to managing lakes.

The Policy requires the establishment of controlled access to lake fisheries. The new participatory approach to enabling access will ensure that poverty-focused licensing promotes access for women and controls the number of boat vessel licenses for sustainable management.

The FSSP details a major Monitoring Control and Surveillance (MCS) programme on water and land to reduce illegal fishing and fish trading practices. The fisheries sector is also striving to improve the quality of fish for domestic consumption and export, reducing losses and increasing value and incomes. This is being done through the improvement of handling, processing and marketing facilities at fish landing sites and throughout the marketing chain. 
Another major component of the FSSP is the collection of information, vital for improved planning and management within the sector. This is beginning to be implemented through BMUs, transferring information to districts, lake wide organizations and central government.

Cabinet has approved the formation of the Uganda Fisheries Authority (UFA). The rationale is that it will provide a more autonomous and cost-effective institution capable of delivering rapid responses to the changing needs in accordance with its core functions to promote, support, guide and monitor the sector. The UFA provides not only the "competent authority" needed to improve and expand fish exports, but also the umbrella framework linked to international fisheries organisations, domestic lake wide management organisations and community BMUs. This is modelled on other parastatals serving specific production sectors such as UCDA.

\section{Priority actions for fisheries}

Government will focus on the following priorities:

- Implementation of the FSSP

- Establishment and capacity-building of community institutions to manage beaches and lakes

- Monitoring and control of illegal practices

- Development of quality guarantees for fish exports

- Development of a central information system

- Stock enhancement for dams and small lakes

- Evaluation of options for fish technologies.

- Protection of children by BMUs against exploitation and abuse

- Management and control of HIV/AIDS among fishing communities

\section{Wetlands}

Wetlands account for $13 \%$ of Uganda's total land surface area and play an important role in the socio-economic development of the country. Wetlands provide a range of benefits including crops (yams, rice, papyrus), fish, inputs into domestic production (including roofing materials, livestock fodder and raw materials for crafts) and services (e.g, water storage, purification, ood control). Wetlands are thought to employ about 320,000 workers directly and provide a subsistence employment for over $2.4 \mathrm{~m}$ people.

Various widely divergent estimates have been made of the economic value of wetlands, depending on the methods used and the benefits and costs included. However, many figures tend towards an annual direct production value of \$300-600 per hectare, whereas high estimates, including services like purification and carbon sequestering, may go as high as $\$ 10,000$ per ha However, there is a shortage of work comparing the economic value of different uses of the wetlands.

Two aspects typical for wetlands require special management measures: firstly, wetlands are often a common property resource, 'owned' by a community rather than by individuals; secondly, the impacts of wetland degradation are carried upstream and 
downstream over hundreds of kilometres, well beyond the view and understanding of those who are causing the degradation.

A significant amount of encroachment on wetlands has occurred. NEMA estimates that $64 \%$ of the total seasonal wetlands in Iganga and $68 \%$ in Pallisa have been reclaimed for rice cultivation. ${ }^{26}$ In Kampala, many sections of wetlands have been converted to industrial use or have gradually been taken over by semi-slum residential housing and associated uses such as cultivation, waste disposal, etc. ${ }^{27}$ Nationally, it is estimated that 2,376 sq. km of Uganda's wetland areas have been drained $^{28}$

Government has acted to ensure that wetlands are protected, as re ected by the endorsement of a Wetland Policy in 1995, the inclusion of extensive wetland legislation and regulations under the National Environment Statute, and the adoption of a Wetland Sector Strategic Plan and part of its funding under PAF.

The Wetlands Sector Strategic Plan (2001-2010) aims to encourage a sustainable use of the resource, focusing on benefits to the poor with collaborative community level participation. Incomes derived from wetlands have the potential to be increased. Focus should be on improving wetlands product quality and pricing and efforts to reach export markets. Alternatives to wetlands resources and better management practices also need to be promoted to reduce on the costs of degradation. There is a need to provide incentives for districts to discharge their wetland management responsibilities as stipulated in the Local Government Act 1997. In this regard, the sub-sector will strengthen linkages with PMA and NAADS. There is need to develop, strengthen and operationalise comprehensive wetlands legislation and enforcement structures to ensure sustainability and resolve ownership issues. The sub-sector will also promote increased community participation through the development and implementation of community wetland management plans as a means to empower communities. to manage their wetland resources and identify opportunities for improving livelihoods. The communities adjacent to the wetlands will implement this with technical support from the local governments and the Wetland Inspection Division.

It has been suggested that water users should pay for some of the benefits of water purification that accrue from the wetlands. It might be possible to allocate some of the proceeds to communities to provide an incentive for them to manage the wetlands.

\section{Priority actions for wetlands}

Government will:

- Assess financial, economic and environmental relative profitability of different wetland uses

- Further development and dissemination of guidelines for wise use of wetland resources

- Improve community skills and diversification of wetland products in order to add value to wetland products

- Enforce appropriate policies, laws, procedures and regulations to curtail degradation of wetland resources 
- Assess wetland resources to determine resource availability and trends

- Support community initiates that promote wise use of wetlands

\section{Climate}

\section{Weather forecasts}

Meteorology provides services to a wide range of government and non-government stakeholders. Participatory data showed that unexpected weather developments impact negatively on livelihoods of the poor and so an effective service that benefits small-scale farmers could help reduce agricultural and other losses. However, the infrastructure of the Department of Meteorology has deteriorated over time. The sub-sector needs to improve the accuracy and spatial coverage of forecasts and advisories. This requires investigation of the cost and feasibility of transmitting such data to poor farmers at the village level. Meeting this challenge will entail strengthening links with PMA and extension services, increasing the coverage of the observation and dissemination network to all districts, and replacing obsolete equipment. For example, the number of rain-gauges now stands at 300, down from 1,040 in the 1960s. There is a need to prepare Uganda to meet the International Standards Organisation (ISO 9000) Certification by 2006 in accordance with International Civil Aviation Organisation requirements.

\section{International environmental goods}

Uganda is a signatory to the United Nations Framework Convention on Climate Change (UNFCCC) and the Kyoto Protocol. Uganda has already benefited from the sale of carbon credits at the Nyagak mini-hydro project ( $\$ 4.0$ million) under the Clean Development Mechanism (CDM) of the Kyoto protocol, which compensates countries which take actions tending to reduce carbon emissions. While opportunities exist under the CDM, Uganda must move quickly to establish a framework (institutional and legal) to attract CDM investments especially where it has a comparative advantage in the region. Potential areas for CDM include renewable energy sources (hydro, solar, thermal, biomass, and waste management).

\section{Research issues in meteorology}

Climate change imposes a number of challenges for Ugandan agriculture. Erratic, unpredictable and poor rains have been observed in the last few years. Current temperatures and rainfall permit growing of coffee in most parts of Uganda. However, an increase of 2 degrees centigrade could have a significant impact on coffee-growing areas and therefore on the whole economy (see Annex Chart A 4.1).. Other crops are also likely to be sensitive to temperature increases. Warm temperatures will also lead to an increase in pests and the emergence of new ones.

The Meteorology Department will collaborate with other parts of Government to ensure that these factors are considered in planning. There are two main implications. First, the identification of economic activities needs to take account of predicted climate change. Secondly, and even more important, there may be actions that can be taken to in uence local climatic conditions, such as reafforestation and the preservation of wetlands. These effects need to be considered in the use of natural resources. 


\section{Priority actions for climate}

Government will:

- Strengthen data collection capacity to ensure adequacy and timeliness of data to generate weather and climate information, with particular focus on reaching the rural poor.

- Carry out an in-depth assessment of user needs including the rural poor and develop, generate and disseminate user-specific products. The analysis should establish effective dissemination, utilisation and monitoring and evaluation mechanisms,

- Strengthen human capacity, including providers and users of the service.

- Investigate and establish the appropriate institutions to take advantage of opportunities under the CDM.

\section{Wildlife}

Wildlife based tourism has an annual economic value of \$163 million, employing around 70,000 people directly. The parks also provide local climatic and water resource benefits, which have not been quantified. Uganda has 10 national parks, 12 wildlife reserves and 5 community wildlife areas with unique wildlife species such as the mountain gorilla. Government has allocated management of these facilities to semi-autonomous organisations such as Uganda Wildlife Authority (UWA) and Uganda Wildlife Education Centre (UWEC). UWA is funded out of park fees as well as project funds. Local Governments are also empowered by the Uganda Wildlife Act to pass user rights and bylaws to manage wildlife resources.

Government's policy objectives in this sub sector include the preservation of wildlife, in particular for species where Uganda has a large share of the world's remaining population, generating income, and ensuring that the communities near the parks share the benefits and are made aware about wildlife conservation. Illegal small-scale trade in wildlife and its products also requires investigation.

The Uganda Wildlife Act provides for $20 \%$ of all entry fee collections to ow directly to the relevant community. A total of US $\$ 516,288$ has been disbursed to the communities neighbouring protected areas in the last four years. Funds are allocated by the communities, and have been used to rehabilitate roads, clinics, schools and water sources. Examples such as Buhoma camp site, Magombe swamp and Lake Mburo sport hunting show the potential for wildlife to contribute towards poverty eradication.

Government is committed to local consultation before taking decisions on the use of land for conserving wildlife. In particular, pastoralists' needs for grazing lands will be taken into account in decisions to create and manage protected areas. Greater community awareness about the value of wildlife to the community will make it easier for livestock and wildlife to coexist. 


\section{Priority actions for wildlife}

- The Wildlife Division will revise the Wildlife policy and legislation

- Inspection and coordination will continue under the Wildlife Division for quality assurance and compliance in management of wildlife resources.

- UWEC will continue to carry out conservation awareness programmes (with healthy wild animal exhibits) and provide quarantine services under the CITES trade arrangement.

- With community and district-level cooperation, all Protected Area (PA) boundaries will be marked and trees will be planted along forested ones. Dialogue with communities will be strengthened to minimise encroachment.

- Offices, accommodation and outposts will be constructed in selected PAs.

- Revenue will be shared with local communities in those PAs where the practice has not yet taken off. A regular (at least annual) disbursement will be institutionalised to ensure that communities benefit from the $20 \%$ of entry fees to which they are entitled. The funds will be used to implement community designed and approved projects to benefit the communities immediately neighbouring the PAs.

- MOUs will be developed with enterprises, communities and local governments to manage wildlife and benefit from wildlife related enterprises, including community tourism.

- UWA will work with districts in the management of problem animals and vermin to reduce crop losses for the community.

- Management plans will be developed, and bylaws introduced where appropriate, to protect critical wildlife habitats outside PAs.

\section{Improving the functioning of the labour market and the productivity of workers}

\section{Enhancing the supply of high-quality labour}

In view of the high growth in Uganda's labour force (discussed in Chapter 2), characterised by a low educational profile, there is a need to intensify efforts to increase the supply of a more educated workforce into the labour market. Such a workforce will have higher productivity and hence earn higher wages. In this respect, the supply of skilled and semiskilled manpower by both public and private education and training institutions will be accorded a high priority for increasing the country's competitiveness.

Public technical and vocational training institutions will be adequately financed and equipped to deliver the required manpower for enhancing production and competitiveness. While public institutions will most likely be the major providers of education and skills training, it is envisaged that private institutions will complement Government efforts in creating new skills and developing training schemes in emerging technological areas. The National Council for Higher Education will advise both public and private universities and tertiary institutions on the type of skills needed to enhance production, competitiveness and subsequently incomes. At the same time, the private sector will need to be encouraged to establish collective agreements that are performance- related to enable employers in the private sector link wages to productivity. 
To improve the functioning of the labour market, the Labour Market Information System and Network to be established will not only serve the traditional role of providing labour related information to employers and workers and school leavers but will focus mainly on strengthening the data base on labour statistics within the Uganda Bureau of Statistics. This system will collect and provide information about the supply of skilled manpower, employment occupation, the demand for selected professional and technical categories such as engineering, health and teaching, training agencies and training programs available. Government also plans to strengthen the provision of information by MGLSD about labour market opportunities available abroad.

\section{Priority actions for enhancing the supply of labour}

- $\quad$ Priorities for the educational system are presented in Chapter 7.

- Government will strengthen labour market information.

\section{Wages and working conditions}

In most cases, people earn more in wage employment than they would earn in selfemployment. Poverty is far less prevalent among wage-earners (whether in private or public sectors) than among people in other sectors. Graduates from tertiary and upper secondary education earn much more if they are in wage-employment than if they are in self-employment. However, open competition among employers can only work well if workers are well informed and adequately mobile. PPA2 found that some estate workers were very immobile, being afraid to move because they did not have G-Tax tickets and having very limited horizons. In other cases, workers are recruited in distant regions by recruitment agents and sometimes find the experience of work on the estates less rewarding than they expect.

Government will continue to review the labour legislation, where necessary, to ensure that provisions in the laws are consistent with international legal instruments, other economic policies and changes in the labour market.

International evidence shows that blanket minimum wages tend to reduce employment opportunities. However, there is a case for some regulation of wages in sectors where employers have great market power, in which case the effects of a minimum wage on employment may not be harmful. Government, in consultation with the private sector will consider whether some regulation of wages or working conditions may be appropriate in certain sectors. It must be emphasised, however, that the most urgent task is to promote employment growth.

The protection of workers' safety is important. Under the Workers' Compensation Act, 2000, businesses are required to purchase compulsory no-fault insurance, covering any accident suffered by workers at the workplace or on the way to the workplace (an unusually generous provision by international standards. Partly because traffic accidents are included, the burden on employers appears to be heavy; estimates vary from 3 to $5.5 \%$ of the wage bill on average. Given that formal sector employment is growing more slowly than is desirable, this burden is a serious concern. Moreover, it dos not create any incentive for firms to make their operations safer. A system of voluntary insurance, 
combined with a system of easily accessible tribunals for adjudication of responsibility for accidents, has been proposed, based on recent successful experience in South Africa.

Another compulsory burden on employment is imposed by the imposition of a $15 \%$ pension contribution on formal sector employees (with a much lower threshold than income tax). This burden is not translated into commensurate benefits for employees, because the pensions sector is not efficient. The pension reforms discussed in Chapter 3 should enable the benefits to employees to increase while reducing employers' costs.

\section{Priority actions for wages and working conditions}

Government will:

- Consult with the private sector on the revision of minimum wages for estate workers

- Consider revision of the Workers Compensation Act, to provide a more effective system with lower burdens on employers.

- Consider the role of labour inspections in the protection of workers' welfare.

\section{Public sector employment}

In the long run, Government should cease to be the main provider of formal employment, which should be mainly generated by the private sector. Hence Government will not undertake activities mainly to generate employment. However, where an activity is being undertaken because it provides valuable public goods, Government will explore the possibilities of using labour-intensive methods in areas of high visible underemployment. This has been done successfully for some road projects.

\section{Priority actions for Public Sector Employment}

- Government will use labour-intensive techniques where technically feasible and economically cost-effective. Knowledge of such techniques will be disseminated by the Labour Department in MGLSD.

- Government will promote community participation in infrastructure development and maintenance.

\section{Increasing Competitiveness}

The fact that Uganda is landlocked and has a small domestic market demands that she develops an export oriented economic development strategy based on high value low volume commodities and services. This can only be achieved if the country is able to exploit Uganda's comparative advantage and promote enterprise competitiveness.

Uganda's geographical position, the huge water masses she posses and big market potential of border countries provide her with the potential to be a regional hub in the Great Lakes region. Improvements in infrastructure and utilities such as railway, water transport and inland port facilities could help exploit this position putting Uganda ahead of her neighbours (DRC and Sudan). In addition, Uganda's electricity generation potential (2,000 MW possible on river Nile alone), plus potential in education, health and tourism services could be exploited by a good mix of technological application and entrepreneurship. For these reasons, Uganda has excellent competitive potential, but much remains to be done to realise this potential. 
For Uganda's products to be competitive in regional and international markets, they must be produced in the most efficient and effective manner. For most of its exports, Uganda is a price taker, meaning that the volume of its exports is not large enough to in uence the price in the international market. For Uganda to be competitive, it needs to work on the factors that in uence the cost of production and transportation. Some of these factors have to do with the businesses themselves and others have to do with the public sector. Companies have to work hard to cut costs of production linked to the structural nature of their businesses; these vary from one company to another. However, in most surveys on business operations in Uganda, the major constraints are largely public in nature, including infrastructural (roads, rail, air), utilities (electricity, water), legislative, and administrative (corruption, taxation) constraints. (See annex tables A 4.1 and A 4.2).

Supply constraints for businesses have to be addressed in a holistic manner and for the entire private sector rather than for selected enterprises, which would undermine competition and discourage foreign direct investment. Smart subsidies can be offered to businesses in a way that is accessible to all firms on an equitable basis, such as establishment of industrial parks with common utility supplies (water, electricity and telecommunications) and infrastructure (roads, sewerage line, waste disposal facilities), thus reducing the costs that individual businesses would incur in accessing them.

International cooperation to strengthen transport networks, such as better links to Mombasa and Dar es Salaam, ould also improve competitiveness. Some of these investments can be handled under public-private partnership involving a group of countries. The NEPAD initiative provides a good framework for this cooperation. Regional integration under the EAC is a step in the right direction and will be used as a framework for investment, while ensuring that the expenditures remain within Government's overall expenditure programme.

On the demand side, while Uganda's export volume may not in uence prices received by exporters, the public sector still has a role to play including negotiating the different trading arrangements to reduce trade barriers, both tariff (such as tariff escalation on finished goods) and non-tariff (such as the stringent sanitary and phytosanitary measures). This calls for capacity building in trade negotiations within the relevant institutions such as the Ministry of Tourism, Trade and Industry (MTTI). Such capacity is currently limited and needs developing. However, the approach to trade negotiation may sometimes bring faster results when done as a trading block rather than as individual small countries. Therefore, government will, where possible negotiate for better trade arrangements under the East African Customs Union (EACU) or the Common Market for Eastern and Southern Africa (COMESA).

Based on the above discussions government will focus on the following actions:

- Strengthen institutions that fight corruption

- Finalise commercial contract legislation

- Establish industrial parks to minimise fixed costs, especially for start-up enterprises

- Invest in capacity building in trade negotiations and market intelligence in MTTI

- Negotiate better trade terms as a part of a trading block rather than on a bilateral basis 


\section{Government Efforts to Increase Competitiveness}

In 2000 the government formulated the MTCS which aims to create a favourable environment for the private sector to grow, become profitable and compete both locally and abroad. The seven priority areas of the MTCS are: Trade, Investment and Export Promotion; Financial Sector Reform; Infrastructure and Utilities; Enabling Environment for Micro, Small and Medium Enterprises (MSMEs); Commercial Justice; Sector Specific issues; and Creating an Enabling Environment The MTCS incorporates initiatives included under the Strategic Export Programme, most of which are being implemented by the agricultural sector.

Supply-side interventions in the MTCS include infrastructure and utilities, legal and regulatory services, market information and access, standards, financial services and business registration and licensing. Annex Tables A 4.1 shows constraints to doing business in Uganda. Since 2000, there have been significant improvement in the communications sub-sector, but the business community still perceive access and cost of financing, tax rates and tax administration, electricity and corruption as key constraints. Annex Table A4.2 shows that businesses suffer delays often caused by bureaucracy. In some cases, such as fish exports, delays can be disastrous for the quality of produce. Delays in tax refunds are of course particularly serious in the context of high interest rates. These constraints are particularly critical for micro, small and medium enterprises (MSMEs) and actions to address them are discussed in detail in Section 4.3

Recent studies have shown that since 2000, when the MTCS was launched, a number of constraints have been addressed but others remain. Under the MTCS framework, priority areas for action will be elaborated and implemented under a coordinated approach led by a high level MTCS Steering Committee supported by a Secretariat.

Some of the constraints that the MTCS intends to address have been discussed above. One common area shared by the MTCS with the PMA is marketing and agro-processing. Studies of agricultural marketing in Uganda suggest that most segments of the marketing chain work quite efficiently, but that the weak social organisation and limited information of farmers reduce the prices they receive.

Marketing cannot be an afterthought but needs to be factored into the production decision. In order for this to happen, the advice given to farmers needs to be based on a sound knowledge of the market as well as the technology proposed. Farmers need to understand the importance of quality and reliability to their buyers. Government is reviewing the MTCS to address the remaining challenges for competitiveness in domestic, regional and international markets.

\section{The Marketing and Agro-processing strategy}

A marketing strategy is expected to link producers to consumers, both domestic and foreign, combines with strategies for processing to add value, reduce bulk and increase shelf life. Government's approach to marketing and agro-processing is set out in the Marketing and Agro-Processing Strategy (MAPS), which was developed by MTTI for implementation under the PMA. Priority actions for public intervention under MAPS that address some of the constraints discussed under NAADS and MTCS include: 
(a) Trade Policy/Negotiations and finance

- Improved capacity to undertake trade negotiations in regional and international fora;

- Establishment of expert teams to provide trade/market analysis and intelligence;

- Improved access to financing for marketing/value-added interventions/agri-business;

- Improved rural contract law to govern producers and buyers in rural areas.

(b) Producer support

- Provision of market information to farmers and traders

- Improved farmer organisation at production and marketing levels

- Educational programmes to engage farmers more effectively in the liberalised market environment.

(c) Infrastructure

- Increased rural road investments to link farmers with input and product markets;

- Reduced rates for air and rail freight

- Strengthening the Uganda commodity exchange

- Establishing and operationalizing the warehouse receipt system

(d) Export Competitiveness

- Strategic Exports development

- Value addition/new product development

- Promotion of products in domestic, regional and international markets

\section{Cooperatives and Area Marketing Cooperative Enterprises}

Co-operative activities in Uganda can be traced as far back as 1913 when indigenous Ugandans started organising themselves into cooperatives to enable themselves participate in trade especially of coffee and cotton. In 1946, the first law was passed to govern cooperative activities. During 1946-1970 co-operatives grew in all sectors of the economy, with the majority in agricultural marketing. However, political turmoil and poor leadership during the 1970s and 1980s adversely affected their performance and many cooperatives became insolvent. The Ugandan Cooperative Alliance is leading the revival of the cooperative movement, and Government will provide extension services to assist their formation, organisation and development.

Area Marketing Cooperative Enterprises are formed by bringing together primary cooperative societies, farmer associations, and large-scale farmers at the sub-county level. The purpose is to match quantity and quality to the needs of the market. As noted in the Agricultural sector, the relationship between cooperatives and farmers' groups under NAADS will need further clarification, since in future both institutions will often exist in the same areas.

\section{Priority actions for cooperatives}

- Government will promote the roll-out of Area Marketing Cooperative Enterprises, working alongside NAADS. 


\section{Access to international markets}

Sustainable economic growth and poverty reduction will depend on access to sustainable markets, both regional and international. Uganda's domestic market is small and can easily be saturated as has been demonstrated from time to time with a glut of maize in just one crop season. Agricultural commodity producers need to be sure that there is a sure market for their products. In order for the market to guide resource allocation efficiently, producers need accurate information on current prices and -even more important - realistic forecasts of future prices. Such information is particularly difficult for the poorest small scale producers to access. Government therefore needs to provide market intelligence to producers.

Negotiations regarding the formalization of a customs union with by the three East African partners (Uganda, Kenya and Tanzania) will see Ugandan goods enjoy free movement within a market of approximately 85 million people. Uganda has also gained from the US market access initiative, African Growth and Opportunity Act (AGOA), which has allowed it to export textiles and apparels to the American market. Furthermore participation in the EU's Everything But Arms (EBA) initiative a well as other Generalized System of Preferences (GSPs) such as those of Canada and Japan has been beneficial to Uganda. At the WTO level, Uganda has continued to comply with its commitments, allowing Uganda to maintain its position in an important forum through which its voice can be heard on trade issues. Challenges include strengthening the capacity of negotiators and ensuring a common position, and continued efforts to reduce tariff and non-tariff barriers. As a lead institution, MTTI has the responsibility for conducting negotiations under the WTO, EPA, EAC and COMESA.

Trade negotiations and regional integration also involve the Ministry of Foreign Affairs (MOFA). Uganda's missions abroad need more support to promote trade, investment and tourism opportunities. For example, commercial attaches can usefully contribute by meeting potential foreign investors. Effectiveness of these roles depends on well articulated responsibilities between MTTI and MOFA.

\section{Priority actions for international trade}

Some of the priorities have already been outlined under MAPS above. Additionally, government will:

- Increase the complementarity of MTTI and MOFA in trade negotiations

- Support Uganda's trade negotiators and trade or commercial attaches at Uganda's foreign missions to promote trade, tourism and investment

- Institutionalise a trade negotiation team to participate actively in trade negotiations

\section{Services to promote exports and investment}

Services to promote exports and investment are provided by Uganda Export Promotion Board (UEPB) and Uganda Investment Authority (UIA). Consideration is being given to merging these two institutions or otherwise clarifying their respective mandates. 
UEPB's major activities are market intelligence, market entry strategy support and export skill training. UEPB has facilitated the development of some infrastructure and is promoting export villages. It is assisting producers to meet the standards under the European Union's Good Agricultural Practices initiatives. UEPB is also pursuing access to 'soft markets' in middle-income countries, which often present less severe barriers than those in Europe and America, and has plans to develop an export training school to inform entrepreneurs about marketing products for export.

UIA aims to offer a 'one-stop shop' for investors in Uganda. Registration with UIA is mandatory for foreign but not domestic investors. A major innovation is the purchase of land for business parks, which will offer a more convenient site for investors.

\section{Priority actions for export competitiveness}

Government will:

- Develop a national export strategy

- Continue to review the relative roles of UIA and UEPB in the provision of services for exports and investment.

- Set up industrial parks; the appropriate balance between public and private investment in establishing them will be considered.

\section{Product Standards}

Recent experience has demonstrated that a further barrier to market entry for the Ugandan private sector has been a failure to comply with international quality standards. Examples include the substandard methods of operation that led to the European Union fish ban and the difficulties faced in complying with the Sanitary and Phytosanitary and European Union Retailer Good Agricultural Practices (EUREPGAP) measures implemented by the developed countries. These examples show that insufficient public monitoring of quality can prove costly.

The Uganda National Bureau of Standards (UNBS) has the mandate to develop and promote standardisation, quality assurance, laboratory testing and metrology. The Bureau provides information and issues certificates on export standards; inspects imports to prevent the import of substandard goods and provides information for importers to send on to suppliers abroad; calibrates measuring equipment and surveys markets to eliminate shoddy products; and, assists industries to meet standards. Currently, the Bureau has no permanent home and has no space for laboratories. It is much smaller than its counterparts in neighbouring countries. The bureau also certifies some private agencies to monitor standards. For agricultural products which form the bulk of Uganda's exports, UNBS must work with the Ministry of Agriculture, Animal Industry and Fisheries (MAAIF) to ensure that standards are developed and maintained to increase competitiveness of the products. 


\section{Priority actions for standards}

In order to improve and maintain standards, Government will:

- Explore the appropriate division of labour between the private sector, sectoral ministries and UNBS in the promotion of standards.

- Ensure that UNBS works closely with MAAIF to ensure that standards are maintained for agricultural products

\subsection{Public expenditure priorities for production, competitiveness and incomes}

\section{Sector-wide approaches}

As mentioned above, there is no overriding strategic framework for the Environment and Natural Resources (ENR) sector. This is holding the sector back from adopting common implementation approaches, exploiting synergies and collaborating to improve efficiency of service delivery. Steps to move towards a Sector Wide Approach are being taken, and should be further supported and accelerated. First steps should be to define the sector against a common vision and a set of shared goals. Then that sector should begin to draw up a sector investment plan.

However, there has been, during the last 5 years, an impressive process of sub-sector level strategic planning. Activities are guided by the National Forest Plan (2002), the Wetlands Sector Strategic Plan (2001), the Land Sector Strategic Plan, the Fisheries Plan (2003) and the National Environmental Action Plan.. The challenge will be to develop a sector-wide plan that recognises the existence of functional sub-sector plans but that contains sectorwide programmes and initiatives for collaborative implementation. Priority 'SWAp' areas might be data collection and analysis, land inventories and mapping, district level coordination and capacity building and landscape restoration.

There is also a lack of a sector-wide approach in the Economic Services sector, which includes MTTI, MEMD and various agencies. Some of the activities in this sector have strong linkages with some activities undertaken in the accountability sector, such as microfinance and support to MFIs. Expenditure in the economic services sector is currently scatted among a number of agencies and projects. Hence a sector-wide approach is badly needed.

The agriculture sector is developing a sectoral investment plan, and the roads sub sector has a long-term plan.

\section{Priorities for expenditure in the agriculture sector}

\section{Agricultural research and extension}

Within the sector, there is good reason to expect returns to agricultural research and extension to be high in Uganda, for three reasons at least. First, international studies within the region suggest high returns. Secondly, research within Uganda has found very high returns to research and extension for poverty reduction ${ }^{29}$. Even with the existing relatively weak systems, the successful introduction of mosaic-resistant cassava had very 
high returns. Lastly, a small continuous increase in agricultural output would more than pay for agricultural research and extension. In practice, extension and research should do well enough to producer returns that are far larger than their costs.

The fact that knowledge generated by a single researcher can benefit many farmers justifies it as a public good. In some sectors and countries, the private sector plays an important role in research, but very little is done by the private sector in $\mathrm{Uganda}^{30}$. In the case of extension, the private sector does conduct effective extension on out grower crops such as tobacco, and NAADS is exploring the best way to cooperate with the private sector on out grower schemes.

For research, Government has defined a target of $2 \%$ of agricultural GDP as compared to the current level of $0.6 \%$, which would imply a cost of about 75 billion shillings a year. However, it would take some time for domestic capacity to reach the level where this amount could be spent. The estimated needs of research and extension alone would fully absorb the sectoral resource envelope in 2003/4.

\section{Agricultural marketing}

The main interventions proposed for agricultural marketing in the agricultural sector concern market information. They will be bolstered by other interventions in the economic services sector.

\section{Other priorities}

There are also other needs, notably in regulation of livestock and disease control. The fisheries sector requires public expenditure both to invest in relevant infrastructure and to regulate the bad fishing practices that have proven very damaging in recent years. These expenditures, however, may be funded out of the levy on fish products received by the new Fisheries Agency.

In addition to the public sector resource envelope, there are other resources available from producers' levies in this sector. These are spent by the various producers' agencies, and are not fully integrated into the sector's programme. In some cases this spending has involved joint ventures with private sector agro processing and marketing ventures. These expenditures have not in the past been fully integrated with the PMA and the rest of the agricultural sector.

The development of a sectoral strategy re ecting these priorities is in progress.

\section{Public expenditure implications for the ENR sector}

All the sector's areas of intervention are potentially important, but unit costs have not been received for most of them. Existing activities have a very high share of project funding, which may be associated with costly modalities of implementation. Moreover, the establishment of agencies with powers to raise their own funds in the forestry and fisheries sub sectors make it harder for expenditure to be monitored or managed in the sector as a whole.

Three sub sectors that have indicated a need for extra funding are meteorology, fisheries and forestry. Amounts involved have been quantified for meteorology; to start the 
revamping of this service is estimated to cost about 6 billion shillings. However, a decision will be needed whether to have meteorological staff at district level; the service might be delivered more cheaply by focusing resources at the centre. The cost of district forest services is currently about 2.4 billion shillings. The cost of supporting beach management units is estimated at about 2 billion shillings per annum, but this may be funded out of the producers' levy to be raised by the newly established Fisheries Agency.

An important area for public action in the medium term is land reform. The implementation of systematic demarcation offers an opportunity significantly to strengthen the property rights of the poor. Current estimates suggest it may be possible to perform phased systematic demarcation of all rural areas for a total cost of the order of $\$ 50-\$ 60$ million. A Poverty and Social Impact Assessment is planned to assess the effectiveness of systematic demarcation in enhancing the property rights of the poor; if favourable, this programme will be treated as a priority for funding in the medium term. In the short term, a priority is improvement of the Land Registry.

The development of a sectoral plan should be undertaken within MTEF ceilings. However, the needs of the sector will be reviewed as the strategy is developed. In the meantime, the piloting of systematic demarcation, the improvement of the Land Registry and the management of the district forest services will be treated as priorities.

\section{Expenditure priorities in the economic services sector}

This sector has no sectoral strategy and a high proportion of the expenditures have hitherto been on projects and often disbursed through agencies. This has led to excessive costs and duplication. The objective must therefore be to develop a sectoral strategy in which all the priorities are dealt with jointly.

\section{MTTI and associated agencies}

The majority of MTTI's expenditure is on projects, particularly the Protected Areas Management project, which may in due course move into the ENR sector. Other than PAMSU, the total for MTTI is about 20 billion shillings, which is shared between several important agencies including UNBS, UEPB, UIA, and UWA. In some cases the agencies have their own source of funds, for example, UNBS generates funds by selling services to the private sector.

Expenditure priorities within the sub sector are:

- Business services and extension for SMEs

- Investment in infrastructure for firms in industrial parks;

- Support to export promotion, for instance the EUREPGAP initiative and collection and dissemination of information about external markets.

- Warehouse receipt system and commodity exchange

- Support to marketing: The main constraint on farmers' marketing appears to be social organisation. Data provided by MTTI shows that pilot project for AMCEs have generated very dramatic increases in farmers' prices, between $30 \%$ and $100 \%$. If nationally replicated, the impact on farmers' incomes would be dramatic (although 
there would also be some negative impact on the incomes of traders). This deserves to be highly prioritised for public funding, but there remains some discussion of the role of different institutions including cooperatives (which are directly the concern of MTTI) and other farmers' groups (which are directly dealing with NAADS). More consensus is needed on the division of labour here to guide funding.

Other actions in this area include the provision of extension services to villages to promote better quality production to meet export production, and the promotion of Ugandan entry into international markets (especially 'soft' international markets). UEPB is performing both of these functions. Expenditure needs cannot be assessed outside the context of a sectoral strategy and involving re-examination of the links between UIA and UEPB.

- Support to tourism: Tourism can generate Government revenue and an increase in exports as well as marketing benefits for farmers and handicrafts. However, the immediate poverty impact may not be very large, because the share of labour in costs is generally rather small.

Tourism can be supported by marketing and training. The public goods aspect of promoting Ugandan's image internationally is strong; in principle this activity could be carried out by a strong producers' association, but in the short run some public support would be justifiable The public goods aspect of training is not so clear, as this activity should usually be undertaken by the private sector.

- protected areas management; while this is important, it appears to be amply funded under the Protected Areas Management for Sustainable Use (PAMSU) project as well as by entry fees from the parks, and there my be scope for reducing costs over time.

- Microfinance: Funds for microfinance are provided as matching grants to encourage extension into more remote areas under a basket funding arrangement. In some cases this may represent a substitution of funding within the MTEF for support that was previously offered off- budget by donors direct to NGOs. The costs are not yet known. In addition, IFAD support is being used to encourage the development of financial services for small-scale farmers. International evidence indicates that, if well managed, the spending may have high returns for poverty reduction and that the provision of financial services to agricultural producers can play an important role in transforming agriculture.

\section{Ministry of Energy and Mineral Development (MEMD)}

The major expenditures in this sub sector is rural electrification and large power projects. Rural electrification is funded through a rural electrification fund to which Government and donors contribute; in addition a 5\% levy on bulk purchases of electricity transmission is paid into the fund. Recent evidence from the household surveys indicates significant returns to electricity. Household incomes are increased by about $8-11 \%$ by the presence of electricity in a village ${ }^{31}$. This would imply very high socio-economic returns to the infrastructure ${ }^{32}$. 
International evidence is that the returns are sensitive to the way in which electrification is implemented. Mechanisms whereby electrification may in uence economic activities include lengthening of the working day and allowing more agro-processing and other offfarm activities. One study in China found that rural electrification had a significant impact on the importance of non-farm activities. However: electricity is not always the cheapest option for energy for production.

The Uganda Rural Electrification Strategy is designed to increase returns by subsiding only a proportion of the costs of expenditure and thus ensuring that the services are only provided where there is potential demand. The strategy estimates costs at $\$ 400-800$ per household for Photo Voltaic; \$2,000-3,000 for mini-grids and \$1,000-2,000 for grid extension. In order to achieve the revised coverage of $10 \%$ by 2012 , public investment of about 12.5 million dollars annually in 2001 prices would be needed (it is assumed that the public sector will bear a third of the cost on average). This is equivalent in today's prices to 27 billion shillings, of which perhaps 2-3 billion shillings could come from the transmission levy. Projects committed for $2004 / 5$ come to 40 billion shillings. Hence the existing project commitments appear sufficient to cover the needs of the strategy even if not all expenditures are implemented.

Another priority is the development of a pipeline from Kenya. This appears to be justified in terms of the reduction in road maintenance costs alone. The projects will be jointly financed by the two governments.

Other priorities in the energy and mining sector include:

- Promotion of improved stoves and energy efficiency

- Monitoring of mining

- Standards for mining products

\section{Foreign affairs}

While there are potential benefits to having a well-organised network of overseas missions, the current structure appears to be overstretched. In order for MOFA to play an effective role in promoting economic development, it will be necessary to avoid the establishment of any more missions in advance of the availability of the needed funds, and possibly to review the existing number of missions.

The expenditure priority action for Government is to streamline the network of missions and ensure that some of these missions are equipped to play an effective role in promoting investment, tourism and other economic linkages.

\section{Transport, housing and communications}

\section{Roads}

Road infrastructure is mainly a public good, but should be built only where returns clearly outweigh the costs. The road sector plan uses a cut-off rate of return of $12 \%$ to appraise road projects (less than the rate of return on concessional borrowing though not than the costs of borrowing domestically). This suggests that road projects at the margin have 
acceptably high rates of return, though not necessarily higher than investments in other sectors. It is known that maintenance is high return. The strategy should be to avoid future increasing costs by targeting rehabilitation and maintenance to limit deterioration.

Rates of returns are typically estimated based on reduced transport costs and the consumer's surplus associated with increased traffic. There may also be positive externalities that drive the returns up further than these calculations show; also, new roads involve new traffic whose benefits are hard to quantify. ${ }^{33}$ Returns are certainly very high for maintenance. The International Food Policy Research Institute (IFPRI) study on public expenditure and poverty reduction also suggests that the return to infrastructural spending in terms of income poverty is higher than that of health and education, though lower than that for agricultural extension and research.

There are, however, specific reasons for slowing down capital spending during the temporary fiscal shortage. First, there is some indirect evidence that costs have been rising in this sub sector (although direct data available from MOWHC do not show cost increases above the general in ationary level). Secondly, it is usually less damaging to delay capital spending than to cut back on recurrent spending, although there is a risk that delaying rehabilitation projects will increase future rehabilitation costs if the roads deteriorate further in the meantime. (See Chapter 8 for more discussion).

Another challenge is the need to increase the share of maintenance within the envelope. The sector has the responsibility to ensure that maintenance expenditure is adequate within the given envelope. This may imply delaying investment projects if they would come at the expense of maintenance.

Community access roads have been neglected, but the rehabilitation of such roads can be addressed through local funds; this is likely to work better than a top-down approach. In some cases, the nonsectoral PMA grants have been spent in this way.

\section{Railways}

Government's strategy of concessioning the sector privately should induce some private investment in rehabilitating the existing lines. There may be a need for some public funding to support the establishment of this concession. Internationally, many railways are subsidised since railway infrastructure is a semi-public good. Government will therefore aim at private financing of the service in the medium run.

Transport costs for Ugandan exports and imports are significantly increased by the poor state of the railway including the wagon maritime service on Lake Victoria. It is thought that a well-run railway should have a $20 \%$ cost advantage over the road network (depending on distance and on the treatment of fixed costs), and a high proportion of the exports and imports in Uganda move along the East-West corridor and could easily be served by the railway, so that improving the state of the network would potentially have a very large overall benefit. In the long run, Government policy is for the railway to cover its operational costs. Major public investment in the railway will be undertaken in physical infrastructure under the concessioning arrangement. 


\section{Air transport}

Airport infrastructure is likely to need public support, depending on the financial position of Civil Aviation Authority (CAA). CAA is not allowed to borrow commercially as a parastatal, and has had problems servicing its loans in the past from Government. It may therefore be necessary to write off some debt and/or put some direct public support into cargo infrastructure. The fast growth in high-value exports make this important. However, it is important to establish a clear expectation about the proportion of costs that CAA will be expected to cover.

\section{Water Transport}

Government will continue to provide ferries. However, private sector entry into this sector is strongly to be encouraged. Local Government investment funding may also be appropriate.

\section{Expenditure issues for water for production}

Water for production is currently divided between the agricultural and water sectors. MWLE has now prepared a subsectoral strategy. This implies annual expenditures of about 18 billion shillings of which 12 billion would be for water for livestock. Under the water for production strategy, the investments proposed during 2003-6 total \$ 37 million of which \$24 million are water for livestock, including \$ 11 million already budgeted by DWD.

Irrigation has an important role to play in increasing production. However, there is need to further establish the cost implications. Efficiency could be improved by accommodating the cost within the agricultural sector.

Water infrastructure for livestock (valley dams) is directly relevant for the livelihoods of some relatively poor people and can also contribute positively to enhancing production, security and stability. 


\section{Security, Con ict Resolution and Disaster Management}

\subsection{Overview}

Uganda continues to be severely affected by natural and man-made disasters and con icts. The prevalence of security in the country has long been recognised as a precondition for improved human welfare and one of the key factors necessary for achieving all the other goals of the PEAP and aspirations of Government. As noted in Chapter 2, the widening inequality since 1997 and the increase in poverty since 2000 are partly the result of persistent insecurity in parts of the North and East. Nationally, over 5\% of the population has been displaced and the effects on poverty spread beyond the distress suffered by the displaced.

Disaster preparedness and management is an area that requires strengthened interventions to reduce poverty among the most disadvantaged and vulnerable populations. The persistent phenomenon of displacement in Uganda implies that Uganda's disastermanagement policy must be closely linked to issues of security and con ict resolution. For this reason, these issues are handled together in this part of the PEAP.

Current circumstances present four major challenges in this part of the PEAP:

- First, the country needs to end the rebel insurgency.

- Secondly, the destructive pattern of cattle-rustling needs to cease.

- Thirdly, the conditions of life of internally displaced people need to be addressed both in the short run (while they are still displaced) and in the long run (by successful reintegration into normal life, including psychological recovery).

- Fourthly, the country needs to develop capacity to anticipate crises including con icts.

It should be appreciated that not all security concerns may be resolved through the PEAP process alone. Other processes, particularly in the political arena need to complement all efforts geared towards con ict resolution in the affected areas. Communities should not only be seen as passive recipients of agreed policy actions but rather should be facilitated to become active participants in peace and disaster preparedness.

\subsection{Security and Defence}

\section{Rebel insurgency}

Northern Uganda has since the mid-1990s experienced con icts and insurgency due to rebel activity particularly in the sub-regions of Acholi (Kitgum, Gulu, Pader), Madi (Moyo and Adjumani) and West Nile (Arua, Yumbe and Nebbi). Concerted efforts by Government to end insurgency have restored peace in most districts. 
The reasons why con ict persists are complex and cannot be attributed to a single cause or failure of any particular dialogue process. Several studies ${ }^{1}$ suggest that con ict has been fuelled by a combination of factors, including external support to rebel groups, the proliferation of guns in the region, poverty and imbalances in access to economic opportunities. The impact of con ict has been to generate regional disparities that may themselves fuel future con icts.

Since 2002, insecurity and violence against civilians and humanitarian organisations has heightened, especially after the termination of the ceasefire in April 2003. This has made humanitarian access to the Internally Displaced Persons (IDPs) very difficult, leading to a further worsening of the humanitarian situation in Northern Uganda. Some relief agencies have been forced to suspend their activities as a result of repeated attacks on their convoys resulting in loss of lives and tonnes of relief aid. Civilians also suffer; about 20,000 children have to walk long distances every evening in search of safety from abduction, and women and girls suffer from sexual abuse. This explains in part why Northern Uganda has the highest infection rates of HIV in the country.

Civilians often get caught in the crossfire. The humanitarian agency AVSI has recently reported that 75 percent of the amputations in the Acholi area are due to war traumas, such as landmines and other weaponry. Table 5.1 gives a snapshot of the total casualties and losses arising from the insurgency during 2001 and 2002. The marked rise in the number of victims poses a great challenge to the development of the north and the country as a whole.

Table 5.1: Impact of rebel activities on northern populations during 2001 and 2002

\begin{tabular}{|l|c|c|c|c|c|c|}
\hline Year & $\begin{array}{c}\text { UPDF } \\
\text { Dead }\end{array}$ & $\begin{array}{c}\text { Rebels } \\
\text { Dead }\end{array}$ & $\begin{array}{c}\text { Civilians } \\
\text { Killed }\end{array}$ & $\begin{array}{c}\text { Civilians } \\
\text { Rescued/ } \\
\text { Released }\end{array}$ & $\begin{array}{c}\text { Civilians } \\
\text { Injured }\end{array}$ & $\begin{array}{c}\text { Civilians } \\
\text { Abducted }\end{array}$ \\
\hline $\mathbf{2 0 0 1}$ & 40 & 60 & 98 & 264 & 125 & 52 \\
\hline $\mathbf{2 0 0 2}$ & 171 & 436 & 670 & 737 & 172 & 1775 \\
\hline
\end{tabular}

Source: UHRC, 2002: 2001-2001 Annual Report

Service delivery in the war-affected zones has been disrupted sometimes resulting in closure of schools and health facilities. Other facilities have been completely destroyed. The cost of delivery is continuously rising, as districts require additional resources and security personnel to offer protection to the service providers.

As a result, Northern Uganda has become the poorest region in the country. Poor people in the sampled Northern districts ranked insecurity as the most important cause of poverty (UPPAP, 2002). Insecurity is not only reducing the quality of life of these communities but also repeated child abuse and traumatisation are sowing seeds of hatred and revenge, which makes the potential for further con ict considerable. 
A combination of strategies will be pursued by Government in collaboration with civil society to restore peace in the con ict af icted areas. Military actions will gradually be replaced by dialogue with the insurgent groups. The country will also need to better position itself to deal with future security threats.

\section{Military actions to end rebel insurgency}

While Government recognises that dialogue offers one of the most desirable options to ending insurgency, it has the obligation to protect its citizens, their property and resist external aggression. Government therefore mounted a military campaign to complement other efforts to end this insurgency. This has involved counter insurgency operations that have made it possible for the army to clean up civilian areas of rebel infestations. Unfortunately, casualties among the rebels include young abducted children and civilians.

Additional efforts to end the insurgency have been spearheaded by the local population through the formation of vigilante groups to fight the rebels and protect themselves. These groups have been facilitated by Government. One critical question is the relative role of police and military forces in dealing with problems such as con ict and organised terrorism. Over time, as security is restored in the North, the role of the police will expand.

\section{Future security threats and defence transformation}

Security in Uganda is threatened by con ict in the Great Lakes region. Over the next 10-15 years, this threat may manifest itself in a number of ways depending on the circumstances. The Defence Review has analysed threats including those that are social, economic, environmental, political and military in origin. They also include new security challenges such as organized crime and international terrorism ${ }^{2}$. Developing effective responses to these threats requires substantial human, financial and other resources. The Defence Review has focused on the long-term objective of building modern, professional and effective defence forces and strengthening the necessary structures to achieve this objective.

Government has developed a Defence Policy and a Security Policy framework, which analyse the security challenges and identify the roles of different Government agencies in addressing them. The Security Policy Framework gives a major role to the National Security Council, created by the National Security Act in 2000, in coordinating securityrelated actions.

While Government is planning for the long-term, the transformation programme must also take into account Uganda's immediate security needs such as ending the con ict in the north. This makes it important to achieve an appropriate balance between activities designed to achieve short term gains in defence capability and those designed to lay ground for long-term gains in efficiency and effectiveness. Human and financial constraints make it necessary for government to prioritise and adopt an incremental approach that ensures cost-effectiveness without compromising either long-term defence transformation objectives or government's ability to address immediate security threats. 
Concerns have been raised about inefficiencies in defence procurement and 'ghost soldiers'. Efforts are under way to increase the efficiency in resource use and addressing leakages through removal of ghost soldiers from the pay role, streamlining of procurement procedures, better management of logistics and supplies, robust financial management, audit and inspection and ensuring the right mix of Regular and Reserve Forces.

\section{Priority actions in security and defence}

Government will:

- Ensure that the defence forces are adequately equipped to protect people throughout Uganda against attack and defeat rebel forces.

- Regularise the status of vigilante forces and ensure that they do not recruit underage children.

- Clarify the roles of the army and other institutions.

- Implement the recommendations of the Defence Review, according to resource availability

- Act urgently to eliminate 'ghost soldiers' and improve procurement.

- Promote good relations between all the security forces and the local population.

\subsection{Con ict-resolution}

\section{Political processes to end rebel insurgency}

Government remains open to dialogue, although the process is hampered by the extreme violence that rebel forces continue to show towards the civilian population and the lack of a well-defined structure to engage through. It is hoped that the national political dialogue now under way, including discussions of the role of political parties, will generate greater national consensus. The strengthened diplomatic ties between Uganda and neighbouring countries in the recent past are a positive move towards finding mutual solutions to ending rebel insurgency.

Government is also committed to equitable resource allocation across the country. In some sectors such as roads, returns to public investment in troubled areas are reduced either by the destruction of infrastructure or by limited economic activity. Government then faces a trade-off between efficiency and equity in its allocation of public expenditure. The geographical allocation of public expenditure is discussed further in Chapter 6.

\section{Priority actions}

Government will:

- Work with CSOs, faith based groups and traditional leaders in con ict resolution and the peace building process.

- Assign responsibility within Government to respond to peace initiatives.

- Strengthen diplomatic ties with neighbouring countries, including participation in regional initiatives for con ict resolution.

- Consider the development of a regular forum for national discussion on con ictresolution. 


\section{Amnesty}

The Amnesty Act 2000 provides amnesty to all Ugandans who have been engaged in acts of rebellion. An Amnesty Commission was therefore set up to demobilize, reintegrate and resettle former rebels as well as sensitize the public on the law. A Demobilization and Resettlement Team is now operational in five regional offices expediting the work of the Commission.

By $31^{\text {st }}$ August 2003, about 9,718 reporters had responded positively to the Amnesty, the largest group being from the LRA (39.60\%), UNRFII fighting group (29.86 percent), followed by the West Nile Bank front (20.48\%), ADF (6.78\%) and other groups ${ }^{3} .89 \%$ of the total reporters are male. Ex-rebels are now receiving amnesty packages to facilitate their return to the community. Reception centers have been established in a number of districts by CSOs and the Commission to promote improved psychosocial support and health care for reporters.

Resources, however, constrain the Commission's ability to settle returnees. By mid-2003 the Commission had been able to resettle only $41 \%$ of the reporters. Delayed issuance of the packages makes amnesty unattractive, particularly to senior members of the rebel ranks. Despite concerns that the recent Anti-Terrorism Act may reduce responsiveness to the Amnesty, amnesty will be upheld for returning rebels.

\section{Priority actions}

Government will:

- Make adequate facilitation for the Amnesty Commission a priority.

- Continue to resettle and reintegrate former rebels by providing amnesty packages, through the Amnesty Commission.

- Take special measures to reintegrate children into supportive home communities.

- Review the duration of the Commission's mandate.

- Resolve perceived disparities between amnesty and anti-terrorist legislation.

- Disseminate information about the Amnesty Act to all parts of the country including the rebels.

\section{Cattle rustling and disarmament}

Cattle-rustling in Uganda is practised by pastoralist communities in Karamoja. This has contributed to insecurity in the neighbouring regions. Since the 1970 s, cattle rustling has become increasingly violent, with the use of firearms much more frequent. There was a particularly serious outbreak in 1999-2000. It has been suggested that raids are increasingly carried out by individuals without community support, and often have a mainly economic motive ${ }^{4}$.

The easy availability and use of small arms and light weapons is a major contributory factor in the escalating con icts in northern Uganda and particularly in Karamoja. In 2001, Government launched a disarmament programme in Karamoja. The first phase of this programme was based on voluntary disarmament. Incentives were provided in the form of an ox-plough. Under this phase, 6,593 weapons were handed in. Subsequently, disarmament has been enforced, and a total of 107 warrior suspects possessing illegal guns had successfully been prosecuted ${ }^{5}$ by mid- 2003 . 
Government's approach to this problem will combine an ongoing effort to encourage the surrender of weapons in the context of regional small arms control with actions to support the development of Karamoja. As discussed below, economic transformation in Karamoja will involve building on and understanding, rather than simply replacing, the existing way of life of pastoralism. In promoting an end to this form of violence Government will work in partnership with civil society and traditional leaderships, recognising that intraand inter-clan violence is an important part of the problem.

\section{Ending cattle-rustling}

\section{Disarmament and small-arms control}

The implementation of the disarmament programme was assisted by sensitisation activities carried out by Uganda Human Rights Commission. This has helped to make the process less confrontational than it would otherwise have been. Despite the recovery of over 10,000 guns from the Karamojong under the disarmament process, it is believed that the majority of weapons in Karamoja have not yet been handed in and many others continue to ow in from neighbouring countries. The Karamojong pastoralists still fear, with good reason, that they will be attacked by tribes based in Kenya if they disarm themselves. Hence Government is committed to participating in regional initiatives to promote small arms control.

Government has established a National Focal Point (NFP), bringing together government departments and civil society to help coordinate remedial actions on this problem and also facilitate interaction with international and regional agencies. Government has developed a National Action Plan which will be implemented as a priority, in close cooperation with neighbouring countries, particularly Kenya and Sudan. Research and information sharing will play a key role in all these efforts.

\section{Peace building initiatives in Karamoja}

A number of civil society initiatives have focused on restoring better relations between different groups in Karamoja and between the Karamojong and neighbouring groups. Actors have included the Acholi Religious Leaders, World Vision, the Centre for Con ict Resolution and the OAU, among many others. In addition to launching operations to recover stolen cattle, Government will also support peace building initiatives and seek to use insights from civil society in promoting peace building in Karamoja. This will be complementary to the actions taken to promote development in pastoralist regions, which are discussed below in the other chapters.

\section{Priority actions}

Government will:

- Proceed with the disarmament programme in Karamoja, while ensuring that it does not lead to abuses of the rights of the Karamojong or expose them to attack from neighbouring tribes.

- Ensure that the disarmament programme forms part of a regional initiative on smallarm control.

- Continue to support the peace building initiatives involving the Karamojong, including recovery of stolen cattle. 
- Strengthen the capacity and coordination role of the National Focal Point for small arms control.

- Support livelihood development in pastoral areas as discussed in Chapter 4.

\section{International initiatives for enhanced regional security}

Both cattle rustling and rebel insurgency have an international dimension, since the weapons used in cattle rustling are also used to resist incursions from tribes in neighbouring countries, and rebels have used bases in neighbouring countries to invade Uganda. Also, the civil war in DR Congo represented a serious security issue. Government will cooperate with neighbouring countries to resolve outstanding differences, and in particular seek mutual agreements that will stop rebels from continuing disruptive activity across the borders.

\subsection{Disaster Preparedness and Management}

\section{Disaster risk management}

Disaster is defined as an event or series of events that give rise to casualties or damage/ loss of property, infrastructure, essential services or means of livelihood on a scale that is beyond the normal capacity of the affected communities to cope unaided. In the short run, the main challenge is the living conditions of people in the IDP camps. Several other disasters relate to the presence of refugees in the country and environmental challenges.

\section{Internal Displacement}

As a result of insecurity, Uganda was estimated in October 2003 to be hosting slightly over 1.4 million internally displaced persons (IDPs) living in camps and other places such as school and church premises (see Table 5.2). About $80 \%$ of the IDPs are women and children. The majority of the IDPs reside in camps in Northern Uganda. By virtue of the large IDP numbers, the camps where they live generally lack the basic amenities such as proper shelter, safe water, clothing and sanitation. Many of the children have dropped out of school due to lack of educational necessities and school facilities.

IDPs' access to farmland and work opportunities is severely hampered by the prevailing insecurity. The IDPs in Northern Uganda are able to access between 35 percent and 50 percent of their own minimum basic food needs through own production, market purchase and casual labour for food. Hence many households are dependent on food aid and some studies have found a high incidence of malnutrition. Together with a relatively high risk of prostitution and low level of awareness, HIV infection is also a major concern for IDPs. 
Table 5.2: Total number of IDPs by district by $10^{\text {th }}$ October 2003

\begin{tabular}{|c|c|c|c|c|}
\hline No & District & District Population & IDP Population & Percentage \\
\hline 1 & Gulu & 468,407 & 419,258 & $89.5 \%$ \\
\hline 2 & Kitgum & 286,122 & 281,372 & $98.3 \%$ \\
\hline 3 & Pader & 293,679 & 79,097 & $78.0 \%$ \\
\hline 4 & Lira & 757,763 & 136,112 & $10.4 \%$ \\
\hline 5 & Soroti & 371,986 & 104,254 & $36.6 \%$ \\
\hline 6 & Katakwi & 307,032 & 97,561 & $79.4 \%$ \\
\hline 7 & Kaberamaido & 122,924 & 59,207 & $15.3 \%$ \\
\hline 8 & Kumi & 388,015 & IDPs with host families estimated at about 50,000 people \\
\hline 9 & Apac* & $\mathbf{2 , 9 9 5 , 9 2 8}$ & $\mathbf{1 , 4 0 5 , 9 7 6}$ & $\mathbf{4 6 . 9 \%}$ \\
\hline
\end{tabular}

Source: OPM

There are also displaced people on the streets of Gulu, Kitgum and Pader, and in towns in neighbouring districts like Soroti, Masindi and Lira. In general these people are not registered as IDPs and therefore are unable to benefit from relief distribution or other assistance. They may therefore be highly insecure. The population of the northern towns grew sharply over the 1990s, re ecting displacement.

\section{Box 5.1: 'Night Commuters'}

A unique form of displacement is known to exist in the town centres and municipalities of war-affected districts; the phenomenon of night commuters. When evening falls scores of children are seen making their way into town centres to seek shelter and security from rebel attacks. These children have come to be known as night commuters. Prior to the establishment of reception centres that now accommodate most night commuters, these children were found sleeping on verandas and under street lamps. Fears of sickness, sexual abuse and spread of HIV/AIDS spreading amongst these children were and continue to be rife.

\section{Refugees}

Uganda has hosted refugees since the 1940s. Most of these refugees ee from neighbouring countries, particularly Sudan, the Democratic Republic of Congo and Rwanda, due to armed con icts and abuse of human rights in their respective countries. Based on records from the Department of Disaster Management and Refugees, as of August 2003, Uganda hosts over 200,000 refugees, 75 percent of whom originate from Sudan. About 80 percent of all the refugees in Uganda live in Northern Uganda, particularly in the districts of Adjumani, Moyo, Arua and more recently Yumbe. The rest of the refugees are settled in the West and South Western parts of Uganda. 
The majority of refugees hosted in Uganda were poor in their countries of origin and come when they have lost all their property. They are usually hosted in remote rural areas where the host communities are also impoverished. The majority of refugees are women, children, physically and mentally handicapped and the aged, which increases their vulnerability to poverty.

\section{Other disasters}

Between 1980 and 2003, one in thirty people in Uganda were affected by a natural or man-made disaster. The death toll resulting from disasters in the country is estimated to exceed 50,000 persons annually (Security, Con ict Resolution and Disaster Management SPRP, 2003). The major disasters that have occurred in Uganda since the 1960s are shown in Annex Table 5.1. Section 5.4 discusses Government's responses to these challenges.

Government has implemented a number of programmes since 1986 to address disaster related problems. These have included:

- Emergency Relief and Rehabilitation Programme (ERRP) that began in 1986 resettling the displaced populations from past civil wars by availing essential communities and provision of essential infrastructure and social services;

- Programme for the Alleviation of Poverty and Social Costs of Adjustment (PAPSCA) implemented during 1989-1995

- Current programmes under the Office of the Prime Minister - Disaster Preparedness and Refugees; Luwero Triangle Rehabilitation; and Pacification and Development of Northern Uganda and Karamoja.

The main challenge with all these programmes is that responses to disaster have been mainly reactive rather than anticipatory and they have tended to focus on only two stages of the disaster cycle - response and rehabilitation. Hence the framework set out here starts with prevention and preparedness.

All the actions discussed below aim to ensure that when people are affected by disasters, they can continue to meet their minimum needs through their own efforts, supported where necessary through assistance that is appropriate in terms of type, timing, location, duration and method of provision. Addressing these challenges will require a multisectoral approach involving various government ministries, local governments, NGOs, humanitarian agencies, private sector and the communities with the Office of the Prime Minister taking the lead.

\section{Disaster prevention and preparedness}

Improving preparedness is the key to reducing disasters. Disaster preparedness aims to minimize the adverse effects of a hazard through effective precautionary measures as well as ensuring timely, appropriate and efficient organisation and delivery. This goes hand in hand with disaster management, which deals with the consequences of the disaster when it occurs.

An example is given by the El Nino rains in 1997-8 and 2000. The heavy El Nino rains 
of 1997-98 saw 35 buried by landslides in valleys of Manjiya County Mbale. The rains in 1999 heavy rains left 18 dead and over 2000 in need of relocation. Roads, bridges and homes valued at over Sh. 30 billion were destroyed. However, this destruction could have been minimised using simple preventive measures. During the 2002 El Nino, with a very small financial support from GTZ the population was prepared three months in advance and no person died when the El Nino and landslides began later.

Many disaster preparedness actions need to be mainstreamed into sectoral programmes. For example, classrooms in earthquake prone areas can be designed to withstand earthquakes, while classrooms in windstorm prone areas such as Bubulo County should be designed to withstand windstorms. More generally, local investments that are needed to avoid disaster, such as strengthening river embankments, can be considered under the district's capital budget under a scheme such as LGDP. Central Government's role will be mainly to promote awareness about the risks and recommend actions to local Governments and to build up a Contingencies Fund, as mandated by the Public Finance and accountability Act. Access to this Fund will be conditional on strict criteria in terns of emergency needs responding to a disaster. Geographical Information Systems will be used to identify the areas of greatest risk.

The national Disaster Preparedness and Management Act and Policy is due for consideration by Parliament and implementation during 2004-5.

\section{Priority actions}

Government will:

- Mainstream disaster preparation considerations into sectoral programmes

- Consider funding disaster preparation measures under the LGDP programme.

- Promote awareness of the need for disaster preparedness measures through provision of public information at all levels.

- Establish an Emergency Contingencies Fund in accordance with the Public Finance and Accountability Act.

\section{Disaster response}

The form of disaster response that is most needed in the immediate future is that of addressing the problems confronted by internally displaced people as well as refugees. The special needs of con icts affected districts and areas in delivering public services need to be recognized.

\section{Internal Displacement}

Government is finalizing the IDP policy. The policy commits Government to ensure freedom of movement for internally displaced persons, as well as the delivery of basic services, and specifies entitlements to such items as food, shelter and clothing. Government aims at ensuring that people return to their previous places of residence or migrate permanently, and that they are secure whichever they choose to do.

Humanitarian assistance to IDPs is mainly provided by international agencies such as 
World Food Programme, UNICEF and Red Cross Society to meet the needs of IDPs. For example, the WFP in 2003 distributed over 75,000 metric tones of relief food commodities valued at US\$ 40.7 million to 1,397,899 IDPs in Gulu, Kitgum, Pader, Lira, Soroti, Kaberamaido, Katakwi and Kumi. However, poor road conditions and insecurity have caused irregularities in food distributions. WFP also supports 95,000 school children in displaced camps and over 17,000 persons affected by HIV/AIDS.

Government treats humanitarian aid as off-budget because of its unpredictable nature and little macroeconomic impact. However, its delivery needs to be better coordinated with security operations and the delivery of other services. This essential coordination role of Government is undertaken at the local level by district authorities and at national level by the Prime Minister's Office. Government appreciates the cooperation of local authorities with donors in promoting block farming in the immediate neighbourhood of some IDP camps.

Consultations with local authorities in some insecure districts have pointed to the need for more exibility in allocating conditional grants to take into consideration the local specific needs. For instance, it may be more appropriate to build learning centres than conventional classrooms in the context of an IDP camp.

Concern has been raised by Civil Society on inadequacy of sanitation facilities. Government will address this and seek the active involvement of IDPs in planning and monitoring the sanitation conditions in the camps regularly. A post-con ict plan that respects IDP rights to security, livelihood, services and participation in decision making will be put in place, including measures to facilitate resettlement and rehabilitation of the IDPs.

While many IDPs will leave the camps, it is possible that some camps will evolve into permanent urban centres. In such cases, the normal structures of local government will be established and services provided as with other urban centres.

\section{Priority actions}

- Government will develop concrete plans to implement the IDP policy, in cooperation with key stakeholders including donors and civil society.

- Where appropriate, increased exibility may be given to distressed districts to divert money from activities that are currently impractical to meeting the immediate needs of the IDPs.

- Better monitoring and improvement of conditions in the IDP camps is a key priority, with a particular focus on health and sanitation.

- Through stakeholder consultations, Government will implement appropriate long term measures to deal with the challenge of IDPs in the country. 


\section{Service delivery in conflict-affected areas}

In addition to emergency-related activities, local authorities have to support normal service delivery in the context of insecurity. Even where the population served is not displaced, insecurity imposes extra costs. For instance, officials travelling in the area need protection, or because it is difficult to recruit staff. Hence there may be a need for extra funding in some cases and tailoring the implementation mechanisms to the con ict situations.

\section{Psycho-social support}

One service that is clearly needed in the context of con ict is psycho-social support for the traumatised, particularly the abducted children. A number of CSOs have played an important role in this area, which Government will support.

\section{Refugee Management}

The national policy on refugees has the twin objectives of protecting refugees in such a way as to protect national interests while meeting international standards. By promoting self-reliance, refugees hosted by Uganda are enabled to become an asset to the country. To this end, arable land has been allocated to enable the refugees become self-sufficient. In total, Government has allocated well over $3300 \mathrm{~km}^{2}$ of arable land for refugees.

The settlement of refugees in rural areas has social and economic implications on the host community which have to be given due consideration. Key challenges include:

- Large numbers of refugees in the allocated areas have put pressure on the environment through deforestation and poor sanitation.

- There is strain on social amenities including health and education services, and land in the districts hosting refugees.

- HIV/AIDS prevalence is relatively high in refugee-affected regions. Displacement and migrations from other countries increases the host communities' exposure to STDs. Redundancy, trauma, poverty and ignorance also contribute to the spread of diseases.

- Refugees also continue to suffer from insecurity like all the other nationals.

- There is need to improve the living conditions in the refugee-hosting communities

Generally, funding for refugee programmes from Government is limited. Refugees are mainly assisted under the UNHCR country programme. However, the annual budget for the country programme has fallen from US\$14 million in 2000 to US\$10 million in 2003. This funding is used to deliver multisectoral activities for refugees in health, education, community services, environment, agriculture and the running costs of UNHCR and NGOs involved in the refugee programme.

Being an emergency issue, expenditure on refugees is not treated as part of the MTEF. However, costs can be saved if the planning of refugees' needs can be integrated into the districts' normal planning. This would imply that the districts received resources adequate to cope with the ow of refugees and included refugees in the services they 
deliver. Districts and development partners are encouraged to cooperate in merging activities as far as possible ${ }^{6}$ to avoid duplication. Successful implementation of this approach can minimise damage to host communities, create infrastructure and promote amicable relations.

A policy on self-reliance of refugees has been implemented since 1999. Its focus is on enhancement of household incomes and well-being of refugees and host communities and development of an appropriate legal and institutional framework to foster productive activities and the relevant civil, social and economic rights.

\section{Priority Actions}

Government will:

- Aim for better integration of humanitarian needs and existing resources into the national plans.

- Implement the policy of self-reliance in cooperation with other partners.

- Encourage donors supporting refugees to cooperate with local authorities in avoiding duplication and cooperating in service delivery.

\subsection{Planning for the aftermath of disaster and insecurity}

\section{Existing and proposed programmes}

During and after the con icts are resolved, there is a clear need to plan for the recovery and development of the affected areas in the northern and eastern parts of the country. There has been a plethora of initiatives designed to address post-con ict needs. The majority of these programmes are currently implemented within the second phase of the Northern Uganda Reconstruction Programme (NURPII). Under NURPII, selective investments are being made in public infrastructure and services and the participation of community based organizations, NGOs, private sector and other stakeholders in development is being promoted through a bottom-up approach.

The challenge is to integrate these various initiatives into a coherent programme that addresses the needs of con ict-af icted areas. Since these expenditures are for development rather than emergency, they form part of the MTEF, and in the long run the actions proposed in them cannot be funded unless they are integrated into the strategies of the various sectors. While some support is provided direct to districts by development partners outside the MTEF, any major increase in this support would raise the same macroeconomic concerns as other forms of increased public expenditure.

A major issue will be the role of transitional support as communities recover. For instance, packages of productive assets might be provided to IDPs who wish to return home and take up productive activities. Given the exceptional circumstances, such 'start-up' help would not necessarily contravene Government's general focus on the provision of public goods rather than productive assets to households. 


\section{Northern Uganda Social Action Fund (NUSAF)}

The Northern Uganda Social Action Fund is a Government project for empowering communities in 18 districts in Northern and Eastern Uganda, by enhancing their capacity to systematically identify, prioritize, and plan for their needs within their own value systems. In common with other social funds internationally, funds are provided for projects identified by communities themselves. Given the exceptional circumstances in the North, NUSAF works directly with communities rather than through the normal structures of local government.

The total financing is sub-divided across the four programme areas as follows:

- Community Development Initiatives (72.8\% of total financing)

- Vulnerable Groups Support (16.7\%)

- Community Reconciliation and Con ict Management (2.1\%)

- Institutional Development (8.4\%)

The Northern Uganda Management Unit (NUMU) has been formed and fully staffed based in Gulu. All the 18 NUSAF districts have signed the MoU and operational and financial manuals have been put in place. The project is yet to deliver tangible benefits given the time lag in bringing it into operation.

\section{Restocking Programme}

This is a long term measure to enable people in the northern districts and other parts of the country to restore their economic base, reinstate the cattle culture and reduce poverty by owning livestock and related infrastructure. The Restocking Project was launched in April 1999 to cover 35 districts with an initial funding budget of Shs 18 billion. Districts covered in the North and North East include Apac, Lira, Kitgum, Gulu, Nebbi, Arua, Yumbe, Moyo, Adjumani, Soroti, Kumi, Katakwi, Pallisa, Moroto, Nakapiripirit, Pader, Kaberamaido and Kotido. Recently, the districts in eastern Uganda have also been included.

The Restocking Programme aims at contributing to poverty reduction through increased agricultural productivity, incomes and improvement in food security in the project areas. A total of over Shs.12.9 billion has been disbursed to the districts of Northern Uganda since April 2000 for the procurement of project animals (cows/heifers, bulls, goats and pigs) and animal inputs like drugs, acaricides and ox-ploughs. In areas not highly affected by insecurity, household incomes are expected to improve.

The programme faces resource constraints and the continued procurement of underage/ undersized animals by districts which have resulted in low calving rates. The guidelines on restocking, procurement of inputs and recovery of funds have been reviewed and issued to the districts and monitoring systems are being strengthened so as to correct these anomalies. Another constraint has been cattle rusting. Government will attempt to ensure that the implementation of restocking is well coordinated with action against cattle rustling. 


\subsection{Public expenditure implications for security, con ict-resolution and defence}

It is important to note that Government's criteria for public expenditure include both rates of return and distributional impact. There is therefore a case for accepting somewhat lower economic rates of return on expenditures in areas that are disproportionately poor and disadvantaged. There is also some international evidence that expenditures in post-con ict countries have unusually high rates of return, and this may also apply to expenditures in post-con ict regions within a country. Sectors are urged to bear these considerations in mind while prioritising expenditures.

\section{Security and defence}

The public sector role in defence is clear. The returns are also high in the event that defence expenditure is effective in ending con icts or preventing new ones. For instance, the approximate cost of the con ict in the North has been estimated at 3\% of GDP, and simulations confirm that the loss of consumption in the North could be of the same order. The returns in terms of human suffering are enormous. It is essential that any increases in expenditure are associated with greater efficiency and effectiveness.

Under the Defence Review, costed options have been prepared for the transformation of the defence forces. The implementation of the Defence Review recommendations will depend on the available resources. The preferred option allows a defensive posture that will be adequate to handle two major security threats simultaneously. The strategy also includes resources needed to address immediate operational needs. Two issues arising are the appropriate pace of the modernisation programme, given the need to achieve other priorities, and the long-run need for military expenditure once security has been achieved nationally.

Cost-savings include:

- Tackling the problem of ghost soldiers

- Streamlining procurement

- More effective procedures for logistics and supplies

- Robust budgeting, financial management, and auditing

- An appropriate mix of regular and reserve forces

The achievement of peace would allow reductions in current defence expenditures. However, the extent of the reduction will depend on the long-run view taken of the necessary size of the army. In particular, it is to be hoped that a reduction in con ict in the region as a whole will reduce the likelihood of external invasion or armed insurgency; this would allow a more modest view to be taken of the country's long-run military needs.

\section{Government will:}

- Ensure adequate funding for meeting immediate security needs

- Phase the re-equipping of the security forces over time to match fiscal constraints

- Review the long-run needs for military expenditure in light of the regional security situation. 


\section{Con ict-resolution and disaster management}

Government will continue to treat humanitarian assistance off-budget, but improve its integration into planning. The current insecurity has a number of implications for public expenditure, namely:

- Increased cost of service delivery during con ict

- The cost of implementing the amnesty process and small arms control.

- The cost of the long run recovery of Northern Uganda

- Dealing with the immediate consequences of con ict. While humanitarian relief is critical, Government has an obligation to act if humanitarian contributions are not available to meet the needs. Moreover, some responses such as water supply and sanitation have long-run implications and require integrated planning (in some cases water sources in camps have become polluted because of the lack of sanitation).

The amounts needed in this sub sector are hard to quantify. Some insecure districts have had difficulty spending their mainstream service delivery conditional grants. The priority is therefore to allow adequate exibility to these districts to spend money on immediate needs, subject to reasonable accounting requirements. Government will therefore make provision for insecure districts to spend their resources in a more exible manner to meet immediate humanitarian needs, with a particular focus on environmental health and sanitation in camps. Incentives are also needed to attract staff to these areas; this is discussed in Chapter 6.

\section{Disaster prevention}

Disaster prevention should mainly be addressed under the local Government investment budget.

\section{Post-con ict reconstruction}

Costs of post-con ict reconstruction are being addressed through NUSAF at a community level. The merits of funding capital investment through the social fund modality (NUSAF), through decentralisation of decisions to local governments (LGDP), or by central conditional grants (e.g. SFG) need to be compared in order to guide future actions in this area. NURP proposes major large-scale investments which, if analysis shows they are high-priority, should be mainstreamed into the relevant sector (mainly transport).

As stability is restored, the implications of damage to infrastructure will need to be factored into the equalisation and conditional grants. There are also specific human development needs after con ict, such as support for abducted children and other traumatised people. The strengthened CDW function should have responsibility for coordinating efforts in this area, and some extra expenditure may be needed (though important work of this kind is already done by NGOs and donors).

In common with other areas of support, planning for post-con ict areas needs to be integrated into sectoral strategies rather than treated in isolation. As discussed in the chapter on public expenditure, the best way of reprioritising public expenditure is to integrate projects into the MTEF and progressively reduce the share of the project modality in public expenditure. Government will therefore ensure that the actions identified in regional plans are discussed with the various sectors, so that the needs of post-con ict areas can be effectively addressed within sectoral strategies. 


\section{Good Governance}

Good governance is a multi-dimensional concept and covers all aspects of the exercise of authority by formal and informal institutions. The National Programme and Action Plan on Democratic Governance defines good governance as the efficient, effective and accountable exercise of political, administrative and managerial authority to achieve society's objectives including the welfare of the whole population, sustainable development and personal freedom.

It is generally agreed that good governance implies democracy; respect for human rights; non-sectarian government; a legal system that is accessible, just and not too slow or costly; transparent, efficient, accessible and affordable Government; a competent and adequately remunerated public service; a strong sense of partnership between Government and other agents; and a positive contribution to international peace and security.

Despite the serious and persistent problem of insecurity in some parts of Uganda and the slow progress in reducing corruption and making Government structures affordable, significant progress has been made with regard to democratisation, decentralisation, and restoration of the structures of Government. The successes have over time bred new challenges as popular demands for enhanced political representation have become stronger, and international standards of good governance have become more explicit. Uganda therefore, now needs to nurture a national political consensus in which people trust and feel allegiance to the basic institutions even though they may disagree about particular political issues. Core priorities are:

- Ensuring respect for human rights

- Pursuing democratisation

- Making government structures affordable, transparent and efficient

- Providing a good judicial system

This pillar is organised around this approach. Section 6.1 covers democracy, human rights and political governance. Section 6.2 covers the justice, law and order sector. Section 6.3 examines the management of the public sector as a whole. Finally, Section 6.4 examines the expenditure implications for areas within the pillar.

\subsection{Democracy, Human Rights and Political governance}

\section{Democratisation}

In 1986, the National Resistance Movement (NRM) developed a Ten Point Programme, which, among other things, called for the restoration of democracy, security and the consolidation of national unity. The National Resistance Council (NRC) was formed as a legislative body. The Executive endeavoured to work with persons of different political persuasions through a broad-based Government. The 1989 Constitutional Commission recommended that party activities continue to be restricted for another 5 years and that the country be governed under the Movement Political System. Under this system, free 
and fair elections have been conducted both at the central and local government levels. Women's participation in public politics is high, the freedom of the press is upheld, and Parliament is independent. The Judiciary also operates with independence and human rights organisations are able to point out human rights abuses ${ }^{1}$.

\section{Table 6.1: Selected key democratisation events in Uganda}

1989, Creation of the NRC

1993, Creation of Constitutional Commission

1993, Start of decentralised system of governance

1994, Constituent Assembly elected

1995, Promulgation of the Constitution of Uganda

1996, 1st Presidential elections

1997, Movement Act passed

2000, Referendum on the adoption of the no-party political system

2001, 2nd Presidential Elections

2001, the Constitutional Review Commission established

2002, Political Parties and Organisations Act adopted

Elements of the democratisation process include the conducting of free and fair elections both at the central and local government levels, the high rate of women's participation in public politics, the upholding of the freedom of the press and independence of Parliament.

\section{Constitutional Review Commission}

In response to popular demand, Government in 2001 appointed a Constitutional Review Commission (CRC) to collect views from the public and recommend revisions to the Constitution $^{2}$. After holding consultations in all 56 districts and considering memoranda from over 140 interested parties, the CRC delivered its report to Cabinet. Critical issues considered by the CRC include:

- The system of Government.

- The structures of Government

- Relations between the judiciary and the executive

- The electoral process

- The roles of various constitutional commissions

- The protection of children

- The death penalty

The Movement system of government, which has prevailed in Uganda since 1986, was intended to create a sense of national identity, and bring about security and development which eventually would lead to the emergence of new social classes which are the basis of healthy party politics. The system was endorsed in a referendum in 2000.

Recent surveys show that national identity is very strongly held across all regions of the country. The second Afro barometer survey ${ }^{3}$ reveals strong support for democracy and opposition to political violence in 2002, and very strong (96\%) public commitment, 
in all regions, to national unity. Slightly more than half of people $(54 \%)$ felt that the existing system was either fully democratic or democratic with minor problems. There were high levels of approval for leadership, particularly at the village level and the Presidency. However, there were high perceptions of corruption particularly among police, government officials and the judiciary.

Over time, restrictions on political parties have caused tensions and there is a perception that party politics can now be successfully operated without a relapse into the sectarian politics of the 1970s and 1980s. It is therefore expected that future Ugandan elections will allow the participation of parties. This will require consideration of the existing provisions of the Political Parties and Organisations Act, in order to enable political parties organise themselves before the next elections, which are due in 2006. Government is committed to seeking a national consensus on the way forward in good time for an orderly transition between systems, to ensure that the elections are completely free and fair, and that the emerging political system will have the following features:

- A credible system of representation, with well functioning political parties/ organisations and interest associations;

- An electoral system that guarantees regular free and fair elections as well as universal suffrage;

- A system of checks and balances based on separation of powers, with independent judicial and legislative branches;

- A vibrant civil society, able to monitor government and private business and to provide alternative forms of political participation;

- Free, strong and independent media, including alternative people's media; and

- Effective civilian control over the military and other security forces ${ }^{4}$

\section{Priority actions}

- Government will respond to the recommendations of the CRC and will finalise a road map for the full participation of parties in the political process.

- Elections will be held according to the provisions of the Constitution.

\section{Electoral Politics in Uganda}

Since the restoration of political sanity in Uganda elections have been successfully held at all levels of Government. These elections have been fundamental in the establishment of a democratic culture. Since 2001, the Electoral Commission has registered over 8.2 million voters capturing both their bio-data and photographs under the Photographic Voter and Identification System (P.V.R.I.S) Project, and produced a photo-bearing register for the whole country. Photo-bearing registers have been used during elections and by-elections in a number of districts, and the infrastructure may facilitate the development of personal registries for other purposes.

Outstanding challenges include the need to review legislation to remove ambiguities on qualifications for office (such as the equivalent of ' $A$ ' level) and the definition of bribery, accompanied by tougher penalties for infringement; the late enactment of enabling laws; the tight election timetable expected over the next two years; the shortage of resources at 
the local level; and insecurity and cultural issues including sectarian politics, lack of trust, and the monetisation of politics and elections.

\section{Priority Actions for elections}

Government will:

- Enact enabling laws with prohibitive, punitive and deterrent provisions to reduce election violence and other election related malpractices.

- Ensure that the enactment and amendment of the enabling laws is done in time to enable and facilitate the proper planning of election activities.

- Work with Civil Society Organisations to ensure the intensification of voter education with a view of ensuring proper political representation and good leadership.

- Implement more effective voter education programmes aimed at increasing public awareness.

\section{Political governance institutions}

\section{Overview}

The terminology 'public administration sector' has been used in Uganda to describe a set of institutions that are mostly engaged with the political process. These institutions include:

- Parliament

- Office of the President

- State House

- Movement Secretariat

- Local Governments

In recent years, the role of Parliament in national planning and resource allocation has been strengthened. The Executive is now required to share the budget proposals with Parliament well in advance, and all external borrowing has to be authorised by Parliament. Parliament is assisted in performing this scrutiny by the Parliamentary Budget Office.

So far, there has been no sectoral approach taken to these areas. These institutions absorb a significant amount of resources, sometimes for projects that do not appear to fall under their mandates. Unpredictable claims on expenditure have also been a problem, with significant supplementary expenditures in this area. The institutions have begun to cooperate in developing a sectoral or sub-sectoral strategy and will proceed to define their institutional mandates. The process of constitutional review has considered the role and size of each of these agencies.

At the local government level, there is a major challenge in ensuring that the political structures are affordable. Recently, districts have been created without a systematic assessment of their affordability. This puts an extra strain on public resources. The system under which new local authorities are created, has encouraged their proliferation over time. Government will review the process for creating new districts to ensure that resource implications are fully considered. 


\section{Human Rights in Uganda}

Human rights are monitored by the Uganda Human Rights Commission (UHRC), together with various national and international civil society organisations and the media. The independence of UHRC has enabled it to present candid annual reports of the state of human rights, which have appeared since 1997. Uganda has been recognised as one of the countries that have fulfilled the Paris Principles governing the establishment of human rights institutions and was the chair of the African National Human Rights Institutions in 2002-3.

The state of human rights in Uganda has continued to be challenging. UHRC received 4,853 complaints between 1997 and 2001. Each complaint is handled on its own merit. Positive developments in recent years include the continued independence of the Judiciary, the roll out of community service in the whole country, the input by UHRC into the Suppression of Terrorism legislation, a more humane approach adopted to captured rebel children, who are now being rehabilitated, and the participatory and sensitive approach to disarmament in Karamoja in 2001-2. Uganda has also adopted the World Fit for Children declaration and programme of action and ratified the optional protocol on use of children in armed con ict and commercial sexual exploitation of children; it has also ratified the ILO convention 182 on the elimination of the worst forms of child labour.

Significant ongoing challenges identified by UHRC include: illegal detentions (mostly due to transport problems and irregular court sessions), the use of torture in detention centres operated by police, military forces, and local administration prisons, and conditions in prisons. There are signs of improvement in central but not local administration prisons. In the worst case, conditions are 'life-threatening, inhuman and degrading' and there are reports of deaths due to starvation, TB and dysentery. Restrictions on political parties may infringe some of Uganda's international commitments, but the political reform process will address this.

Human rights are also violated by bodies other than Government. Some of the most serious violations are by other forces; the continued abductions by the LRA, totalling 31,000 people between 1990 and 2001; a number of appalling recent massacres by rebel forces in early 2004; occasional abuses by religious cults such as that of Joseph Kibwetere which burnt 1,000 of its followers to death in 2000: and some inter-ethnic violence in Kibaale; and sexual abuse, neglect, prostitution and trafficking of children.

Domestic violence is a widespread problem, which the legal system does not always adequately address. Contributory factors include the limits on women's empowerment posed by bride price, limited ownership of assets, lack of custody rights in the case of separation, discriminatory divorce rights, and widespread acceptance of the normality of the practice of domestic violence in society and even in some parts of the legal system. A survey in 2002 identified the most frequently mentioned human rights abuses as: domestic violence, sexual harassment, unlawful detention, denial of education to girls, ritual killings and corruption. 
Key Human Rights Actions over the medium term

- Government will take action to prevent any of the violations reported by UHRC from continuing.

- The J/LO sector will treat the humane treatment of prisoners as a priority and the security sector will ensure that its agencies do not exceed their legal powers, for instance by illegal detention.

- The UHRC is establishing a sub-regional office in Moroto. The Civil-Military Liaison offices in Moroto, Kotido and Nakapiripirit will continue to implement a framework of engagement between Government and civil society to achieve disarmament in Karamoja. The Civil-Military liaison offices will be extended to Katakwi, Kumi Soroti, and Kaberamaido next year.

- UHRC is coordinating a national civic education framework with other human rights organisations for the next three years to increase awareness among Ugandans about their human rights and obligations.

- In line with the UN Convention on Rights of the Child and the Children's Statute, UHRC will support and coordinate data collection on abuse, neglect and exploitation of children.

\section{International Conventions and National Governance}

Ugandan is signatory to a number of international conventions and regional agreements. However, the Human Rights Commission Report points out that Uganda has not been able to fulfil its reporting requirements on some of the international conventions to which it is a signatory.

Regional initiatives to which the country is a party include the East African Community (EAC) and the New Partnership for Africa's Development (NEPAD).

NEPAD provides a strategy to identify sub-regional and regional projects that countries are to cooperate on. As a member of the EAC, Uganda is participating in a number of regional initiatives including joint action on concessioning the railway with Kenya and Tanzania to a private sector manager, joint action for safe navigation on Lake Victoria, and joint design of road investments: and the proposed Kenya-Uganda oil pipeline and rail/road Northern Corridor.

Any actions that Uganda takes under such initiatives need to be embedded in Government's own sectoral strategies. Hence sectors need to be cognisant of international cooperation efforts which may affect the prioritisation of their activities; for instance, the returns to a road project are affected if it s seen as part of a joint international project Equally, no commitment should be made to international projects without sectoral officials being fully aware.

Under NEPAD, an African Peer Review Mechanism (APRM) has been put in place to ensure that countries conform to agreed codes and standards of governance. The APRM identifies challenges and scrutinises the country's draft programme of action to deal with them. The Peer Review Mechanism's report will be published after discussion with the government, the APR panel (comprising eminent persons) and the APR forum (comprising 
heads of state who are members of the APR). The report will assess the performance of the country on identified criteria covering:

- Democracy and good political governance

- Economic management

- Corporate governance

- Socio-economic development

\section{Priority actions}

- Government will continue to participate actively in EAC and NEPAD.

- Government will aim to fulfil all its reporting requirements under international conventions.

\subsection{Justice, Law and Order}

State intervention in justice, law and order is justified by the effects of lawlessness on poverty. Crime prevention matters for poverty reduction, not only because people are directly hurt by it, but also because their ability to invest is reduced. The effects of cattle-rustling were described in the last chapter, but less dramatic petty crime also has an impact. For instance, in the second UPPAP report ${ }^{5}$ in fishing communities 'use of illegal nets was attributed to both cost and insecurity. It was explained that legal nets are expensive and are particularly targeted by thieves. Fear of net theft was said to deter fishermen from getting loans to buy legal nets'. Similarly, some vanilla farmers maintain overnight vigils in their gardens to deter thieves.

Incarceration of convicts also involves fiscal and human costs. The imprisonment of an adult very often removes a breadwinner from a household, leaving a spouse and children in a very difficult situation. Experience shows that Government has found it difficult to devote adequate resources to prisons, especially Local Administration prisons. Slow processing of cases means that, despite a relatively low overall prison population by international standards, Uganda's prisons remain overcrowded partly because too may people stay on remand for too long a time. In July 2003, the prison population stood at about 18,000 prisoners whereas there was habitable space, by international standards, for only 8,000. ${ }^{6}$ The ratio of prisoners to warder has fallen from 9.2 in 2000 to 8 in 2003. However, death rates among prisoners have fallen from about 13 per thousand in 1993 to 6 per thousand in 2002.

Crime increased until 1999 and levelled off thereafter ${ }^{7}$, partly because of sectoral reforms including community policing and implementation of anti-corruption measures. The number of reported crimes, excluding traffic offences, rose from 40,979 in 1996 to 68,322 in $2001^{8}$. While men reportedly commit the great majority of all crimes in every category, there has recently been a sharp increase in the numbers of women arrested/accused. Between $52 \%$ and $65 \%$ of reported crimes are committed in rural areas.; however, given the rural (80\%) / urban (20\%) population ratio, crime rates are actually higher in the urban areas. This may be explained by the proximity of police, migration from rural to urban areas, density of population and the higher prevalence of wealth symbols in urban areas. 
Juvenile crime (especially economic crime) is on the increase, particularly among females. Two categories are of particular importance: defilement and economic crime. Defilement cases reported have risen by $87.9 \%$ over the period of 5 years, contributing to a $95 \%$ increase in youth charged with capital crimes Defilement is related to poverty, armed con ict, orphan hood and 'street children'.

Economic crime among young people is often a re ection of poverty and domestic problems. A study by Save the Children, $\mathrm{UK}^{10}$ argues that "physical and emotional deprivation is a factor behind juvenile crime (especially theft)... and needs to be addressed in terms of general poverty alleviation...[and] raises the agenda of investigating general parenting patterns and supporting parents in positive parenting roles." At the time of the study $73 \%$ of the children detained at Kampiringisa National Rehabilitation Centre had been accused of theft; only $2 \%$ had been convicted. Most young offenders come from low income earning families. " $70 \%$ of the convicted children said that they stole to meet their needs (mainly food), [while] 79\% [of those]... admitting to carrying out a crime said that they know it was wrong, with 49\% [adding] there was no way they could avoid the offence."

The sector also faces some new challenges including international money-laundering and terrorism. Even where these crimes have little direct bearing on the day-to-day lives of ordinary Ugandans, they cannot be ignored, because the country's international reputation depends on its response to them with effects on tourism, international investment and foreign relations.

The administration of justice lost public confidence during the 1980s and 1990s, as was re ected in the very negative findings about the police in the first service delivery survey. The institutions that have most public confidence - the LC courts - have a limited mandate and have until now received limited support.

All of these problems are being addressed by the reform process in the JLOS sector ${ }^{11}$, which was formed in the period after the launch of the PEAP in 1997.

\section{Access to justice}

Physical access to JLOS institutions varies geographically. Criminal and commercial case administration depend on a set of institutions. Where key agencies are absent the processing of cases from entry to exit is constrained. Currently, the Judiciary and Prisons have the most comprehensive and equitable coverage of Uganda's fifty-six (56) districts, although some offices lack adequate staff and a permanent presence. The Uganda Police Force, Directorate of Public Prosecutions, Government Analytical Laboratory and Ministry of Justice and Constitutional Affairs have a more problematic distribution.

The lowest court is at the Local Council level; these are further discussed under decentralisation.. LC Courts provide a good avenue to sort out local disputes and some petty criminal matters without recourse to more formal systems. They are in general popular, although there are concerns that they are not always adequately responsive to cases of domestic violence and sometimes adjudicate matters beyond their jurisdiction. 
The Uganda Police Force has a total strength of about 14,352 personnel; there are also 11,060 auxiliary staff including 4,500 special police constables and 6.560 local administration police ${ }^{12}$. In addition, Local Defence Units under the control of the LC3 contribute to crime prevention. The centralised Uganda Police Force is concentrated in urban areas. The higher qualifications and lower crime rates among regular forces make them preferable. Nationally the coverage is equivalent to 1 regular officer per 1,663 people compared to an international norm of 1:600. In the short run, the international norm is not affordable, but the sector is seeking to improve the ratio by recruitment of 500 constables per annum.

Figure A6.2 in the annex presents a comparison of the presence of judicial officers and prosecution staff by region.

Particular social groups face specific obstacles in gaining access to justice. For example, ethnic minorities can suffer from lack of literacy and awareness of the justice system ${ }^{13}$. There are an estimated 1.4 million IDPs and 230,000 refugees, mainly in Northern Uganda. With limited JLOS presence in the Northern region, the ability to provide the required levels of service delivery is severely constrained. As a result of the con ict in the northern region JLOS activities have been badly affected, and the police anticipate increased crime in the aftermath of con ict because of youth unemployment and possible acts of revenge.

The strengthening of the juvenile justice system will involve synergies between the $\mathrm{J} /$ LO and social development sectors, including the rehabilitation of remand homes and the reintegration of offenders and prevention of crime through the work of community development workers.

JLOS is cooperating with legal aid service providers to increase access to justice, particularly for vulnerable groups. In 2002, Legal Aid Service Providers (LASPs) established a civil society partnership of seven key NGOs and identified their area of geographical coverage and quality and quantity of service delivery nationally. Preliminary research indicates limited coverage, particularly in the North and North Eastern region of the country. Even where there is coverage, the tendency to offer "niche" services such as for women, juveniles or those charged with capital crimes constrains overall service delivery. JLOS and civil society are preparing an action plan to expand service delivery, and make services more comprehensive where they exist.

\section{Priority actions for increasing access to criminal justice}

Government will:

- Assess the options for recruitment of new officers and/or reintegration of auxiliary forces to ensure adequate coverage of the Uganda Police Force

- Review projections of the prison population in the long term to assess needs for resources, and integrate a rights-based approach to penal reform in light of the findings of the recently completed Prison Census and the Human Rights Commission report

- $\quad$ Strengthen service delivery for legal aid 
- Continue to recruit judicial and legal officers, prison warders and police officers as resources permit.

- Make Family and Children's Courts functional.

\section{Efficiency and effectiveness}

While the Uganda Constitution, 1995 sets limits for the time spent on remand for noncommitted charges, as at September 2003 64\% of prisoners were on remand. Of those $64 \%, 71 \%$ are charged with capital offences, $41 \%$ of which are cases of defilement. Only the High Court has jurisdiction to hear capital cases, which includes defilement, so that prison overcrowding and lengthy stays on remand are directly linked to case backlog at the High Court. Hence the J/LOS Sector has developed institutional targets for disposing of matters from the point of arrest to final conviction or acquittal.

Lower courts, such as Magistrates' courts are both cheaper to operate and quicker to resolve cases than higher courts. Hence the Sector programme has completed a Magistrate's Courts' (Amendment) Bill to increase the pecuniary and criminal jurisdiction for lower courts. Thus Chief Magistrate's Courts will be able to adjudicate defilement cases.

Oversight of the courts falls within the local Government sector. The LC courts deal with civil matters including land disputes and marital disputes, and some criminal matters including children in con ict with the law. They are generally appreciated, although there are complaints that they are sometimes gender-biased, especially when dealing with domestic violence, where there is often a strong preference to leave the matter to be settled privately within the household. In some communities women disputed men's views that the LC1 is important in dispute settlement and provision of security and complained that the LC1 is corrupt and biased against them. In Wakiso district, barmaids reported: 'Violent drunkards pay LC1 officials some money and our cases are dismissed.'

The LC courts handle many children's cases, but their knowledge of children's rights and record-keeping is inadequate. Further training is needed, especially because office bearers change at election time.

A Local Council Courts Bill has been developed to repeal and replace the Resistance Committees (Judicial Powers) Statute of 1988. The new Bill will strengthen the administration of justice by Local Councils and introduce recording of proceedings and maintenance of records, in the local language at village level and English at the sub-county level.

Significant improvements in efficiency, as well as prisoners' welfare, are offered by the introduction of non-custodial community service as an alternative to imprisonment. To date, only $10 \%$ of those sentenced to a community service have re-offended, compared to $40-60 \%$ of those sentenced to prison. Other benefits include a much lower risk of rape for women and reduced exposure to communicable diseases. The successful pilot scheme (operated in Masaka, Masindi, Mpigi and Mukono) suggests that more than 10,000 people annually may qualify. Consequent labour savings for Local Councils are estimated at Shs. 157 million per annum and savings on prison non-wage recurrent costs at Shs. 954 million per annum. Hence the introduction of community service is a 'win-win' solution, allowing better service delivery at lower cost. 
The Chain Linked Initiative, first piloted in Masaka District, demonstrated that cooperation in scheduling of criminal cases between the police, the DPP and the prisons reduced case backlogs in Masaka High Court to virtually nil. Using best practice principles, the project has now been rolled out to all 29 magisterial areas as a "normal business practice" to ensure that scheduled court sessions yield a high case completion rate.

The Case Backlog Project began in 2000/2001 and is part of the Poverty Action Fund (PAF). Police and Prisons are facilitated to transport witnesses and suspects, the Judiciary and DPP enabled to schedule "extra" court sessions, and the Government Analytical Laboratory and CID to completed investigations. In the first year of the project the case backlog was reduced by $15 \%$ with cases dating back to 1995 being completed.

Uganda Prisons Service is the only institution in Uganda with relatively modern demonstration farms in a pure rural setting, where the majority of the poor live. In the context of poverty eradication, evidence suggests that over $85 \%$ of prisoners are poor with no employable skills, and 59\% have families. Prison Farms assist in the rehabilitation of prisoners as well as providing examples of good agricultural practices. For example, storage cribs for maize farming at Kitayla Prison farm have now been adopted by the surrounding communities. Potentially, the programme should generate more than enough income to cover its costs.

\section{Priority actions to increase efficiency and effectiveness}

Government will

- Establish Policy and Planning units in all sector institutions

- Review the jurisdiction of courts at different levels

- Support LC children's secretaries to understand their role in protecting children's rights.

- Roll out the Community Service programme

- Expand the Prison Farm system

- Institutionalise the Chain Linked Initiative and Case Backlog projects.

\section{Quality of justice}

Poor knowledge of rights and obligations by the public and JLOS staff, and poor compliance with the law, are major constraints on the quality of justice. The Judicial Service Commission has established an Education Department and coordinates the JLOS Publicity Committee, which conducts radio advertisements and participates in discussions on mob justice and community service.

\section{Priority actions}

- Government will launch publicity campaigns and civic education campaigns.

- User guides will be published and help and complaints desks established for each institution. 
- Stronger links with communities and local administration are envisaged in the medium term.

\section{Promoting the rule of law}

The Uganda Law Reform Commission is reviewing the laws of Uganda to bring them into compliance with the Constitution of 1995. Some laws are obsolete and create red tape, while others are discriminatory towards the poor. Women's access to justice, in particular, is hindered by discriminatory laws such as land legislation, where inequities in land ownership were not corrected by the Land Act. The Constitutional Court has been instrumental in amending offending legislation including the abolition of corporal punishment, and voiding the inequality of access to divorce between male and female petitioners.

\section{Priority actions}

Government will:

- Seek passage of the Executive Committees (Judicial Powers) (Amendment) Bill.

- Seek passage of the Penal Code (Amendment) Bill to amend the law on defilement and proceed with reform of the Defilement law. Introducing a maximum sentence of life imprisonment would allow the matter to be heard by Magistrates' Courts, and gradation by age would allow cases where both victim and accused are juveniles to be heard by the Family and Children's courts.

- Seek passage of the trial by Indictment (Amendment) Bill to reform trial procedure and sentencing guidelines including making community service available for juveniles.

- The sector will continue to advocate the amendment of legislation relating to marriage and divorce to end gender discrimination.

\section{Commercial Justice Reform Programme}

The Commercial Justice Baseline Survey ${ }^{14}$ highlighted the negative impact of poor services on private sector development. $70 \%$ of businesses surveyed perceived the commercial justice system to be expensive, slow and corrupt, with $60 \%$ adding that their businesses would prove more profitable, by at least $5 \%$, if the system were improved. The need for efficient and effective commercial dispute resolution mechanisms was also demonstrated with $50 \%$ of businesses interviewed having had a serious commercial dispute in the past three years, and nearly $90 \%$ having sought resolution in a court or other official forum. Poor enforcement of commercial justice also affects the poor, because it makes it harder for them to protect their property rights.

The Commercial Justice Reform Programme (CJRP) focuses on improving the regulatory and service delivery framework for businesses in Uganda. The key areas for reform in the CJRP have included Courts, Commercial Registries (that is the Company Registry and Land Registry), law reform and strengthening the legal profession. Significant progress has been made in areas such as the Commercial Court and law reforms. On the other hand, there is still little to show in improvements at the commercial registries. At the same time, new challenges have come up even in those areas where progress has been noted. Both the old problems and the new challenges can be identified in terms of access to justice, efficiency and effectiveness, and quality of justice. 
The Sector seeks to promote alternative dispute resolution mechanisms to ease access for those enterprises that face barriers due to financial and other constraints. A key initiative has been the establishment of a Centre for Arbitration and Dispute Resolution (CADER) with enabling legislation - The Arbitration and Conciliation Act - to allow disputants to seek arbitration, mediation or negotiation as an alternative to adjudication in the commercial court.

According to the Commercial Justice Baseline Survey 50\% of businesses believe that aspects of Uganda's commercial laws have a negative impact on their operations. For the informal sector, 32\% believed that the Income Tax Act placed undue burden on smaller enterprises thereby making them less competitive. In the Legal Profession $71 \%$ identified commercial laws, particularly the Companies Act, as having a negative effect on commercial practice. With the support of CJRP, the Uganda Law Reform Commission has begun the process of identifying and drafting new or amendment laws in response to the survey findings.

\section{Priority actions:}

- Government will continue to implement the commercial justice reform programme.

\subsection{Managing the public sector}

Given that public expenditure currently constitutes over $20 \%$ of GDP, it is of major importance for national development that resources are well used. Government is committed to managing the public sector efficiently, transparently and affordably.

\section{Planning, finance and coordination}

The integration of finance and planning is a fundamental aspect of Uganda's planning system. With this integration, the planning and allocation of public resources have improved. A detailed discussion of budgetary allocation and the link with planning is provided in Chapter 8. Sectoral Working Groups are responsible for the annual sectoral Budget Framework papers, in which sectors' proposals for expenditure are set out. With the integration of donor-funded projects into the MTEF, these groups will also be responsible for vetting project proposals to ensure that projects are consistent with overall sectoral priorities.

\section{Priority actions}

- As of 2004/5, projects will be fully integrated into the MTEF.

- MFPED and NPA will discuss the best ways to cooperate in national planning.

\section{Accountability and Transparency in Public Life}

International indicators show some improvement in Uganda's corruption ranking from 3rd to 17th in the world (Annex Table A 6.2). Corruption takes various forms including embezzlement of public funds: misuse of public property, nepotism in appointments, acceptance of bribes in returns for awards of contracts or other favours, and undersupply or over specification on contracts. While some of these can be detected by a sound accounting system, bribery typically takes place outside the accounting system. For this reason, the occurrence of corruption has to be controlled by social expectations as much 
as by formal mechanisms. Government's objective is to develop a culture in which noone expects to pay or receive a bribe.

\section{The experience of corruption at household, institutional and Government level}

Progress in reducing the incidence of corruption was recorded during the Second National Integrity Survey carried out in $2003^{15}$. The occurrence of bribery is higher in institutions that have legal powers over their clients (JLOS institutions) or have specific inputs to sell (health and veterinary units). Encouragingly, the rate of bribery has fallen somewhat in recent years for those institutions where comparison is possible, but it is still clear that unofficial payments are normal in some institutions. Amounts paid vary very widely. The mean bribe in the health sector, for instance, is about Shs. 12,000. If this figure is representative ${ }^{16}$, it suggests that the total volume of bribes paid in health centres could be around Shs. 50 billion annually. The consequences for the poor can be catastrophic, because they can be denied access to vital services because they are not able to pay the relevant bribe even though the service is meant to be free.

In the second PPA poor people reported that corruption in government bodies, especially in the tendering process, impacts negatively on service delivery. Few cases were found where districts or communities held corrupt officials or politicians accountable. Some people pointed out that they cannot effectively question their leaders because they are not aware of their responsibilities. In some cases, weak capacity may be mistaken for corruption.

Corruption contributes to inequality and has consequences for the business sector. As noted in chapter 2, corruption is the most often named constraint on private investment. Annex Table A 6.4 shows the experiences of institutions in public and private sector in dealing with various public offices.

Businesses find that corrupt practices are more frequent within the public than private sector. Whereas in the private sector $83 \%$ said that there was no external in uence on recruitment, in the public sector $47 \%$ either said that there was or that they 'did not know'. $86 \%$ of people in the private sector report that merit is the main criterion for promotion, compared to $74 \%$ in the public sector, and $78 \%$ of people in the private sector report that budgetary control is effective or very effective, compared to $54 \%$ in the public sector.

The consequences for Government are equally serious. First, corruption drives up the costs of public sector projects. Secondly it can lead to the failure of public spending to achieve its objectives, for instance because classrooms are provided with inadequate materials and then collapse. Finally, corruption can lead to distortions in policy decisions, leading to misallocated resources and eroded public confidence. 


\section{Actions to reduce corruption}

Government is preparing the second anti-corruption plan. The following areas of action are central to the approach

\section{Strengthening Monitoring and Financial Controls}

Government is introducing the Integrated Financial Management System (IFMS), a computerised budgeting, accounting and reporting application. Pilot implementation of IFMS was launched in February 2004 in six ministries and four local government pilot sites; depending on the success of the pilots, it will be extended to all central government votes and more local governments over the medium term. In addition, the Fiscal Decentralisation Strategy (discussed below) will streamline the fiscal transfer system of resources to local governments. The PAF monitoring system has been made an integral part of the overall PAF programme $5 \%$ of the PAF budget is devoted to monitoring.

The Public Finance and Accountability Act empowers the Auditor General to examine, inquire and audit classified expenditure centres. MFPED has issued regulations providing for the exercise of this function on classified expenditure and its presentation to Parliament. The Act also requires the Accountant General to monitor the Internal Audit function in all ministries/departments and agencies. The Accountant-General's office is being equipped to fulfil this function.

Under the Public Procurement and Disposal of Public Assets Act, 2003, procurement is being decentralised from the old Central Tender Board to Procurement committees within public institutions themselves. Companies that engage in corrupt practices can now be blacklisted. However, one of the challenges is to recruit qualified Procurement Officers. Of the originally intended 80 Officers, so far $54(68 \%)$ have been recruited. A Public Procurement and Disposal of Public Assets Authority has been established to oversee the system, and it is proposed that all Procurement Officers should belong to a National Procurement Professional Association.

Until now, local government tender boards have been appointed by local authorities without reference to any higher vetting authority, whereas the District Service Commission members are appointed by their respective Councils but vetted and approved by the National Public Service Commission. Awards of contracts to incompetent firms, or absorption of projects costs in bribing officials to win the contract, have led to wastage. Government has recently conducted a study on Procurement in Local Government and will extend the Public Procurement and Disposal of Public Assets Authority (PPDA) to the regions. New and comprehensive LG procurement regulations are being developed.

Another fundamental aspect of the procurement system is the dissemination of information. Often the performance of contractors is easier to monitor for people on the ground than for Government. For this reason, better public information about the terms of contracts is needed.

Local Governments submit monthly and quarterly accountability reports to MoFPED and the Ministry of Local Government. Releases are now withheld if the reports are not submitted. However, this has the unfortunate effect of punishing the population for the failures of local officials. Hence in future Government will consider applying the action 
to individual councillors and errant officials and not the LG council as an institution. Most local authorities have now produced accounts for the financial year 2000/01. Local statutory bodies (the Local Government Public Accounts Committees, the Local Government Tender Boards and the District Service Commissions) are now funded directly by the centre under the monitoring and accountability grant, to reduce their allegiance to local leaders and in uence peddling.

Under the LGDP programme, $20 \%$ bonuses and penalties are applied to LGs that comply well or poorly with reporting requirements. As a result, compliance has improved. Inspections have also helped to improve local authority finances. Most LGs now prepare balanced budgets, maintain recommended books of accounts and prepare monthly and quarterly financial reports. PAF inspection reports indicate that in most districts, central government transfers reach the targeted sector in time (from more than one month in 1998 to less than two weeks in 2001/02).

MoLG also disciplines errant Local Governments that do not comply with laws, policies and regulations issued by central government. Some Chief Administrative Officers have recently been deprived of the role of Accounting Officer and replaced with others on the advice of the MoLG.

\section{Priority actions}

- Government will continue to roll out IFMS incorporating systematic tracking and measurement of impact.

- The current PAF monitoring system will be reviewed.

- Reporting systems will be established to ensure that local governments fully comply with LGDP accountability requirements.

- Responsibility for handling corruption issues in local government will be clearly assigned.

- Government will seek passage of the Auditor General Bill.

- Government will implement at least three value for money audits each year, and mount a pilot study to estimate the scale of public corruption.

- Government will computerise the audit function in the OAG's office, complete the audit of classified expenditure, and establish the internal audit function in all ministries.

- Government will complete the recruitment and training of 80 procurement officers and establish a national association for procurement professionals. PPDA will be mandated to approve all appointments made by local tender boards.

- At the local level, Enhanced Monitoring Information and Evaluation systems through introduction of information technology packages like Local Government Information and Communication System (LOGICS) and Local Government Financial Information Analysis System (LGFIAS).

- Strengthened cooperation between LGs and CSOs will be strengthened.

- Annual reviews of decentralisation, starting in 2004, will be conducted.

\section{Strengthening the legal framework and codes of conduct}

Government enacted the Inspectorate of Government Act, 2002 and amended the Leadership Code Act 2002. The Public Finance Act of 2003 replaced the Public Finance 
Act of 1964 and provides for greater control of Parliament over utilisation of public resources. The Public Finance and Accountability Regulations came into force on 1st July 2003, including specific regulations for classified expenditure.

Further legislative reform is planned. A Money Laundering Bill has been developed. The amended Prevention of Corruption Act is due to go to Cabinet. Principles for the Access to Government Information Bill are being prepared, and a working Committee has been set up to work on the principles for a Whistleblower Act.

Uganda has been an active member in the formulation of the United Nations Convention Against Corruption, and the African Union Convention on Combating Corruption. These conventions need to be ratified.

In addition to legislation, the Directorate of Ethics and Integrity has produced a strategy for developing Codes of Conduct for policy makers and members of Professional Associations. Codes of conduct have been prepared by the Uganda Revenue Authority, the Ministry of Health and the Ministry of Public Service. Ethical guidelines for Internal Auditors have been formulated and will soon be launched and Local Governments Associations have already launched a Good Governance Charter for their members.

\section{Priority actions}

Government will:

- Seek passage of the revised prevention of Corruption act (2003/4), the Whistleblowers Act (20045/5), the Qui Tam Act (2005/6), the Freedom of Information Act (2004/5), and the Money Laundering Act (2004)

- Seek ratification of the UN and AU anti-corruption acts

- Introduce legislation for maximum periods within which public offices are required to issue decisions (2004-6).

\section{Investigating and acting against corruption}

Commissions of Inquiry are used to address issues of major public concern where there are alleged breaches of standards of accountability and where the situation is not amenable to normal systems of auditing and investigation.

The following commissions of inquiry have been conducted:

- Commission of Inquiry into the Conduct of the Police Force

- Commission of Inquiry into Closure of Banks

- Commission of Inquiry into Helicopter Purchases

- Commission of Inquiry into the Alleged Exploitation of DRC's Natural Resources

- Commission of Inquiry into the Uganda Revenue Authority

The office of the IGG has carried out a large number of investigations as summarised in Table A6.5 in the Annex. As a result of the above investigations, the IGG's office prosecuted a total of 189 cases in the period July 2000 to December 2002. In addition 
the IG's investigations recovered Shs. 7.8 billion in the same period for the Consolidated Fund.

Government cannot end corruption on its own; this requires active involvement from the population. People have both a right and a duty to do what they can to resist corruption. Popular involvement, however, is constrained by limited information and by not knowing where complaints can be made. Progress has been made in the spread of information by the publishing of financial transfers in the press. However, less progress has been made on publicising the terms of contracts. Consultations have shown that many people are interested in monitoring the performance of contractors at a local level, but are unable to get access to the contracts issued. When people encounter corruption, they may not know who to complain to, or be afraid to complain even where formal mechanisms exist. Government will aim to strengthen formal channels of complaint and to ensure that people feel safe in using them.

\section{Priority actions}

Government will:

- Act as appropriate on the findings of Commissions of Inquiry and ensure their timely publication

- Ensure that the IGG is able to perform its functions without interference, according to its mandate.

- Ensure that all ministries and agencies cooperate actively with the IGG. Other organisations including the private sector, civil society and donors are also expected to offer the IGG maximum cooperation in doing its work.

- Hold regular consultations with civil society on cooperation in the fight against corruption.

- In addition to the Freedom of Information Act, introduce regulations for the release of information in each ministry.

- Introduce codes of conduct and client charters with formal complaints procedures for ministries and public sector agencies.

\section{Improving Government practices to reduce corruption}

The general process of public sector reform offers a number of opportunities to make corruption less easy and tempting to practice and easier to detect. Issues include pay reform, public information, the avoidance of firm-specific incentives, public scrutiny of expenditure proposals including unit costs, the increased emphasis on budget support ad the integration of projects into the budgetary process, the existence of checks on the professional performance of staff and where possible the separation of the handling of money from decision-taking powers (as has recently worked successfully in improving the performance of the traffic police).

Tackling corruption and building accountability across the public sector requires a great deal more than the establishment of formal structures. With active political support there is confidence that real progress can be achieved in promoting transparency and reducing corruption. 


\section{Public Information}

In 2001, MFPED developed a Medium Term Communication Strategy to strengthen government's communication capacity to articulate and manage economic policies and public expenditure programmes to enhance poverty eradication, and to increase stakeholder understanding and involvement in Government programmes. The strategy was reviewed in 2003 and it was found that a number of communities supported by civil society organisations were using the information provided to monitor budget implementation.

Significant achievements include regular dialogue with Local Governments through budget and PEAP workshops, the issue of simplified versions of the budget, the PEAP and the PMA, which are translated into local languages, ad the publication of the monthly report on the Performance of the Economy on the Website. Drafting of the Public Information Bill is in its final stages. All funds released to local governments are now published in the newspapers, and increased use is being made of Ministry websites to provide easily downloadable information including funds releases, and budgets.

In 2003 Government commissioned a survey to evaluate progress made in the implementation of the Communication strategy and to find out how far government messages were reaching. A number of challenges were identified, including; lack of information and standardisation for the local Government budget process, the cost of availing information in diverse languages, and the sometimes contested status of local monitors (which will be rectified when the Public Information Bill is passed into law. Stronger civil society and increased literacy, especially for women, will also help to strengthen the public's ability to access information. Poor women have noted the difficulty in accessing information by radio because men control the use of the family's radio. When information boards are used to circumvent this problem, illiteracy hinders information ow.

Government will expand the approach of public information strategies in other sectors. Public information is particularly critical for such areas as preventive health and agricultural extension, where the service itself consists of the transfer of information.

\section{Priority actions for public information}

- Government will expedite the enactment of the Public Information bill.

- The Medium term Communication plan will be reviewed every two years.

- The inter-agency communication committee, established last year, will be strengthened.

- Government will promote the role of local budget monitors including Local Councils at village or parish level, organised citizen's groups or individuals. Government is committed to providing the necessary information to such groups.

- The District Information Officers will be supported to perform a more effective function. 


\section{Decentralisation}

Overview

Decentralisation in Uganda has been implemented over the last 10 years, guided by the Local Government Statute of 1993, the 1995 Constitution and the 1997 Local Government Act. There are five tiers of local government in Uganda. Most executive decisions are taken at the LC5 (district) or LC3 (sub-county) level, although the LC1 (village) level has important responsibilities for instance in administering the LC courts. MOLG oversees the decentralisation process, and recommendations on revenue and fiscal mechanisms are made by LGFC.

Local authorities have the responsibility to deliver most of the basic services that Government provides. For this purpose, they are allocated conditional grants by central Government in addition to the unconditional and equalisation transfers that are made. Most conditional grants are assigned to specific services, but the grants under the PMA and the LGDP can be allocated by LC3s to a variety of activities at the LC's discretion, subject to guidelines under each programme. Districts also raise revenues mainly from the Graduated tax, which is raised from individuals in a 4-band structure between Shs. 3,000 and Sh. 100,000, and market dues whose collection is often contracted out to the private sector.

While improvements in fiscal mechanisms and the publication of fiscal transfers have led to a dramatic improvement in the passage of funds to their intended destinations, local autonomy in fiscal allocation has been slower to develop. Unconditional transfers and revenues are small, relative to conditional grants, and they are often used mainly to pay administrative costs, including councillors' allowances, rather than to deliver services tailored to local needs.

There are some encouraging signs of progress in improving service delivery under decentralisation. For example, decentralised primary school classroom construction has demonstrated substantially reduced unit costs and faster construction rates than previous centralised programmes. The economic evaluation of the LGDP quotes research by UNCDF, DANIDA and others showing Social Returns on Investment (SRI) for investments by local governments ranging from $12 \%$ to over $180 \%$, which compare well with returns on central government investment.

In the further implementation of decentralisation, Government's objective is to increase local autonomy while strengthening upwards and downwards accountability, so that the autonomy is used to meet the needs of the population.

\section{Managing local Government}

The Ministry of Public Service in collaboration with the Ministry of Local Government commissioned a study in 2002 on the restructuring of Local Governments, taking into account their increased responsibilities as a result of the decentralisation process. The study proposed three model structures. The report is now before Cabinet and once approved, Local Governments will be free to choose any of the models, based on individual needs and circumstances. It is envisioned that restructured Local Governments 
will be capable of delivering services in a more efficient and cost-effective manner. Fiscal implications will need review.

Other important management issues include the establishment of standards for service delivery, the inclusion of adequate time in the planning cycle for the poor to be properly consulted in the development of District Development Plans, and the burden of workshop attendance due to uncoordinated central Government and donor initiatives.

Some laws, including the Country and Planning Act 1964, the Public Health Act, the Trading Licensing Act, and the Markets Act need to be revised to make them consistent with the Constitution and the LG Act 1994. Review of the legislation which governs poverty reduction activities such as the Local Government Act 1997, LG Financial and Accounting Regulations 1998, the Internal Audit manual, the Town and Country planning Act 1964, the LG Rating Decree 1979, the Trading Licensing Act 1964 and the Markets Act 1942 among others will be conducted to bring them in line with the changing environment.

Urban planning presents a particular challenge. Capacity for urban planning in LGs is weak. Orderly infrastructure development and sanitation are being neglected as a result, and the urban environment is being degraded. MWLE and MOLG have prepared an Urban Planning Bill to provide a legal framework. In some countries, interventions designed to improve the quality of life have had the perverse effect of making the poor worse off because they impose standards that the poor cannot meet and therefore effectively make their existing structures illegal. Government will therefore seek to identify forms of standards and planning that will enhance the quality of life in urban areas without presenting the poor with unaffordable requirements.

Government has implemented measures of affirmative action in LGs. There is a legal requirement that $30 \%$ of the Parliament and Local Councils is comprised of women representatives in addition to provision for representatives of youth and people with disabilities. This has produced a major increase in the political representation of women, but this does not apply to administrative positions. In Kabale out of the 19 sub county chiefs there was only 1 woman, out of 7 Head of Departments there was only one woman, of the 41 Parish chiefs, there were only 2 women.

Affirmative action at the local level can reduce domestic violence, increase confidence amongst women, and strengthen their access to land by women. Three main constraints are low literacy/education levels, negative attitude by husbands, and domestic chores and family responsibilities. The PPA2 found out that women were more critical of the LC1 than men. Sometimes men look down on the women representatives and hold meetings/ take decisions without them. In Moroto, men maintained that whatever they decided in the LC1 was 'for the good of the whole community', so they could afford to ignore the women's views.

Project-based experience has shown that children can participate actively in community decisions. These experiences will be used to encourage greater participation by children. 


\section{Priority actions}

- Government will expedite the process of restructuring Local Governments in order to produce structures which are affordable appropriate and responsive to needs of the population.

- Enhanced planning processes will be introduced through the use of the Harmonised Participatory Planning Guidelines (HPPG) in Local Governments.

- Government will revise the legal framework for local governments.

- Government will seek passage of the Urban Planning Bill.

- MOLG will work with MGLSD to implement the Gender Mainstreaming Strategy in Local Government

\section{Fiscal decentralisation}

The Fiscal Decentralization Strategy (FDS), which was adopted in 2002 and is currently being piloted in selected LGs, includes a number of measures to increase allocational autonomy for local governments, particularly on the development budget, as well as simplifying and streamlining the transfer system. The number of transfers per month will be reduced from nearly 30 to only a handful, basically divided between a development transfer and a recurrent transfer. Under the LGDP, LC3s allocate resources to investments of a public goods nature. The PMA non-sectoral conditional grant is available for activities that contribute to the productivity of agriculture. Government is considering streamlining these two mechanisms.

\section{Priority actions}

- The Fiscal Decentralisation Strategy will be rolled out to all local governments over the medium term if the pilots prove to be successful.

- LGDP will be extended throughout the country and mainstreamed into the FDS.

\section{Geographical allocation of local Government transfers}

The Local Government Finance Commission (LGFC) has recommended revisions of the allocational formulae by which conditional grants are allocated across districts. Major elements include population, area, and the existing level of coverage or unserved need.

Three issues for the geographical allocation include:

- Equalisation grants are currently a very small share of the total allocation

- There is no allowance for poorer districts to pay higher wages or other incentives for staff to come from other parts of the country.

- There is no allowance for insecurity; while this is hoped to be a temporary problem, it imposes some extra costs on service delivery.

\section{Priority actions}

- Government will continue to review allocations to ensure that they address the need of less advantaged districts

- Government will examine the exibility of transfers to insecure districts. 


\section{Local Government Revenue generation}

Fiscal autonomy will also be increased if local Government revenues are enhanced. However, local government revenues have recently declined, leading to difficulties in operating basic administration and meeting co financing obligations under various programmes.

Like other forms of taxation, local taxation should be designed to raise revenue as efficiently and equitably as possible. Equity is usually measured by examining the incidence of the taxation to see whether the poor pay a lower proportion of their income in tax than the better off. Efficiency requires that the pattern of production and consumption should be disturbed as little as possible by the tax.

It is sometimes suggested that local taxation should finance most of the operations of local authorities. This is impractical. In most systems of Government, including those of highly developed economies, local governments depend on transfers from the centre generated by centrally collected taxes such as income tax, VAT and import duties. However, there are some forms of taxation that can be efficiently collected at the local level and the use of these taxes helps to generate a sense of local ownership and accountability.

\section{Graduated tax}

The structure of G-tax has been simplified and in principle G-tax could be a progressive tax. However, in practice there are serious problems in the administration of the tax. First, mixed signals from leaders have given many people the impression that the paying tax is optional. Secondly, its assessment is very poor; some rich people get away with not paying the highest band, while some poor people are forced to pay a higher band than they should because the appropriate tickets are not available. Thirdly, the administration of the tax is often publicly humiliating and the costs of supporting those who are jailed for default are not negligible. Lastly, administration of the tax diverts local administrative staff from productive work.

As a result, G-tax has been performing very badly. First, collections declined from Sh. 67.9 Billion in 1997/98 to Shs.36.9 Billion in 2001/02, and the share of G-tax in local revenue fell from $75 \%$ to $51 \%{ }^{17}$. Secondly, the tax is regressive in effect though not in design. Whereas the bottom quartile pay $2.7 \%$ of their income as G-tax, the richest pay just $1.1 \%^{18}$. No other tax in Uganda is so regressive.

\section{Market dues}

Local governments are encouraged to tender out market dues to private contractors. However, there are some concerns about this policy. First, the dues constitute a widely varying share of the product price on different products, producing possible distortions in incentives. Secondly, they fall more heavily on small traders than large traders. Thirdly, and most seriously, there is serious evidence that the prices paid by contractors for the tender are much less than the revenue potential of the tender, suggesting that there is a lack of competition or transparency in the process of awarding tenders ${ }^{19}$. 


\section{Property taxes}

Many countries raise property taxes locally. In Uganda, taxes on property may be more acceptable if paid at a local level. Hitherto, property rates have been limited and restricted to urban areas only. A Local Governments Rating Bill has been developed to repeal and replace the Local Government Rating Decree of 1979. The Bill will decentralise the administration and collection of property rates, and will allow rural Local Governments to levy and collect property rates on commercial and industrial properties in rural areas.

\section{Priority actions}

- Using the results of the study into Best Practices in Local Revenue Enhancement and the Local Taxation study, Government will work with local authorities through LGFC to improve methods of revenue collection.

- The aim of the reforms will be to collect tax equitably and efficiently, as well as increasing local Government revenue.

- Particular attention will be given to evidence of collusion in the award of tenders and the poor performance of the G-tax in both collection and incidence.

- Government will keep the need for further legal reform under review.

\section{Managing human resources in the public sector}

\section{Overview}

During the implementation of the Rehabilitation and Development Plan, 1987/19881990/91, Government realised that the Public Service as its implementing machinery had become inefficient, ineffective, irresponsible and demoralised and was generally not performing. Government therefore introduced the first Public Sector Reform programme from 1991 to 1996, and has increasingly focused public sector reform on implementation of PEAP priorities. The second phase of public service reform ran from 1997 to 2002, and a revamped strategy for public service reform is currently being developed.

Over the last few years, the size of the public service has expanded because of recruitment of teachers and health workers. It can be seen that most of the wage bill is taken up by the needs of service delivery, with the army and teachers being the largest single component. Administration of the central government is much smaller, being included in the 'other' category which comes to 111 billion shillings. 
Table 6.6: Public service establishment by category

\begin{tabular}{|l|c|}
\hline \multicolumn{1}{|c|}{ Category } & Number \\
\hline Central ministries & 6,576 \\
\hline Local government & 47,999 \\
\hline Police & 15,313 \\
\hline Prisons & 2,996 \\
\hline Teachers & 15,6782 \\
\hline Hospitals & 2,575 \\
\hline judiciary total & 1,381 \\
\hline Other & 4,249 \\
\hline \multicolumn{2}{|c|}{} \\
\hline
\end{tabular}

Note: the army is not included.

Source: MoPS 2004

Political appointees (including ministers, advisors, MPs and RDCs) also impose a significant cost, which has been estimated at 34 billion shillings a month. Government also spends a considerable amount on human resources through the development budget.

\section{Achievements and challenges in human resource management in the public sector}

Over the last few years, Government has expanded the number of people employed to deliver basic services, while restructuring central ministries in light of their new role under decentralisation. Payroll management has improved. For instance, the average time needed to access health workers and primary school teachers on the payroll has been reduced from 7 months to just 1 month. Meanwhile, results-oriented management has been introduced in several ministries to facilitate better performance management.

However, several challenges remain:

- Effective management of the public service without adequate remuneration and incentives. This has adverse consequences on output and quality of service delivered.

- Pay in senior technical and administrative positions in the civil service is believed to be considerably lower than what these staff could earn in the private sector. Consequences may include high turnover, poor performance or no transparent behaviour.

- Pay at other levels has also been estimated to be below levels available in the private sector, with various negative consequences.

- Supervision and performance is inadequate at various levels. For instance, in the education sector supervision is funded out of district revenue and is therefore under resourced ${ }^{20}$.

- Staff absenteeism is widespread in some cadres. For instance, studies of human resources in schools have found that the headmasters are often absent and hence other 
teachers also get away with absenteeism. A World Bank study ${ }^{21}$ found that $26 \%$ of teachers were absent; similarly, $35 \%$ of primary health workers were absent. Teacher absenteeism seems to be worse in Uganda than in other comparable countries.

- There are massive differentials in pay between autonomous agencies and commissions and the public service itself. For instance, in 2000/1 it was found that drivers in six commissions, including their allowances, earned between $58 \%$ and $162 \%$ more than the pay of an economist in the public service ${ }^{22}$.

- The amounts spent on consultancy on the development budget are remarkably large in proportion to the amounts spent on the core civil service on the recurrent budget.

- Payroll management is deficient. For instance, in 1998 9.2\% of teachers were found to be 'ghosts'; even in 2003, the tracking study has found that about 205 of teachers are irregularly on the payroll.

- Human resource planning has mostly not been systematic. Most sectors do not have a systematic way of accounting for the effects of HIV/AIDS on their staffing or of predicting future requirements of staff as a result of HIV.

- Training institutions in some sectors have high failure rates, reducing the availability of qualified staff.

- Training courses and workshops absorb significant amount of money and staff time, and are sometimes used as an incentive without being suited to the training needs of the institution.

- Government has accumulated pension arrears and still has a recurrent deficit on terminal gratuities.

- Entrants into the civil service are not always given enough responsibility or stimulus.

- Some districts find it very difficult to recruit staff.

- There have been some policy changes over time that have caused difficulties in the management of human resources.

- The effect of HIV /AIDS on productivity in the public service.

Government has developed the Public Service Reform Strategy 2002-2007 to meet these challenges. This strategy has four components: performance management, capacityenhancement, public sector remuneration, and efficiency and cost control.

\section{Strengthening performance management}

In order to improve performance throughout Government, Result-Oriented Management will be extended and linked with the budgetary process (so that civil servants are assessed on their ability to deliver the outputs specified in the budget). Using the service delivery surveys, Government will establish, publicise and monitor service standards for agencies in the public sector. An open and transparent system of staff appraisal, associated with a rewards and recognition scheme, will be extended throughout Government.

These reforms need to be accompanied by a better culture of management in the public service. Ministries and agencies need to identify the capacities that they expect newly recruited staff to acquire on the job, and ensure that staff are given assignments appropriate to their level of qualification. It is also important, both for capacity-development and transparency reasons, that staff are not kept in the same post for too long. 


\section{Capacity enhancement}

The public sector reform includes capacity enhancement from both the demand and the supply side. On the demand side, Government has engaged in many capacity-building efforts. There are some conditions for the success of these initiatives:

- Incentives and opportunities

- The right people getting the training -hence embed in a sectoral strategy and the learning plan as part of the overall system of performance appraisal.

- The skills actually being needed.

- Skills closely linked to the needs of ministries and agencies.

- Learning on the job needs to complement any formal training effort and not be disrupted by it.

Capacity-building is best delivered in the context of sectoral strategies. While a specific fund has been proposed, in general sectors should find resources within their sectoral envelopes. Except for the very early stages of sectoral plan formation, this should be feasible as savings are made from reduced projects. Capacity-building initiatives will be mainstreamed into sectoral programmes and will re ect the demands of the sectors themselves. Experience shows that this leads to a more economical use of expensive resources such as consultancy.

On the supply side, Government will build capacity in the following key areas: payroll management, IFMS, records/archives management, communication and procurement.

\section{Priority actions}

- Development of a sector strategic plan

- Government will prepare a comprehensive capacity building policy for the public service.

- Sectors will mainstream capacity-building in their strategies.

- Having appropriate structures and systems that will facilitate efficient and affective service delivery.

\section{Public sector remuneration}

The objective of pay reform is to provide incentives that will enhance performance and hence improve service delivery. Therefore, the implementation of pay reform must prioritise areas where there are recruitment and retention difficulties, or where improved pay can be linked to improved performance or a change in job description.

In 1999-2002, Government commissioned studies of market comparison and job evaluation, which were used to develop a pay reform strategy. Under this strategy, it is planned to implement the recommendations of the job evaluation study over the next ten years. A single spine structure has been introduced, and the short-run challenge is to implement the recommendations of the job evaluation study, while in the long run the objective is to move towards market-comparable salaries. 
In the period 2000/1 - 2002/3, pay reform was focused on areas where problems of recruitment, retention or poor performance were being experienced: health in 2000/1 (which coincided with the introduction of free services and a major increase in patient numbers), middle and senior level managers and professionals including Engineers, Scientific Officers, Accountants, Agriculture Officers and Primary School Head teachers in 2001/2, and Systems Analyst/Programmers, Economists and Auditors. In 2003/2004 the Ushs.15 billion that was provided for the Public Service Pay Reform was used to harmonise the existing structures into a Single Spine Salary Structure.

For these reasons Government will continue to implement the PEAP pay reform strategy with special focus on (i) achieving the job evaluation salary targets for managerial, technical and professional cadres and (ii) preserving the purchasing power of public sector salaries.

Two areas requiring special attention are the best way of attracting and retaining qualified staff to work in remote areas, and developing a comprehensive pay policy for the public service that integrates the pay in executive agencies into the pay scale.

Government is also obliged to pay its pension obligations.

\section{Priority actions}

- Implementation of the Pay Reform Strategy will continue with special focus on (i) achieving the job evaluation salary targets for managerial, technical and professional cadres and (ii) preserving the purchasing power of public sector salaries.

- Government will either introduce hardship allowances or find other mechanisms to attract staff to hard-to-reach areas.

- Government will explore efficiency improvements such as allowance for double-shift teaching, removal of vehicles, etc.

- The need for, and impact of, increased pay will be monitored by examining rates of turnover, qualifications of staff, absenteeism and performance.

- Pay in agencies will be brought into line with the public sector where staff are of similar experience and calibre (this will involve careful assessment in each case). Modalities will be developed to strengthen the supervision of remuneration decisions in agencies.

- Government will develop and implement a schedule for paying off pension arrears.

- Pension Reform will be undertaken to (i) design and implement an affordable pension scheme; (ii) secure a pension fund by separating pensions from the general consolidated fund; (iii) eliminate anomalies in the pension scheme and to improve fairness and transparency; and (iv) protect pension awards which have accrued and have been granted.

\section{Efficiency and cost control}

The strategy for efficiency and cost control includes the rationalisation of costs and structures throughout the public sector. These issues are discussed in more detail in Chapter 8. The divestiture of non-core functions was intended to reduce costs; however, evidence on the performance of autonomous agencies suggests that they are sometimes more costly to run than equivalent Government departments. For this reason, divestiture will be pursued only where there is a specific rationale. 


\section{Making Government affordable}

A major challenge that confronts the various sectors in public sector management is the design of structures that are affordable in Uganda's circumstances. Government intends to meet this challenge in a number of ways, including the integration of projects into sectoral strategies and the MTEF and review of the functioning of autonomous agencies. These reforms, which are closely linked with the allocation of public expenditure, are discussed below in Chapter 8 .

\subsection{Public expenditure priorities for governance}

\section{Priorities for democracy and human rights}

This area of public expenditure includes: Parliament, the President's Office, State House, the Movement Secretariat, the Human Rights Commission, and the Electoral Commission. There is also expenditure on political institutions at the local level, funded out of the unconditional grant and local revenue.

Political governance needs to be funded, but the institutions need to be more modest in their expenditures and more disciplined in adhering to budgetary ceilings. There has, hitherto, been no sectoral strategy for these institutions, and some institutional development (e.g. the Parliamentary budget office and the Human Rights Commission) has been based on a project modality that needs to be integrated into a sustainable strategy.

Government will therefore aim to curtail expenditures in this area and explore the political feasibility of reducing the size of political structures while strengthening the capacity of the institutions concerned, particularly the Parliamentary budget office and the UHRC.

Areas of savings

National administrative structures have grown over time imposing a heavy burden on public expenditure.

- There is substantial central Government representation in the local governments, with RDCs at district level supported by assistant and deputy RDCs.

- a number of advisors have been appointed outside normal civil service structures.

- Cabinet and Parliament have both increased in size over time. Parliament had 82 members at independence and now has 305 . The Cabinet has more than 60 ministers compared with the constitutional provision for 21 .

As a result of this proliferation, the direct budgetary costs of political appointees (including advisors, ministers, MPs and RDCs) have been estimated at Shs 34 billion per annum. Indirect costs are also significant. The political structures therefore offer some opportunities for cost savings. Government will seek at least to curtail any further growth and if possible to reduce the scale of expenditure on the political system.

Increases in expenditure pressures have come from the proliferation of the number of district authorities, which have grown from 39 in 1995 to 56 now. Comparisons with other countries show that Uganda's local government system is unusually permissive in the process required to authorise the creation of new political structures. Districts can vote 
to subdivide and Parliament can approve this. In other countries, rigorous evaluations may be required, the decision may be left to an independent Demarcation Board, or there may be other legal safeguards ${ }^{23}$.

The Human Rights Commission does very valuable work, but is mainly project-funded. It is likely that some cost savings can be achieved by moving away from the project modality. The Electoral Commission receives large allocations in election or referendum years. This is an inevitable consequence of the democratic political system. However, cost savings may be possible in the modalities of elections.

\section{Priorities for JLOS}

As noted earlier, the reduction of crime, more humane forms of punishment and better enforcement of contracts are all important for poverty-reduction, but it is difficult to quantify the returns precisely. For instance, specific joint security operations such as 'Operation Wembley' have had an impact on specific crimes, but there is no easy way to measure the impact of crime prevention in general.

\section{Police}

About half of the sector's expenditure is on the police force. The police are currently both under equipped and undermanned, although their numbers are complemented by auxiliary forces. The police are in the medium term aiming to recruit 300-500 extra police a year, to deal with an estimated 150-300 natural wastage (due partly to AIDS). The police are in the long run aiming at a ratio of 1:600 police per head of population (based on international norms) compared to a ratio of about 1:1,700 if regular officers are included or as low as 1:1,015 if all officers are included ${ }^{24}$. The educational qualifications and discipline of the auxiliary forces are inadequate, and there would be significant costs of upgrading them.

There is also good evidence that the experience of crime deters economic investment at all levels of society and therefore perpetuates poverty. However, there is limited evidence that the impact of increasing police numbers of equipment will lead to a reduction in the crimes suffered by most households.

There are two more specific reasons for strengthening the police force. First, the country faces some newer forms of crime such as terrorism and money laundering that potentially pose a threat to national stability and international reputation that need to be combated by specialised police functions. Secondly, police responsibilities in the North will increase as responsibility for security is transferred from the army.

\section{Prisons}

Currently the national prison service has more than twice as many prisoners as the prisons were designed to hold. There are about 8 prisoners per warden (the international norm is 3). Only 13,300 of the 18,500 prisoners are fed by the prison service. Although the prisons directly affect only the 18,000 prisoners, the effects on these prisoners' families as well can be severe. Conditions in local authority prisons are even worse, as discussed in Chapter 6. The average cost per prisoner to the state of incarceration in Uganda is about 
$1,000,000$ shillings a year (and would rise if prisoners were better treated; the true cost of feeding is estimated at 750,000 shillings).

Hence more money is needed in the short run to support prisoners' welfare. In the long run, the needs will depend on the size of the prison population, which may be reduced by the introduction of community service (which could handle 10,000 cases a year) and the reduction of case backlog.

\section{Other aspects of the judicial system}

The proper functioning of the criminal and civil systems of justice will require the continued recruitment for the judiciary. Unfortunately, this is necessarily quite expensive and will have to be phased in over a period of years.

Some activities in the sector generate cost savings and therefore pay for themselves - e.g. the 'chain linked' initiative which is speeding the treatment of cases through the judicial system, and the introduction of community service as an alternative to imprisonment for minor offences, and the prison farm programme.

\section{Priorities for justice, law and order}

The highest priorities among under funded expenditures therefore appear to be the feeding of prisoners, prison farms, conversion of prisons into remand homes for children, and social welfare workers for adolescents no remand. Facilitation for the existing police force is also important in the medium term. Needs for the prisons will need review in the light of estimation of the likely long-run size of the prison population.

Some cost savings might be achieved by rationalising agencies in this sector. However, overall it is clear that the sector is likely to need extra resources.

\section{Priorities for the public sector}

This area of expenditure covers the existing sectors of accountability, public service, local Government, and parts of public administration (OPM and NPA). It is proposed to integrate these areas in a single sector, public sector management.

Expenditures in this area are justified by the need to improve the efficiency and effectiveness of public expenditure as a whole. It is important that these expenditures are themselves undertaken as efficiently as possible. Hitherto, one of these areas has developed a sectoral strategy to guide their expenditures, and hence expenditures in these areas have tended to be project-driven. The sector is also burdened by heavy arrears arising out of unpaid pensions. While it is harder to define unit costs for activities in this sector than in other parts of Government, it is important to find less expensive ways to achieve the efficient functioning of Government.

\section{Accountability}

Promoting accountability is clearly a public sector role; while civil society can play a part, it cannot remove the need for accountability to be monitored by public sector institutions. While the sector has developed a stronger sectoral approach over the years, there is still no sectoral strategy and the expenditure decisions have in the past been driven by immediate needs and projects rather than a long-term strategy. 


\section{Public service}

The main expenditure in this area is pensions. Expenditures in recent years are not enough to cover the demands of gratuities let alone to meet the arrears. Government also faces an accumulation of salary arrears estimated at Shs. 18 billion for teachers and health workers. Further arrears are being accumulated by the non-payment of terminal gratuities. These are estimated at Shs. 17 billion annually.

For this reason Government's main priority within the sector is the meeting of current obligations on terminal gratuities and the repayment of pension arrears. This will be phased over the medium term.

The design and implementation of public sector pension reform, introducing a selffinancing contributory system for future pension obligations, is intended to control the growth of pension commitments. Past simulations indicate that the pension obligation could grow alarmingly unless corrective action is taken. It will be important to develop estimates of the future expenditure implications of already existing commitments (i.e. the pensions that will be owed to existing civil servants and teachers when they retire, based on the years they have already worked).

Public service reform will need extra funds, specifically for pay reform, investments for a national records and archive centre and the Integrated Personnel and Payroll systems. However, these proposals will need to be phased over time and some cost savings may be possible.

Another area where more expenditure may be justified is in the management of URA because of the need to improve tax administration.

\section{Local Government}

Local Government courts are a fundamental aspect of the judicial system and will need further support and strengthening, for instance in helping them deal with cases of domestic violence. 


\section{Human Development}

\subsection{Introduction}

A healthy and well-educated population is both a necessary condition for development and one of the central objectives of development. In Uganda, households' economic status is linked with their health and educational status as well as their social capital. In 2003, the lowest income quintile had the highest proportion (35\%) of household members with no formal education compared with $15 \%$ in the middle quintile and 7 percent in the highest quintile1. Despite the increased educational attainment of the population, the economic returns to education did not increase during the 1990s2. Households continue to name ill health as a cause of poverty more often than any single factor ${ }^{3}$. So the achievement of human development is central to the reduction of poverty.

The status of health and education also affect the overall rate of economic growth. Some studies have found a very dramatic impact of health on economic growth. One study found that more than half of Africa's growth shortfall vis á vis that of East Asia was explained in terms of disease burden, demography and geography, rather than by the more traditional macroeconomic variables ${ }^{4}$. Other studies have found a very powerful impact of malaria on per capita income, even halving per capita income in the long run. ${ }^{5}$. A recent study ${ }^{6}$ finds that AIDS reduces per capita growth by an effect of $0.7 \%$ on average. Studies have also found evidence that the level of secondary education in particular in uences the growth rate.

On a similar note, water is a key strategic resource, vital for sustaining life, promoting development and maintaining the environment. UPPAP II demonstrated the links between lack of access to safe water and sanitation and poverty.

Finally, participation, protection from abuse and neglect, and access to information are necessary conditions for the well-being of a population and human development. Several studies $^{7}$ and analyses of poverty have highlighted the need to address participation and protection in order to address poverty. These studies all make a strong case for the holistic conceptualisation of poverty to include participation and protection. Uganda has opted to have a wider definition of poverty to include voiceless ness, social exclusion and lack of information. The lack of participation and protection from abuse, violence, neglect, discrimination and exploitation results from, and leads to poverty. The remainder of this chapter focuses on progress and challenges in human development, followed by intersectoral issues in human development (i.e. nutrition, sanitation, HIV/AIDS, and fertility), before a detailed discussion of individual sectors.

\section{Progress and challenges in human development}

During the first and second PEAPs, Government invested in a huge expansion of primary education. It also gave increased attention to adult literacy under the second PEAP. UPE's very success in increasing access poses challenges. Despite the enormous increase in numbers of children in school, the numbers successfully completing primary education 
have grown more slowly. The full achievement of UPE requires, not only that children start school, but also that they move through the whole system and graduate from P7. This requires improved retention and quality. In addition, because of the increased number of primary school children, there is need for expanding post-primary education in the medium term.

As set out in Chapter 2, child health outcomes did not improve during the 1990s. To confront the challenge of child and maternal health, Government has prepared an Infant and Maternal Mortality strategy ${ }^{8}$. The strategy re ects the understanding that health outcomes are not the sole responsibility of the health sector. The key interventions in this strategy are:

- Improving the quality of health care and treatment of malaria

- Sanitation

- Community mobilisation

- Family planning

Access to water supply improved substantially during the 1990s and early 2000s. However, balancing the roles of public and private sectors in urban and rural areas remains of critical importance.

Finally, the achievement of human development rests on the mobilisation of communities. All Government's major programmes of service delivery can work only if households themselves play their part - sending children to school, participating in the location and maintenance of water supplies, taking preventive health actions and using the health services when they are needed. The social development sector has the responsibility for supporting community mobilisation through the work of Community Development Workers and support to functional adult literacy.

\section{Human resources for economic transformation}

Changing patterns of employment will equally require changing patterns of skills. To some extent, this happens through the market. As people spot economic opportunities, they invest in relevant skills through private sector training. However, Government is a large player in the supply and demand for education. In particular, Government intends in future to target educational funds at the tertiary level at economically productive disciplines. These decisions need to be informed by projections of the likely evolution of demand and supply of the relevant skills.

Currently in Uganda, self-employment forms the overwhelming majority of employment. However, among secondary and tertiary graduates, those in wage employment are generally better off than those in self-employment. To accelerate the process of economic growth, it is desirable that graduates at all levels are equipped both for self-employment and for wage-employment. Over time, wage employment will play an increasingly large part in driving poverty reduction, but this requires the emergence of a larger group of successful entrepreneurs to generate employment. 
The balance between vocational and academic education within the post-primary sector, and the relative public sector role in both of these, are important areas for policy. The 2003 Labour Force Survey found that 93\% of people with vocational training are active in the labour force, a higher proportion than for any other group. This suggests that the skills provided in vocational training are being found useful in the market. Government aims to encourage students to enter this sector after the first four years of secondary education,

Planning for human resources within each sector is the responsibility of the sector, and will be strengthened by the availability of a Long-Term Expenditure Framework which projects the overall resource envelope for future years. Those sectors that provide skills to the economy - including education, agriculture, and social development will aim to ensure that the skills provided by the sectors match national economic needs. As the capacity for projecting human resource needs is strengthened, sectors will need to give consideration to the effects of HIV and other causes of adult illness and death on the availability of human resources.

\section{Inter-sectoral issues in human development: nutrition, sanitation, AIDS and fertility}

\section{Nutrition}

Nutritional indicators in Uganda remain poor. In 2001, 39\% of children less than five years were stunted, compared to $38 \%$ in 1995 . Poor nutrition is a result of low incomes, unequal bargaining power within the household, the heavy burdens on women's time, and poor health. All of these factors are addressed by actions in the health sector as well as in actions to promote higher incomes, discussed in Chapter 4. There are some specific concerns with regards to the kind of crops grown; for instance, matooke is highly bulky and hence children whose diet contains a high proportion of matooke can face a risk of malnutrition. Government will promote awareness of the nutritional properties of different foods, with cooperation between the agricultural and health sectors.

Government is preparing a Food and Nutrition Bill, accompanied by a strategy and an investment plan. As with other cross-cutting strategies, it will be necessary for the proposed actions to be mainstreamed into sector plans.

\section{Sanitation}

The increased emphasis on sanitation, as re ected in the Infant and Maternal Mortality Task Force Report (MoFPED, 2004), is being followed up through implementation of a Memorandum of Understanding reached in 2001 between MoES, MoH and MWLE which allocates responsibilities across sectors. An inter-sectoral Sanitation Working Group (SWG) has been established (Dec. 2003) to provide national co-ordination of all stakeholders in Hygiene Promotion and Sanitation. As Secretariat to the SWG, the Environmental Health Division in $\mathrm{MoH}$, is cooperating with the Directorate of Water Development in MWLE, MoES and MGLSD to revitalise Best Practices in hygiene promotion and sanitation through the establishment of Test Model areas in selected districts. A number of districts (most notably Dubane Sub-county in Busia district) have already achieved considerable success with their Home Improvement Campaigns. Such 
good stories about "total sanitation" (achieving a faecal-free environment combined with hand-washing) are in turn being used as part of an advocacy campaign to expand hygiene promotion and sanitation to all other districts. Following the EHD hosted Sanitation Conference (Sep. 2004) every District Health Inspector has since prepared an activity plan to test model new approaches towards achieving hygiene and sanitation in their respective districts. The GoU/Donor Joint Sector Review for the Water and Sanitation Sector (Sep. 2004) has an Undertaking (2004/05) to support improved district integration of existing resources through establishment of District Water and Sanitation Coordination Committees (DWSCCs).

Far too many children still die of diseases which would be preventable by better hygiene and sanitation. The key challenge in sanitation is to break the faecal-oral route to disease transmission. To achieve this, safe disposal of all human faeces (especially children's stools) needs to be combined with hand-washing. While the presence of latrines is important, hygiene promotion towards achieving positive behaviour change is also essential if sanitary practices are to improve and child health outcomes to benefit. There have been several encouraging international experiences like Social Marketing (to encourage hand-washing and the use of soap) and Community Health Clubs (that encourage social cohesion towards adoption of a raft of improved behaviour changes) that Uganda should benefit from.

Government will therefore aim to use the existing administrative structures at district level, supported by the health, water, gender and education sectors, to mount precisely focused and integrated hygiene and sanitation campaigns. Such campaigns, focusing down at the household level, may also productively be linked with other public health interventions such as improved nutrition and precautionary actions against malaria.

Sanitation in IDP camps is a particularly urgent issue, because major inadequacies in sanitation are causing outbreaks of disease such as cholera.

\section{AIDS in Uganda}

Uganda has been one of the countries hardest hit by the AIDS epidemic. However, significant progress has been made in reducing prevalence, which now stands at about $6 \%$ nationally. Despite doubts over the accuracy of the current estimate of the prevalence rate, as a result of constraints on HIV/AIDS reporting and uneven coverage of sentinel sites (UAC, 2003), there is no doubt that Uganda has succeeded in providing a significant decrease in HIV prevalence rates over the last decade. This partly re ects the deaths of many people infected by HIV/AIDS, but also a marked reduction in new transmissions.

This has been achieved by a mixture of methods, including abstention, fidelity and condom use. Although this compares favourably to most countries similarly af icted, many people are still affected by the epidemic in Uganda with devastating health, psychosocial and economic consequences. It is now estimated that over one million people (of which 100,000 are children under the age of 15) are currently infected and probably over a million have already died from HIV disease. The risk of mother to child transmission (MTCT) remains at 15-25\% (UAC, 2004). 
Consistent commitment at national and decentralised level to combating HIV and AIDS remains critical. There is need to commit locally generated funds at both national and district levels to HIV and AIDS interventions. A crucial part in dealing with the consequences is also being played by civil society and households themselves.

\section{Prevention}

Continued emphasis on public information is needed. Education is key to the fight against AIDS. It can help eliminate prejudice and myths about how the disease is spread and avoid the social stigma associated with it. Studies have shown that educated women are more likely to know how to prevent HIV infection, to delay sexual activity and to take measures to protect themselves when they do become sexually active than non educated women. A recent analysis suggests that if all children received a primary education, the economic impact of AIDS could be greatly reduced. If universal primary education was fully implemented, around 700,000 cases of HIV in young people would be prevented every year (UNHSII, 2002-2003).

\section{Impact Mitigation}

In addition to prevention, HIV/AIDS policies have increasingly emphasised the mitigation of impact and the universal provision of ART. Indeed, AIDS is a development issue: there is an interaction between HIV and poverty, and re ects inequalities between different population groups.

At national level, HIV/AIDS robs sectors of both skilled and unskilled workforce, and diverts meagre resources. It increases absenteeism from work due to frequent illness of staff or/and nursing of sick family members leading to decreased productivity. The impact of HIV on labour supply has clearly affected agricultural growth in some regions, and this has had some impact on overall growth and on inequality. This translates to reduced acreage and thus food insecurity. The sharp increase in the proportion of investors reporting that AIDS is a constraint reported in Chapter 3 indicates that the effects on growth in industry and services may be becoming more severe.

The epidemic also affects public sector service delivery, household savings and the intergenerational transmission of knowledge, and imposes a greater burden on the elderly while reducing their economic security. By killing primarily young adults, AIDS does more than destroy the human capital; it also deprives their children of the requirements (parents' care, knowledge, and capacity to finance education) to become economically productive adults. This weakening of the mechanism through which human capital is transmitted across generations becomes apparent only after a long time lag, and it is progressively cumulative in its effects.

HIV/AIDS also affects development at the micro level. Particular social groups like children, OVC, women, refugees and internally displaced people have been specially hit by the epidemic due to their disadvantaged position and low incomes. It is estimated that Uganda has over 2 million orphan children, around 50\% of whom are due to AIDS. This number is expected to increase over the next decade, increasing the risk of children becoming street children, or a target for abuse and exploitation. 


\section{ARV diffusion}

Government has decided to provide free treatment for HIV/AIDS. The treatment will be accompanied by close monitoring, because if patients do not adhere to treatment protocols resistance to drugs will emerge. Experience shows that patient adherence to treatment regime is more achievable in urban than rural settings. However, this requires very close follow up. Recent data suggest that close to 30,000 clients are receiving antiretroviral treatment (UAC, MoH 2003). While this is evidence of clear progress, only $6.30 \%$ of those urgently in need of HAART in Uganda are actually receiving it (UAC, 2004). In Uganda to date, close to 150000 require ARV treatment. The national target is to have $50 \%$ of them on treatment by the end of 2005 (UAC, 2004). This requires enormous commitment to capacity building with additional training of health care workers and development of a stable health care infrastructure.

Currently despite the national policy to provide free ARV to all those in need, at household level the cost of AIDS treatment (when paid out-of-pocket) competes with other crucial expenditures, such as food, shelter, and educational expenses. The burden of AIDS care falls heavily on the most vulnerable members of the household, such as orphan children. Even if treatment is subsidized, there are other costs associated with treatment such as cost of transport to the distributing center for treatment, costs of other medications, potential loss of income during times of illness, and diversion of funds toward healthcare.

This is a dynamic and a critical time in Uganda as HIV treatment is expanding. Questions remain as to how to ensure sustainability and equality in distribution throughout the country as treatment is rolled out. With the vast majority of Ugandans living in rural settings it is critical that they too have equal opportunity to access these life prolonging medications. Thus, the existing health care infrastructure must be strengthened in this landscape, to ensure sustainable and favorable treatment outcomes. Multi-district wide programs represent potential targets for embracing the expanded response for antiretroviral treatment in Uganda. Indeed, the majority of antiretroviral treatment has been limited to urban settings and private, self-paying patients. This illustrates the fact that the distribution of ARV requires government planning as market forces left alone fail to take into account the social costs of the epidemics.

\section{Mainstreaming and coordination of AIDS policies}

Actions to prevent HIV and the treatment of AIDS are the responsibility of all sectors particularly education and social development and health, while treatment issues are clearly the domain of the health sector. Women's vulnerability both socially and physically to HIV compounds existing gender inequality and demands greater commitment and involvement of men in prevention and care initiatives. Actions to deal with the consequences of AIDS affect all sectors, and need to be factored into human resource planning in each of them. The particular problems of orphans are discussed under the social development sector.

The National Strategic Framework (NSF) guides the implementation of all the policies on HIV/AIDS and its mainstreaming into the development of sector policies. Most sector line ministries and districts have designed integrated HIV/AIDS strategies and developed 
appropriate budget lines. In addition, resources have been mobilised by both government and civil society to help run HIV/AIDS programmes at district level, and help the poor access such services. The coordination of the effort to fight the epidemic, both in the public and private sector, is guided by the "Three Ones" principle: One national coordinating authority with a broad based mandate in this case Uganda AIDS Commission, One national framework for AIDS action that forms the alignment of all stakeholders, and One national monitoring and evaluation system.

\section{Key Priorities}

- To reduce HIV prevalence by $25 \%$ by 2006

- To mitigate the impact of HIV/AIDS: to improve the quality of life of people living with AIDS (PHA); to mitigate the psychosocial and economic effects of HIV/AIDS; to mitigate the impact of the epidemics on the development of Uganda

- To strengthen the national capacity to coordinate and manage the multisectoral response to HIV/AIDS

\section{Fertility}

As chapter 2 discussed, large family size is a significant cause of poverty. The control of fertility is directly handled by the provision of reproductive health services by the health sector. However, there is a need for public debate on the issue, since the consequences of large family size and the high burden of the dependency ratio are not generally understood in Uganda. While preserving the freedom of individual choice and respecting diverse religious and cultural values, Government will promote an extensive public discussion of the issue. There are potential links with other sectors such as education and adult literacy.

\subsection{Education and Skills Development}

Investment in education contributes to the accumulation of human capital, which is essential for higher incomes and sustained economic growth. Evidence in Uganda shows that education is both a privately and socially profitable investment. Estimated rates of return to education in Uganda increased in the 1990s for all sub sectors, partly because self-employment opportunities outside agriculture opened up ${ }^{9}$. Based on incomes alone, social returns to primary are highest at $24 \%$, followed by tertiary $(13 \%)$ and then secondary $(10 \%)$. Non-income returns are also significant; parental education is a powerful factor in child survival, and education above the primary level is associated with lower fertility. The total fertility rate for women with secondary education is only 3.9 , in comparison with 7.9 for those with no education and 7.8 for those with just primary education ${ }^{10}$. Women with secondary education are also much more likely to receive antenatal care and have deliveries attended by a health professional. Education can also play a critical role in strengthening civil institutions and building a democratic society, empowering women and protecting the environment.

Government is committed to achieving the MDGs on universal completion of secondary schooling by 2015 and eliminating gender disparity in both primary and post-primary by 
2005. Support to post primary education to increase access, quality and relevance is being intensified to sustain the gains from UPE.

The education sector in Uganda comprises the Ministry of Education, several agencies and the extensive network of private and public educational institutions. Most of the sector's funds are spent on primary education, which is delivered by the districts. The planning of public expenditure, however, has to take into account the possibility that education would take place even without public intervention. For this reason, Government will aim to focus its resources on those who would otherwise not access education, particularly secondary and tertiary education, where universal access is not yet achievable.

The education sector therefore faces the twin challenges of delivering primary education, according to the aspirations of UPE, and strengthening the performance of higher levels of education. The medium term strategy is therefore to improve the quality of education, expand post primary education and skills development opportunities, further decentralise post primary education services and increase the participation of the private sector in the provision of post primary education. This strategy is underpinned by the awareness for the need to adopt a national approach to human resource development that is based on the manpower requirements of the national growth path.

Over the next ten years, Government wishes to achieve the following: (i) increase the transition from primary to senior one from $50 \%$ to $80 \%$ while transition to BTVET falls from its current rate of $10 \%$, (ii) reduce transition from S4 to S6 from the current rate of $77 \%$ to $40 \%$, (iii) increase transition from S4 to BTVET from the current $10 \%$ to $50 \%$, and (iv) a drop out rate of $10 \%$ from S4 into the labour market. Thus, most children would proceed from primary school to secondary school, and after 4 years $40 \%$ would continue to higher secondary school, while half would proceed to vocational education.

Progress in implementing this strategy will depend on the level of resources available and on the efficiency with which resources are targeted at those who could not otherwise go to school, as well as efficiency improvements such as an increase in post-primary class size.

\section{Primary Education}

Articles 30 and 34 (2) of the Constitution provide for the right to basic education for every Ugandan. The 2025 Vision for Uganda's development formulated in 1997 incorporated a commitment to education as a development priority, giving rise to the Education Strategic Investment Plan (ESIP) 1997-2003 framework. Under the $1^{\text {st }}$ and $2^{\text {nd }}$ PEAP, Universalizing Primary Education was Government's chief education priority and is therefore central to the current ESIP.

Sectoral indicators shown in Table 7.1 below show advances in line with the targets for most indicators. Enrolments have been increasing steadily at all levels of primary education as shown in Annex Table 7.1. 
Table 7.1: Key indicators of access and quality in primary education

\begin{tabular}{|c|c|c|c|c|c|c|}
\hline Indicator & 2000 & 2001 & 2002 & 2003 & $\begin{array}{l}\text { Mid-term } \\
(2006)\end{array}$ & $\begin{array}{l}\text { Lo o } g \text { - } \\
\text { term }\end{array}$ \\
\hline $\begin{array}{l}\text { Primary enrolment (administrative } \\
\text { data) }\end{array}$ & $6.6 \mathrm{~m}$ & $6.9 \mathrm{~m}$. & $7.3 \mathrm{~m}$ & $7.6 \mathrm{~m}$. & & \\
\hline $\begin{array}{lll}\begin{array}{l}\text { Gross } \\
\text { data) }\end{array} & \text { enrolment (administrative }\end{array}$ & $128 \%$ & $130 \%$ & $126 \%$ & $127 \%$ & & \\
\hline Net enrolment (administrative data) & $116 \%$ & $87 \%$ & $89 \%$ & $100.7 \%$ & & \\
\hline $\begin{array}{l}\text { Net enrolment (household survey } \\
\text { data) }\end{array}$ & $84 \%$ & & & $86 \%$ & & \\
\hline Female share of enrolment & $49 \%$ & $49 \%$ & $49.2 \%$ & $49.4 \%$ & 50.1 & \\
\hline Pupil/classroom ratio & 98:1 & 99:1 & 95:1 & 94:1 & 94:1 & $40: 1$ \\
\hline Pupil/teacher ratio & $65: 1$ & $58: 1$ & $58: 1$ & $58: 1$ & & $40: 1$ \\
\hline Pupil/textbook ratio (P3 -P7) & $6: 1$ & & & $\begin{array}{l}3: 1(\mathrm{P} 3 \\
\& 4)\end{array}$ & & $1: 1$ \\
\hline
\end{tabular}

Source: Annual Education Statistical Abstracts 2000, 2001, 2002, UBOS National Household Survey.

Total enrolment increased from 3 million in 1997 to the current 7.6 million in 2003. Enrolment of children with special needs rose from 20,000 in 1997 to 218,286 in 2002, of which $54 \%$ were males. The proportion of enrolled children from the lowest income quintile increased from $50 \%$ in 1992 to $83.7 \%$ by 1999.The earlier UPE policy of enrolling four children per family: two girls and two boys had the effect of increasing girls' enrolment to about $50 \%$ of total enrolment, thus significantly reducing the gender parity gap. Whereas in 1998 there was a clear gender gap at all levels of primary education, by 2003 there was very little gap during the first five grades. Currently the policy is for all children in the family to attend UPE.

Net enrolment rates in administrative data and survey data differ; those in administrative data are sometimes implausibly high (sometimes reported above 100\%, which is impossible by definition ${ }^{11}$. Survey data give net enrolment rates for primary education of $86 \%$, which is slightly higher for girls $(86 \%)$ than boys $(85 \%)$. This rate has been steady since the introduction of UPE in $1997^{12}$.

Government has prioritised improvement of the quality of UPE with results showing positive trends in select quality indicators. Provision of instructional materials has resulted in the reduction of the pupil/book ratio from 6:1 in 2000 to 3:1 in 2003. School sanitation and hygiene has also improved from a stance: pupil ratio of 700:1 in 1997 to 96:1 in 2000, with one third of schools having separate facilities for girls. Notably, focus of funding has been mostly on new facilities, often neglecting the maintenance of existing infrastructure. A policy for the educationally disadvantaged children was also put in place and provides among other things for basic education for children who are experiencing barriers to learning and includes the COPE, ABEK and BEUPA programmes. 
However, the improvement in quality indicators is yet to translate into concrete improvements in proficiency in all subjects, with the exception of science. As can be seen from table 7.2 below, proficiency in all subjects declined between 1997 and 2000, but the performance was mixed between 2000 and 2003 .

Table 7.2: Percentage of pupils achieving the required minimum proficiency

\begin{tabular}{|l|l|c|c|c|c|c|}
\hline & \multicolumn{5}{|c|}{$\begin{array}{l}\text { Percentage of pupils in P3 and P6 achieving } \\
\text { minimum proficiency levels }\end{array}$} \\
\hline Grade level & Subject & $\mathbf{1 9 9 7}$ & $\mathbf{1 9 9 8}$ & $\mathbf{1 9 9 9}$ & $\mathbf{2 0 0 0}$ & $\mathbf{2 0 0 3}$ \\
\hline Primary 3 & English (Literacy) & 29 & & 20 & & 34 \\
\hline & Mathematics (Numeracy) & 47 & & 39 & & 43 \\
\hline & Science & & 92 & & 90 & \\
\hline & SST & & 98 & & 98 & \\
\hline & English (Literacy) & 24 & & 13 & & 20 \\
\hline & Mathematics (Numeracy) & 49 & & 42 & & 20 \\
\hline & Science & & 35 & & 30 & \\
\hline & SST & & 58 & & 40 & \\
\hline
\end{tabular}

Source: Annual Education Statistical Abstracts 2000, 2001, 2002, UBOS National Household Survey.

Retention of children in schools remains a challenge to the sub-sector. Out of the 2,159,850 pupils enrolled in P.1 in 1997, only about 33\% reached P6 by 2002 and 22\% reached P7 in 2003. Explanatory factors for high drop out rates include poor quality, including the limited availability of instructional materials. Participatory studies suggest that costs including uniforms and the difficulty of providing lunch are also problems that may cause drop-out. Inadequate school hygiene and sanitary facilities has been shown to impact negatively on attendance and drop-out rates, particularly of girls.

Despite the UPE policy under which Government covers fees, costs borne by parents ${ }^{13}$ remain a major cause of drop-out. Other causes include poor quality, distance from schools, involvement in economic activities, lack of appropriate facilities in schools and harassment by teachers. Improving survival rates by improving quality and management is therefore a major challenge for Government.

Inequities associated with poverty, gender, geographical isolation and cultural attitudes persist. While there is little difference between the national enrolment rates for boys and girls, in some areas such as the North girls' enrolment remains very poor. In upper primary classes, the drop out rate for girls $(9.4 \%)$ is higher than for boys $(8.2 \%)$. Actions such as improved sanitation are needed to address this problem. 
Other outstanding challenges facing the sub-sector include high repetition rates arising from parents' preference to have their children promoted on merit as opposed to the policy of automatic promotion, and addressing requirements of girl children and children with special needs. The pupil: teacher and pupil: textbook ratios also remain high.

\section{Priority actions in primary education}

\section{Improving the efficiency}

The costs of UPE are very large, so that even after seven years of the policy Uganda is still a long way from providing each teacher with a classroom. Hence efficiency-enhancing measures are needed. Namely:

- Multi-grade teaching is being operated as a way of reaching isolated communities with inadequate numbers of teachers.

- Double shift teaching will be implemented as a means of catering for the large numbers in primary schools and improving the TPR, PCR and pupil-textbook ratio. Adequate compensation, in-service training and motivation are necessary for the success of the initiative.

- Government is providing incentives to teachers in hard-to-reach areas with a view to improving the performance of teachers and impact on learning outcomes.

- Area-specific interventions will be applied to reduce drop-out.

Improving the quality

Government will take the following measures

- Improvement of teacher quality through the Primary Teacher Training Colleges (PTCs) and through the Teacher Development and Management System (TDMS).

- Implementing the use of mother tongues in parallel to English in instruction in lower primary school.

- Increasing the relevance of the curriculum by including aspects of education related to sustainable development

- Adjusting the assessment and examination system in order to match changing needs and realities of Ugandan society.

- (resources permitting) recruitment and retention of high quality teachers by putting in place attractive terms and conditions of service for teachers.

- Better support and supervision for teachers.

Improving access

Government will use the following methods of improving access:

- Provision of basic education in emergency situations e.g. psychosocial support, construction of temporary infrastructure in cases of disaster among others.

- Provision of incentives for teachers in hard-to-reach areas to improve the performance of teachers and impact on learning outcomes

- Continued provision of classrooms and latrines with hand-washing facilities

- Construction of schools / provision of resource rooms 
- Training and retraining of teachers in specific areas of SNE, SWT, guidance and counselling to take care of children with learning disabilities

\section{School feeding}

In order to improve retention while also improving schoolchildren's health and nutrition and developing agricultural markets, Government is introducing a "home based" targeted school-feeding programme. The programme is targeted because it would be prohibitively expensive to provide meals for all schoolchildren. The effectiveness of this intervention in improving retention and educational performance will be monitored as a guide to the appropriate scale of the intervention.

\section{Post Primary Education and Training}

The transition rate from primary to post primary education rose over the $1^{\text {st }}$ and $2^{\text {nd }}$ PEAP period from $35 \%$ in 1997 to $50 \%$ in 2002 . This increase is partly attributed to the liberalisation of the education sector which increased private sector participation in the provision of education. The number of pupils completing primary education and demanding secondary education is estimated at over 406,500 as of 2003. Support to post-primary education to increase access is therefore being intensified. The second Education Sector Strategic Plan (ESSP2) includes costed plans for post-primary and tertiary education. Keeping up the transition rate will therefore require an increase in the total volume of secondary education.

\section{Secondary education}

The secondary education sub sector includes 751 Government-aided schools and over 2100 private schools with a total enrolment of 749,000 , of which $57 \%$ are boys. At present, Government aided secondary schools employ 26,402 teachers though only 15,060 are on the Government payroll. The rest (i.e. over 9,000) are recruited and paid locally by parents through Board of Governors' (BOG) and Parent Teachers Associations (PTA) charges. This re ects a freeze on teacher recruitment which was in operation from 1996.

Table 7.3 below gives the secondary education enrolments by government and private owned schools. In 2003 total enrolment in private secondary schools surpassed that in public schools. This trend is expected to continue.

Table 7.3: Trends in Enrolment in Secondary Schools in Uganda

\begin{tabular}{|l|c|c|c|}
\hline Year & Private & Government & Total \\
\hline $\mathbf{1 9 9 9}$ & 170,000 & 240,000 & 410,000 \\
\hline $\mathbf{2 0 0 0}$ & 228,931 & 290,000 & 513,931 \\
\hline $\mathbf{2 0 0 1}$ & 230,000 & 309,400 & 539,786 \\
\hline $\mathbf{2 0 0 2}$ & 290,060 & 317,806 & 607,866 \\
\hline $\mathbf{2 0 0 3}$ & 347,240 & 336,362 & 683,609 \\
\hline $\mathbf{2 0 0 4}$ (proj.) & 361,137 & 349,816 & 710,953 \\
\hline $\mathbf{2 0 0 5}$ (proj.) & 375,582 & 363,809 & 739,391 \\
\hline $\mathbf{2 0 0 6}$ (proj.) & 390,605 & 378,361 & 768,966 \\
\hline
\end{tabular}

Source: MoES (2004) 
At management level, $98 \%$ of the 751 government-aided schools have substantive head teachers (2002), up from just 357 in 1998. The current textbook ratio in secondary schools varies from school to school. Government has recently prioritised science, maths and English textbooks, for which the ratio has improved from 1:10 (1977) to around 1: 5 (2002). However, in other subjects the ratio remains about 1:20. Government has also constructed 50 laboratories in rural secondary schools between 2000 and 2002, bringing the total number of government aided secondary schools with laboratories to 271.480 secondary schools (government) still do not have science laboratories. Because of poor facilities, less than $50 \%$ of secondary school students reach criterion-referenced levels of achievement in main subjects. Small and poor schools, mainly in rural areas, perform poorly because they are unable to muster enough resources. Schools with less than 250 students have twice the proportion of pupils achieving the lowest grades; these are in remote rural areas supported by relatively poor communities.

Given the existence of a significant private sector, the main justification for public expenditure is to provide education to those children who would not otherwise be in private secondary schools. Overall, the incidence of secondary education is highly unequal, although this does not apply to rural schools ${ }^{14}$. Secondary school education is skewed toward the higher income groups and urban and semi-urban families. About half of the sub-counties (over 500) in rural areas do not have secondary schools and these are in rural areas, which are unattractive to private investors in education. While gender disparities have been overcome in the primary sub-sector, there are between $20 \%$ and $35 \%$ more boys than girls in S1-S4 and over 60\% more in S5-S6. Indications are that in contrast to primary education, the incidence of education has been becoming more unequal, and that the public sector is not yet successfully targeting the poor (World Bank, 2004).

\section{Priority actions for secondary education}

In order to broaden access to secondary education, Government is seeking to target its expenditures more effectively at the poor by focusing increased expenditures on rural schools. This objective is being pursued by:

- Grant aiding of 270 private community Secondary Schools within the planning period. Already 94 have been grant aided and nine (09) former PTC's transformed into secondary schools. Grant aiding of an additional 176 is in progress in subcounties without any Government aided secondary school.

- Construction of sixty (60) seed secondary school in sub-counties where they do not exist. As of December 2003, seventeen (17) were operational and work on an additional seven (07) had been commissioned.

- Rehabilitation of facilities in existing rural secondary schools. As of December 2003, 34 secondary schools have benefited.

- Construction of new classrooms, laboratories and libraries most especially in selected girls and mixed secondary schools in a bid to increase the number of girls offering science subjects. A total of 56 laboratories and 79 libraries are to be constructed.

- Provision of the students' bursary scheme to the needy but bright students who cannot afford the cost of Secondary Education commenced this year. A total of 7,544 students will benefit from this scheme by the end of the planning period, increasing the number of beneficiaries per sub-county from two (2) to eight (8). 
- The bursaries will be targeted to girls and disabled students. It is envisaged that $70 \%$ of the bursaries will be allocated to girls, in order to accelerate Uganda's progress towards gender equity in secondary education.

- Government will consider affirmative action for children from districts affected by con ict to access post primary education and training through targeted bursaries and more generous entrance requirements.

- Government will also encourage access for girls who have had a child and want to return to education

- Regular and periodic review of the teachers' terms and conditions of service, including the professional code of conduct and improving the enforcement of regulations.

- If resources permit, the sector will aim to increase the number of teachers paid by Government.

- Provision of incentives to private not-for-profit providers.

- Review of the secondary curriculum and teacher professional development to make it more relevant.

- Increasing efficiency through double shift teaching and increasing the teacher: student ratio to above 30 .

As more children enter secondary schools, it will be possible to use teachers more efficiently by allowing class sizes to rise somewhat.

\section{Business, technical and vocational education}

The BTVET system comprises of three pillars - public, private and firm based training. There are 144 public institutions; about 600 private training service providers, and an unknown number of apprenticeship and enterprise-based training programmes operating in Uganda. ${ }^{15}$ As Table A 7.2 shows, enrolments have been rising, but the public sector institutions reach only a fraction of potential demand. The private sector provides an unknown but significant volume of training of various kinds.

\section{Priority actions for vocational education}

Vocational education needs to be well matched with the economy's need for skills. This objective will be pursued by:

- Establishing and operationalising the Uganda Vocational Qualifications framework (UVQF) to increase exibility, accessibility, attractiveness, affordability and relevance both to trainees and employers.

- Offering modularised courses.

- Ensure BTVET institutions are accessible to students with disabilities.

- Conclude community polytechnics (CPs) pilot project.

\section{The Academic-Vocational Balance in Post-Primary Education}

Given the tight overall resource constraint, it will be important to achieve an appropriate balance within post-primary education between academic and vocational education. As noted above, the participation rates of gradates from vocational training are good, and communities expressed more appreciation for vocational than academic secondary 
education (PPA2, 2002); this corresponds with the importance of non-agricultural selfemployment as a route out of poverty. However, these objectives can also be pursued by enhancing the vocational component of secondary education. The secondary curriculum is being reviewed to make it more responsive to national labour demands, and 56 secondary schools are being vocationalised.

The Education Sector Plan envisages that vocational education will become a alternative to academic education in the last two years of the secondary level, rather than an alternative to the early years of secondary education. The introduction of short modularised courses should also make it possible for adults to acquire skills over their lifetime.

\section{Agricultural education}

One of the pillars of the PMA is agricultural education. A National Agricultural Education Strategy is to be put in place and integrated into the adult literacy and education programmes.

\section{Tertiary education}

Tertiary education supports poverty reduction by training a qualified and adaptable labour force, including high-level professionals like scientists, technicians,. business leaders, and teachers for basic and secondary education, and builds the capacity to generate and use knowledge.

Higher education in Uganda is becoming increasingly diverse, with over fifty institutions of higher learning including 16 licensed universities, (4 public and 12 private) and many programmes of study. There are over 75,000 students enrolled at this level. Assuming the target age group of 18-22, this yields a gross tertiary enrolment rate of $2 \%$, whereas the rate for sub-Saharan Africa is 3.9\% and that of less developed countries is $10 \%$. Although numbers have increased, the proportion of students taking science and technology is low.

The incidence of tertiary education is highly unequal both by income group and gender. A study carried out by the Ministry of Education and Sports revealed that out of over 700 Government schools, 139 elite Government schools, with high paying fees contributed $59 \%$ of the total enrolment on Government scholarships to Makerere University from1996 to $2000^{16}$. The richest $1 \%$ of society access over $40 \%$ of available positions at Makerere and other universities ${ }^{17}$

The private sector share of financing in the sector is significant, and most of the increase in numbers has come from private sponsorship. As with secondary education, the aim of Government policy will be to make tertiary education accessible to qualified and able students who could not otherwise afford it. The increase in numbers has also stretched the resources of universities.

Government's long-term plan for tertiary education is to raise student numbers to 126,000 by 2015 (of which half should be at universities, and half should be female), the introduction of bursary schemes to target poorer students, and improvement in curriculum and facilities. 


\section{Priority actions}

Over the medium term, the following interventions will be prioritised:

- Curriculum reform to emphasise science and technology in a broad higher education context,

- Use of a credit system to increase mobility amongst disciplines and institutions.

- Review financing to focus on financing students rather than institutions

- Strengthened affirmative action on admissions to favour students with disabilities

- Operationalisation of a Loan System accessible to all qualified students and an Open university; both of which will increase access to the poor.

- Target Government scholarships on science and technology

- Support research.

\section{Sports}

The promotion of sports is valued for its contribution to social capital and national unity. A Comprehensive 5-year Strategic Development Plan has been developed and will be discussed together with the Sports Policy. It covers the period 2003/04-2008/09. Emphasis is placed on the twin objectives of sports for all citizens and talent identification, development and management. Key aspects include the revision of the legal framework and the integration of Physical Education and Performing Arts into the school curriculum (this has been done for primary education already).

- Government will work in partnership with the private sector in order to achieve the desired outcomes.

\section{HIV/AIDS and education}

Over the past decade, HIV/AIDS has had an effect on the demand for education services. Over the last three years, $7 \%$ of total enrolments were estimated to be double orphans. Ensuring that they receive education is vital; to this end, more evidence is needed of their relative enrolment rates compared to other children of the same age. Buffering the loss of teachers and teacher time and effective HIV education is also needed. The education sector will work with other stakeholders to address the impact of HIV/AIDS on the sector.

\subsection{Health}

\section{Overview: the role of the public sector, and health sector reform}

The health sector comprises government agencies, NGOs, private and community providers, and various partners. It exists to promote better health outcomes through the monitoring and provision of preventive and curative health services. Its responsibility stretches not only to the public provision of services but also to supervision of the private sector, which provides a very significant proportion of health care in Uganda. Public sector services are provided through a seven-tier structure. Health centres 1-4 provide services at the LC1-4 levels; above these levels there are general hospitals at the district level 
and regional and national referral hospitals. Village health teams are being introduced to work at the community level. According to the 2002/03 National Household Survey, the majority of out patient consultations take place in the private facilities (including NGO facilities that may be publicly subsidized). Moreover, the poor are proportionately more likely than the non-poor to use the public sector.

The health sector is slowly recovering from the general decline in social services witnessed during the periods of economic and political mismanagement in the $70 \mathrm{~s}$ and 80s. The burden of disease, however, remains high. In 1995, over $75 \%$ of the life years lost due to premature death were due to mainly preventable diseases. Prenatal and maternal conditions, malaria, acute respiratory tract infections, AIDS and diarrhoeal diseases together account for over $60 \%$ of the total national death burden ${ }^{18}$. As a result, infant (88), under five (150) and maternal (504) mortality have persistently remained high over the last decade. Uganda is also experiencing an increase in the occurrence of noncommunicable diseases such as hypertension, diabetes, cancer, mental illness and chronic heart disease. In addition, poor health was the most often mentioned cause of poverty (UPPAP, 1999, 2002)

Health care is delivered by the private sector, including commercial units and NGO or religious facilities, as well as by Government. In Uganda, the majority of consultations are with private facilities, and the poor are proportionately more likely than their wealthier counterparts to depend on the public sector. In 2002, 44\% (19\%) of household in the poorest (top) quintile who consulted a health unit used a public facility. There is little overall difference in the pattern by gender ${ }^{19}$.

The reasons for public financing and provision in Uganda include the following:

- Market-led health outcomes are likely to be very unequal. The richest $20 \%$ of households spend almost ten times as much on health care as the poorest $10 \%$

- To protect households from the financial burden of catastrophic illnesses. Note, $38 \%$ of Ugandans live in poverty, and no insurance scheme is made available to them.

- People either lack information about the causes of ill-health or else fail to change their behaviour despite having the knowledge, and this has been found to be an important contributor to child mortality in Uganda.

- One person's health choice affects other people, both by determining whether they are infectious, and by in uencing the development of resistance to drugs. For instance, undisciplined prescription of chloroquine in pharmacies may have contributed to its reduced effectiveness against malaria.

These arguments suggest that Government should focus its interventions on preventive care and on making sure that the poor, who would not otherwise be able to pay for good private care, have effective access to the public health system. The health sector reforms recently undertaken in Uganda address these objectives. 


\section{Health sector reforms in Uganda}

Uganda has been undertaking health sector reforms since the early 1990s. The goal set for the health sector under the National Health Policy (NHP) is to reduce morbidity and mortality from major causes of illness. This is operationalized through the Health Sector Strategic Plan (HSSP), 2000/01 - 2004/05. This plan is aimed at achieving the delivery of the Ugandan Minimum Health Care Package (UMHCP) to all Ugandan households. Interventions in the package were chosen to target the most common diseases using the most cost-effective interventions. The achievement of the UMHCP is not yet affordable in its entirety. These reforms were designed to shift spending towards areas of greatest effectiveness. These include: increased resource allocation for PHC activities, abolition of user fees in public facilities in March 2001, expansion of rural lower health facilities, provision of subsidies to the Private Not For Profit (PNFP) sub-sector, the introduction of Health Sub-Districts structure, recruitment of qualified health workers and increases in the volume of essential drugs purchased for the health centres. Under the HSSP, Government has also built 400 new HC2s, upgraded $180 \mathrm{HC} 2$ s to HC3 status (including maternity services), and is upgrading $150 \mathrm{HC} 4 \mathrm{~s}$ to provide emergency obstetric and surgical services. The major priorities identified during the biannual joint sector reviews under HSSP, include: immunization, malaria control, health education, reproductive health, sanitation and HIV/AIDS.

Important subsectoral actions include:

- The revitalisation of EPI, which has provided increased service points backed by increased funding,

- Public provision of anti-retrovirals (ARVs)

- The extension of voluntary counselling and testing services, and services for prevention of mother-to-child transmission

- A multidisciplinary approach to treatment of HIV/AIDS has to be developed. Health care workers have to be trained to undertake the delivery of antiretroviral therapy and the treatment of their side effects as well as potentially high rates of immune reconstitution that may be seen. There is a need to integrate counsellors adapting already learned techniques and incorporate arising issues, as treatment becomes more available, nutritionists, etc.

- Launching of the Home-based management of fever programme for combating malaria in 10 districts; $74 \%$ of under-five children in these areas now receive appropriate treatment within 24 hours of onset of symptoms and mortality and morbidity have fallen.

- The prices of insecticide treated materials (ITMs) have been reduced by waiving taxes on bed nets and insecticide, and a national policy on ITMs has been prepared and disseminated ITMs, however, are still not yet affordable by the majority of the population especially the most vulnerable groups; only $15 \%$ of adults and $8 \%$ of children sleep under a mosquito net ${ }^{20}$.

- Government has entered into partnership with the private sector for the procurement and social marketing of ITMs. A national voucher system have been developed which will make ITMs available especially to the most vulnerable groups.

- The introduction of free primary care in public health facilities. 
These reforms have been accompanied by changes in funding. Allocations to district health services ${ }^{21}$ have increased from $32 \%$ of the Government health budget (including development partner budget support, but not donor project support) in 1999/00 to 54\% in 2003/04. Meanwhile, the share of the sector's expenditures financed by donor projects (as opposed to Government revenue and budget support) has fallen from 59\% of the 1999/2000 budget to $31 \%$ in 2003/4. As a result, the district health services received Shs. 115 billion in 2003/4 compared to Shs. 25 billion in 1999/2000. To ensure that essential inputs are provided, at least $50 \%$ of the budget for units below the hospital level is earmarked for drugs.

\section{Usage of health services in Uganda}

While there is no evidence yet available on the impact of health sector reforms on health outcomes, there is clear evidence that usage of the health system has expanded dramatically.

Since 2000, there have been significant improvements in health sector outputs, re ecting improved access to and utilisation of the Minimum Health Care Package by the Ugandan population. A number of PEAP indicators, which were selected to assess performance of the health sector, have shown marked improvement (see table 7.4).

Table 7.4: Health sector PEAP performance indicators

\begin{tabular}{|l|c|c|c|c|}
\hline PEAP Performance Indicator & $\begin{array}{l}\text { B a s e lin e } \\
\text { value } \\
(99 / 00)\end{array}$ & $2000 / 01$ & $2001 / 02$ & $2002 / 03$ \\
\hline $\begin{array}{l}\text { OPD utilisation } \\
\text { (Total GoU and PNFP) }\end{array}$ & $41 \%$ & $48 \%$ & $63 \%$ & $84 \%$ \\
\hline DPT 3 coverage (<1 year) & $33 \%$ & $40 \%$ & $42 \%$ & $53 \%$ \\
\hline $\begin{array}{l}\text { Proportion of approved posts } \\
\text { filled with trained health staff }\end{array}$ & $25.2 \%$ & $22.6 \%$ & $209 \%$ & $20 \%$ \\
\hline $\begin{array}{l}\text { Deliveries in health units } \\
\text { Urban/rural specific HIV sero- } \\
\text { prevalence (national average) }\end{array}$ & $6.8 \%$ & $6.1 \%$ & $6.5 \%$ & $6.2 \%$ \\
\hline
\end{tabular}

Include 2003/04 data

Out Patient Department (OPD) attendance has increased dramatically in most health facilities across the country, from 9.3 million new cases in FY 1999/00 to 17.7 million in FY 2002/03. The OPD utilisation rate has therefore improved from a baseline rate of 0.40 visits per person per year in FY 1999/2000 to 0.72 visits per person per year in FY 2002/ 03. This was most prominent after the abolition of user fees in March, 2001. Similarly, immunisation coverage has increased dramatically. 
Survey data ${ }^{22}$ confirm that usage has increased, although the change in the survey data is not as dramatic (possibly re ecting sampling or definitional issues). The proportion of people in the poorest $20 \%$ of the population who seek care when ill has risen from $46 \%$ to $73 \%{ }^{23}$. Within the public sector health system, there has been a shift towards clinics rather than hospitals, re ecting the increased availability of health infrastructure at local level. The increase in usage is concentrated among the poorest part of the population, suggesting that the health reforms have succeeded in making the public sector health system much more accessible to the poor in particular, while the richest groups have continued to use private care. However, maternity services still seem to be consumed primarily by richer groups in urban environments.

The increase in quantity has put some strain on quality. However, the evidence is more encouraging than might have been feared, because Government supported the reforms with increased funding. Public health facilities and NGO facilities are found to be of higher quality than their private counterparts ${ }^{24}$.

Reproductive health services, however, have not improved. Whereas the rates of antenatal clinic attendances have continued to improve ( $92 \%$ attended at least once), the proportion of deliveries conducted in health facilities has declined from $25.2 \%$ in 1999 to $20 \%$ in 2002/3. The 2000/01 UDHS found the contraceptive Prevalence Rate (CPR) to be $23 \%$, which is still below $30 \%$, the minimum level necessary to impact on fertility. Constraints include low access to maternity services (access to live - saving emergency maternal and obstetric services (EMOC) in $\mathrm{HC} 4 \mathrm{~s}$ and $\mathrm{HC} 3 \mathrm{~s}$ was only $6 \%$ in a recent study), shortage of inputs such as qualified midwives, reproductive health drugs and supplies, and poor attitudes by staff towards mothers. Under the leadership of the Ministry of Finance, a Task Force on Maternal and Infant Mortality was set up, and a report to address the maternal and infant mortality under a multi sectoral approach developed.

Government has continued to implement active HIV prevention strategies that have effectively sustained the declining trend of HIV sero-prevalence. This has now stabilised at around $6.2 \%$ at the Antenatal Clinic surveillance sites. These prevention strategies must be further strengthened to ensure that HIV infected patients in this era of treatment in Uganda do not revert to risky behaviours that may perpetuate the epidemic. It is hoped that the increasing trend in condom use and the rise in age at first intercourse will sustain this positive trend.

Government is also finalising HSSP II 2005/6 - 9/10 which represents a consolidation and extension of the achievements of HSSP I. The HSSP II is premised on the expectation that over the medium term, perinatal and maternal conditions, malaria, acute respiratory tract infections, diarrhoeal diseases and AIDS will together continue to account for the overwhelming part of the causes of disease and premature death in Uganda.

\section{Priority actions in the health sector}

- Government will continue to implement the health sector reforms discussed above.

- As resources permit, Government will increase spending on the priorities listed in Table 7.8. Particular priority will be given to preventive care, including hygiene 
promotion and sanitation, insecticide treated nets for malaria, vaccines for children, establishing village health teams, family planning commodities, provision of Anti Retroviral Therapies and IEC messages.

The total range of extra priorities has been costed at 297 billion shillings. However, extra resources of this magnitude will not be available for a long time. Current projections in the LTEF suggest that, even if the health budget expands to $14 \%$ of the envelope, it will take until 2010 for real expenditure to expand by this amount (and longer if per capita spending is projected). It will therefore be necessary to phase these priorities over time and find efficiency savings within the sector, including a thorough review of remaining donor projects (which still finance $32 \%$ of sectoral expenditures). Experience suggests efficiency savings may be possible.

Table 7.5: Priorities for the health sector

Increase per capita expenditure on drugs (including ORS) and supplies from \$1.2 per
capita to $\$ 2.5$

Recruitment and deployment of health workers

Pay Reform: general wages and hard to reach allowances

Procure additional reproductive health commodities:

Ensure free essential drugs and supplies for all pregnant women

Family planning supplies for 3 million couples per year

Procure malaria commodities (preventive and curative):

Free bed nets for 4 million pregnant women and children

Chemicals and pumps for indoor residual spraying in key institutions

Home based management of fever rolled out- all districts

Combination therapy for 5 million treatments

Operationalise village health teams across the country with particular focus on hygiene promotion and sanitation

Strengthen delivery and EmOC services in all facilities

Procure vaccines to immunise all children against priority communicable diseases, replacing GAVI funds

Extend blood transfusion services to HCIV level

Health promotion through IEC messages

Expand VCT, PMTCT, and ART

It is projected that in the long term, if health expenditure rises to $15 \%$ of the budget and population growth is as projected, health spending will rise to about $\$ 10$ per capita 
in today's prices by 2014-5. This will allow significant quality improvements in health services, even as usage is expected to increase.

\subsection{Water and sanitation}

\section{Overview}

This section considers water supply and sanitation ${ }^{25}$. The sector has developed sector investment plans for rural and urban water. The sector's plans (which cost $\$ 951$ million for rural water from 2001-2015 and about \$481 million for urban water) are likely to be fiscally constrained. Hence there is a need to prioritise within this sector to achieve the highest-priority objectives.

\section{Rural water supply}

Improved access to water supply has two potential benefits: improved health and savings in time collecting water. Water-borne diseases are an important part of the disease burden in Uganda, though more study is needed of the magnitude of the effects of improved water on these diseases ${ }^{26}$. However, there is increasing concern that despite improving access to safe water supplies, the quality of water when finally consumed is frequently diminished as a result of poor domestic hygiene practices in maintaining a safe water chain. The time burden of water collection falls mainly on women and girls in rural areas, and can be very significant.

Data from the Directorate of Water Development (DWD) shows that the percentage of people with access to safe/improved water sources increased from about $20 \%$ in 1991 to $55 \%$ in 2002 . Notably, the data does not take into account over utilisation, which may lead to long queues. In 1999, the absence of safe water sources was still a key problem, and households identified water supply as a priority. ${ }^{27}$. There was little change in rural water collection times between 1995 and 2000; the median collection time remained at 30 minutes ${ }^{28}$. Time saved by the children from fetching water from long distances permits them to attend to school. For some households, the distances and time are much longer; a study in Eastern Uganda ${ }^{29}$ found that households were spending 660 hours a year on water collection. Water use is also low. Average water consumption ranges from 12 to 14 litres/person/day in rural areas, compared to a national target of 20 litres/person/day. Shortage of water also affects the quality of health care and education.

The cost of investment in rural water supply makes it almost prohibitive as an up-front investment for most rural communities. There is however, more scope for private sector involvement in rural growth centres, small towns and urban centres where population densities are higher, alternative options are lacking and factors of privacy come in to play. Government has assumed responsibility for most of the costs of rural water supply. The second PEAP prioritised rural water supply in light of the participatory evidence. Government expenditures have increased over the last three years, but the cost of producing water has also been rising, so that the rate of coverage has grown fairly steadily.

Figure 7.1 shows the change in the percentage of rural people served with access to improved water sources between 1991 and 2002. The figure shows a strong positive trend 
in rural water coverage, from around $20 \%$ at the start of the 1990 s to around $60 \%$ today. Differences between the data sets are likely to re ect the different way in which coverage is measured as well as sampling errors.

\section{Figure 7.1: $\quad$ Percentage of rural people served with improved water sources} (MWLE, 2003a)

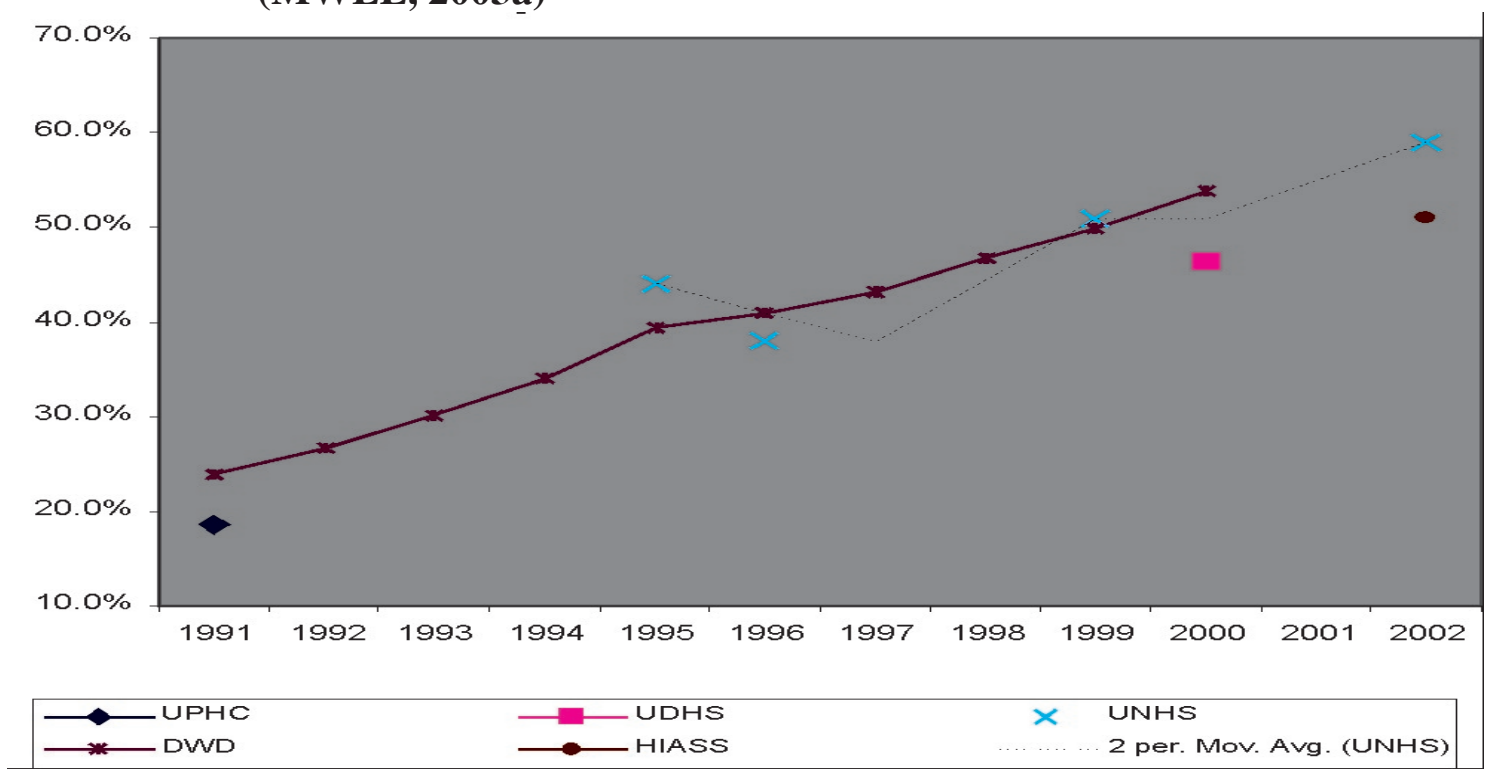

Issues in allocation of the water grant include equity and efficiency. Government is allocating funds to enable every district to reach the same level of coverage in 2015. This is regionally equitable; however, the simultaneous implementation of the programme in every district of the country, under the policy of 'Some for all not all for some', may have some efficiency cost because contractors have to move equipment between districts. Government is exploring the economies of scale that might be achieved by central award of contracts.

A Value for Money Audit (DWD, 2001b) and Tracking Study (DWD, 2003c) were undertaken to monitor the ow of resources, efficiency of systems and delivery of the outputs of investment. The tracking study found that funds were correctly remitted from the centre to district water accounts through CAOs. Use of the funds was more problematic; $50 \%$ of communities felt they had received good value-for-money while about $60 \%$ thought the works had been well-constructed and about $65 \%$ were satisfied with the service delivery of the water and sanitation installation in question. The Value for Money Audit revealed the following problems: deficiencies associated with 'top-down' planning; lack of coordination between districts, sub-counties and NGOs, poor quality tender documents; political interference in the tendering process; insufficient contract supervision and a weak private sector at local government level. Government will address these issues in the sector.

Rural water supply is maintained under the supervision of Water User Committees. Previously maintenance has been a major problem, which drives up the effective costs of delivering water supply. Expenditures on capacity-building in the sector have been large. 
The challenge, however, is to develop an effective participatory system than achieves successful community management.

\section{Priority actions in the rural water sector}

- Government will continue to invest in expanding rural water supply, taking efficiency measures to ensure that the facilities are maintained and that costs are kept down.

- In order to achieve Government's targets in this area, there is need to reallocate expenditures within the sector towards rural water supply.

\section{Urban Water supply}

The urban water supply and sanitation sub-sector in Uganda is defined as service to gazetted towns and centres with population of more than 5,000 people. Presently, there are 150 urban centres spread throughout Uganda with a population of 3.67 million people in June 2003 (DWD, 2003j). These are sub-divided into 15 large towns under National Water and Sewerage Corporation (NWSC), serving 2.1 million people and 135 small towns under Local Governments with technical support from Ministry of Water, Lands and Environment (MWLE), serving 1.57 million people (DWD, 2003j).

\section{Coverage}

In total, water coverage of the Urban Water Sector is estimated at about $60 \%-65 \%$ of the total population (rising from $54 \%$ in 2000). Figure 7.2 illustrates changes in access to improved water sources for urban households. It appears that after rising from $75 \%$ access in 1991 to nearly $90 \%$ by the mid-1990s, access rates have fallen back to around $80 \%$ today. This probably re ects the rapid growth in peri-urban and informal urban settlements that have outpaced the supply of improved water points in these areas hence the variation. The NWSC information is based on its areas of operation and actual water consumption.

Figure 7.2: Percentage of urban people served with improved sources

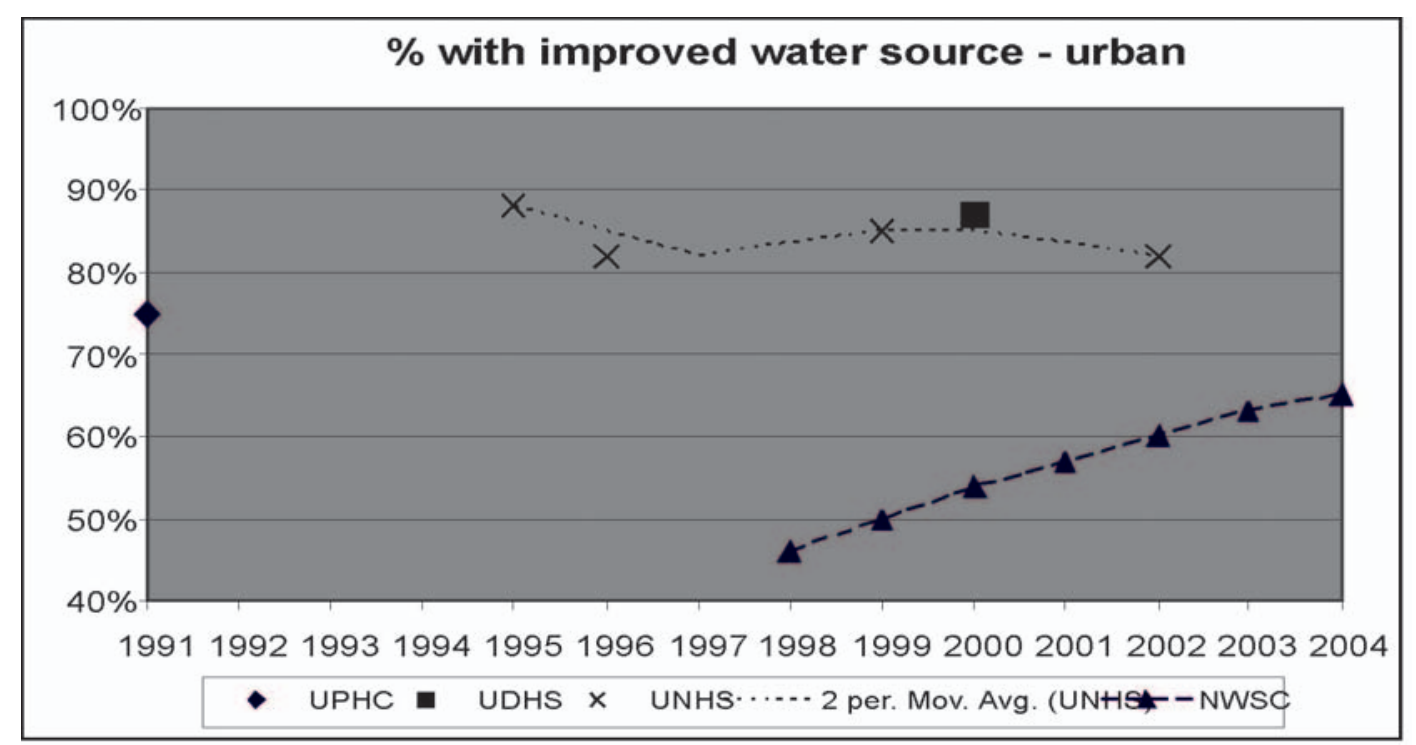


People in urban areas tend to be much closer to water sources than those in rural areas, but they often have to pay for their water. Only $18 \%$ of urban households have their own house or yard tap connection, and $60 \%$ of urban households paid for water compared to $5 \%$ of rural households. When water is paid for, the costs can form a substantial proportion of household expenditure; those households in the bottom $20 \%$ who paid for water devoted as much as $22 \%$ of their income to it $^{30}$. Average consumption is below 17 1/p/d in urban areas. The CSO input into the PEAP put particular emphasis on the costs of sanitation for urban households, which can be prohibitive; in the crowded circumstances of urban slums, this can cause serious public health problems.

The median time taken to collect water for urban households fell significantly from 15 to 9 minutes between 1995 and 2000. Given that urban access to improved water worsened over this period, the time saving may re ect a higher proportion of households using unsafe but nearer water sources (MWLE, 2003a).

\section{Large towns}

Currently, the Large Towns are managed by NWSC under a performance contract arrangement with Government. NWCS has achieved significant improvement in efficiency in recent years. The Kampala area, which accounts for about 70\% of NWSC's activities, has been contracted out to private operators since 1998. Further use of the private sector and sector reforms are envisaged with a proposed 10 to 15 year lease contract for a number of large towns.

NWSC's operational expenditures are now only $78 \%$ of its income. However, the NWSC is also burdened by a debt of Shs. 128 billion. Tariffs are currently sufficient to cover recurrent costs and physical depreciation, but not to service old debt or cover the costs of commercial borrowing. To enable loan servicing, the current tariff would have to be increased by about $60 \%$.

The Large Towns have considerable excess capacity. Hence the priority is to invest in distribution rather than extra capacity. Some, but not all, of these investments will be commercially viable - i.e. their costs could in principle be recouped through the water tariff. However, as noted above, the tariff currently charged is not sufficient to finance new investment.

\section{Financing urban water}

Cabinet has decided that the financing of urban water is a public responsibility. Existing estimates suggest that the investment plan for the urban water sector will be difficult to finance within Government's resource envelope. However, some funding is received from donors directly by the NWSC which is not treated as part of the resource envelope, since the support is intended to promote commercial viability of the enterprise.

Given that average incomes in urban areas are much higher than in rural areas and that access to water is generally better in urban than rural areas, Government is aiming to set tariffs that will make investments in urban water commercially viable where possible. This would release public sector resources to finance those parts of the investment (for 
instance, peri-urban areas) that will require public support. However, Government will retain overall responsibility for the sector and some up-front funding will be needed by NWSC. Civil Society Organisations have given some strong examples of the burden sometimes placed on the urban poor by the need to pay for water and sanitation; targeted subsidy in such cases is likely to be more appropriate than blanket support for urban investment.

\section{Small towns}

Investment in small towns is managed by DWD. Scope for private financing is more limited in the case of small towns than in large towns. Therefore, much of the investment expenditure will need to be funded by Government.

\section{Priority actions for water sector}

Government will:

- Review the water sector targets in light of the LTEF projections

- Priortitise provision of water and sanitation services to the rural population and the urban poor

\section{Sanitation}

Good sanitation blocks the faecal-oral route of disease transmission. Recent studies indicate that the safe disposal of human waste is seldom practiced and a big number of the population do not wash their hands with soap and water after faecal disposal. Even in homesteads where latrines exist, there is widespread open faecal disposal.

\section{Coverage}

Piped sewerage services are accessible to an estimated $8 \%$ of the urban centres while the remainder of the urban population (92\%) use on site systems, which are predominantly pit latrines (MWLE, 2003h). In peri-urban areas people tend to utilise pit latrines, VIPs, septic tanks or dispose of their faeces in polythene bags or " ying toilets" which are discarded in banana plantations, rubbish bins, or drainage channels (MoH, 2000; Carl Bro, 2001). Solid waste management is almost non-existent. In Kampala for example, refuse is collected from only $20 \%$ of the population and only half of this is disposed of in a proper way with the rest being dumped indiscriminately. Little attention has been given to wastewater disposal or storm drainage. Drainage is poor and limited to major roads and pathways; the resulting oods cause high road maintenance costs and damage to buildings. Government will provide financial resources to improve solid waste management and drainage.

The rapid increase in primary school classrooms and enrolment in response to Universal Primary Education (UPE) increased pressure on the limited sanitation facilities available. In 2000 only $8 \%$ of primary schools had sufficient latrines for the number of students attending, and only one third of the schools had separate latrines for girls. According to the Ministry of Health (2000) $2.7 \%$ of all students' time is lost to sickness from sanitation related illnesses. Sanitation is a particularly important issue in the crowded circumstances of IDP camps. 


\section{Institutional structure}

In the past, hygiene promotion and sanitation strategies in Uganda were embedded within rural WSS projects such as RUWASA and WES or in large NGO projects. However, the funding for personnel and institutional support is now no longer available as the sector has undertaken a number of reforms in line with the Sector Wide Approach and decentralisation. This has raised the issue of institutional and funding responsibility for sanitation (DWD, 2003d).

As explained in the introduction to this chapter, sanitation is an inter-sectoral issue, the coordination of which is being undertaken by the Sanitation Working Group. DWD in MWLE and EHD in MOH are cooperating to test pilot interventions in a number of areas. Community mobilisation will be critical.

\subsection{Social Development Sector}

\section{Overview}

The mandate of the social development sector, which was formed in 2000, covers community-level actions to reduce poverty. Direct interventions in this sector concern community mobilisation, hygiene promotion and sanitation, functional adult literacy, care of vulnerable groups, and promotion of culture - discussed in this section - and labour market interventions, discussed in Chapter 5. Indirect interventions include the mainstreaming of gender and social protection throughout government. The leading role in the sector is taken by the Ministry of Gender, Labour and Social Development (MGLSD). Actions are guided by the Social Development Sector Strategic Plan (SDIP), which was formulated over a three-year period under the leadership of the MGLSD with the participation of key stakeholders including local governments, CBOs, NGOs and the donor community.

\section{Social development and social protection}

The various interventions in the social development sector are intended to strengthen the social capital of the poor, and particularly of disadvantaged and vulnerable groups. By 'social capital' is meant the whole variety of networks and social resources which people use to support themselves and manage their lives. Social development aims to strengthen these networks for developmental ends.

As a result of strengthening the social capital of communities; three outcomes are expected: greater social inclusion: social and economic security: and empowerment achieved through community mobilisation.

The sector has also begun work on a framework for social protection. Social protection deals essentially with the reduction of risks facing households and the enhancement of their ability to manage them. 


\section{Community Mobilisation and Empowerment}

Government has decided to revitalise the community development function. This function, which worked well in the 1960s, had seriously declined and its importance was not widely understood. The decision to revitalise it rests on the judgement that the community development worker can play a crucial role in interfacing between service deliverers and the community. Communities and households play a critical part in all the major services, for instance:

- Sending children to school

- Taking preventive health actions like improved hygiene and sanitation practices at households and community level

- Deciding when curative treatment must be sought

- Maintaining water supply sources

- Running LC1 courts and deciding when higher-level judicial intervention is needed

- Supporting local defence units

- Protecting children from violence, abuse, neglect and discrimination.

- Supporting home based care for people living with AIDS

Community Development Workers (CDWs) can help in promoting awareness of all these responsibilities at the community level. They are also directly involved in implementing the functional adult literacy and community rehabilitation programmes within the Social Development Sector (SDS).

To avoid duplication, a national Community Mobilisation and Empowerment Strategy (CMES) was initiated and is due to be finalized. In the revitalisation of the community development function, Government is planning to recruit and facilitate a community development worker for each sub-county. They will work with voluntary community development agents at the parish level.

Available statistics in the SDS indicate that out of the 930 established positions of one CDW per sub-county, the community development staffing level has improved from 661 filled positions by the end of July 2001 to 742 filled positions (79.8\%) as at end of July 2003. The number of graduate community development staff has also increased from 17 (2.6\%) by the end of FY 2001/02 to the $102(13.5 \%)$ by the end of FY 2002/03.

To strengthen the community mobilisation and empowerment component of the SDIP, Government has created a new conditional grant - the Community Development Workers Conditional Grant (CDWCG) - under the PAF. The conditional grant will be used to finance Community Development Workers (CDW) as a supplement to Local Government efforts to finance Community Development. The grant is made up of a wage and nonwage component. The wage component is to cater for payment of salaries for the newly recruited sub-country CDWs while the non-wage component will be utilised to facilitate CDW at sub-country levels with the necessary logistical support and to a limited extent, to cater for the operational costs of CDWs at district level. 
While CDWs' work is by its nature varied and hard to quantify, it will be important to establish some indicators that verify that they are delivering a useful service. MGLSD is planning to develop a monitoring strategy. This will include the role of CDWs in representing probation and social welfare officers in the community.

Government is considering what role NGOs should have in the implementation of the community development function and whether there is a role for contracting some of this function out.

\section{Priority actions}

- Government will aim to continue to fill vacant CDW posts.

- The management of CDWs will be strengthened.

\section{Functional Adult Literacy (FAL) and public libraries}

Literacy is one of the most important attributes conferred by education. Programmes of functional adult literacy, where literacy is provided in a context of social functions that helps retention of the skill, offer a relatively cheap way of expanding adult literacy.

The FAL programme started in 8 districts in 1992 and had expanded to 22 districts by 1999. During the last PEAP, it was decided to place more stress on this activity and the programme is now working in 56 districts. The CDWs are the focal persons who mobilise communities to enrol. Several NGOs, CSOs and the private sector also participate.

Table 7.6: Enrolment in FAL

\begin{tabular}{|c|c|c|c|}
\hline Year & Male & Female & Total \\
\hline 1997 & 18,571 & 74,718 & 93,289 \\
\hline 1998 & 32,105 & 102,136 & 134,241 \\
\hline 1999 & 25,230 & 76,635 & 101,865 \\
\hline 2000 & 17,786 & 86,805 & 113,871 \\
\hline 2001 & 30,658 & 118,351 & 149,009 \\
\hline 2002 & 86,293 & 271,971 & 358,264 \\
\hline 2003 & 89,119 & 323,579 & 412,698 \\
\hline
\end{tabular}

Source:

A major challenge for the programme is that instructors, most of who are not paid, often resign. The sector is therefore considering the introduction of honoraria subject to availability of resources. Civil society groups have suggested that some of the delivery of adult literacy programmes should be subcontracted to NGOs. In accordance with practice elsewhere, Government will consider this proposal according to the cost-effectiveness of different forms of delivery. 


\section{Priority actions}

Government will:

- $\quad$ Continue to support the FAL activity, and will consider the option of contracting - out some of the service to CSOs.

- Promote access to public information through the public library network. A National Library of Uganda is being established.

\section{Social Protection for Vulnerable Groups ${ }^{31}$}

\section{Orphans and Other Vulnerable Children}

Orphans and other vulnerable children constitute a large and growing share of Uganda's population largely as a result of HIV/AIDS and war related deaths of parents over the past decade or so. As of the year 2002/03 $32,3.2 \%$ of children aged less than 18 years had lost both parents while $8.4 \%$ and $2.2 \%$ had lost the father and mother respectively.

Orphan hood is partially responsible for the in ux of children into urban centres; it is estimated that the country has 10,000 street children, mainly in 10 major municipalities and towns. In order to survive, street children become involved in both legal and illegal activities. Orphans are more likely than other children to have to undertake child labour, raising concerns about the conditions of work.

About 2 million Ugandan children have been orphaned by AIDS. There are a growing number of child-headed households as a result of AIDS-related orphanhood, which are particularly vulnerable. Indeed, orphans may be vulnerable to sexual abuse, thereby increasing their risk of contracting HIV.

Transition to adulthood is characterised by reproductive health concerns including HIV and other STDs, early marriages, unwanted pregnancies, unsafe abortions and low contraceptive use. Major progress has been achieved in increasing access to educational programmes on sexuality, responsible parenthood and reproductive health services. The adolescent reproductive life programme is functioning over a wide area.

The legal framework for children's rights in Uganda is embedded in the Children's Statute, 1996. This consolidates the law relating to children and provides for their care, protection and maintenance; it covers parents' responsibilities, local authority support (including provision for a family and children's court) and the treatment of children charged with offences.

Implementation of the Act commenced on August 1 ${ }^{\text {st }}$ 1997. However, district Councils have not fully embraced the Statute largely due to the limited number of Probation and Social Welfare Officers needed for the proper functioning of the family and children Courts. Most districts have not yet identified suitable facilities to be gazetted as Remand Homes and this has resulted in the continued incarceration of children in police cells and prisons with adults, contravening the Children's statute. 
In view of the above, MGLSD aims to establish close collaboration with MJCA under the Community Services Act, to better ensure that child offenders and offences receive due justice and appropriate rehabilitation respectively through the engagement of its Probation and Social Welfare Officers as well as Community Development Workers with LC 1 and Magistrate Grade II Courts.

\section{Support to the Elderly}

Recent work on social protection has identified the elderly as a potential target group for social protection. The elderly increasingly have to care for people living with HIV/AIDS and orphans, giving them an important role in economic growth. There are some specific public efforts in support of the elderly such as their representation on the Local Councils and promotion of awareness on issues of ageing through advocacy by CSOs, but there may be a need for a more comprehensive approach. Government will study the needs of this group.

\section{Support to Persons with Disability}

Uganda is estimated to have 2.46 million persons with disability ${ }^{33}$. There has been increased awareness among the public on disability related issues over the past years which resulted, among others things, into the representation of PWDs in Parliament and in local councils giving them a voice to lobby for and access services. Parliament recently approved the National Disability Council to promote the rights of PWD.

The SDS is also implementing the Community Based Rehabilitation Programme for the Disabled. As of 2003, community based rehabilitation services (home care visits) were being offered to persons with disability in 13 districts and assistive devices had been accessed to over 500 PWDs. Vocational skills development centres for the PWDs are however operating, at only $30 \%$ capacity.

In line with Government's commitment to ensure equitable poverty reduction and in view of the large proportion of PWDs, expansion of community based rehabilitation services (in addition to other mainstreaming interventions) emerges as an issue for priority attention requiring more public intervention.

\section{Priority actions for vulnerable groups}

Government will:

- Mobilise and strengthen community-based response for better care of orphans and other vulnerable children.

- Support empowerment of adolescents with reproductive health information and life skills

- Strengthen informal community-based support for older persons

- Support expansion of community-based rehabilitation for persons with disabilities 


\section{Culture}

Apart from being intrinsically valuable and an important dimension of identity, culture is also a form of capital which when well harnessed can help to move people out of income poverty. Traditional skills and indigenous materials are often accessible to poor and disadvantaged groups, and as such form a potentially viable avenue for povertyreduction.

The past few years have witnessed a revival in the cultural industry with the private sector playing a leading role. The number of theatre companies and performing groups as well as individual artists has been on the rise. More importantly, given the behavioural in uence that theatre has on population lifestyle, Government is keen to enhance its use as one of the channels for bringing about positive lifestyle change. The role and use of indigenous knowledge is also gaining recognition in sectors such as health where herbal medicines and traditional health care service providers have become partners in the delivery of the sector's programmes. However, more work is required to build up the necessary capacity to ensure best practices in the use of indigenous skills and knowledge in the development process. Instances of malpractices by some traditional health practitioners for example, show the clear need for a regulatory framework for activities of cultural practitioners in the country.

In view of the above, formulation and implementation of national culture policy shall be expedited. This will go a long way, not only in protecting the rights to indigenous knowledge but also in addressing the existing gaps.

\section{Priority actions for culture}

- Government will support the recording of traditional music and oral literature for preservation.

\section{Gender mainstreaming and empowerment of women}

Gender and Basic Rights of the poor and vulnerable are crosscutting development concerns and as such they can best be addressed using a cross-sectoral approach. The realisation of gender equality and basic rights for all people therefore requires for all actors in the development process to address these concerns in their respective areas of mandate and capacities. There is compelling evidence to show that, due to systematic social-cultural practices of discrimination against women, there is an intrinsic tendency for most sectoral development programmes not to equitably reach or benefit women. There is therefore need to enhance deliberate efforts to institute policy mechanisms for purposes of in uencing the national development process, to consciously target and benefit both women and men. In light of this, the SDS seeks to boost its effort to actively engage all sectors and local governments in mainstreaming these concerns in their plans, programmes and policies.

Experience from the previous PEAPs shows that despite the numerous efforts to mainstream gender in the national development process, the overall level of gender responsiveness still remains low. 
This is largely due to inadequate capacity among sector and local government planners and implementers (especially at sub-county level) to apply gender analysis skills to the policy making process; limited gender awareness among the communities; bureaucratic resistance to gender mainstreaming among decision makers; and weak support, supervision and monitoring among others.

On the demand side, the communities have inadequate information on their civic and human rights. As a result, the poor and vulnerable remain subject to abuse as exemplified by the continued instances of gender-based violence and child abuse among others. In addition, women are physically more vulnerable in terms of maternal health and HIV.

\section{Priority actions for gender mainstreaming}

In view of the above, the SDS plans to undertake the following interventions towards mainstreaming gender and rights of the poor and vulnerable in the national development process:

a) Implement the Revised National Gender Policy

b) Implement a paralegal programme focusing on gender-based violence and basic rights of the poor and vulnerable in 24 districts.

c) Undertake capacity strengthening activities for enhancing gender and RBA skills of decision-makers and planning/implementing officers to mainstream gender and rights in at least 5 priority sectors (Education, Health, Water, Agriculture and Roads) and in all sub-counties in half of the districts;

d) Conduct monitoring missions focusing on assessment of progress in implementing gender and basic rights mainstreaming,

e) Conduct gender and equity budgeting analyses for selected sector and district BFPs,

f) Provide inputs to the review of domestic relations laws,

g) Produce and disseminate gender disaggregated data for development planning, monitoring and evaluation

h) Provide training programs on capacity building of women and youth leaders in LCs, NYC, and NWC at district and sub-county levels, as well as PWD organisations Countrywide,

i) Develop a Gender Management System to review and audit government policies, plans and programmes for gender/equity responsiveness.

\section{Institutional Development}

In view of the wide range of interventions and actors with shared goals and approaches in the SDS, there is need for better coordination of Government interventions and support from development partners in order to realise more cost effective use of resources and effective and sustainable delivery of services in the sector. 


\section{Key priorities for the pillar}

Key priorities include:

- Primary and secondary education with a clear focus on quality and the ultimate objective of learning, and with better targeting of public expenditure on secondary education at those who could not otherwise afford it.

- Improving health outcomes; this will be the joint achievement of several sectors.

- Increasing people's ability to plan the size of their families.

- Adult literacy

\subsection{Public expenditure priorities for human development}

\section{Public expenditure implications for education}

Public subsidy to education is justified by externalities of market failure (young people cannot finance education even if the economic return to it is high), and by income distribution (by educating people, the state endows them with a permanent and inalienable asset, and the provision of basic education allows this asset to be broadly spread across society). Public expenditure on education may to some extent substitute for private provision. The returns to public expenditure on education depend not only on the returns to education itself but also on the impact of public expenditure on the quantity, quality and incidence (across income groups) of education delivered.

\section{Primary education}

In the short run, the top priority is to maintain current levels of provision of primary education. This will be a significant challenge. Hence cost-saving measures will be important, including sequential teaching. The challenge will be compounded if pay reform for teachers is implemented, as the wage component of the sector is large. It has been suggested that the share of primary education should be reduced. This is a reasonable medium-term objective, because expenditure on secondary education will need to expand to meet demand, but implementing it immediately would jeopardise the existing achievements in tertiary education. One priority for increases in this area is education for children with disabilities. There may also be a need for some spending to reduce the costs of schooling to parents.

\section{Post-primary education}

Post-primary education will need more expenditure in the medium term, although the urgency is less than anticipated because drop-out in the primary sector has made the UPE 'bulge' smaller than expected. The sector is trying to improve incidence of new expenditures in this area by focusing on underserved areas and including bursaries for poor children. The highest priority, as identified in the BFP, is teacher recruitment in both secondary and BTVET.

Government will also aim to invest in secondary and vocational education through constructing secondary schools in rural areas and increasing the number of bursaries. 
Unlike subsidies to schools in urban areas, which may merely substitute for private provision, these forms of expenditure are more likely to reach poorer students and therefore contribute to the expansion of secondary education in general.

\section{Tertiary education}

Major investments in the tertiary sector should be channelled through support to students for particular courses rather than through institutions. However, given the pressing needs in primary and post-primary and the overall need to expand recurrent rather than capital spending, these investments may need to be deferred.

\section{Public expenditure priorities for health}

Priority expenditures in this sector are of two kinds: continued strengthening of the basic curative services, and preventive measures. In order to finance this, cost savings have to be found through continued reallocation within the envelope away from donor projects. The sector has succeeded in achieving major efficiency savings in this area already, and further progress is possible.

In the short run, the scope for implementing further improvements in service delivery will be limited. In the long run, however, the LTEF projections indicate that health spending could reach $\$ 10$ per capita in today's prices by $2013-14$, which would allow most basic services to be delivered (although emergency obstetric services might not be fully funded).

Government will avoid treating global funds as additional but will consider the appropriate treatment of drugs provided in kind. In some cases, these have not been included in the resource envelope in the past (e.g. the vaccines provided under GAVI) and it is important to use a consistent accounting treatment in order to assess trends in the resources going to the sector over time.

The rationale for public expenditure on health depends on distributional considerations, limited information, failures in insurance markets and externalities (particularly in the treatment of communicable diseases). The top priority for the health sector must be that the most basic preventive and curative measure are available to the population as a whole. Ugandan's health outcome improved very little over the period from the mid-1960s to 2000, with a major deterioration due to HIV/AIDS and very little improvement in child and infant mortality. This shows that both the actions previously undertaken by the public sector and the market do not necessarily deliver improved health outcomes, even in the context of rising incomes and were not working very effectively.

As with education, the impact of public expenditure on heath depends both on the returns to the services provided and the extent to which increased expenditure translates into improved access to services. Recent health service reforms have caused a major increase in usage of the public health system, and a significant proportion of this usage is additional rather than being substitution between private and public clinics. Increased usage of curative services has been accompanied by a jump in the usage of preventive services such as immunisation. The services provided are based on analysis of the importance of various conditions in the disease burden confronting the country and the costs of treatment. Hence there is good reason to be confident that extra expenditures on basic curative and preventive health services will generate improvements in health outcomes. 
Some have argued that people can afford basic treatments; what they can't afford is to pay for catastrophic interventions of life-threatening nature and so the state should concentrate on providing more sophisticated interventions and let people to pay for basic treatments ${ }^{34}$. This argument has more force for middle-income countries, where mortality has already begun to fall and basic conditions are no longer killing large numbers of people, than in the Ugandan context where many people (especially children) are still dying from conditions that could be prevented (through improved personal hygiene and domestic sanitation practices) or treated by basic methods (such as malaria, diarrhoea and respiratory infections). In the Ugandan context, meeting the need for prevention and cure of basic conditions clearly has to come first. However, there are some major health risks that af ict adults that do require more advanced forms of treatment, notably maternal mortality and AIDS.

The priorities listed by $\mathrm{MOH}$ are shown in Table 7.5

While these priorities are generally consistent with the emphasis on basic curative and preventive heath sector reform, the costs are in some cases (e.g. village health teams) highly approximate and might be reduced through better integration of existing district resources and extension staff and improved cooperation with other sectors including social development, education and water.

In the long run, the per capita spending in the sector in $20145 / 5$ is projected at 20,800 shillings per capita in today's prices - about $\$ 10$. While this could fund a significant improvement in services, it would not achieve everything the health sector was hoping for. In particular it will be difficult to finance adequate service for maternal health within this envelope.

\section{Public expenditure implications for water and sanitation}

The provision of infrastructure for water supply has increasing returns to scale, because the costs of the marginal connection are much lower than the costs of providing the infrastructure. In the case of a well or a public tap, the source is effectively a public good. The benefits of water supply come in the form of improved health outcomes and reduced time burden. Evidence on the impact of water supply on health outcomes is mixed, partly because water infrastructure needs to be complemented equitably by hygiene and sanitation promotion, if significant reduction in disease transmission is to be achieved. The time use benefit can be significant, and accrues mainly to women and children.

Government is therefore committed to ensuring water is made available for both rural and urban households. Water supply investment is best seen in the context of long-run sectoral targets. The table below shows the costs of the programme. The LTEF resources are converted to constant prices using the public investment de ator and then converted to constant dollar terms by using the exchange rate prevailing last year (Shs 2000). The results are quite sensitive to the price assumptions used. 
Table 7.7: Water supply: resource needs and LTEF projections

\begin{tabular}{|l|c|}
\hline Water sector strategy: & $\mathbf{1 5 4 0}$ \\
\hline if 95\% coverage by 2015 & $\mathbf{1 1 9 3}$ \\
\hline if 77\% coverage by 2015 & \\
\hline o/w & 956 \\
\hline RWSS for 95\% & 609 \\
\hline RWSS for 77\% & 281 \\
\hline Large towns & 136 \\
\hline Small towns & 58 \\
\hline Water for crops & $\mathbf{9 1 2}$ \\
\hline Water for livestock & 102 \\
\hline Water for aquaculture & $\mathbf{1 2 5 9}$ \\
\hline Excluding large towns: with 95\% rural & 724 \\
\hline Excluding large towns: with 77\% rural & \\
\hline Amounts already spent 2000/-2003/4 & \\
\hline
\end{tabular}

The targets will need to be reviewed in the light of LTEF allocations. Within the sector, priority needs to be given to rural water supply. Government will therefore prioritise continuing the programme of rural water supply, with an increased focus (liaising with CDWs) on community maintenance, and cross-subsidy of water and sanitation for poor urban and peri-urban communities.

For urban water, investment in distribution (connections between households and the water mains) will be paid for largely by the concession-holders out of tariffs, with some cross-subsidy of low-income households in low-income areas (the existing tariff for Kampala, for instance, is stratified by residence). Where communities cannot afford the tariffs, Government may provide some support. 
Investment in waterworks, however, is likely to need Government or donor support, as the ownership of these assets will stay with Government under the asset-holding authority. In the short run, most towns have excess capacity, but Entebbe and Kampala are approaching full usage. In the long term, urbanisation may create further needs for new investment. However, Government will avoid investing prematurely in excess capacity. This may make it possible to revise downwards some of the plan targets.

Water for production can partially be funded out of local government investment budgets.

\section{Public expenditure implications for social development}

The short run priorities are to focus on making the CDW function work well and continuing the programme of FAL. Community Development Workers are critical because the other activities in the sector go through them and because, if deployed effectively, they can generate savings in other sectors. There is a strong case for ensuring that this conditional grant is allocated to all districts. Clear output/performance indicators are needed for CDWs (although admittedly quite difficult). The costs of managing the CDW function have been estimated at 5-10 billion shillings, of which 7 billion is needed to recruit CDWs in areas not covered by the existing PMA grant. The sector estimates the costs of scaling up FAL at an extra Shs. 2 billion, with the cost of introducing honoraria for instructors estimated at Shs. 5 billion. Although the payment of honoraria is a reasonable proposal, the current fiscal constraint makes it difficult to implement.

In the long run, the sector needs to develop precise and targeted interventions for its other responsibilities including OVCs and the disabled, within a realistic projection of resources available. 


\section{Public expenditure to implement the PEAP}

\subsection{Introduction}

The previous chapters set out the strategic challenges and policy priorities for the PEAP. This Chapter sets out the criteria for public expenditure allocation and Government's approach to funding the PEAP priorities. It examines what is required of budget policy to ensure that public expenditure best meets the requirements of the economic and sectoral strategies of the PEAP. The success of this PEAP requires a coherent strategy which can deliver improvements in the efficiency of public expenditure and ensure that expenditure allocations are focused on its priorities. The chapter also identifies the reforms to budget processes, especially at the sectoral level, which are essential to achieving PEAP goals.

The strategic objective of the PEAP is to build a private sector driven economy which can generate rapid and sustainable broad based economic growth and propel structural transformation of the economy. Such structural transformation will entail the growth and diversification of exports and the modernisation of agriculture. The economic and sectoral strategies set out in chapters 2-7 have implications for public expenditure.

The role of the public sector is primarily to provide the public goods and services which complement private investment, and which can promote a more equitable pattern of development. These include the essential public services which cannot be supplied in an optimal manner through the market mechanism alone.

The demands for public expenditure always outstrip the resources which are available to fund them. Therefore, Government will rigorously prioritise its expenditures and provide taxpayers with value for their money. If public expenditure is to maximise its contribution to the PEAP, it is imperative that three conditions are met:

- Inter-sectoral budget allocations be shifted in favour of those sectors which can make the strongest contributions to tackling the core challenges of the PEAP: accelerating pro-poor growth, human development and restoring security and support for regions af icted by con ict.

- Intra-sectoral budget allocations be shifted in favour of projects and programmes which most clearly contribute to poverty eradication in a cost effective manner.

- Efficiency is improved in all areas of public expenditure, so that better value for money, in terms of the quality and quantity of services, can be achieved with the scarce resources available to Government. In particular it is necessary to rationalise public sector structures to avoid duplication and reduce costs, thereby freeing up resources for PEAP priority expenditures. The sector working groups (SWGs) must take the lead in driving pro-poor expenditure reallocations within their sectors and in enhancing the efficiency of their spending. 
It must be emphasised that public expenditure is inevitably resource constrained and that the growth of aggregate public expenditures must be contained within the budget resource envelope set out in the LTEF if the strategic economic objectives of the PEAP are to be realised. The fundamental principal underlying fiscal policy in the PEAP is that the medium/long term spending plans of all sectors face a hard budget constraint which is determined by macroeconomic objectives and the imperative to maintain public finances on a sustainable basis. Whatever the perceived spending requirements of the different sectors are, their spending plans must be accommodated within their sector expenditure ceilings. Expenditure ceilings cannot be stretched in the hope that somehow more resources will be found to fund higher expenditures.

\subsection{Public expenditure and poverty eradication spending: 1997-2003}

\section{Overview}

During the period of the first two PEAPs, public expenditure expanded very rapidly. Table 8.1 shows that public expenditure rose sharply in the 1990s and the early 2000s. Nominal public expenditure grew by more than $10 \%$ per annum, and sometimes above $15 \%$, between $1997 / 8$ and 2002/03. ${ }^{1}$ Real public expenditure grew more slowly, mainly because of increases in the unit costs of public consumption and investment goods, which rose much more quickly than the consumer price in ation rate. Government consumption, however, still rose much faster than population in real terms. It is important to note that Government consumption includes items such as recurrent spending on health and education services, which contribute to future well being and prosperity.

Table 8.1: Public expenditure in Uganda

\begin{tabular}{|l|l|l|l|l|l|l|}
\hline & $97 / 8$ & $98 / 9$ & $99 / 00$ & $00 / 01$ & $01 / 02$ & $02 / 03$ \\
\hline $\begin{array}{l}\text { Nominal terms (Ushs million) } \\
\begin{array}{l}\text { Government consumption } \\
\% \text { growth }\end{array}\end{array}$ & 947.1 & $\begin{array}{l}1051.1 \\
(11.0)\end{array}$ & $\begin{array}{l}1224.4 \\
(17.4)\end{array}$ & $\begin{array}{l}1384.0 \\
(13.0)\end{array}$ & $\begin{array}{l}1590.8 \\
(14.9)\end{array}$ & $\begin{array}{l}1799.1 \\
(13.1)\end{array}$ \\
\hline $\begin{array}{l}\text { Public investment } \\
\% \text { growth }\end{array}$ & 352.7 & $\begin{array}{l}443.0 \\
(25.6)\end{array}$ & $\begin{array}{l}572.5 \\
(29.2)\end{array}$ & $\begin{array}{l}580.8 \\
(1.4)\end{array}$ & $\begin{array}{l}547.5 \\
(-5.7)\end{array}$ & $\begin{array}{l}552.9 \\
(1.0)\end{array}$ \\
\hline $\begin{array}{l}\text { Total public expenditure } \\
\% \text { growth }\end{array}$ & 1299.8 & $\begin{array}{l}1494.1 \\
(14.9)\end{array}$ & $\begin{array}{l}1796.9 \\
(20.3)\end{array}$ & $\begin{array}{l}1964.8 \\
(9.3)\end{array}$ & $\begin{array}{l}2138.3 \\
(8.8)\end{array}$ & $\begin{array}{l}2352.0 \\
(10.0)\end{array}$ \\
\hline
\end{tabular}

Source: National income accounts, UBOS

\section{Achievements}

\section{Increased allocations for poverty-eradication}

The increased levels of expenditure have delivered major increases in funding for basic services including construction and maintenance of main and feeder roads, primary 
education, primary health care, rural water supply, and adult literacy. This was achieved both by increases in total public expenditure and by reallocations within the part of the budget resource envelope funded by revenue and budget support (the GOU budget). The Poverty Action Fund has been used to protect directly poverty-reducing expenditures from intra-year cuts and to increase their share over time. The PAF share of the budget has risen from $17 \%$ in 1997/98, when it was first established, to $35 \%$ in the preliminary 2003/04 outturn ${ }^{2}$.

\section{The development of sectoral programmes and inter-sectoral strategies}

The shifts in expenditure have been accompanied by the development of coherent sectoral programmes. These have been fundamental in ensuring that the increased resource ows have been used to finance a well-identified set of priorities, reducing wasteful expenditures on low-priority items.

As noted in previous chapters, sectoral or subsectoral programmes have now been developed for education, health, roads, water (including urban and rural water and water for production), J/LO (criminal and commercial justice reform), subsectors of environment (land and wetlands), and social development. A sectoral plan for agriculture is at an advanced stage of development. Strong sectoral programmes are essential to the Partnership Principles for relations between Government and development partners and the approach to co-ordination set out in the third volume of the PEAP 2001.

Government has also strengthened the inter-sectoral linkages between expenditure in the productive sectors by the introduction of cross-cutting strategies, the PMA and the MTCS. The PMA ensures that expenditures on the promotion of rural incomes are looked at as a whole. The MTCS will play the same role for the productive sectors outside agriculture. A central aspect of both plans is that they aim to establish a shared understanding of the role of the state in promoting production, and they will review relevant sectoral expenditures in the light of this.

\section{Efficiency improvements in public expenditure}

Sectoral programmes have led to improved efficiency in some areas, reducing wasteful or duplicative expenditure including some technical assistance, and increasing the share of resources actually being spent on service delivery. A notable example of this is in the health sector, where the shift from donor funded project spending to spending through the GOU budget has brought about a major improvement in the allocation of expenditures towards the priorities identified in the Health Sector Strategic Plan. The share of the Health Sector's budget which comprises donor funded projects fell from 54\% in 2000/01 to $43 \%$ in $2003 / 04$ and is projected to fall further to $38 \%$ in the $2004 / 05$ budget. Recent analysis by the Ministry of Health found that that only $32 \%$ of the expenditures under donor funded projects comprise the priority expenditures costed in the Health Sector Strategic Plan.

A number of measures have been taken to ensure that the increased expenditures have in fact been translated into increased service delivery. These include: 
- Tracking studies, which examine the extent to which financial ows actually reach service providers on the ground. The first of these studies revealed that most of the non wage funding for the primary education sector was not reaching the schools; since then, the direct transfer of funds has ensured that schools receive the funds intended for them.

- Publication of financial ows in the newspapers.

- Strengthened formal accountability, as shown by the increased timeliness of auditing reports discussed in Chapter 6.

\section{Outstanding challenges}

Despite these positive achievements, there are many serious challenges facing the public sector with regard to the efficiency and effectiveness of public expenditure.

- The rapid growth in public spending which has taken place since the late 1990s outstripped the implementation capacity in the public sector and in the wider economy, with the result that costs were driven up and the quality of many projects was unacceptably poor. For example, there is evidence showing that many school classrooms were very badly constructed. Capacity constraints have been particularly acute in the roads sector, where construction costs are rising rapidly, cost overruns are commonplace, and there are long delays before donor funded road projects can get off the ground. ${ }^{3}$ Higher costs in the public sector, whether for wages and salaries or goods and services such as construction, have knock on effects in the wider economy, and help to drive up costs in the private sector.

- Budget implementation has been damaged by a lack of budget discipline in some 'powerful' ministries, especially in the public administration and security sectors, which have persistently overspent their budget estimates, thereby requiring supplementary budget allocations. In 2002/03 resource based supplementary expenditures amounted to Shs 91 billion, while in 2003/04 they climbed to Shs 127 billion, which is more than $5 \%$ of the total GOU budget. Table 8.2 below presents a sectoral breakdown of the resource based supplementaries in 2002/03. Resource based supplementaries can only be funded by making cuts in other areas of expenditure, hence less powerful ministries and agencies suffer severe cuts to their operational and development budgets. This problem is compounded because a large share of the budget, comprising approximately $80 \%$ of the GOU budget, is effectively protected from cuts because of the nature of the expenditures involved (e.g. they are statutory, wages or PAF expenditures), and hence the burden of funding supplementaries falls entirely on the small share of the GOU budget which is afforded no protection.

- Although the introduction of the Commitment Control System has curbed the accumulation of expenditure arrears, it has not eliminated them, especially as budget cuts caused by the need to fund resource based supplementaries are likely to exacerbate pressure to incur arrears. In addition, Government has accumulated a huge volume of pension arrears, possibly in excess of Shs 200 billion, although the precise amount has not been verified. 
Table 8.2: Supplementaries by sector, 2002/03

\begin{tabular}{|l|r|r|}
\hline Sector & $\begin{array}{c}\text { Amount of Resource } \\
\text { Supplementary }\end{array}$ & Percentage Share \\
\hline Security & $32,775,051$ & $35.92 \%$ \\
\hline Roads \& Works & 367,263 & $0.40 \%$ \\
\hline Agriculture & $5,478,490$ & $6.00 \%$ \\
\hline Education & 382,309 & $0.42 \%$ \\
\hline Health & $2,431,194$ & $2.66 \%$ \\
\hline Water & $1,448,600$ & $1.59 \%$ \\
\hline JLO & $14,289,953$ & $15.66 \%$ \\
\hline Accountability & 573,712 & $0.63 \%$ \\
\hline EF \& SS & $12,926,019$ & $14.17 \%$ \\
\hline $\begin{array}{l}\text { Public } \\
\text { Administration }\end{array}$ & $20,566,831$ & $22.54 \%$ \\
\hline TOTAL & $\mathbf{9 1 , 2 3 9 , 4 2 2}$ & $\mathbf{1 0 0 . 0 0}$ \\
\hline
\end{tabular}

- Sectors still undertake too many high cost donor funded capital projects, even when these are not explicit sector priorities. The counterpart funding and recurrent cost implications of such projects have to be met through the GOU budget and often crowd out essential spending in priority areas. A prime example is the road sector where an imbalance between capital projects and operational expenditures has led to the severe underfunding of essential road maintenance. It has to be pointed out that the responsibility for these expenditure misallocations often rests as much with donors who are eager to fund specific projects in which they have an interest as it does with Government.

- Some sectors take on too many activities or make unaffordable policy commitments in the hope of obtaining more funding; hence there are under funded programmes, which cannot achieve the desired targets.

- Although employment growth in the core civil service has been strictly controlled, there has been a proliferation of semi autonomous agencies and commissions, which now number more than 80 , and in which unit costs, including wage costs, are far higher than in the civil service. Spending in many of these agencies and commissions is pro igate because their managements and boards of directors do not exercise effective expenditure control. These agencies and commissions have diverted both financial resources and scarce high calibre public service professionals away from the core civil service. 
- Sector wide approaches have not yet been extended throughout Government. Some sectors without sectoral programmes, such as accountability, have taken on projects that are the proper concern of other sectors. Some areas of action fall under the mandate of more than one sector, with resulting confusion.

- Some expenditure in Government serves the purpose of staff incentives when it is classified for another purpose; for instance, training, travel abroad and vehicle expenses. This has efficiency costs, because it would be far cheaper and more effective to improve incentives by increasing the relevant cadre's pay than to provide incentives in this indirect form.

- The capacity for budget planning and implementation remains weak in many sectors. Unit costs of inputs and outputs are poorly scrutinised. Moreover, there are inadequate incentives for staff to minimise costs both in Government and in donor agencies. Overpriced contracts can generate opportunities for corruption. Supervision of spending is weak in some cases - both top-down and bottom-up mechanisms need strengthening.

- Sectors are still learning how to meet the needs of the poor; for instance, despite the success of UPE, the net enrolment rate has not risen above $85 \%$, indicating that $15 \%$ of primary school-age children are out of school. Table 2.5 in Chapter 2 shows that poorer people benefit less from existing Government programmes than better-off people, so targeting still needs to improve.

- In view of alarmingly high rates of infant and maternal mortality and morbidity and the heavy burden of disease that impacts so negatively on the nation's productivity and poverty, the GoU is giving increasing priority towards significantly improving hygiene and sanitation at the household level ("health is made in the home and is only repaired at health centres"). To this end, budget mechanisms for sanitation need to be strengthened at all levels. This is complicated by the fact that, like HIV/AIDS, this will require a cross-cutting, inter-sectoral response.

\subsection{Criteria for public expenditure allocation}

In order to guide decisions about public expenditure in the medium and long term, MFPED has identified criteria for prioritising allocations. These criteria should be explicitly incorporated into each of the sector's medium/long term expenditure plans and applied during the budget process. Sectors which can demonstrate that their expenditure plans are based on the application of these criteria are more likely to be allocated a larger share of the overall budget than sectors which cannot do this. These criteria should also provide the framework for the evaluation of projects by the Development Committee.

The criteria are as follows:

- There must be a clearly articulated role for the public sector in any activity funded by public expenditure. Public expenditure should be restricted to the supply of goods and services which have the nature of "public goods" and which cannot be supplied 
in an optimal manner by the private sector through the market. Government should not provide goods and services which can be supplied on a commercial basis through market channels, because this competes with the private sector which can produce and sell these goods more efficiently than can Government and because it diverts scarce public resources away from the provision of public goods, for the supply of which Government has a clear advantage over the private sector.

- Expenditures should have a clear link to the strategic priorities of the PEAP.

- Expenditures will be prioritised according to the returns to different alternative activities; i.e. those expenditures with the highest returns are accorded the highest priority. The returns may be presented in terms of income or in terms of dimensions of the quality of life (e.g. improvements in child or adult mortality). Box 8.1 below discusses how the returns to public expenditure can be measured. Using realistic calculations of projects' internal rates of return to guide expenditure allocations will contribute to improving the efficiency of public expenditure.

- Spending proposals should have precise output targets and realistic outcome targets.

- All activities, including projects, must be fully costed and the unit costs for the activity should be realistic and based on standard costs within Government.

- The allocation of responsibilities for the activity should re ect well-defined mandates, avoiding duplication and addressing inter-sectoral issues

- The impact on future public sector costs (and revenues, if any) must be articulated and fully taken into consideration in the relevant sector's medium/long term spending plans.

- Spending proposals must take account of the distributional impact of the spending; spending that has direct or very clearly demonstrated spin-off benefits for the poor, particularly within the poorest regions of the country, is encouraged.

- Spending should make use of existing administrative structures rather than create additional structures.

\section{Box 8.1 Comparing returns to public expenditure in different activities}

It is often asked how the budget is allocated across, and within, sectors. There are a number of techniques which are used to compare returns across different sectors. Government will use the following techniques in allocating funds. All expenditure proposals will be assessed using these techniques.

\section{Cost-benefit analysis}

In cost benefit analysis, the costs of a project and its benefits are calculated for each year of the project's existence. Both costs and benefits are discounted, so that costs and benefits in the present year are valued more highly than those in future years. The analysis 
produces a rate of return for the project ${ }^{4}$. Estimates can be adjusted to take employment creation into account and to value benefits more highly if they accrue to poorer people (unfortunately, this is rarely done). In the roads sector, projects are included if their rate of return is higher than $12 \%$. In the education sector, studies indicate that there are particularly high returns to primary education (even without correcting the estimates of returns for the better targeting of primary education) and that returns to education rose during the 1990s.

\section{Cost-effectiveness analysis}

Some programmes produce benefits that cannot easily be economically valued, such as improved health. Cost-effectiveness analysis measures the effectiveness of each shilling spent in terms of some non-economic objective such as the number of years of life ${ }^{5}$ saved. This can be used to compare returns to different medical treatments. The interventions included in the basic health package are intended to be highly cost-effective. Many preventive measures, like hygiene promotion and sanitation, are particularly costeffective. While cost-effectiveness analysis can show how to prioritise within the health sector, it cannot show how much the health sector can receive.

\section{Public-private substitution}

Ideally, expenditure evaluation should take into account whether the activity would occur if it were not publicly funded. For instance, in the absence of a public service some people will pay for private health care. In the Ugandan case, the provision of free primary health care and primary education produced a large increase in total demand for these services.

\section{Econometric and participatory methods}

In order to assess benefits, some estimate is needed of the effects of public expenditure. These can be derived by econometric study of Uganda's rich household survey data. In Uganda, one such study ${ }^{6}$ find that the impact of public expenditure on poverty is largest for agricultural research and extension, followed by roads, education and lastly health. Other studies have found significant positive effects of agricultural extension and electricity on household incomes ${ }^{7}$.

Participatory evidence also sheds light on the needs of the poor. Evidence available from UPPAP has shown that soil fertility decline and deforestation are practical problems facing poor people in Uganda now, and that while UPE is much appreciated, households still have problems financing costs such as books and uniforms.

\subsection{Funding PEAP expenditure priorities}

The earlier chapters have identified the priority expenditures in each pillar. Funding these priorities is a major challenge in the context of fiscal consolidation. The LTEF projections show that nominal public expenditure is expected to increase by $3 \%$ in $2005 / 6$ and about $7 \%$ per year from then on until 2009/10, followed by growth above $11 \%$ from then on. Given public sector in ation of about $4 \%$, this implies modest real growth during the early years of the LTEF period. 
Government's approach to funding the PEAP priorities is therefore as follows.

\section{Ensure that service delivery is maintained and pension obligations are met}

Government will aim to ensure that service delivery in major programmes is maintained. This implies that recurrent expenditures in real per capita terms on primary health and primary education are maintained, or that cost savings are found in these programmes (such as the use of radio or double-shift teaching in education). It will also imply some continued investment in classrooms (enough to keep the PCR roughly constant) and higher expenditures on road maintenance in the transport sector envelope.

Existing commitments also need to be honoured. This applies particularly to pension payments. Government is committed to honouring its current payment obligations and settling pension arrears.

\section{Continue with infrastructural programmes, but phase them over the LTEF period}

Government is committed to major programmes of investment in infrastructure, including roads and infrastructure for the supply of clean and safe water. These programmes are justified on expenditure criteria and remain a commitment of Government. However, there is a case for slowing down expenditure during the early years of the LTEF. The reason for this is that while a cut in recurrent expenditure would cause deterioration of existing services, a reduction in investment will cause a reduction in the speed of improvement ${ }^{8}$. For these reasons Government will consider 'back-loading' these investment programmes by slowing them down temporarily and increasing them during the outer years of the LTEF as more resources become available.

\section{Increase expenditures in previously underfunded priority areas}

This PEAP has identified various areas of service delivery that require increased support. These are organised hereunder by pillar. (Pillar 1 does not cover expenditure except for interest payments; as discussed in Chapter 2, control of these is critical for long-run sustainability).

\section{Pillar 2: production, competitiveness and incomes}

Within agriculture, Government will focus its expenditures on activities which clearly have the nature of public goods, and which complement private sector activity or correct market failures. It will not undertake activities which can be undertaken by the private sector, such as directly funding production or marketing of agricultural produce.

Within the environment and natural resource sector, water resource management, forestry and land reform are major priorities. Public action is required to stem the decline in Uganda's forest cover. Strengthening the property rights of poor farmers is also important if these farmers are to undertake the necessary investments to raise their productivity and incomes,

As noted above, the existing Road Sector Programme caters for the needs of the roads sector, with the important exception of community roads. Government is aiming to 
enhance other aspects of infrastructure including access to electricity in rural areas, air transport links and rail links as well as urban infrastrure improvements.

Within the economic services sector, Government is aiming at providing better infrastructure for industrial parks and strengthening business development services more generally. Rural financial services are also to be strengthened under the Microfinance Outreach Plan.

Key priorities for increased support in this pillar during this PEAP period are therefore:

- Agricultural research

- Agricultural advisory services

- Disease control

- Support to agricultural marketing and cooperatives

- district and community forests

- Business development services

- Industrial parks

- Rural financial services

- Rural electrification, as guided by the sectoral strategy

- Community roads (perhaps supported by local investment funds)

- Urban and community infrastructure improvement

\section{Pillar 3: Security, conflict-resolution and disaster management}

Ending the insecurity and coping with its aftermath imply a number of specific public expenditure requirements, including:

- Support to districts where service delivery costs are increased by insecurity (e.g. armed escorts).

- Flexible funding to allow special service delivery measures for areas where conventional service delivery is impractical (e.g. learning centres for children in IDP camps). This may not require funding which is additional to existing allocations, because such districts often have problems spending the existing conditional grants.

- Assistance to people in camps, especially for sanitation. Food and shelter receive significant donor support, but it is reported that sanitation is a problem.

- Psycho-social support to people traumatised by con ict, especially abducted children.

- Post-con ict security: it will be necessary to review policing needs as the con ict ends.

- Amnesty; it is important for Government to provide support to rebels who have asked for amnesty, although the support should not be so generous that people falsely claim rebel status.

- Support to IDPs who wish to return to their previous residence, and/or support to the long-term evolution of some IDP camps into urban settlements.

- Small arms control in the region (especially for Karamoja).

- Hardship allowances or other facilitation for recruitment of frontline staff in insecure districts. (This should be mainstreamed into the relevant sectoral strategies). 


\section{Pillar 4: Good Governance}

Many expenditures in this pillar need to be reduced rather than increased. However, some areas of the $\mathrm{J} / \mathrm{LO}$ sector require improvement. In the short run, Government can save resources by reducing case backlog, implementing community service, and strengthening prison farms. In the long run, Government will aim to strengthen the judicial system by recruiting and equipping officers as needed.

Key priorities in this pillar therefore include:

- Implementing case backlog project and community service roll-out

- Strengthening prison farms

- In the medium term, strengthening the manning and equipment of judicial services including the police.

\section{Pillar 5: Human development}

In the education sector, the major areas of expanded service delivery will be secondary and tertiary education. Since universal free access to these services is unaffordable in the medium term, Government will aim to target its support effectively at those who could not otherwise afford it.

Some additional support is needed for special needs students in primary education. It is also imperative that cost savings are achieved through measures such as sequential teaching and distance learning, and that excessive increases in salaries are avoided.

In the health sector, Government aims to enhance preventive and basic curative care, including the introduction of free treatment for HIV patients.

In the social development sector, some support is needed to strengthen the community development function. This will help to reduce the costs of service delivery in other sectors.

\section{Urgent short-term priorities}

In the short term, there is particular urgency for increases in service delivery in the following areas:

- Agricultural advisory services

- District and community forests

- Preventive health measures (especially at a household level in the form of improved personal hygiene and domestic sanitation).

Agricultural advisory services have very high returns and has been underfunded in the past; district and community forests and preventive health care have high returns and also reduce future social and fiscal costs (of environmental degradation and medical treatment respectively). Delay in action for any of these can have grave consequences, so they will be given special consideration in expenditure allocation. 


\section{Costs of improved service delivery}

The costs of increased service delivery have been estimated for each of the major items discussed above, although in some cases estimates are approximate. The largest cost items in this set are curative health (especially AIDS drugs and the cost of delivering them in adequate infrastructures), preventive health, agricultural advisory services, and secondary education.

Costs of preventive health may be reduced by using existing administrative structures to run information campaigns. The costs of NAADS may also be reduced by moving from a project/agency mode. However, the costs of the agency modality will be justified if they produce a significant improvement in performance of extension.

Secondary education costs are being estimated under the Education Sector Review. The sector is taking measures to reduce the unit cost of secondary education, but it inevitably remains more expensive than primary education, because class sizes are smaller and teachers need to be more highly qualified. The feasibility of the sector's targets will depend on how much of the expansion is supported by the private sector.

The costs for curative health are inevitably highly approximate. One major area of uncertainty is the treatment of drugs. A major new challenge is presented by the fact that anti-retroviral drugs (ARVs) for the treatment of HIV/AIDS, which were previously unaffordable, have become much cheaper in the past few years. The cost-effectiveness of spending on ARVs remains lower than those of some other medical interventions that are not yet afforded by Government. However, the scale of the HIV epidemic presents Government with a significant policy issue.

While Government is committed to free provision of AIDS drugs, the financial implications have not yet been factored into the health sector's envelope and could be very large. Initially, there are perhaps 100,000 people who need the drugs, and if the costs of treatment (including counselling) are conservatively estimated at 700,000 per month the annual cost would be about 84 billion shillings. However, as the numbers of people qualifying for treatment rise, the costs are likely to increase overtime. There are between 500,000 and 1 million people infected with HIV in Uganda (according to different estimates), so the ultimate costs could be very large if the price of drugs does not come down further. Government will therefore aim to identify funding modalities that allow these drugs to be supplied sustainably to the accumulating number of patients who are likely to need them. Possible financing options include donor subsidy of drugs, so that the cost of drugs is included in the budget but at less than full cost. The use of generic drugs, wherever feasible, will also be necessary in order to keep the overall costs realistic.

In some cases, such as microfinance and rural electrification, the costs depend on the effectiveness of subsidy in eliciting private supply. This is not perfectly predictable and will need to be monitored. 


\section{Restrain growth in other areas}

Areas that are not identified as needing increases in expenditure will be restrained. In general, Government will aim to keep these areas constant in real terms or reduce them, by finding cost savings, where feasible. In this way, the real growth in the total envelope will be available for increases in PEAP priorities. This will give increasing scope for funding PEAP priorities later in the period, when total public expenditure is expected to increase faster. In the first few years of the LTEF period, the nominal growth of public expenditure is projected at about 7\%, and the real growth at between $3 \%$ and $4 \%$; this gives some scope for reallocations to priority areas, but only if expenditures in lower priority areas are tightly controlled

\section{Cut back on areas of waste}

During the past PEAPs, it has been relatively easy to finance increased high-priority expenditures, because the resource envelope was increasing fast. This is no longer the case given projected limited growth in real public expenditure over the next few years. It is therefore imperative to identify areas of lower-priority expenditure. These are of three main kinds:

First, some sectors are too large for the mission they are expected to conduct. In particular, expenditures on public sector management and political governance are excessive (with the important exception of pensions).

Secondly, there are areas within most sectors that are not well-prioritised. This re ects the lack of coherent strategies in some sectors, and the adoption of projects that do not cohere well with the sector's overall objective in others.

Both of these issues are discussed below as the individual sectors are discussed.

Thirdly, there are cross-cutting issues that would allow the cost-effectiveness of expenditure to be reduced. The major issues are:

- Projects

- Agencies

- Managing human resources

These issues are discussed in section 8.6.

\section{Account for possible increases in unit costs}

The LTEF projects that the costs of Government consumption will rise by about $4 \%$ a year, compared with consumer price in ation of about 3.5\%. This allows room for some increase in real wages in the public sector, though not necessarily enough to keep pace with wage growth in the private sector.

While Government has to maintain pay in real terms, this is coupled with the objective of improving service delivery by increasing personnel in key sectors. Government will 
therefore be very cautious in implementing pay reform, and the sequencing of pay increases will be guided by the pay reform strategy as set out in Chapter 6. Any increases in pay outside this strategy will increase costs and jeopardise service delivery, as well as have serious implications for future pay and pension liabilities.

It may be possible to increase wages while not increasing the overall costs of human resources in the public sector by bringing pay in agencies into line with the rest of the public sector and by reducing the reliance on particularly expensive forms of human resources such as international consultants.

\subsection{Sectoral allocations}

To show how the sector shares are expected to evolve over the long term, table 8.3 sets out the LTEF sector ceilings for 2003/04 and 2013/14. For the fiscal years 2004/05-2006/ 07, the LTEF sector ceilings are taken from the current MTEF. For the subsequent years, the LTEF sector ceilings were determined on the following basis. ${ }^{9}$

First, the aggregate budget resource envelope for each year of the LTEF was derived using a financial programming framework in which fiscal policy is made consistent with macroeconomic targets and targets for the sustainability of public finances, notably reducing the dependence of the budget on donor aid and reducing the external debt burden to the sustainability threshold in the HIPC initiative. Secondly, the annual interest payments were computed on the basis of projections of the domestic and external debt stocks and nominal interest rates on Government debt. Thirdly, the expenditure areas which comprise the Government's strategic priorities as identified in the PEAP were allocated rates of expenditure growth over the LTEF period which raise their sectoral shares in the budget. The sectors identified as priorities are health, education, agricultural extension and research, and district road maintenance.

Fourthly, to fund the higher shares of the priority sectors it is necessary to cut the shares of sectors which contribute less to the PEAP priorities or where there is major scope for expenditure savings. These sectors were allocated rates of growth which are lower than the average for public expenditures, with the exception of those items of expenditure over which Government has little discretion because of their statutory nature, such as pension payments, where independent estimates of the long term funding requirements were used.

The sector ceilings in the LTEF cover all of the sectors' expenditures, including wages, non wage recurrent expenditures, GOU development expenditures and donor funded projects. The LTEF includes some unallocated resources within the budget resource envelope which could be used to increase funding for priority expenditures. 
Table 8.3: Provisional Sector Shares, 2003/04 and 2013/14: Shs billions

\begin{tabular}{|l|l|ll|}
\hline Sector & $\mathbf{2 0 0 3 / 0 4}$ & $\mathbf{2 0 1 3 / 1 4}$ \\
\hline Security & $336 \quad(10.4 \%)$ & $674 \quad(9.2 \%)$ \\
\hline Roads and Works & $303 \quad(9.4 \%)$ & $915 \quad(12.4 \%)$ \\
\hline Agriculture & $97 \quad(3.0 \%)$ & $326 \quad(4.4 \%)$ \\
\hline Education & $575 \quad(17.8 \%)$ & $1474 \quad(20 \%)$ \\
\hline Health & $375 \quad(11.6 \%)$ & $1169 \quad(15.9 \%)$ \\
\hline Water & $89 \quad(2.7 \%)$ & $327 \quad(4.4 \%)$ \\
\hline Justice Law and Order & $208 \quad(6.4 \%)$ & $329 \quad(4.5 \%)$ \\
\hline Accountability & $261 \quad(8.1 \%)$ & $229 \quad(3.1 \%)$ \\
\hline $\begin{array}{l}\text { Economic Functions and Social } \\
\text { Services }\end{array}$ & $273 \quad(8.5 \%)$ & $745 \quad(10.1 \%)$ \\
\hline Public Administration & $382 \quad(11.9 \%)$ & $826 \quad(11.2 \%)$ \\
\hline Interest payments & $245 \quad(7.6 \%)$ & $273 \quad(3.7 \%)$ \\
\hline Pote: Sector shares are in paren & & & \\
\hline
\end{tabular}

Note: Sector shares are in parentheses; sector shares do not sum to $100 \%$ because of unallocated budget resources. Source:LTEF

In accordance with the above analysis, the shares of agriculture, health, education, roads and works are projected to increase over the period. The following issues arise:

- There is a strong case for phasing infrastructural expenditure over the period of the LTEF so that most of the increases come in the second half, when resources are expected to be less scarce.

- The scope for further control of the less directly poverty-reducing expenditures.

- The need for continuing analysis on the implications of these shares for real service delivery in each sector and reviewing them accordingly.

\section{Procedures for determination of sector ceilings}

Budget reforms will entail a fundamental shift in the method by which sector expenditure ceilings are determined. In future, all sector expenditure ceilings will be determined on the basis of allocating a centrally determined budget resource envelope for aggregate Government expenditures, including donor projects, according to the Government's strategic spending priorities, which will re ect PEAP priorities. This means that sector expenditure ceilings will be determined independently of the resources which any donors 
propose to give to a sector, whether through project aid or sector budget support. It will not, therefore, be possible for a sector to obtain an increase in its expenditure ceiling simply because donors are offering more aid to that sector. To increase its sector share, a sector must provide compelling evidence that it requires more budget resources to undertake the priority expenditures identified in this PEAP; that it can implement increased expenditures efficiently; and that, at the margin, higher expenditures in that sector will contribute more to achieving the PEAP objectives than expenditures in other sectors of the budget. This reform in the method of determining sector expenditure ceilings is crucial for understanding the role which sectors will be expected to play in delivering PEAP priorities, which is discussed in section 8.6 below.

\section{The future of the Poverty Action Fund}

The Poverty Action Fund (PAF) was set up in 1997 to provide a mechanism for strengthening the pro-poor orientation of the budget. It is a so called "virtual fund" in that PAF resources are part of the pool of general budget resources in the Uganda Consolidated Fund and PAF expenditures are an integral part of GOU expenditures, they are not in any way "off budget". The PAF consists of a subset of the GOU budget which is considered to contribute directly to poverty reduction (these are expenditures which fall under the former pillars 3 and 4 of the PEAP), notably primary education, primary health care, water and sanitation, agriculture and rural roads.

The subset of the GOU budget which comprises the PAF receives privileged treatment in three respects. First, Government has progressively increased the share of the GOU budget allocated to expenditures in the PAF, from $17 \%$ in $1997 / 98$ to $35 \%$ in 2003/04. Secondly, PAF budget allocations are protected from the within year cuts to other components in the GOU budget which are often necessary to accommodate budget resource shortfalls or resource based supplementaries expenditures. Thirdly, PAF expenditures by line ministries and local governments are subject to much stricter reporting and monitoring requirements than other parts of the budget, to ensure that the money is spent on the intended items of the budget.

One of the benefits of the PAF is that it has contributed to enhancing donor confidence that budgetary resources are being used to tackle poverty, and thereby encouraged the shift from donor project aid to budget support. However, there are also important drawbacks to the PAF which are intrinsic to its design. In particular, as its share of the budget has increased, it has tended to distort budget allocations towards specific social sectors which are favoured by donors, at the expense of other national priorities such as support for more productive activities. The within year protection afforded to PAF budget allocations has also reduced the exibility in the budget to respond to budget shocks, thereby intensifying the burden of cuts on the "non protected" sectors, many of which also make an important contribution to PEAP objectives. Because a large share of the PAF consists of conditional grants to the districts, it has also reduced the exibility of local governments to allocate the transfers that they receive from central government to the priorities determined at the local level, rather than those dictated by the centre, and has thereby undermined the autonomy and accountability of local governments to the local electorate. Finally, the special reporting and monitoring arrangements for PAF expenditures have distracted attention and incentives, from the need to strengthen accountability throughout the public 
sector, and not just on those sectors favoured by donors. Scarce Government resources for monitoring public expenditures have been concentrated on PAF expenditures to the detriment of other components of the budget. ${ }^{10}$

Virtual poverty funds such as the PAF should be an interim arrangement, designed to circumvent weaknesses in budget systems while more comprehensive public expenditure management reforms to tackle these weaknesses are put in place and poverty focussed expenditures are mainstreamed into the budget. Government has made progress in implementing public expenditure management reforms since the PAF was set up in 1997. Given the drawbacks described above, it is desirable to phase out the PAF over the long term and instead focus on ensuring that all parts of the Government budget, and not just a subset of the budget, contribute to meeting PEAP objectives. Obviously this will require further strengthening of the existing budget systems, where many weaknesses remain. In particular it will be necessary to demonstrate to the budget support donors and other stakeholders that Uganda's public expenditure management systems are capable of consistently formulating a pro-poor budget, of implementing that budget in line with the budget estimates appropriated by Parliament, and of ensuring that budgetary resources actually fund the intended expenditures and that these expenditures are implemented efficiently. The inter sectoral reallocations described in this section, the reforms to sector budgeting discussed the next section and the measures to rationalise government structures to increase efficiency discussed in section 8.7, together with the reforms to monitoring and accountability addressed in chapter 9 will all be necessary to ensure that phasing out the PAF does not undermine the contribution of the budget to fighting poverty.

\subsection{Strengthening Budgeting at the Sector Level}

Within all sectors there is scope for improving the allocation of expenditures, shifting resources from low priority to high priority programmes and projects and especially towards programmes and projects which best contribute to poverty eradication. The key to this objective is better budgeting at the sectoral level.

Sector wide approaches will be extended to all areas of the budget. Sectors will be responsible for drawing up medium/long term expenditure plans with explicit expenditure priorities guided by the criteria set out in section 8.3. Each sector's expenditure plans must be affordable within that sector's expenditure ceiling, as delineated in the MTEF and LTEF. Sectors (and ministries/agencies within the sectors) must avoid making public policy commitments which are unaffordable within their expenditure ceilings in the hope that this will generate pressure for extra funding, as this is not compatible with sound budgetary procedures, to say nothing of the credibility of Government policy. Even policy commitments endorsed by Cabinet can only become meaningful if resources are available to fund them. The essence of good budgeting is prioritisation within a hard budget constraint. Sector spending plans, and the hard budget constraints under which they operate, must cover all forms of expenditure, including the donor funded projects. Project appraisal must become much more rigorous. These issues are examined in more detail below: 


\section{Expanding sectoral approaches to cover the whole of Government}

As noted above, the main successes in public expenditure have come from those sectors with strong sectoral approaches, such as health and education, and the main difficulties have arisen in those sectors where the sectoral approach is weak. For this reason Government will seek to ensure that within the next two years all remaining sectors adopt a sector-wide approach in which the sector as a whole prioritises its activities and allocates resources accordingly.

\section{Sector Budgeting}

Each sector will be responsible for drawing up medium/long term expenditure plans which clearly delineate the sector's spending priorities within its expenditure ceiling. Sector spending plans must be realistic and in particular take full account of the recurrent budget requirements of the sector, including its wage requirements, as well as requirements for counterpart funding of donor funded projects. The budget submissions by the relevant ministries/agencies to the MFPED during the annual budget process must be consistent with the spending plans of the sectors to which those ministries/agencies belong.

Currently the wage budget is largely determined independently of the sectors, but over the long term Government intends to provide the sectors with more exibility to determine manpower levels within the sectors so as to allocate resources between the wage and non wage budgets most efficiently.

Sectors must strive to reverse the imbalance that has emerged in recent years between the capital and recurrent budgets, and which has squeezed resources for essential maintenance expenditures. Adequate maintenance of existing capital assets must take precedence over the construction of new assets because the former is far more cost effective than the latter.

All sectors are expected, as part of their regular work, to examine the incidence of the benefits of their services and the extent to which the poor are benefiting. Sectors are expected to monitor incidence (if feasible) by income group, geographical region and gender. Other dimensions of incidence, such as the participation of orphans in education and health care, will be important in particular sectors.

In their sector expenditure plans, the sectors should also consider the opportunities for, and the costs/benefits of, private sector participation in service delivery, through for example, the contracting out of services and for projects, build operate and transfer systems.

\section{Integrating project aid into the MTEF}

As noted above, prioritisation requires the existence of a clear hard budget ceiling, which is operated through the MTEF. Government is therefore integrating project aid into the MTEF expenditure ceilings starting in fiscal year 2004/05.

Sectors will receive ceilings for both recurrent and all development expenditures, including donor funded projects. ${ }^{11}$ In the event that the sector takes on donor funded projects greater than the value of these projects in its sector expenditure ceiling, its GOU 
budget ceiling will be cut accordingly, to maintain the integrity of the overall expenditure ceiling. It is, therefore, the sector's responsibility to ensure that donor funded project expenditures are controlled and don't crowd out its GOU budget expenditures.

The integration of project aid within the MTEF will have the following benefits:

(1) Externally funded projects will be made subject to a hard budget constraint and normal budgetary controls will be imposed on them. This process will enhance budget discipline, as line ministries will not be able to circumvent budget ceilings by lobbying donors for project aid instead of budget support.

(2) Because of the hard budget constraint imposed by the sector ceiling, the integration of projects will encourage ministries and agencies within each sector to compete for expenditure demands when accepting a donor funded project, which gives them an incentive to ensure that the accepted projects are in line with the sector's spending priorities. This will ensure that donor-funded projects are properly brought into the annual budget process and that they re ect the priorities set out by the Sector Working Groups (SWGs).

(3) It will encourage donors and line ministries to shift within the sector from project aid to budget support in line with Government policy. As noted in section 8.2 above, this will bring major improvements in the efficiency of public expenditures, because donor projects frequently comprise low priority expenditures and much higher unit costs than GOU budget expenditures.

Sector expenditure ceilings will be determined on the basis described in section 8.5 above, independently of donor funded project proposals. Sectors that wish to argue for a higher expenditure ceiling should make a case that their sector as a whole needs more money to fulfil its mandate, rather than proposing isolated projects in the hope that they will be funded additionally.

It must be noted that the integration of projects has major implications for the way in which the sector operates. It is very important that both sector ministries and donors understand that project commitments will have a negative effect on exible resources owing to the sector through the GOU budget. Projects should, therefore, be accepted only if they are in line with the sector's priorities and can be accommodated within the sector's expenditure ceiling. No activity should be undertaken because there are project funds available; rather, the sector should identify its priorities and allocate project funds and exible resources accordingly, within its sector ceiling.

\section{Evaluation of Projects}

An explicit procedure for evaluating and accepting all development projects, whether funded through the GOU budget or the donor project budget, will be put in place.

Under the PEAP partnership principles both Government and donors are committed to avoiding any stand-alone donor projects. So far, this has not been fully implemented; only in those sectors where a clear sectoral strategy exists has it been possible to enforce 
this. From now on, Government will only consider projects that are submitted through a sector working group. The sector must demonstrate how a project fits within the sector's expenditure plans.

The sectors will be responsible for submitting all project proposals to the Development Committee (DC) in the MFPED. When submitting a project proposal, the sector must demonstrate that:

- The project is consistent with that sector's expenditure priorities as articulated in its sector expenditure plan;

- It can be accommodated within the sector's integrated expenditure ceiling without squeezing higher priority items out;

- All counterpart and recurrent cost implications have been accurately determined and can be accommodated with the expenditure ceiling;

- The project falls within the sector's mandate. If not, the project will be referred back to the appropriate sector;

- The project utilises appropriate inputs. For instance, projects that involve large elements of expatriate technical assistance or project vehicles will be very carefully scrutinised to ensure that these highly expensive inputs are really needed. Government allocated more than 100 billion shillings for consultancy in the 2003/04 budget; there is serious concern that these resources are not efficiently used and crowd out the employment of qualified Ugandans on assignments where their capacity would be developed;

- The unit costs are convincing. Previous project proposals, even from donor agencies, have often been extremely vague in their explanations of the costing of projects.

When it becomes understood throughout Government that the sector ceiling represents a hard budget constraint, the incentive to submit low-quality project proposals will rapidly diminish. Also, it will be much easier to identify an exit strategy from old projects, because sectors will be able to anticipate that a reduction in their project expenditures will be compensated by an increase in the availability of exible resources in the GOU budget or at least other project resources.

There have in the past been cases where projects are overpriced, either because donors wish to have some 'slack' in the budget to allow exibility in the management of the project, or because of corruption in the procurement process. Such practices are unacceptable. In future, the sector will have an incentive to ensure that project costs are minimised, because this will free up resources for other purposes within its overall sector ceiling. This is crucial, because the sector is often in a better position than MFPED to make a realistic judgement on the appropriate costs. Where donors wish to include a contingency, this needs to be made explicit.

Currently a large proportion of development expenditure is recurrent in nature. Ideally development projects should be implemented within a specified period, following which the activities hitherto implemented should be integrated into the normal operations of Government. In addition, now that the new Chart of Accounts has unified the expenditure codes for both recurrent and development expenditures, and projects are now regarded as 
cost centres, Government will consider whether expenditures of a recurrent nature should be reclassified under the recurrent budget. This should help with integrating human resource management throughout Government, which is discussed in section 8.7 below.

If the project funding involves an external loan, the MFPED will evaluate the terms and conditions of the proposed loan to ensure that they are consistent with Uganda's external debt strategy. No external loan which is not consistent with the external debt strategy can be accepted by Government.

The procedures for evaluating and accepting development projects will be set out in regulations to be issued by the Minister of Finance, Planning and Economic Development under the Public Finance and Accountability Act. These regulations will also impose requirements on project executing agencies for the timely and accurate reporting to the MFPED of disbursements of donor project aid resources and project expenditures.

\section{Inter-sectoral issues and local Government flexibility}

A number of important practical issues require specific inter-sectoral coordination because weak coordination can lead to inadequate public action or duplication of expenditures. Examples include sanitation, the management of training institutions, irrigation, and agricultural marketing. In each case the sector that supplies the services may not be the sector that will be most affected by their performance. It may then be necessary for MFPED to draw sectors' attention to the impact of their actions on other sectors.

There are also a number of cross-cutting issues that in uence actions in various sectors. Examples include gender, HIV/AIDS, vulnerable groups and child mortality. In a number of cases, strategies have been developed to address these cross-cutting issues. For the purposes of expenditure allocation, these strategies are not additional to the budget; they make recommendations which sectors can integrate into their priorities. However, the sector has to decide how the recommendations of particular cross-cutting strategies rank with other priorities, within their overall resource envelope. Hence cost estimates in cross-cutting strategies should not be used as the basis for specific project proposals unless they have been integrated into the priorities of the relevant sector. In the case of the PMA, a regular mechanism has been established by which the PMA secretariat provides input into the budgetary process to ensure that the PMA needs are addressed.

Sectoral expenditures include spending at local government level on basic services, much of which is transferred from central government under conditional grants. Over time, the allocation of an increasing proportion of funds will be determined by local governments themselves. It will still be necessary, however, for central government to project and monitor the allocation of expenditures in order to ensure that national objectives for service delivery are achieved. In the short run, exibility is being introduced in the sectoral allocation of local governments' investment budgets. Funds made available for this purpose under the LGDP can therefore be used to achieve some of the PEAP priorities including hygiene promotion and sanitation and water-for-production. 


\subsection{Rationalising public sector structures}

PEAP priorities cannot be funded within the budget resource envelope without a serious and sustained effort to reduce waste throughout Government. Four key areas have been identified where major efficiency savings are possible: donor projects (which are discussed in section 8.6 above), commissions and autonomous agencies, Government structures, and human resources.

\section{Rationalising commissions and autonomous agencies}

As discussed in section 8.2 above, there are concerns about the large number of commissions and agencies, the use of revenues raised by the agencies, and the remuneration paid in them. A rationalisation of these structures offers some scope for cost savings. Government will therefore undertake the following actions:

(a) Government will review the functions and expenditure of all the executive agencies and Commissions. Without pre-empting the results of this review, there are various criteria that should be applied to see whether the establishment of an agency is justified. In particular, agencies should fulfil at least one of the following criteria:

- The function is closely related to the market, with potential for revenue-raising (e.g. producer bodies).

- The function involves regulation or service delivery that is clearly outside the scope of ministries' normal work (e.g. electricity regulatory authority, universities),

- The function involves contracting technical services (e.g. NAADS, RAFU, service commissions).

- The function requires independence from political pressure (NEMA, BOU, UHRC, UBOS, EPRC).

Agencies that do not fulfil any of these criteria will be reintegrated into central Government. It is crucial that there should be no duplication between the agencies and the traditional civil service.

(b) Government will ensure that the expenditure proposals of executive agencies are fully scrutinised as part of the budget process. Cost-inefficient agencies, or agencies that fail to make detailed and justified budget submissions, will have their budgets cut. Every agency should be required to identify, in its annual budget submission, areas where cost savings will be made.

(c) Consideration will be given to requiring agencies to remit revenues that they raise to the Consolidated Fund. This would ensure that the use of these resources is included in the budget process. In this context it is important to note that agencies that raise revenue do so by using quasi-fiscal powers or by using a national resource. These resources should be used as carefully as other national resources, and subject to the same budget procedures, including Parliamentary scrutiny, as the use of normal budgetary resources.

(d) As noted in Chapter 6, MOPS is mounting a study on the relation between pay in agencies and in the public service, with a view to applying the single-spine approach to posts in executive agencies. 
(e) The use of performance contracts will be explored to ensure that agencies efficiently carry out their functions and perform well on monitorable indicators, as the rest of Government is expected to.

(f) The creation of new agencies will be avoided unless they clearly meet the conditions given above.

(g) The costs of agencies will be reappraised in the context of sectoral strategies.

In some cases, such as NEMA, agencies have been established with strong donor support but without being properly integrated into sectoral strategies. Donors need to be aware that Government cannot undertake to continue to finance such agencies at existing levels of funding unless the relevant sector clearly identifies them as a priority. In future, projects to support executive agencies need to consider the long-run sustainability of the institutions involved far more carefully than has been the case in the past.

The cost savings achievable by these cross-cutting measures can be estimated in some cases. A study of the constitutional commissions found that Shs. 6 billion could be saved if technical staff in them were paid at public service rates. This represents the vast majority of their wage costs. In total, executive agencies and Constitutional Commissions cost at least Shs. 175 billion a year, of which Shs. 115 billion is recurrent expenditure; this total does not include the BOU or any funds that are raised from hypothecated taxation. Assuming that recurrent expenditures could be reduced by half by integrating pay scales and other efficiency-savings measures, the cost savings would be at least Shs 57 billion, and much more may be achievable.

\section{Rationalising Government structures}

As discussed in Chapter 6 and section 8.5, there is scope for cost savings from reducing the size of governmental structures or at least arresting their growth. The following areas need review:

- The number and mandates of ministries and ministers.

- The process of establishing district authorities. Uganda's regulations are unusually relaxed in the conditions under which they allow new authorities to be created, and this has encouraged districts to proliferate over time.

- The size and affordability of district authorities' establishments.

- The role of political appointees in ministries and local Government, including advisors and RDCs.

- The size of Parliament.

\section{Integrating human resource expenditures throughout the public sector}

As noted in chapter 6, the existing pattern of expenditures on human resources is not optimal. Government is spending much less on the administrative civil service within ministries than on consultancy; project staff also absorbs a considerable amount of resources. There are three major concerns. 
First, expenditures on human resources in the development budget are not well coordinated with the overall strategy.

Secondly, there appears to be an excessive use of highly expensive inputs such as consultancy in some sectors.

Thirdly, there are unjustifiable discrepancies between wages paid in central Government and the remuneration in projects and agencies. There may be cases where pay above the public sector pay scale is needed to attract staff of the right calibre. As pay reform proceeds, this should progressively apply to fewer posts in agencies. Even before pay reform, existing discrepancies are in many cases unjustifiable. As noted above, many economists in the public service are paid less than drivers in agencies, and drivers are paid much more than the private sector comparator study suggests is needed. Even for skilled cadres, many of those employed in agencies have skills that are specific to the public sector and would not necessarily have extensive opportunities in the private sector; often, also, they are recruited directly from the public service. In such cases there is no justification for a large differential with rates of pay in the public service, especially as the jobs done in agencies are often less critical for the good management of Government and the design of policy than the jobs in the public service. 


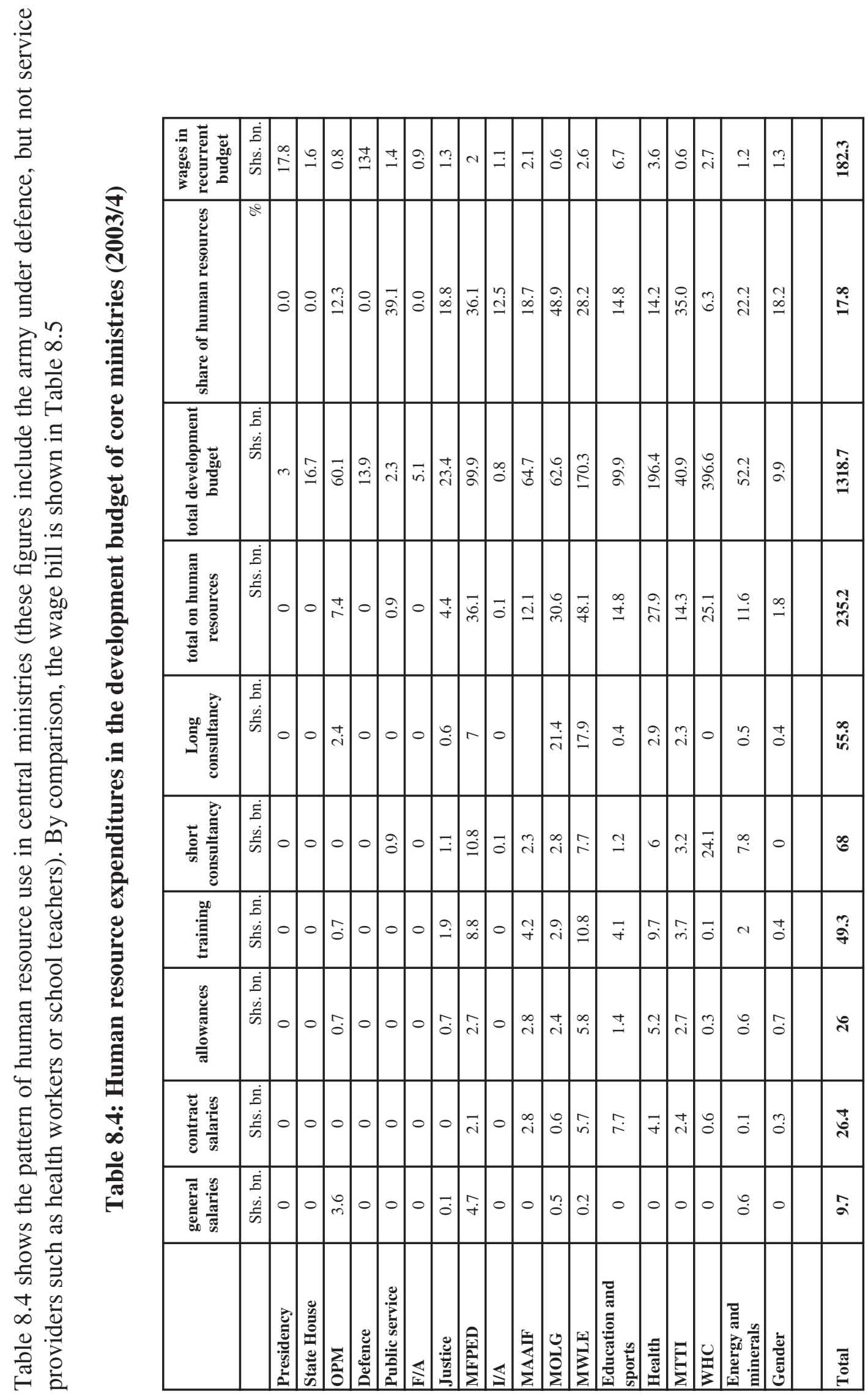


Table 8.5: The wage bill in $2003 / 4$

\begin{tabular}{|l|l|}
\hline Category & Wages, Shs. Billion \\
\hline Defence & 134 \\
\hline District education & 279 \\
\hline District health & 45 \\
\hline Police and prisons & 46 \\
\hline District unconditional grant & 47 \\
\hline ISO/ESO & 13 \\
\hline Foreign missions & 6 \\
\hline $\begin{array}{l}\text { Central Government ministries other than } \\
\text { defence }\end{array}$ & 48 \\
\hline Other & 45 \\
\hline Total & 673 \\
\hline
\end{tabular}

It can be seen that human resource expenditures in the development budget in core ministries $^{12}$ amount to Shs 235 billion, in comparison with Shs 673 billion on the wage bill and only Shs 48 billion on the core administrative civil service. If Government were able to reallocate the amounts on human resources in the development budget to the wage bill, there would be considerable scope for pay reform without increasing the total amount being spent on human resources.

One complication here is that the pattern of expenditures on the development budget across sectors is different from that of the wage bill. Hence the strategy of reallocating between the recurrent and development budgets will affect sectoral allocations.

Operationally, better management of human resources will need to be pursued by better scrutiny of project proposals. Every project that has a significant consultancy component will be reviewed to establish whether the needed skills could be developed within the public service.

\section{Priority actions for integrating human resource expenditures}

- Government will aim to control the total amount spent on human resources in recurrent and development budgets, and to reallocate within this amount from other forms of expenditure to the wage bill 
- Government will monitor recruitment and retention problems and prioritise pay increases for cadres and geographical areas where the pay reforms are needed.

Pay scales in agencies and on projects will progressively be reconciled with equivalent grades in the public service. Government will aim to reduce expenditures on consultancy by enhanced scrutiny of projects.

\subsection{Donor support for public expenditure}

Donor aid can support the public expenditure requirements of the PEAP by contributing to the government's budget resource envelope. To maximise the contribution which donors can make, the nature of donor aid is as important as its magnitude, if not more so. The LTEF projections of long term donor aid requirements indicate that the annual requirement for donor aid for central government will average just under $\$ 800$ million during the 2004/05 to 2013/14 period, which is only slightly higher than the average aid in ow over the last four fiscal years of around $\$ 766$ million. ${ }^{13}$ Aid requirements will increase slightly in the second half of the LTEF period. In the first five years of the LTEF period an annual average of about $\$ 765$ million of aid is required to fund the budget, whereas in the subsequent five years an annual average of $\$ 810$ million is needed.

Hence government does not require donors to increase significantly the magnitude of their aid, in dollar terms, to Uganda. What government does require to maximise the contribution of donor aid to the PEAP is a shift in the composition of aid, in its predictability and in the manner in which donor aid programmes are articulated with the government budget.

Government has repeatedly expressed its preference for budget support instead of project aid, for reasons which were explained in detail in the previous PEAP vol III. In brief, providing aid in the form of budget support instead of project aid enhances government ownership of the budget and enables a more internally coherent budget to be formulated, in which scarce budgetary resources are allocated according to the government's own strategic spending priorities and the relative costs and benefits of competing expenditure demands. Project aid leads to a fragmentation of the budget, with decisions about donor project expenditures being divorced from the normal budget process and taken without proper consideration of the relative merits of all competing expenditure demands. Donor funded projects often involve much higher unit costs than projects funded from the GOU budget and consist of much lower priority expenditures, because they are in uenced heavily by donor priorities.

Over the last four years, donor aid to central government has been split on average equally between budget support and project aid. Over the course of the LTEF, government envisages the share of budget support rising to around $62 \%$ of total aid to central government.

As well as a preference for budget support over project aid, government prefers general budget support over sector budget support. If donors wish to give sector budget support to a specific sector it should be understood that this cannot in uence the size of that 
sector's expenditure ceiling. As was explained in section 8.5 above, sector expenditure ceilings are determined centrally through the national budget process, on the basis of the government's strategic spending priorities, not by how much sector support donors are promising to favoured sectors. A sector's expenditure ceiling cannot be increased simply because a donor has offered more sector support, or more project aid, to that sector. That would be antithetical to any notion of rational public finance, because it means that the sectoral composition of the budget would be determined by decisions taken by individual donors, in isolation from broader considerations about the optimal composition and size of the budget and the relative merits of competing expenditure demands. It would also undermine government ownership of the budget. Donors have a right to contribute to the debate about government's spending priorities, but this right should be exercised through participation in the many fora which take place during the budget process, such as the Public Expenditure Review, not by trying to use their own aid as a lever to channel expenditures towards sectors which they favour.

\subsection{Conclusion}

Wide ranging reforms to public expenditure management are required to achieve the PEAP objectives. Given that budgetary resources are scarce, it is essential that they are allocated optimally in line with PEAP priorities. Public expenditures should be focussed solely on the provision of public goods and services which cannot be supplied in an optimal manner by the private sector through the market mechanism. There is no point in dissipating scarce public resources funding commercial activities which can be undertaken far more efficiently by the private sector.

The three core challenges of the PEAP are accelerating pro-poor economic growth, human development and con ict resolution and support for recovery in con ict af icted areas. To maximise the contribution of the budget to meeting these core challenges it is imperative to ensure that aggregate public expenditure remains within the budget resource envelope set out in the LTEF, which is consistent with the macroeconomic objectives of the PEAP and ensuring the sustainability of public finances, and to shift budget allocations towards pro-poor expenditures. Therefore each of the sectors must prioritise their expenditures within a hard budget constraint. In line with the PEAP priorities, the LTEF envisages an increase in the sector shares of the budget for agriculture, roads and works, education and health. This will only be possible by reducing the share of the budget consumed by interest payments through cutting the fiscal deficit, and the budget shares of the public administration, accountability and the economic functions and social services sectors. Cuts in the budget share of the public administration sector will require a rationalisation of political and administrative structures, whereas the excessive share of donor funded projects in the accountability and economic functions and social services sectors affords scope for reducing their sector shares without undermining priority expenditures.

Strengthening budgeting at the sector level will be crucial to achieving the PEAP objectives. Sector wide approaches, which have already generated important benefits for budget planning, will be extended to cover all areas of the budget, and all budget submissions by line ministries and other spending agencies must be consistent with the relevant sector expenditure plan. All sectors will draw up medium/long term expenditure plans to cost and 
prioritise their expenditures within their LTEF sector expenditure ceilings. These ceilings will incorporate the donor funded projects which will be integrated into the MTEF and will no longer offer the sectors additional spending opportunities over and above their sector ceilings. Sectors must ensure that essential maintenance and operational activities are not under funded because resources are drawn away to fund high cost capital projects, as has occurred in the roads and works sector. All projects, including donor funded projects, will have to satisfy a range of criteria, including affordability within the relevant sector ceiling, full consideration of counterpart funding requirements and recurrent cost implications, and (if funded with an external loan) compatibility with Uganda's external debt strategy before they can be accepted by the Development Committee.

There is considerable scope to rationalise Government structures and thereby free up resources for PEAP priorities. The role of all autonomous commissions and agencies will be re-examined to determine whether their functions can be reintegrated into the normal public service structures, thereby generating savings. The donor funded projects offer scope for saving on expensive consultancies. There are huge and often unjustified differentials in salary scales between different parts of the public sector, with staff on projects and in autonomous agencies receiving far more generous remuneration than those in the traditional civil service. Rationalising wage structures throughout the public service offers scope for resource savings and is also necessary to create better incentives for public servants, especially those in the traditional civil service.

To summarise, although the economic strategy of the PEAP entails private sector driven economic growth, the public sector still has a vital role to play in providing essential public goods and services which complement private investment and promote an equitable pattern of development. To maximise the contribution of the public sector to the PEAP objectives, public expenditure management must focus on strengthening the pro-poor allocation of budget resources within a hard budget constraint and improving the efficiency of public expenditure. 


\section{Monitoring and Evaluation of the PEAP}

\subsection{Introduction}

The objective of Monitoring and Evaluation (M\&E) is to enable Government to make decisions that will keep the implementation of the PEAP on track. M\&E derives its value from the ow of relevant information to decision makers, who can then make informed decisions on whether modifications to policies and spending programmes are necessary. M\&E functions when it supplies managers with a ow of reliable information and analysis about what works and what doesn't, as a basis for public action. It also keeps other stakeholders (the legislature, the public, civil society organisations and development partners) informed about the progress being made in implementing the PEAP, and therefore enables them to offer informed advice to decision makers and, where appropriate, to modify their own policies and programmes.

Progress has been made in the development of capacity for M\&E. Attention to M\&E has increased the quality of decision making in terms of formulation, budgeting and operational management. The increased availability of information concerning national poverty eradication efforts has also allowed civil society, Parliament and development partners to exert more in uence over public policy.

A major part of the progress derives from the Poverty Monitoring and Evaluation Strategy (PMES), developed in 2001, which represents an overarching plan for M\&E within the context of the PEAP. The PMES identified a set of 33 priority indicators for implementation of the PEAP, for which a systematic effort was made to establish a baseline and target. The PMES classifies indicators along five links of the results chain: input, output, process, outcome, and impact (sometimes also called 'final outcome'). Information is available on these indicators, albeit to a variable degree of regularity and accuracy. The PMES also identifies institutional responsibilities for poverty monitoring.

The PMES uses three main types and sources of data: those collected by Uganda Bureau of Statistics (UBOS) on the basis of surveys; those collected by sector ministries through their management information systems; and those collected by Uganda Participatory Poverty Assessment Process. UBOS has developed a robust demographic and household poverty dataset, which allows monitoring of national progress against many of the priority indicators outlined in the PMES, including the MDGs. Since 2003, UBOS has been responsible for the National Service Delivery Survey on client satisfaction with services. It also maintains a district resource endowment profiles database. Sector ministries have developed/are developing management information systems in line with the establishment of sector programmes under the Sector Wide Approach (SWAP). The Uganda Participatory Poverty Assessment Process (UPPAP) provides qualitative perspectives on the nature of poverty by bringing the voices of the poor into planning processes. 


\subsection{Challenges for monitoring and evaluation}

In spite of the good progress made in developing Uganda's M\&E framework, challenges remain:

\section{Limited Flow of Relevant Information}

Although M\&E capacity is developing, the co-ordination of the ow of relevant information to top decision makers still remains weak. Decision making on policies and spending programmes ultimately has to be conducted at the highest level of the Executive, namely the Cabinet, which is the only body that can request the approval from the legislature for the spending of financial resources. Making informed decisions requires the timely and systematic availability of relevant data. The main regular source of information provided to Cabinet is the Annual Budget Framework Paper. This paper contains relevant information on progress in implementing the PEAP and challenges that need to be addressed. However, it is mainly concerned with the budget for the next year.

\section{Weak M\&E Co-ordination Arrangements}

Multiple M\&E arrangements have developed over the years, resulting in wasteful duplication and repetition of efforts. The burdensome nature of all these efforts is detracting from the time necessary to deliver the services. This is obviously counterproductive to attaining the PEAP objectives. It also greatly diminishes the usefulness of the M\&E effort for decision making, as the data ow is not systematically organised and contains much irrelevant and low quality data that is mixed up with data that is useful for decision making purposes. The incentives to the conduct of M\&E focus on reporting geared towards budget releases, as opposed to critically assessing the underlying performance revealed by $\mathrm{M} \& \mathrm{E}$. The definitional differences in basic concepts and terminology of the different M\&E systems also diminish their usefulness.

The multiplicity has arisen mainly through the numerous different $M \& E$ arrangements that have been established in respect of numerous conditional grants, and donor projects and sheer lack of effort in co-ordination. The result is a complex and formidable burden of inspection activity, indicator data collection and reporting formats that planners and managers at the sector, district and facility levels have to relate to, using a range of IT systems often incompatible with each other. These problems should diminish over time as a result of: (i) the Fiscal Decentralisation Strategy currently being piloted, which drastically condenses the number of conditional grants and simplifies reporting requirements; (ii) the move towards general budget support away from traditional project aid; and (iii) greater efforts of agencies to coordinate with each other. The reduced multiplicity of systems will therefore ease the task of producing a coherent M\&E framework.

Most of the Management Information Systems (MIS) operate in isolation and are not integrated at either the local government level or the national level. For example, the Health Management Information Systems (HMIS) and Education Management Information Systems (EMIS) are not linked to the National Statistical System in UBOS. UBOS and EMIS collect data on education independently of each other, whereas efficiency savings are probably possible if they co-ordinated their efforts and shared their data. 
Furthermore, interfaces between sector MIS are non-existent, as no harmonised structures and mechanisms for information ow and feed back exist between sector MIS. This is a serious deficiency given strong sectoral interlinkages, for example between health and water and sanitation. Each sector and programme runs different systems yet serve the same clients. In the process, efforts are duplicated and resources wasted. Local Governments themselves use non-standardised information systems to collect, analyse and process information. As most services are delivered at the local government level, obvious efficiency gains could be achieved if local government information gathering systems fed directly into the sectoral MIS.

\section{Inadequate Performance-based Public Management Culture}

Effective M\&E requires a performance based management based culture, planning and management of public service delivery processes based on long term objectives. Much progress is being made in this area through the twin concepts of Outcome-Oriented Budgeting and Results-Oriented Management, particularly in the health and education sectors, where the sector wide approach was first developed. The M\&E grants under PAF have also helped, as has the mandatory practice of posting of notices on PAF funding allocations in order to enhance community awareness. The use of the M\&E PAF grants has been less than perfect and the posting of notices patchy. Community pressure for greater accountability may increase, however, through an initiative underway to establish a system of facility level "client score cards".

\section{Gaps in Information and Underused Information}

Effective M\&E also requires a reasonably comprehensive information base, but some gaps exist in the Uganda data base, which weaken M\&E. For example, household surveys are incomplete in areas of insecurity. Surveys of users of services (beneficiaries) have been less systematic than the surveys on expenditures and activities on the one hand and poverty impact on the other hand (the "missing middle" problem). Over time, these weaknesses should diminish in importance as the security situation improves, the quality of the National Service Delivery Surveys improve, and the concept of "client score cards' catches on.

One area where better monitoring is particularly badly needed is in the conditions of IDPs in the camps. Government's ability to respond quickly enough to problems in the camps depends on timely and accurate information.

\subsection{Government's strategy for addressing the current weaknesses in the M\&E Framework}

As a first step towards rationalising M\&E in Uganda, the Government has prepared the National Integrated M\&E Strategy (NIMES) with a secretariat in the Office of the Prime Minister. NIMES will address the challenges identified above by providing mechanisms for the systematic ow of data relevant to the tracking of progress in implementing the PEAP. NIMES is not a new system but a framework for harmonizing the existing systems to reduce duplication of effort and enhance timeliness, quality of data generated and actual use of M\&E information by decision makers. 
The progress in implementing the PEAP will be captured through the PEAP Results and Policy Matrix, presented at the end of this chapter. The matrix mainly contains output and outcome indicators related to PEAP strategic objectives.

\section{Methods for Data collection}

Data will be collected from a wide range of sources using a variety of methods. These will include:

\section{Censuses and Surveys}

UBOS conducts/maintains the following surveys/databases:

- Two yearly household expenditure surveys: These are the major source of information for many of the non sectoral outcomes indicated in the matrix. These surveys have shed extensive light on the living conditions of households in Uganda.

- Past Integrated surveys: These give very rich information, particularly on incomes.

- Demographic and health surveys (every five years), and censuses (every decade).

- District resource endowment profiles database: comprising information about topographical characteristics, natural resources and land use in the districts.

- National Service Delivery Surveys (NSDS): This surveys client (beneficiary) satisfaction with public services.

- Agriculture Sector Surveys.

The Inspector General of Government has commissioned two National Integrity Surveys.

\section{Administrative Data}

Most administrative information is generated by the local governments, the implementers of government programmes: In order to determine how the quality of this information can be improved, UBOS has conducted a Data Needs Assessment Study in 13 districts.

It is envisaged that the information ow in the districts will be coordinated through the Local Government Information and Communication System (LOGICS) that has been developed by the Ministry of Local Government. Sector specific information systems would "talk to each other" at district level through LOGICS, thereby enabling stakeholders in NIMES to be able to directly monitor progress in implementing the PEAP in each local government.

Making LOGICS compatible with the District Resource Information System (DRIS) that UBOS is trying to revitalize, and with the sectoral MIS, are challenges that require addressing in order to support the success of NIMES.

At the sectoral level, information will continue to be generated by the various sector management information systems (MIS): The health; education; transport and; justice, law and order MIS are reasonably well established. MIS for other sectors are being 
developed. To enhance reliability and reduce the duplication with UBOS, plans are under way - through the Producer-Producer Committees coordinated by UBOS - to agree on a "clearing house" system. Thus, at the national level, sector specific information systems will be able to talk to each other through UBOS.

\section{Participatory Poverty Assessments}

Qualitative information will continue to complement quantitative data in M\&E activities. Since 1998, Government has conducted Participatory Poverty Assessments (PPAs) in partnership with civil society and research/academic institutions. These have been designed to bring the perspectives of the poor into the national and local level planning processes.

\section{Beneficiary Assessments}

In addition to NSDS, various initiatives within both Government and CSOs have been/are being developed to use beneficiary assessments to gauge the level of satisfaction with service delivery. Such assessments are important information to decision makers. The Uganda Debt Network (UDN) coordinates the civil society monitoring of PAF activities in the districts and is also piloting a community- based monitoring and evaluation system under which the public verifies expenditures and service delivery. The Uganda Management Institute is piloting the use of score cards under the Kampala Report card Initiative in partnership with other research institutions. A client scorecard system is being piloted in the health sector by the Uganda National Health Consumers Association. Mandatory posting of notices of funding allocations for PAF programmes enhance administrators' dialogue with clients or end users. The display of information is also part of the minimum conditions under the Local Government Development Programme.

\section{Economic Data}

Ministry of Finance, Planning and Economic Development, Bank of Uganda and UBOS produce statistics on the public finance, monetary, external and real sectors of the economy.

\section{6. $\quad$ Research Studies}

Various agencies prepare adhoc poverty studies and reviews, of potential value to NIMES. The Economic Policy Research Centre; the Makerere Institute of Social Research; Centre for Basic Research; the Community Development Resource Network and Development Research and Training in particular, have strong capacities for research and evaluation. Since 1996, expenditure tracking studies have been undertaken in the health, education and water sectors.

The planning and conduct of such studies is not always well coordinated, and the NIMES envisages a more coordinated approach. To this end, MOFPED has prepared an annotated inventory of poverty - related studies in Uganda. Priority research areas have been identified in the National Research Guide. 


\section{Outputs of the Monitoring System}

The main output of NIMES will be the "National Policy and Program Performance Status Report", produced every six months, and incorporating the information that will be channelled into NIMES. In addition to the ow of statistical information, various reports already produced on a routine basis will feed into NIMES. These include:

1. The Poverty Status Report, which is produced every two years by the MFPED, and the PEAP progress report, produced every other year in between.

2. Sectoral Joint Review Reports every six months

3. Participatory Poverty Assessment Reports

4. Statistical Survey Reports by UBOS

5. Budget Framework Papers, annual

6. Background to the Budget document by MFPED, annual.

\section{Dissemination and Use of data by the sectors}

Reports and discussion papers, including "popular versions" of these, will be produced under NIMES and widely disseminated. NIMES is planning to use Uganda Info $^{1}-$ developed by UBOS to be the database for disseminating the social economic indicators used to monitor and evaluate the PEAP.

The dissemination strategy will encourage an interactive ow of information at all levels of Government through the Producer- Producer and Producer-User Committees that will be established under NIMES. The institutionalised feed back mechanism with CSOs will also provide a channel for disseminating the M\&E results.

One use for M\&E information will be in applying the gender and equity guidelines that have been developed by the Ministry of Finance, Planning and Economic Development in collaboration with Ministry of Gender, Labour and Social Development.

\section{Structure, Institutional Roles and Responsibilities}

The NIMES will have a National Coordination Committee (NCC) responsible to the Technical Implementation Coordination Committee under the new coordination and monitoring framework that was approved by Cabinet in August 2003. The NCC will be served by three working groups namely:

1. Spatial/Geographical Information systems; this group has been in place for a year.

2. District information systems; this group has yet to be formed; and

3. Research and Evaluation; this group is already in place.

The NIMES Secretariat will support NCC. The coordinating functions of NIMES will be at the various levels as depicted in Diagram 9.1 below.

M\&E capacity at the local government level will be strengthened, thereby allowing inter-district sharing of information, strong interactive CSO monitoring and enhanced beneficiary assessment of services. The local government M\&E institutional framework 
will link with strong SWG M\&E frameworks, themselves interlinked, thus providing feedback between the sectors and the local governments on how issues of implementation performance have been treated at the two levels. As a result, local government managers will be able to develop innovative options for better public service performance.

All the four levels of the coordination mechanism are supported by a strong national statistical system, providing a vital role of UBOS.

A spatial data infrastructure system enhances analysis and reporting in support of NIMES. Spatial Data Infrastructure refers to the managing of the necessary skills, technology and use of Geographical Information Systems (GIS). This coordination mechanism helps to clarify what the minimum dataset at any level of Government necessary for decision making is, and who should be the custodian of that data set. IT-supported GIS are a very effective means of monitoring, particularly of physical infrastructure.

\section{Diagram 9.1: The National Integrated Monitoring and Evaluation Framework}

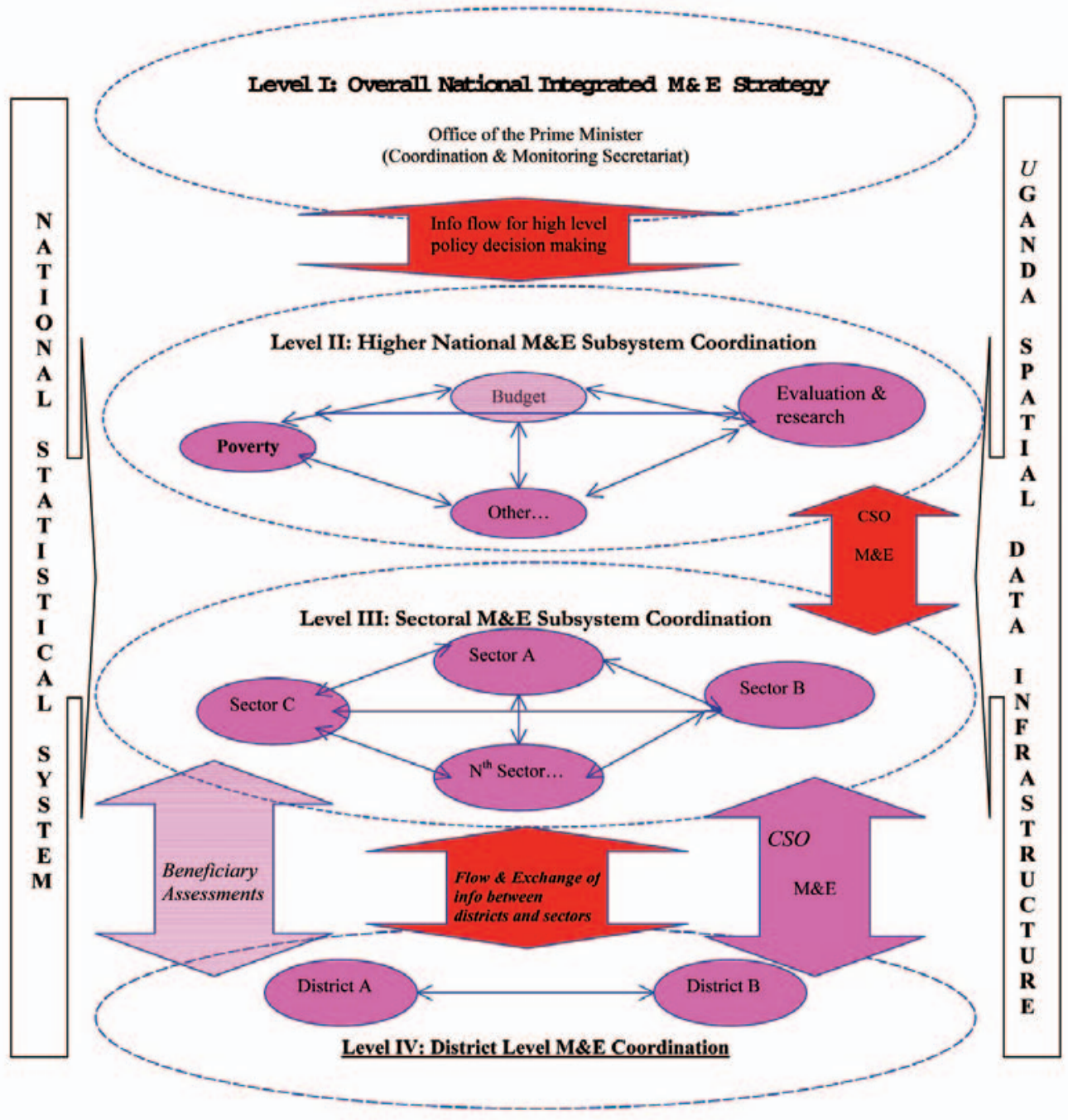




\subsection{Prospects for the Millennium Development Goals}

It is widely asked whether existing expenditure projections will allow Uganda to achieve the MDGs ${ }^{2}$. The answer is in general yes, though with some possible exceptions.

Major MDG targets are as follows:

- Halving poverty 1990-2015; even with the more cautious macroeconomic projections in the revised PEAP, poverty should fall to $28 \%$ by $2013 / 4$ and $26 \%$ by 2015 and further if inequality is reduced or fertility falls (both of which are objectives of the PEAP).

- Achieving universal primary education by 2015: this implies increasing net enrolment from $85 \%$ now to $100 \%$ in 2015 . After the huge increase in net enrolment rate in 1997, there has been little change since. The achievement of this objective depends on addressing the reasons why children drop out of school. Extra public expenditure could certainly help with this, as can better management. The objective may be achievable within existing projections of expenditure, provided the education sector remains focused on outcomes and on including the poorest.

- Achieving gender parity by 2005 in primary and secondary and in all levels of education by 2015 . Uganda has succeeded in reducing gender imbalance so that no gender disparity is now evidence for P1-6. The female gender ratio in secondary education are now at about $43 \%$. It would be difficult to achieve $50 \%$ by 2005 by any practical policy, with or without extra public expenditure. The target for tertiary is very ambitious, but may be achievable. Its achievement does not depend primarily on extra public expenditure.

- Halving the prevalence of malnutrition by 2015; little progress is being made in this area at the moment. However, if actions are taken to reduce child disease (see below) and to address income inequality, very substantial progress could be made within existing resources.

- Reducing under-five mortality by two-thirds by 2015. This indicator stagnated in the 1990s and reducing it by two thirds is highly ambitious. However, improved health services may well have started to make an impact. The projections for health expenditure would allow all the necessary curative treatment to be delivered to achieve this objective; the critical question is the delivery and uptake by the population of preventive measures, including better public understanding of how to prevent illness (e.g. improved personal hygiene and domestic sanitation practices). If the issue is given enough public profile, this might be achieved within existing resources (although the Infant Mortality Strategy argues that more resources are needed).

- Reducing maternal mortality by three quarters by 2015; no progress is being made on this and the health sector has warned that it may not be achievable on existing resource projections, since it necessarily involves some costly medical interventions.

- Halting the spread of AIDS and starting to reverse it by 2015; Uganda should do better than this, provided the issue continues to receive attention.

- Halting the spread of malaria and other major diseases by 2015; as above - Uganda should be able to take interventions both on introducing bed nets and on promoting cleaner environment that should bring this down. Some progress has been made very recently. 
- Halving the proportion of people by 2015 without sustainable access to safe drinking water and improved sanitation; UNDP calculates that this implies increasing overall coverage to $62 \%$. Household surveys indicate rural water coverage of about $60 \%$, in which case (given higher urban coverage) the target has already been met by the fast expansion of the 1990s. Facility-based data from DWD estimate existing rural water coverage is closer to $55 \%$, in which case the national target of $62 \%$ has not yet been achieved, but should be achieved by 2015 . The water and sanitation sector itself has costed two more ambitious targets, for $77 \%$ water coverage and $95 \%$ rural water coverage by 2015 . These are not likely to be achieved within existing resource projections, since the water and sanitation sector also has to meet the demands of urban water and sewerage works, hygiene promotion and sanitation in rural growth points and urban centres and water for production. (The definition of the MDG in this case is highly sensitive to the base year chosen, because access increased fast during the 1990s).

- Improving the lives of slum dwellers: If the land market can be improved so that slum-dwellers are given better security of tenure, their lives could be improved significantly. A general rise in incomes should also improve their lives.

Overall, the only MDG where resources appear to be insufficient is that for maternal mortality. There may also be a need for more resources to achieve the full implementation of universal primary education by 2015 . However, this is not yet clear and requires more analysis of the determinants of drop-out and quality.

In the end, the level of public expenditure will be determined by resource availability and macroeconomic stability. Subject to these constraints, Uganda will devote increased resources to improved performance on all dimensions of poverty including those re ected in the MDGs. 


\section{PEAP RESULTS AND POLICY MATRIX}

\section{Key Strategic Results}

1. Reduced income poverty and inequality

- $\%$ of population below poverty line reduced from 38\% in 2003 to $28 \%$ by $2013 / 14$

- Inequality reduced from 0.43

2. Improved Human Development

- Reduced infant mortality rates from 88 in 2003 to 68 in 2008

- Reduced maternal mortality from 500 in 2003 to 300 in 2008

- Increased literacy (by gender) from $70 \%$ in 2003 to $85 \%$ in $2009 / 10$

3. Increase GDP growth

- Real GDP from 5.2\% in 2003 to an average of 7 percent subsequently

\begin{tabular}{|l|l|l|l|l|l|l|l|}
\hline Strategic Objectives & $\begin{array}{l}\text { Challenges/ } \\
\text { Constraints }\end{array}$ & PEAP Outcomes/indicators & $\begin{array}{l}\text { Baseline } \\
\mathbf{2 0 0 2 / 0 3}\end{array}$ & $\begin{array}{l}\text { Target } \\
\mathbf{2 0 0 7 / 0 8}\end{array}$ & $\begin{array}{l}\text { Target } \\
\mathbf{2 0 1 3} / \mathbf{1 4}\end{array}$ & PEAP Policy Actions \\
\hline
\end{tabular}

\section{PILLAR ONE. ECONOMIC MANAGEMENT}

\begin{tabular}{|c|c|c|c|c|c|c|c|}
\hline \multirow[t]{2}{*}{$\begin{array}{l}\text { 1.0 Macroeconomic } \\
\text { stability consistent } \\
\text { with rapid private- } \\
\text { sector led growth }\end{array}$} & $\begin{array}{l}\text { - Low revenue-GDP ratio } \\
\text { - Rising non-poverty } \\
\text { related spending }\end{array}$ & $\begin{array}{l}1.1 \text { Reduced fiscal deficit } \\
\text { - Fiscal deficit (\% of } \\
\text { GDP) } \\
\text { - Revenues (\% of GDP) } \\
\text { - Expenditures (\% of } \\
\text { GDP) }\end{array}$ & $\begin{array}{l}11.3 \\
12.6 \\
23.9\end{array}$ & $\begin{array}{c}8 \\
13.5 \\
21.5\end{array}$ & $\begin{array}{c}6.5 \\
15.8 \\
22.5\end{array}$ & $\begin{array}{l}\text { - Strengthened revenue collections, } \\
\text { including through tax administration } \\
\text { and new tax policy measures } \\
\text { - Rigorous public expenditure prioritiza- } \\
\text { tion to fund poverty reducing programs } \\
\text { and ensure value for money within con- } \\
\text { strained resource envelope }\end{array}$ & MoFPED \\
\hline & $\begin{array}{l}\text { - Controlling in ation in } \\
\text { spite of Liquidity pres- } \\
\text { sures from large fiscal } \\
\text { deficit. }\end{array}$ & $\begin{array}{l}\text { 1.2 Low in ation maintained } \\
\text { - CPI in ation (exclud- } \\
\text { ing foodstuffs, average } \\
\text { period) }\end{array}$ & 2.4 & $<5.0$ & $<5.0$ & $\begin{array}{l}\text { - Monetary policy to continue to } \\
\text { focus on delivering low and stable } \\
\text { in ation. } \\
\text { - Government to ease liquidity pres- } \\
\text { sures by reducing deficit. }\end{array}$ & UBOS \\
\hline
\end{tabular}




\begin{tabular}{|c|c|c|c|c|c|c|c|}
\hline Strategic Objectives & Challenges/ Constraints & PEAP Outcomes/Indicators & $\begin{array}{l}\text { Baseline } \\
2002 / 03\end{array}$ & $\begin{array}{l}\text { Target } \\
\text { 2007/08 }\end{array}$ & $\begin{array}{l}\text { Target } \\
\text { 2013/14 }\end{array}$ & PEAP Policy Actions & $\begin{array}{l}\text { Data } \\
\text { Source }\end{array}$ \\
\hline & $\begin{array}{l}\text { Lending to private sec- } \\
\text { tor low by international } \\
\text { standards. }\end{array}$ & $\begin{array}{l}\text { 1.3 Increased private sector ac- } \\
\text { cess to finance } \\
\text { - Private sector credit (\% } \\
\text { of GDP) } \\
\text { - Savings to GDP ratio }\end{array}$ & $\begin{array}{l}7.1 \\
6.6\end{array}$ & $\begin{array}{l}10.4 \\
10.7\end{array}$ & $\begin{array}{l}17.5 \\
13.6\end{array}$ & $\begin{array}{l}\text { - Reduce government's fiscal deficit to re- } \\
\text { duce issuance of Treasury Bills, thus freeing } \\
\text { up resources for private sector lending. } \\
\text { - Reform pension system }\end{array}$ & $\begin{array}{l}\text { BoU; } \\
\text { UBOS }\end{array}$ \\
\hline & $\begin{array}{l}\text { External debt ratio high, } \\
\text { despite recent debt relief }\end{array}$ & $\begin{array}{l}\text { 1.4 Reduce external debt to sus- } \\
\text { tainable levels } \\
\text { - NPV of external debt (\% } \\
\text { of export earnings) }\end{array}$ & $305 \%$ & $238 \%$ & $187 \%$ & $\begin{array}{l}\text { - Reduce fiscal deficit and seek donor } \\
\text { financing through grants rather than loans } \\
\text { - Implement programmes to boost export } \\
\text { performance } \\
\text { - New loans only for productivity enhance- } \\
\text { ment not consumption }\end{array}$ & MoFPED \\
\hline & $\begin{array}{l}\text { Maintain Balance of Pay- } \\
\text { ments stability }\end{array}$ & $\begin{array}{l}\text { 1.5 International reserves at a } \\
\text { minimum of } 5 \text { months of } \\
\text { imports }\end{array}$ & 6.2 & 5.0 & 5.0 & $\begin{array}{l}\text { BoU to pursue prudent reserve management } \\
\text { policy and maintain a free- oating exchange } \\
\text { rate }\end{array}$ & BoU \\
\hline
\end{tabular}


PILLAR TWO. ENHANCING PRODUCTION, COMPETITIVENESS \& INCOMES

\begin{tabular}{|c|c|c|c|c|c|c|c|}
\hline Strategic Objectives & Challenges/ Constraints & PEAP Outcomes/Indicators & $\begin{array}{l}\text { Baseline } \\
\text { 2002/03 }\end{array}$ & $\begin{array}{l}\text { Target } \\
2007 / 08\end{array}$ & $\begin{array}{l}\text { Target } \\
2013 / 14\end{array}$ & PEAP Policy Actions & $\begin{array}{l}\text { Data } \\
\text { Source }\end{array}$ \\
\hline $\begin{array}{l}\text { 2.1 Increased and more } \\
\text { efficient private sector } \\
\text { production }\end{array}$ & See below & $\begin{array}{l}\text { 2.1.1 } \begin{array}{l}\text { Increased private sector } \\
\text { competitiveness }\end{array} \\
\text { - } \begin{array}{l}\text { Private Investment as \% } \\
\text { of GDP }\end{array} \\
\text { - Total export as \% of GDP }\end{array}$ & $17 \%$ & $21 \%$ & & $\begin{array}{l}\text { - Government maintains stable macro-econom- } \\
\text { ic policies minimize risks of investments } \\
\text { - Maintain liberal trade policy } \\
\text { - Minimize domestic and international barriers } \\
\text { to trade } \\
\text { - Harmonize activities under Strategic Exports } \\
\text { program with PMA\& MTCS programs }\end{array}$ & $\begin{array}{l}\text { UBOS } \\
\text { UBOS }\end{array}$ \\
\hline $\begin{array}{l}2.2 \text { Increased and more } \\
\text { efficient agricultural } \\
\text { production }\end{array}$ & $\begin{array}{l}\text { - Limited agricultural } \\
\text { growth } \\
\text { - Limited access by farm- } \\
\text { ers to technology } \\
\text { - Limited access by farm- } \\
\text { ers to advisory services } \\
\text { - Limited operationalisa- } \\
\text { tion of crop, livestock } \\
\text { and fisheries regulations } \\
\text { and standards } \\
\text { - Inadequate and unimple- } \\
\text { mented soil management } \\
\text { strategies } \\
\text { - Limited agricultural } \\
\text { information } \\
\text { - Inappropriate irrigation } \\
\text { strategy and program }\end{array}$ & $\begin{array}{ll}\text { 2.2.1 } & \text { Increased agriculture } \\
& \text { production } \\
\text { - } & \text { Growth rate of agriculture } \\
& \text { sector }\end{array}$ & $3.8 \%$ & & & $\begin{array}{l}\text { - Enact and implement provisions of National } \\
\text { Agricultural Research System (NARS) } \\
\text { System } \\
\text { - Extend National Agriculture Advisory Serv- } \\
\text { ices (NAADS) } \\
\text { - Strengthen meteorological services to support } \\
\text { farmers' decision making } \\
\text { - Prepare livestock policy to help livestock } \\
\text { sector } \\
\text { - Finalize and implement policy to strengthen } \\
\text { agricultural education in schools } \\
\text { - Finalize \& implement the water for produc- } \\
\text { tion study } \\
\text { - Operationalise crop, livestock and fisheries } \\
\text { regulations and standards } \\
\text { - Implement sole management strategies and } \\
\text { programs } \\
\text { - Establish and implement agricultural data- } \\
\text { base and information systems } \\
\text { - Develop and implement irrigation strategy }\end{array}$ & \\
\hline
\end{tabular}




\begin{tabular}{|c|c|c|c|c|c|c|c|}
\hline Strategic Objectives & Challenges/ Constraints & PEAP Outcomes/Indicators & $\begin{array}{l}\text { Baseline } \\
2002 / 03\end{array}$ & $\begin{array}{l}\text { Target } \\
2007 / 08 \\
\end{array}$ & $\begin{array}{l}\text { Target } \\
2013 / 14 \\
\end{array}$ & PEAP Policy Actions & $\begin{array}{l}\text { Data } \\
\text { Source }\end{array}$ \\
\hline & $\begin{array}{l}\text { Tariff and non tariff barri- } \\
\text { ers to Uganda' s exports }\end{array}$ & $\begin{array}{l}\text { 2.2.1 } \begin{array}{l}\text { Increased marketing of } \\
\text { agriculture products }\end{array} \\
\text { - } \begin{array}{l}\text { Agriculture product } \\
\text { marketed as \% of total } \\
\text { agriculture production }\end{array} \\
\text { - Agriculture export as \% } \\
\text { of total value of agricul- } \\
\text { ture output }\end{array}$ & $20 \%$ & & $70 \%$ & $\begin{array}{l}\text { - Harmonize some of the current Strategic } \\
\text { Export Programs (SEP) with the PMA and } \\
\text { MTCS programs and activities, co-ordinate by } \\
\text { the MTCS Secretariat. } \\
\text { - Focus SEP activities along the commodity } \\
\text { value chain } \\
\text { - Encourage private sector leadership (through } \\
\text { commodity associations and other stakehold- } \\
\text { ers) in the identification and implementation of } \\
\text { interventions }\end{array}$ & \\
\hline & $\begin{array}{l}\text { Limited access to ownership } \\
\text { of land }\end{array}$ & $\begin{array}{l}\text { 2.2.3 } \begin{array}{l}\text { Increased access to land } \\
\text { titling }\end{array} \\
\text { - } \% \text { of households with } \\
\text { land titles for agriculture } \\
\text { production } \\
\text { - } \% \text { of titled land }\end{array}$ & $<1 \%$ & $1.5 \%$ & $3 \%$ & $\begin{array}{l}\text { Implement Land Sector Strategy, which in- } \\
\text { clude: } \\
\begin{aligned}- & \text { Provision of more equitable land rights } \\
- & \text { Revitalization of land registries to } \\
& \text { facilitate functioning of land market } \\
- & \text { Operationalize Land Tribunal in order } \\
& \text { to strengthen con ict resolutions } \\
& \text { mechanisms } \\
- & \text { Finalize National Land Use Policy } \\
- & \text { Operationalize Land Fund for funding } \\
& \text { resettlement and Land adjustment }\end{aligned}\end{array}$ & \\
\hline $\begin{array}{l}\text { 2.3 Increased and sustain- } \\
\text { able fisheries produc- } \\
\text { tion }\end{array}$ & $\begin{array}{l}\text { - Extensive unrecorded } \\
\text { and unregulated fishing \& } \\
\text { trading fishing and trading } \\
\text { activities } \\
\text { - Poor infrastructure of } \\
\text { Fish landing Sites } \\
\text { - Inadequate private } \\
\text { investment in the fishery } \\
\text { sector }\end{array}$ & $\begin{array}{ll}\text { 2.3.1 } & \begin{array}{l}\text { Increased annual capture } \\
\text { of fish }\end{array} \\
\text { - } & \begin{array}{l}\text { Growth rate of fishery } \\
\text { sector }\end{array} \\
\text { - } & \text { Value of fish exports } \\
& \text { (US\$ million) }\end{array}$ & 88 & & & $\begin{array}{l}\text { Implement the } 2003 \text { Fisheries Sector Strategic } \\
\text { Plan (FSSP), which include: } \\
\text { - } \quad \text { Establishment and capacity-building } \\
\text { of community institutions to manage } \\
\text { beaches and lakes } \\
\text { - } \quad \text { Monitoring and control of illegal prac- } \\
\text { tices } \\
\text { - Development of quality guarantees for } \\
\text { fish exports } \\
\text { - Development of a central information } \\
\text { system }\end{array}$ & \\
\hline
\end{tabular}




\begin{tabular}{|c|c|c|c|c|c|c|c|}
\hline \multirow[t]{3}{*}{ Strategic Objectives } & Challenges/ Constraints & PEAP Outcomes/Indicators & $\begin{array}{l}\text { Baseline } \\
\text { 2002/03 }\end{array}$ & $\begin{array}{l}\text { Target } \\
\text { 2007/08 }\end{array}$ & $\begin{array}{l}\text { Target } \\
\text { 2013/14 }\end{array}$ & PEAP Policy Actions & $\begin{array}{l}\text { Data } \\
\text { Source }\end{array}$ \\
\hline & & & & & & $\begin{array}{ll} & \text { Stock enhancement for dams and } \\
\text { small lakes } \\
\text { - } \\
\text { Evaluation of options for fish tech- } \\
\text { nologies }\end{array}$ & \\
\hline & $\begin{array}{l}\text { Limited participation of } \\
\text { local people in fishery man- } \\
\text { agement }\end{array}$ & $\begin{aligned} \text { 2.3.2 } & \text { Improved sustainable } \\
& \text { management of fishery } \\
& \\
\text { - } & \text { Number of functioning } \\
& \text { Beach Management Units }\end{aligned}$ & 100 & 700 & & $\begin{array}{l}\text { Formation of legally empowered Community } \\
\text { Beach Management Units }\end{array}$ & \\
\hline $\begin{array}{l}2.4 \text { Increased and Sustain- } \\
\text { able Forestry Produc- } \\
\text { tion }\end{array}$ & $\begin{array}{l}\text { Degradation of forest land } \\
\text { due to Unsustainable har- } \\
\text { vesting of forest products }\end{array}$ & $\begin{array}{ll}2.4 .1 & \text { Increased forest cover } \\
\text { - } & \% \text { of land under forest } \\
& \text { cover } \\
\text { - } & \begin{array}{l}\text { Distance travelled by } \\
\text { villagers to firewood } \\
\text { source }\end{array}\end{array}$ & $24 \%$ & $27 \%$ & $\begin{array}{r}30 \% \\
<0.5 \mathrm{~km}\end{array}$ & $\begin{array}{l}\text { Enhance implementation of the National Forest } \\
\text { Plan, which include } \\
\text { - Promote private sector investment in private- } \\
\text { ly owned forests } \\
\text { - Promote the establishment of community } \\
\text { woodlots through DFS extension and advisory } \\
\text { services to private and community members. } \\
\text { - Develop National Tree Seed Centre and } \\
\text { establish National Tree Fund }\end{array}$ & \\
\hline $\begin{array}{l}2.5 \text { Increased and more } \\
\text { efficient production of } \\
\text { non-agriculture goods } \\
\text { and services }\end{array}$ & $\begin{array}{l}\text { - MSMEs luck of entre- } \\
\text { preneurial skills and access } \\
\text { to business development } \\
\text { services } \\
\text { - Inadequate business regu- } \\
\text { latory environment }\end{array}$ & $\begin{array}{ll}\text { 2.5.1 } & \text { Increased growth of MS- } \\
& \text { MEs } \\
\text { - } & \text { Value of production of } \\
& \text { MSMEs (MSMEs as \% } \\
\text { of GDP) } & \\
\text { - } & \text { Time spent by MSMEs in } \\
\text { obtaining licenses }\end{array}$ & & & & $\begin{array}{l}\text { - Continue to enhance linkages and informa- } \\
\text { tion ow between the government and MS- } \\
\text { MES, particularly with regards to new trading } \\
\text { regulations and any changes to international } \\
\text { standard requirements. } \\
\text { - Work with local governments to streamline } \\
\text { taxation systems of MSMEs in both rural and } \\
\text { urban areas. } \\
\text { - Improve the investment climate by creating a } \\
\text { conducive regulatory framework, enhancing the } \\
\text { efficiency of the registration and trade related } \\
\text { services. } \\
\text { - Provide entrepreneurial skills and business } \\
\text { development services in partnership with the } \\
\text { private sector. }\end{array}$ & \\
\hline
\end{tabular}




\begin{tabular}{|c|c|c|c|c|c|c|c|}
\hline Strategic Objectives & Challenges/ Constraints & PEAP Outcomes/Indicators & $\begin{array}{l}\text { Baseline } \\
2002 / 03\end{array}$ & $\begin{array}{l}\text { Target } \\
2007 / 08 \\
\end{array}$ & $\begin{array}{l}\text { Target } \\
2013 / 14 \\
\end{array}$ & PEAP Policy Actions & $\begin{array}{l}\text { Data } \\
\text { Source }\end{array}$ \\
\hline & $\begin{array}{l}\text { - Limited infrastructure } \\
\text { and security around tour- } \\
\text { ism sites } \\
\text { - Inadequate promotion of } \\
\text { Uganda tourism resources }\end{array}$ & 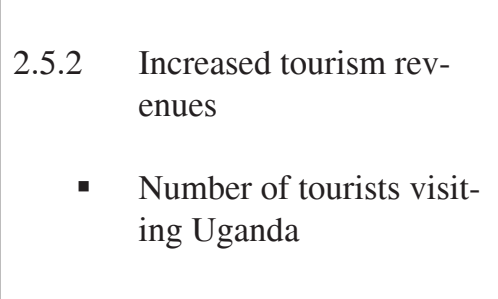 & & & & $\begin{array}{l}\text { - Promote abroad of Uganda as a tourist des- } \\
\text { tination } \\
\text { - Promote diversification of tourism products } \\
\text { including rural tourism, cultural routes, etc } \\
\text { - Training of staff in the tourism industry } \\
\text { - Provide business development services for } \\
\text { tourism, in cooperation with the private sector. }\end{array}$ & \\
\hline & $\begin{array}{l}\text { Undeveloped \& under-ex- } \\
\text { ploited mining sector }\end{array}$ & $\begin{array}{l}\text { 2.5.3 Increased growth of min- } \\
\text { ing industry } \\
\text { - Value of production of } \\
\text { mining industry (by sub- } \\
\text { sector) }\end{array}$ & & & & $\begin{array}{l}\text { - Develop and implement Mining Regulations } \\
\text { to operationalize the new mining law. } \\
\text { - Provide improved information to investors } \\
\text { and artisanal miners } \\
\text { - Establish an environmental and social man- } \\
\text { agement framework for mining activities. }\end{array}$ & \\
\hline
\end{tabular}




\begin{tabular}{|c|c|c|c|c|c|c|c|}
\hline Strategic Objectives & Challenges/ Constraints & PEAP Outcomes/Indicators & $\begin{array}{l}\text { Baseline } \\
2002 / 03\end{array}$ & $\begin{array}{l}\text { Target } \\
2007 / 08\end{array}$ & $\begin{array}{l}\text { Target } \\
2013 / 14\end{array}$ & PEAP Policy Actions & $\begin{array}{l}\text { Data } \\
\text { Source }\end{array}$ \\
\hline & $\begin{array}{l}\text { Limited energy supplies to } \\
\text { rural areas }\end{array}$ & $\begin{array}{l}\text { 2.6.2 Improved rural household } \\
\text { access to electricity } \\
\text { - } \% \text { of rural households } \\
\text { accessing electricity }\end{array}$ & $3 \%$ & & $10 \%$ & $\begin{array}{l}\text { - Implement the rural electrification strategy } \\
\text { - Facilitate private sector participation } \\
\text { - Promote technologies to reduce the use of } \\
\text { fuel wood }\end{array}$ & \\
\hline & $\begin{array}{l}\text { Undeveloped infrastructure } \\
\text { and services }\end{array}$ & $\begin{array}{l}\text { 2.6.3 Increased railway haulage } \\
\text { capacity } \\
\text { - Annual tones of freight } \\
\text { carried by rail }\end{array}$ & & & & $\begin{array}{l}\text { - Finalize negotiations for the concessioning of } \\
\text { the railway system in Uganda in a joint opera- } \\
\text { tion with Kenya. } \\
\text { - Improve private sector incentives to invest } \\
\text { in the rehabilitation of operational lines, in the } \\
\text { re-opening of closed lines and in connecting } \\
\text { the Ugandan Railways network including the } \\
\text { marine wagon service on Lake Victoria with } \\
\text { that of the neighbouring countries. }\end{array}$ & \\
\hline & $\begin{array}{l}\text { - Inefficient airport han- } \\
\text { dling } \\
\text { - Underdeveloped airport } \\
\text { infrastructure }\end{array}$ & $\begin{array}{l}\text { 2.6.4 Increased airport utiliza- } \\
\text { tion } \\
\text { - Annual cargo export rate } \\
\text { - Annual passenger traffic } \\
\text { rate }\end{array}$ & & & & $\begin{array}{l}\text { - Consider the best way of funding necessary } \\
\text { infrastructure at Entebbe including a new run- } \\
\text { way, taxi way, lighting system and apron } \\
\text { - Upgrade the navigational system at Entebbe } \\
\text { Airport }\end{array}$ & \\
\hline & $\begin{array}{l}\text { - Limited water supply to } \\
\text { supplement rainfall }\end{array}$ & $\begin{array}{ll}\text { 2.6.5 Increased water for pro- } \\
\text { duction } \\
\text { - } \\
\text { Cumulative storage ca- } \\
\text { pacity for WfP } \\
\text { Increase in irrigation } \\
\text { areas }\end{array}$ & $\begin{array}{l}131 \mathrm{~m} \mathrm{~m}^{3} \\
7,600 \text { ha }\end{array}$ & $\begin{array}{l}150 \mathrm{~m} \mathrm{~m}^{3} \\
8,500 \mathrm{ha}\end{array}$ & $\begin{array}{l}187 \mathrm{~m} \mathrm{~m}^{3} \\
10,500 \text { ha }\end{array}$ & $\begin{array}{l}\text { - Finalise water for production strategy } \\
\text { - Establish a coordination mechanism }\end{array}$ & \\
\hline
\end{tabular}




\begin{tabular}{|c|c|c|c|c|c|c|c|}
\hline Strategic Objectives & Challenges/ Constraints & PEAP Outcomes/Indicators & $\begin{array}{l}\text { Baseline } \\
2002 / 03\end{array}$ & $\begin{array}{l}\text { Target } \\
2007 / 08\end{array}$ & $\begin{array}{l}\text { Target } \\
2013 / 14\end{array}$ & PEAP Policy Actions & $\begin{array}{l}\text { Data } \\
\text { Source }\end{array}$ \\
\hline \multirow[t]{2}{*}{$\begin{array}{l}\text { 2.7 Strengthened Environ } \\
\text { ment and natural re- } \\
\text { source (ENR) manage- } \\
\text { ment regime in support } \\
\text { of sustainable production } \\
\text { of good and services }\end{array}$} & $\begin{array}{l}\text { - Degraded forests re- } \\
\text { sources } \\
\text { - Environmental impact } \\
\text { assessment regulations not } \\
\text { enforced }\end{array}$ & $\begin{array}{l}\text { 2.7.1 } \begin{array}{l}\text { Improved forest resources } \\
\text { management }\end{array} \\
\text { - } \% \text { of forest land covered } \\
\text { by sustainable forest } \\
\text { management plan }\end{array}$ & & & & $\begin{array}{l}\text { - Prepare a ENR strategy to ensure that eco- } \\
\text { nomic activities consistent with sustainable } \\
\text { use of natural resources and protection of the } \\
\text { environment. } \\
\text { - NEMA rationalized in interests of cost ef- } \\
\text { fectiveness. } \\
\text { - Prepare National Environmental regulations, } \\
\text { standards and guidelines. }\end{array}$ & \\
\hline & $\begin{array}{l}\text { - Significant degradation of } \\
\text { wetlands }\end{array}$ & $\begin{array}{ll}\text { 2.7.2 } & \text { Improved Wetland Man- } \\
\text { agement } \\
\text { - } \% \text { of wetlands with } \\
\text { sustainable Management } \\
\text { plan }\end{array}$ & $7.5 \%$ & $20 \%$ & $35 \%$ & $\begin{array}{l}\text { - Develop and disseminate guidelines for wise } \\
\text { use of wetland resources } \\
\text { - Improve community skills and diversification } \\
\text { of wetland products in order to add value to } \\
\text { wetland products } \\
\text { - Enforce appropriate policies, laws, proce- } \\
\text { dures and regulations to curtail degradation of } \\
\text { wetland resources } \\
\text { - Assess wetland resources to determine re- } \\
\text { source availability and trends } \\
\text { - Support community initiates that promote } \\
\text { wise use of wetlands }\end{array}$ & \\
\hline $\begin{array}{l}\text { 2.8 Strengthened financial } \\
\text { sector in support of } \\
\text { increased production } \\
\text { of goods and services }\end{array}$ & $\begin{array}{l}\text { Limited availability finance } \\
\text { for agriculture activities }\end{array}$ & $\begin{array}{ll}\text { 2.8.1 } & \text { Increased access to } \\
& \text { finance } \\
\text { - } & \text { Number of clients served } \\
& \text { by MFIs }\end{array}$ & & & & $\begin{array}{l}\text { - Continue to implement the Microfinance } \\
\text { Outreach Plan to ensure increased coverage } \\
\text { - reaching out to more poor people in rural } \\
\text { areas. } \\
\text { - Develop and monitor mechanisms through } \\
\text { which MFIs can meet the needs of small-scale } \\
\text { agriculture. } \\
\text { - Support capacity building and business skills } \\
\text { development, especially for MSMEs. }\end{array}$ & \\
\hline
\end{tabular}




\section{PILLAR THREE. SECURITY, CONFLICT RESOLUTION AND DISASTER MANAGEMENT}

\begin{tabular}{|c|c|c|c|c|c|c|c|}
\hline Strategic Objectives & Challenges/ Constraints & PEAP Outcomes/Indicators & $\begin{array}{l}\text { Baseline } \\
2002 / 03\end{array}$ & $\begin{array}{l}\text { Target } \\
2007 / 08\end{array}$ & $\begin{array}{l}\text { Target } \\
2013 / 14\end{array}$ & PEAP Policy Actions & $\begin{array}{l}\text { Data } \\
\text { Source }\end{array}$ \\
\hline \multirow[t]{4}{*}{$\begin{array}{l}\text { Protection of per- } \\
\text { sons and their } \\
\text { property through } \\
\text { elimination of } \\
\text { con icts and cat- } \\
\text { tle rustling, reset- } \\
\text { tlement of IDPs, } \\
\text { and strengthened } \\
\text { disaster manage- } \\
\text { ment }\end{array}$} & $\begin{array}{l}\text { - Rebel insurgency in the } \\
\text { North }\end{array}$ & $\begin{array}{l}\text { 3.1 Reduced insurgency con ict } \\
\text { - } \quad \text { No civilian casualties } \\
\text { from con ict (disaggre- } \\
\text { gated by killed, wounded, } \\
\text { abducted) } \\
\text { - } \% \text { returnees/reportees that } \\
\text { are resettled }\end{array}$ & & & & $\begin{array}{l}\text { - Work to end the rebel insurgency } \\
\text { - Work with faith based groups and traditional } \\
\text { leaders through a regular forum of national } \\
\text { discussion on con ict-resolution } \\
\text { - Implementation of defence review recommen- } \\
\text { dations, which include removing Ghost workers } \\
\text { from defence pay. }\end{array}$ & \\
\hline & $\begin{array}{l}\text { Cattle rustling and prolifera- } \\
\text { tion of small arms especially } \\
\text { in Karamoja region }\end{array}$ & $\begin{array}{l}\text { 3.2 Reduced proliferation of il- } \\
\text { legal arms } \\
\text { - No. of cattle rustling } \\
\text { incidents } \\
\text { - No. of small arms decom- } \\
\text { missioned }\end{array}$ & & & & $\begin{array}{l}\text { - Proceed disarmament programme in Karamo- } \\
\text { ja, while ensuring that it does not lead to abuses } \\
\text { of the rights of the Karamojong or expose them } \\
\text { to attack from neighbouring tribes. } \\
\text { - Continue to support the peace building initia- } \\
\text { tives involving the Karamojong, including } \\
\text { recovery of stolen cattle } \\
\text { - Support livelihood development in pastoral } \\
\text { areas }\end{array}$ & \\
\hline & $\begin{array}{l}\text { Over } 1.6 \text { million people are } \\
\text { internally displaced with } \\
\text { poor condition of life. }\end{array}$ & $\begin{array}{l}\text { 3.3 Reduced number of people } \\
\text { internally displaced } \\
\text { - Number of people inter- } \\
\text { nally displaced (million) }\end{array}$ & 1.6 & 0 & & $\begin{array}{l}\text { - Develop concrete plans to implement the IDP } \\
\text { policy, in cooperation with key stakeholders } \\
\text { including donors and civil society. } \\
\text { - Better monitoring and improvement of condi- } \\
\text { tions in the IDP camps is a key priority, with a } \\
\text { particular focus on health and sanitation. }\end{array}$ & \\
\hline & $\begin{array}{l}\text { Uganda hosts over } 200,000 \\
\text { refugees, which add pres- } \\
\text { sure on the use of local } \\
\text { resources }\end{array}$ & $\begin{array}{l}\text { 3.1 Enhanced refugees self reli- } \\
\text { ance } \\
\text { \% of MTEF budgetary resourc- } \\
\text { es allocated to Refugee programs } \\
\text { in targeted districts }\end{array}$ & & & & $\begin{array}{l}\text { - Integrate humanitarian need and existing } \\
\text { resources into the national plans } \\
\text { - Implement the policy of self-reliance in coop- } \\
\text { eration with other partners } \\
\text { - Encourage Donors supporting refugees to } \\
\text { cooperate with local authorities in refugees } \\
\text { service delivery }\end{array}$ & \\
\hline
\end{tabular}




\section{PILLAR FOUR. GOOD GOVERNANCE}

\begin{tabular}{|c|c|c|c|c|c|c|c|}
\hline Startegic Objectives & Challenges/Constraints & PEAP Outcomes/indicators & $\begin{array}{l}\text { Baseline } \\
\text { 2002/03 }\end{array}$ & $\begin{array}{l}\text { Target } \\
2007 / 08\end{array}$ & $\begin{array}{l}\text { Target } \\
2013 / 14\end{array}$ & PEAP Policy Actions & $\begin{array}{l}\text { Data } \\
\text { source }\end{array}$ \\
\hline $\begin{array}{l}\text { 4.1 Strengthened } \\
\text { political } \\
\text { Governance }\end{array}$ & $\begin{array}{l}\text { Absence of participation of } \\
\text { multi parties in the political } \\
\text { process during the previous } \\
\text { elections }\end{array}$ & $\begin{array}{l}\text { 4.1.1 Strengthened system of } \\
\text { representation } \\
\text { \% public satisfac- } \\
\text { tion with the extent } \\
\text { of democracy }\end{array}$ & $54 \%$ & $90 \%$ & & $\begin{array}{l}\text { The Government to ensure that the elections to be } \\
\text { held in } 2006 \text { are completely free and fair, and that } \\
\text { the emerging political system will have the following } \\
\text { features: } \\
\text { - A credible system of representation, with well } \\
\text { functioning political parties/organizations and inter- } \\
\text { est associations; } \\
\text { - An electoral system that guarantees regular free } \\
\text { and fair elections as well as universal suffrage; } \\
\text { - A system of checks and balances based on separa- } \\
\text { tion of powers, with independent judicial and legisla- } \\
\text { tive branches; } \\
\text { - A vibrant civil society, able to monitor government } \\
\text { and private business and to provide alternative forms } \\
\text { of political participation; } \\
\text { - Free, strong and independent media, including } \\
\text { alternative people's media; and } \\
\text { - Effective civilian control over the military and other } \\
\text { security forces }\end{array}$ & \\
\hline $\begin{array}{l}4.2 \text { Improved } \\
\text { human rights }\end{array}$ & $\begin{array}{l}\text { Illegal detentions and use } \\
\text { of torture in some detention } \\
\text { centers were identified by } \\
\text { UHRC }\end{array}$ & \begin{tabular}{|ll} 
4.2.1 & $\begin{array}{l}\text { Improved human } \\
\text { rights }\end{array}$ \\
- & $\begin{array}{l}\text { No. of human rights } \\
\text { abuses reported by } \\
\text { UHRC }\end{array}$
\end{tabular} & & & & $\begin{array}{l}\text { - Government will take action to prevent any of } \\
\text { the violations reported by UHRC from continuing., } \\
\text { in particular, the J/LO sector will treat the humane } \\
\text { treatment of prisoners as a priority and the security } \\
\text { sector will ensure that its agencies do not exceed } \\
\text { their legal powers, for instance by illegal detention. } \\
\text { - UHRC will continue coordinating a national } \\
\text { civic education framework with other human rights } \\
\text { organizations for the next three years to increase } \\
\text { awareness among Ugandans about their human rights } \\
\text { and obligations. } \\
\text { - In line with the UN Convention on Rights of the } \\
\text { Child and the Children's Statute, UHRC will support } \\
\text { and coordinate data collection on abuse, neglect and } \\
\text { exploitation of children. }\end{array}$ & \\
\hline
\end{tabular}




\begin{tabular}{|c|c|c|c|c|c|c|c|}
\hline Strategic Objectives & Challenges/ Constraints & PEAP Outcomes/Indicators & $\begin{array}{l}\text { Baseline } \\
\text { 2002/03 }\end{array}$ & $\begin{array}{l}\text { Target } \\
\text { 2007/08 }\end{array}$ & $\begin{array}{l}\text { Target } \\
\text { 2013/14 }\end{array}$ & PEAP Policy Actions & $\begin{array}{l}\text { Data } \\
\text { Source }\end{array}$ \\
\hline \multirow[t]{2}{*}{$\begin{array}{l}\text { 4.3 Strengthened legal } \\
\text { and justice systems }\end{array}$} & $\begin{array}{l}\text { - Crime rate is high } \\
\text { - Justice system is slow, } \\
\text { inefficient } \\
\text { - Some laws are obsolete, } \\
\text { absent or discriminatory } \\
\text { - Access to JLOS institu- } \\
\text { tions is limited } \\
\text { - Inadequate capacity in } \\
\text { JLOS institutions }\end{array}$ & \begin{tabular}{|ll} 
4.3.1 & Reduced crime \\
- & Crime rate (incidents per \\
& 10,000 people) \\
4.3.2 & $\begin{array}{l}\text { Increased Efficiency in } \\
\text { the Justice System }\end{array}$ \\
- & $\begin{array}{l}\text { Average length of stay on } \\
\text { remand }\end{array}$ \\
4.3.3 $\quad \begin{array}{l}\text { Increased Quality of } \\
\text { Justice }\end{array}$ \\
- $\%$ of public confidence in \\
legal and justice system
\end{tabular} & $30 \%$ & $70 \%$ & $95 \%$ & $\begin{array}{l}\text { - Continue with programme to strengthen } \\
\text { other justice agencies including the increase of } \\
\text { their services at local levels and skilled planning } \\
\text { units } \\
\text { - Enact pending bills (criminal laws, Local Coun- } \\
\text { cil Courts, Magistrates Court, and Domestic Re- } \\
\text { lations \& Sexual Offences Bills) } \\
\text { - Extend Alternative Dispute Resolution mecha- } \\
\text { nisms } \\
\text { - Develop and implement National Strategy for } \\
\text { Gender \& Juvenile Justice, including operation- } \\
\text { alisation of Family \& Children's Courts and reha- } \\
\text { bilitation of regional juvenile remand centres } \\
\text { - Strengthen and extend legal aid procedures } \\
\text { through establishment a of Legal Aid Fund \& } \\
\text { better enforcement of the Advocates Act provi- } \\
\text { sions on pro bono services }\end{array}$ & CJR \\
\hline & $\begin{array}{l}\text { - Complex regulatory } \\
\text { framework } \\
\text { - Inefficiency of commer- } \\
\text { cial registers } \\
\text { - Limited access to effi- } \\
\text { cient commercial dispute } \\
\text { resolution institutions }\end{array}$ & $\begin{array}{l}\text { 4.3.4 Increased Efficiency in } \\
\text { the Commercial Justice } \\
\text { - Commercial court case } \\
\text { backlog growth rate (per } \\
\text { month) }\end{array}$ & 30 & 70 & 95 & $\begin{array}{l}\text { Institutionalise chain link and case backlog } \\
\text { initiatives } \\
\text { - Continue implementing commercial Justice } \\
\text { Reform Programme } \\
\text { - Strengthen the Commercial Court, Inspector of } \\
\text { Courts, Company and Land Registries } \\
\text { - Reform commercial laws and regulations, (in- } \\
\text { cluding strengthening of claims against insolvent } \\
\text { debtors) and enact pending bills } \\
\text { - Simplify court procedures and strengthen Al- } \\
\text { ternative Dispute Resolution procedures }\end{array}$ & \\
\hline
\end{tabular}




\begin{tabular}{|c|c|c|c|c|c|c|c|c|c|}
\hline \multicolumn{2}{|c|}{ Strategic Objectives } & \multirow{2}{*}{\begin{tabular}{|l} 
Challenges/ Constraints \\
- Weak public financial \\
management and account- \\
ability systems \\
- Complex LG transfer \\
system
\end{tabular}} & \multicolumn{2}{|c|}{ PEAP Outcomes/Indicators } & \multirow{2}{*}{$\begin{array}{l}\text { Baseline } \\
2002 / 03\end{array}$} & \multirow{2}{*}{$\begin{array}{l}\text { Target } \\
2007 / 08\end{array}$} & \multirow{2}{*}{\begin{tabular}{|l|}
$\begin{array}{l}\text { Target } \\
\text { 2013/14 }\end{array}$ \\
\\
\end{tabular}} & \multirow[b]{2}{*}{$\begin{array}{l}\text { PEAP Policy Actions } \\
\text { - Implementation of agreed CIFA action plan } \\
\text { - Timely preparation, submission and auditing of } \\
\text { financial statements } \\
\text { - Roll out IFMS to all central and local government } \\
\text { - Roll out Fiscal Decentralisation Strategy to all local } \\
\text { governments } \\
\text { - Finalisation and Enactment of revised Audit Bill } \\
\text { Compliance with international public sector auditing } \\
\text { standards } \\
\text { Establish Internal Audit function in all ministries } \\
\text { New procurement laws and regulations (at central and } \\
\text { local levels) fully operational, with procurement units } \\
\text { in ministries /agencies and regulatory procurement } \\
\text { body fully functional }\end{array}$} & \multirow{2}{*}{\begin{tabular}{|l|}
$\begin{array}{l}\text { Data } \\
\text { Source }\end{array}$ \\
\\
\end{tabular}} \\
\hline & $\begin{array}{l}\text { Strengthened Public } \\
\text { Sector Management } \\
\text { and accountability }\end{array}$ & & 4.4 .1 & $\begin{array}{l}\text { Public Financial Man- } \\
\text { agement Strengthened } \\
\text { \% of clean audit re- } \\
\text { ports } \\
\% \text { of Ministries / LAs } \\
\text { preparing regular } \\
\text { financial statements } \\
\text { in accordance with } \\
\text { financial regulations }\end{array}$ & & & & & \\
\hline & & $\begin{array}{l}\text { - Uganda is still considered } \\
\text { among the countries with } \\
\text { wide spread corruption } \\
\text { - Lack of transparency in } \\
\text { the procurement systems } \\
\text { and accountings }\end{array}$ & $\begin{array}{r}4.4 .2 \\
\cdot \\
\cdot\end{array}$ & $\begin{array}{l}\text { Reduced Corruption } \\
\text { \% Perceived incidence } \\
\text { of corruption meas- } \\
\text { ured by the National } \\
\text { Integrity Survey } \\
\text { \% satisfaction with } \\
\text { Local Government } \\
\text { services }\end{array}$ & 23 & 12 & & $\begin{array}{l}\text { Implement National Anti-Corruption Strategy } \\
\text { IGG verifies annual asset declarations and takes ap- } \\
\text { propriate action } \\
\text { Government will act as appropriate on the findings of } \\
\text { commissions of inquiry } \\
\text { Complete updating and table legislation (Prevention of } \\
\text { Corruption Act(Revised); Whistleblower Bill; Freedom } \\
\text { of Access to } \\
\text { Information Bill; Leadership Code Amendment Bill) } \\
\text { Implement central and local government procurement } \\
\text { regulations and systems } \\
\text { Promote best practice models of codes of conduct and } \\
\text { client charters }\end{array}$ & \\
\hline
\end{tabular}




\begin{tabular}{|c|c|c|c|c|c|c|c|}
\hline Strategic Objectives & Challenges/ Constraints & PEAP Outcomes/Indicators & $\begin{array}{l}\text { Baseline } \\
2002 / 03\end{array}$ & $\begin{array}{l}\text { Target } \\
2007 / 08\end{array}$ & $\begin{array}{l}\text { Target } \\
2013 / 14\end{array}$ & PEAP Policy Actions & $\begin{array}{l}\text { Data } \\
\text { Sourc }\end{array}$ \\
\hline & $\begin{array}{l}\text { - Inadequate quality \& } \\
\text { effectiveness of public } \\
\text { services }\end{array}$ & $\begin{array}{ll}\text { 4.4.3 } & \text { Improved public sector } \\
& \text { performance } \\
\text { - } & \% \text { satisfaction with public } \\
& \text { service delivery }\end{array}$ & & & & $\begin{array}{l}\text { Timely implementation of Public Service Re- } \\
\text { form Program } \\
\text { Enhance public service pay with more rapid } \\
\text { increase for technical, professional and mana- } \\
\text { gerial cadres and monitor impact on rates of } \\
\text { turnover, qualifications of staff, absenteeism } \\
\text { and performance } \\
\text { Extend Results Oriented Management, and link } \\
\text { with budgetary process } \\
\text { Increase cost effectiveness of public adminis- } \\
\text { tration and political governance agencies } \\
\text { Under take a comprehensive pension reform } \\
\text { program }\end{array}$ & \\
\hline
\end{tabular}

\section{PILLAR FIVE. HUMAN DEVELOPMENT}

\begin{tabular}{|c|c|c|c|c|c|c|c|}
\hline Strategic Objectives & Challenges/ Constraints & PEAP Outcomes/Indicators & $\begin{array}{l}\text { Baseline } \\
2002 / 03\end{array}$ & $\begin{array}{l}\text { Target } \\
2007 / 08\end{array}$ & $\begin{array}{l}\text { Target } \\
2013 / 14\end{array}$ & PEAP Policy Actions & $\begin{array}{l}\text { Data } \\
\text { Sourc }\end{array}$ \\
\hline $\begin{array}{l}5.1 \text { Better Educated Ugan- } \\
\text { dans }\end{array}$ & $\begin{array}{l}\text { Not all primary school age } \\
\text { are attending school }\end{array}$ & $\begin{array}{ll}5.1 .1 & \text { Increased primary enrol- } \\
\text { ment } \\
\text { - Net primary enrolment } \\
\text { rate (Disaggregated by } \\
\text { gender) }\end{array}$ & $86.7 \%$ & $90 \%$ & $100 \%$ & $\begin{array}{l}\text { Government will use the following methods of } \\
\text { improving access: } \\
\text { - Provision of basic education in emergency } \\
\text { situations e.g. psychosocial support, construc- } \\
\text { tion of temporary infrastructure in cases of } \\
\text { disaster among others. }\end{array}$ & \\
\hline
\end{tabular}




\begin{tabular}{|c|c|c|c|c|c|c|c|}
\hline Strategic Objectives & Challenges/ Constraints & PEAP Outcomes/Indicators & $\begin{array}{l}\text { Baseline } \\
2002 / 03\end{array}$ & \begin{tabular}{|l|} 
Target \\
2007/08
\end{tabular} & \begin{tabular}{|l|} 
Target \\
2013/14
\end{tabular} & PEAP Policy Actions & \begin{tabular}{|l|} 
Data \\
Source
\end{tabular} \\
\hline & & $\begin{array}{l}\mathrm{M} \\
\mathrm{F}\end{array}$ & $\begin{array}{l}87 \% \\
86.4 \%\end{array}$ & $\begin{array}{l}90 \% \\
89 \%\end{array}$ & $\begin{array}{l}100 \% \\
100 \%\end{array}$ & $\begin{array}{l}\text { - Provision of incentives for teachers in hard- } \\
\text { to-reach areas to improve the performance of } \\
\text { teachers and impact on learning outcomes } \\
\text { - Continued provision of classroom facilities } \\
\text { - Construction of schools / provision of re- } \\
\text { source rooms and } \\
\text { - Training and retraining of teachers in specific } \\
\text { areas of SNE, SWT, guidance and counselling } \\
\text { to take care of children with learning disabili- } \\
\text { ties }\end{array}$ & EMIS \\
\hline & $\begin{array}{l}\text { - Limited availability of } \\
\text { instructional material } \\
\text { - Lack of appropriate facili- } \\
\text { ties in schools }\end{array}$ & $\begin{array}{l}\text { 5.1.2 Improved quality of Pri- } \\
\text { mary Education } \\
\text { - } \\
\text { Primary completion rate } \\
\text { (Disaggregated by gen- } \\
\text { der) } \\
\mathrm{M} \\
\mathrm{F}\end{array}$ & $56 \%$ & $69 \%$ & & $\begin{array}{l}\text { To improve the quality of education, Govern- } \\
\text { ment will take the following measures } \\
\text { - Improvement of teacher quality through the } \\
\text { Primary Teacher Training Colleges (PTCs) and } \\
\text { through the Teacher Development and Manage- } \\
\text { ment System (TDMS). } \\
\text { - Implementing the use of mother tongues } \\
\text { in parallel to English in instruction in lower } \\
\text { primary school. } \\
\text { - Increasing the relevance of the curriculum } \\
\text { by including aspects of education related to } \\
\text { sustainable development } \\
\text { - Adjusting the assessment and examination } \\
\text { system in order to match changing needs and } \\
\text { realities of Ugandan society. } \\
\text { - Recruitment and retention of high quality } \\
\text { teachers by putting in place attractive terms and } \\
\text { conditions of service for teachers. } \\
\text { - Better support and supervision for teachers. } \\
\text { - Ensure all pupils have access to better sanitary } \\
\text { facilities }\end{array}$ & EMIS \\
\hline
\end{tabular}




\begin{tabular}{|c|c|c|c|c|c|c|c|c|}
\hline Strategic Objectives & Challenges/ Constraints & PEAP & Outcomes/Indicators & $\begin{array}{l}\text { Baseline } \\
\text { 2002/03 }\end{array}$ & $\begin{array}{l}\text { Target } \\
\text { 2007/08 }\end{array}$ & $\begin{array}{l}\text { Target } \\
\text { 2013/14 }\end{array}$ & PEAP Policy Actions & \begin{tabular}{|l|} 
Data \\
Source
\end{tabular} \\
\hline & $\begin{array}{l}\text { Secondary school education } \\
\text { is skewed toward the higher } \\
\text { income groups and urban } \\
\text { and semi-urban families }\end{array}$ & $\begin{array}{r}5.1 .3 \\
.\end{array}$ & $\begin{array}{l}\text { Increased post-Primary } \\
\text { Education enrolment } \\
\text { Post- Primary Gross } \\
\text { enrolment \% (Disaggre- } \\
\text { gated by gender) } \\
\text { M } \\
\text { F }\end{array}$ & $18 \%$ & $\begin{array}{l}30 \% \\
25 \%\end{array}$ & & $\begin{array}{l}\text { - In response to UPE bulge, increase access } \\
\text { to secondary schools and BTVET institu- } \\
\text { tions through: (i) constructing seed second- } \\
\text { ary schools in sub-counties without any; (ii) } \\
\text {, increasing grant aid funding for secondary } \\
\text { schools; (iii) constructing community poly- } \\
\text { technics in } 56 \text { sub-counties and vocationalizing } \\
\text { secondary schools; } \\
\text { - Improve equity of access to secondary } \\
\text { schools and thereby effectiveness of system } \\
\text { through providing bursaries to poor, bright stu- } \\
\text { dents (increase to } 8 \text { students per LC3 by } 06 / 07 \\
\text { from } 2 \text { in } 02 / 03 \text { ). }\end{array}$ & EMIS \\
\hline & $\begin{array}{l}\text { Limited quality of Post-pri- } \\
\text { mary Education curriculum }\end{array}$ & $\begin{array}{r}5.1 .4 \\
.\end{array}$ & $\begin{array}{l}\text { Improved quality of Post- } \\
\text { Primary Education } \\
\text { Completion rate of senior } \\
4 \text { (Disaggregated by gen- } \\
\text { der) } \\
\quad \text { M } \\
\quad \text { F }\end{array}$ & $\begin{array}{l}18 \% \\
20 \% \\
17 \%\end{array}$ & $\begin{array}{l}25 \% \\
26 \% \\
23 \%\end{array}$ & & $\begin{array}{l}\text { - Improve effectiveness of secondary school/ } \\
\text { BTVET curriculum through developing vo- } \\
\text { cational qualifications and assessment frame- } \\
\text { work, and a competency-based curriculum and } \\
\text { strengthening the Uganda Examinations Board } \\
\text { and Education Standards Agency. } \\
\text { - Finalize and implement strategy for expand- } \\
\text { ing sports curriculum. }\end{array}$ & EMIS \\
\hline & $\begin{array}{l}\text { Tertiary student enrolment } \\
\text { rate is among the lowest } \\
\text { rate among the sub-Saharan } \\
\text { Africa (2\%) }\end{array}$ & $\begin{array}{r}5.1 .5 \\
\cdot \\
\end{array}$ & $\begin{array}{l}\text { Improved tertiary enrol- } \\
\text { ment } \\
\text { Tertiary Gross enrolment } \\
\text { rate }\end{array}$ & $4 \%$ & $5.5 \%$ & & $\begin{array}{l}\text { - Improve curriculum to emphasis science and } \\
\text { technology and use the credit system } \\
\text { - Introduction of mechanisms to improve } \\
\text { access to the poor students (i.e. loan system, } \\
\text { bursary schemes) } \\
\text { - Provide for increased physical access to terti- } \\
\text { ary educational institutions through expanded } \\
\text { and rehabilitated facilities } \\
\text { - Establishment of a Labour Market Informa- } \\
\text { tion System and Network linked to UBOS to } \\
\text { facilitate planning of curriculum in secondary } \\
\text { and tertiary institutions. }\end{array}$ & \\
\hline
\end{tabular}




\begin{tabular}{|c|c|c|c|c|c|c|c|}
\hline Strategic Objectives & Challenges/ Constraints & PEAP Outcomes/Indicators & $\begin{array}{l}\text { Baseline } \\
2002 / 03\end{array}$ & \begin{tabular}{|l} 
Target \\
$2007 / 08$
\end{tabular} & $\begin{array}{l}\text { Target } \\
\text { 2013/14 }\end{array}$ & PEAP Policy Actions & $\begin{array}{l}\text { Data } \\
\text { Source }\end{array}$ \\
\hline \multirow[t]{5}{*}{ 5.2 Healthier Ugandans } & & $\begin{array}{l}\text { 5.2.0 Improved Key Strategic } \\
\text { Health objectives } \\
\text { - Infant mortality rate } \\
\text { - Maternal mortality rate } \\
\text { - } \% \text { population undernour- } \\
\text { ished } \\
\text { - HIV/HAID Prevalence } \\
\text { rate }\end{array}$ & $\begin{array}{l}88 \\
(\mathrm{x} 1,000) \\
505 \\
(\mathrm{x} \\
100,000) \\
6.2 \%\end{array}$ & $\begin{array}{c}68 \\
(1,000) \\
354 \\
(x \\
100,000) \\
\\
5 \%\end{array}$ & & $\begin{array}{l}\text { See specific policies below } \\
\text { - Promote better health care seeking behaviour. } \\
\text { Improve and expand delivery of quality health } \\
\text { care services. } \\
\text { - Promote multi-sectoral response to health target- } \\
\text { ing nutrition, population and reproductive health, } \\
\text { sanitation and community participation }\end{array}$ & \\
\hline & $\begin{array}{l}\text { Low access and utilization } \\
\text { of health care services in } \\
\text { remote and rural areas }\end{array}$ & $\begin{array}{ll}\text { 5.2.1 } & \text { Improved utilization of } \\
& \text { health care } \\
\text { - } & \text { OPD utilization rate }\end{array}$ & $0.79 \%$ & $1.0 \%$ & & $\begin{array}{l}\text { Increase access and utilization of health care } \\
\text { through rehabilitating, staffing \& equipping } \\
\text { Health Centres, and ensuring regular supplies of } \\
\text { medical supplies. }\end{array}$ & \\
\hline & $\begin{array}{l}\text { Shortage of skilled health } \\
\text { care staff }\end{array}$ & $\begin{array}{l}\text { 5.2.2 } \begin{array}{l}\text { Improved quality of } \\
\text { health care }\end{array} \\
\text { - } \% \text { of facilities without } \\
\text { any stock outs of chloro- } \\
\text { quine, Fansidar, measles } \\
\text { vaccine, Depo Prevera, } \\
\text { ORS and cotrimoxazole } \\
\text { - } \% \text { of approved filled } \\
\text { posts filled by formally } \\
\text { trained health workers }\end{array}$ & $\begin{array}{l}40 \% \\
68 \%\end{array}$ & $\begin{array}{l}60 \% \\
90 \%\end{array}$ & & $\begin{array}{l}\text { - Improve the qualification levels of Health } \\
\text { Care staff through rehabilitation and recruit- } \\
\text { ment of trained staff. } \\
\text { - Improve availability of essential drugs } \\
\text { - Improve the qualification levels of Health } \\
\text { Care staff through rehabilitation and recruit- } \\
\text { ment of trained staff. }\end{array}$ & \\
\hline & Poor maternal health & $\begin{array}{l}\text { 5.2.3 Improved access to mater- } \\
\text { nity services } \\
\text { - } \% \text { of deliveries in health } \\
\text { care centres }\end{array}$ & $24.4 \%$ & $50 \%$ & & $\begin{array}{l}\text { - Ensure HCIVs are functional. } \\
\text { - Maintain adequate supplies of reproductive } \\
\text { health care commodities and drugs. } \\
\text { - Staff and equip maternity units }\end{array}$ & \\
\hline & High fertility rate & 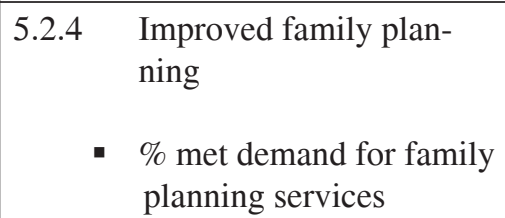 & & & & $\begin{array}{l}\text { - Stronger promotion of family planning in health } \\
\text { care centres in order both to strengthen health and } \\
\text { to reduce the current burdensomely high popula- } \\
\text { tion growth rate }\end{array}$ & \\
\hline
\end{tabular}




\begin{tabular}{|c|c|c|c|c|c|c|c|}
\hline Strategic Objectives & Challenges/ Constraints & PEAP Outcomes/Indicators & $\begin{array}{l}\text { Baseline } \\
2002 / 03 \\
\end{array}$ & $\begin{array}{l}\text { Target } \\
2007 / 08\end{array}$ & $\begin{array}{l}\text { Target } \\
2013 / 14\end{array}$ & PEAP Policy Actions & $\begin{array}{l}\text { Data } \\
\text { Source }\end{array}$ \\
\hline & $\begin{array}{l}\text { Sustain immunization } \\
\text { services }\end{array}$ & $\begin{array}{l}\text { 5.2.5 Improve children access } \\
\text { to immunization care } \\
\text { - } \% \text { of children immunized } \\
\text { (DPT 3) }\end{array}$ & $83 \%$ & $90 \%$ & & $\begin{array}{l}\text { - Ensure adequate supplies for vaccines } \\
\text { - Mobilize communities }\end{array}$ & \\
\hline \multirow[t]{2}{*}{$\begin{array}{l}\text { 5.3 Improved Water and } \\
\text { Sanitation Systems }\end{array}$} & $\begin{array}{l}\text { Limited access to safe } \\
\text { water in rural areas }\end{array}$ & $\begin{array}{l}\text { 5.3.1 Improved access to safe } \\
\text { water supply \& sanitation } \\
\text { - \% population using safe } \\
\text { water (disaggregated by } \\
\text { rural and urban) } \\
\mathrm{R} \\
\mathrm{U} \\
\text { \% Population using sani- } \\
\text { tation facilities } \\
\mathrm{R} \\
\mathrm{U}\end{array}$ & $\begin{array}{l}55 \% \\
65 \%\end{array}$ & $\begin{array}{l}90 \% \\
100 \%\end{array}$ & & $\begin{array}{l}\text { - Continued implementation of plans to install/ } \\
\text { upgrade water and sanitation facilities in rural } \\
\text { and urban areas. } \\
\text { - Implement cost-effectiveness improving } \\
\text { measures: DWD reorganization and strength- } \\
\text { ening, private sector partnership } \\
\text { - Review water sector policy, particularly } \\
\text { subsidy policy. } \\
\text { - Implement plan for dam construction in } \\
\text { areas of variable/limited rainfall for multiple } \\
\text { users. }\end{array}$ & \\
\hline & $\begin{array}{l}\text { Inadequate maintenance of } \\
\text { water facilities }\end{array}$ & $\begin{array}{l}\text { 5.3.2 Improved water facilities } \\
\text { maintenance } \\
\text { - } \% \text { of rural W\&S facilities } \\
\text { functional }\end{array}$ & $70 \%$ & $85 \%$ & $90 \%$ & $\begin{array}{l}\text { - Ensure sustainability through operations and } \\
\text { maintenance strategies, including through pay- } \\
\text { ment of user fees (by strengthening Water Use } \\
\text { Committees, } \\
\text { - Review water sector policy, particularly tariffs } \\
\text { and private sector involvement. }\end{array}$ & \\
\hline $\begin{array}{l}5.4 \text { Inclusive and Empow- } \\
\text { ered Communities }\end{array}$ & $\begin{array}{l}\text { - Limited community par- } \\
\text { ticipation in public service } \\
\text { delivery } \\
\text { - Gender inequality among } \\
\text { women and men in the de- } \\
\text { velopment process }\end{array}$ & $\begin{array}{l}\text { 5.4.1 Revitalised Community } \\
\text { Development Function } \\
\text { - No. of filled CDW Posts } \\
\text { - No. of Graduate Commu- } \\
\text { nity Development Staff } \\
\text { - } \% \text { of functional commu- } \\
\text { nity management } \\
\text { committees }\end{array}$ & 742 & 930 & & $\begin{array}{l}\text { - Revitalizing the Community Development } \\
\text { Function } \\
\text { - recruiting more CDWs. } \\
\text { - Implementing the Social Protection Frame- } \\
\text { work } \\
\text { - Implementing the Revised National Gender } \\
\text { Policy }\end{array}$ & $\begin{array}{l}\text { MoGL } \\
\text { SD }\end{array}$ \\
\hline
\end{tabular}




\section{Annex Tables}

Table A 2.1: Average assets owned by households: dollar value

(value in parentheses: the percentage of assets that are in the form of land) ${ }^{1}$

\begin{tabular}{|c|c|c|c|c|}
\hline & Central & \multicolumn{2}{|c|}{ Eastern } & Northern \\
\hline 199 & $3691(57)$ & $1518(62)$ & $734(30)$ & $1974(61)$ \\
\hline 1999 & $4647(50)$ & $1597(50)$ & $798(31)$ & $2624(69)$ \\
\hline
\end{tabular}

Table A 2.2: Open unemployment, \% of labour force ${ }^{2}$

\begin{tabular}{|l|c|c|c|}
\hline & male & female & Total \\
\hline Total & 2.5 & 3.9 & 3.2 \\
\hline urban & 7.5 & 16.3 & 12.0 \\
\hline rural & 1.6 & 1.8 & 1.7 \\
\hline Region & & & \\
\hline Kampala & & & \\
\hline central except Kampala & 10.0 & 22.5 & 16.5 \\
\hline east & 2.5 & 5.2 & 3.9 \\
\hline west & 2.1 & 2.4 & 2.3 \\
\hline north & 2.2 & 1.9 & 2.1 \\
\hline & 0.9 & 1.1 & 1.0 \\
\hline Educational level & & & \\
\hline no schooling & & & 1.8 \\
\hline primary & 2.5 & 1.5 & 2.3 \\
\hline secondary & 1.6 & 3.1 & 7.2 \\
\hline above secondary & 4.5 & 11.2 & 5.0 \\
\hline
\end{tabular}


Table A 2.3: Proportion of households with access to services at a community level ${ }^{3}$

\begin{tabular}{|c|c|c|c|c|c|c|c|c|c|c|c|c|}
\hline & \multicolumn{2}{|c|}{ Quintile 1} & \multicolumn{2}{|c|}{ Quintile 2} & \multicolumn{2}{|c|}{ Quintile 3} & \multicolumn{2}{|c|}{ Quintile 4} & \multicolumn{2}{|c|}{ Quintile 5 } & \multicolumn{2}{|c|}{ Total } \\
\hline & $\begin{array}{r}1999 / \\
00\end{array}$ & $\begin{array}{r}2002 / \\
03\end{array}$ & $\begin{array}{r}1999 / \\
00\end{array}$ & $\begin{array}{r}2002 / \\
03\end{array}$ & $\begin{array}{r}1999 / \\
00\end{array}$ & $\begin{array}{r}2002 / \\
03\end{array}$ & $\begin{array}{r}1999 / \\
00\end{array}$ & $\begin{array}{r}2002 / \\
03\end{array}$ & $\begin{array}{r}1999 / \\
00\end{array}$ & $\begin{array}{r}2002 / \\
03\end{array}$ & $\begin{array}{r}1999 / \\
00\end{array}$ & $\begin{array}{r}2002 / \\
03\end{array}$ \\
\hline $\begin{array}{l}\text { Prim a ry } \\
\text { school: }\end{array}$ & & & & & & & & & & & & \\
\hline$<=3 \mathrm{~km}$ & 85.9 & 88.4 & 89.1 & 91.5 & 89.7 & 93.2 & 89.9 & 93.9 & 92.3 & 96.6 & 89.7 & 93.1 \\
\hline$>3 \mathrm{~km}$ & 14.1 & 11.6 & 10.9 & 8.5 & 10.3 & 6.8 & 10.1 & 6.1 & 7.7 & 3.4 & 10.3 & 6.9 \\
\hline $\begin{array}{l}\text { Secondary } \\
\text { school: }\end{array}$ & & & & & & & & & & & & \\
\hline$<=3 \mathrm{~km}$ & 32.7 & 38.4 & 38.2 & 49.2 & 44.1 & 54.5 & 52.5 & 62.8 & 66.4 & 80.4 & 48.9 & 59.3 \\
\hline$>3 \mathrm{~km}$ & 67.4 & 61.6 & 61.8 & 50.8 & 55.9 & 45.5 & 47.5 & 37.3 & 33.6 & 19.5 & 51.1 & 40.7 \\
\hline $\begin{array}{l}\text { Govt. hosp/ } \\
\text { clinic: }\end{array}$ & & & & & & & & & & & & \\
\hline$<=3 \mathrm{~km}$ & 24.4 & 35.8 & 25.2 & 37.5 & 28.0 & 40.9 & 32.1 & 43.7 & 41.9 & 53.4 & 31.5 & 43.2 \\
\hline$>3 \mathrm{~km}$ & 75.6 & 64.3 & 74.7 & 62.5 & 72.0 & 59.2 & 67.9 & 56.3 & 58.1 & 46.7 & 68.5 & 56.8 \\
\hline $\begin{array}{l}\text { Private } \\
\text { hosp/clinic: }\end{array}$ & & & & & & & & & & & & \\
\hline$<=3 \mathrm{~km}$ & 26.1 & 36.8 & 30.8 & 44.5 & 35.3 & 50.6 & 42.9 & 60.7 & 61.4 & 78.1 & 41.5 & 56.9 \\
\hline$>3 \mathrm{~km}$ & 73.9 & 63.2 & 69.1 & 55.5 & 64.7 & 49.4 & 57.1 & 39.4 & 38.6 & 21.9 & 58.5 & 43.2 \\
\hline $\begin{array}{l}\text { Telephone } \\
\text { in } 2 \mathrm{~km}\end{array}$ & 3.5 & 11.2 & 6.8 & 17.1 & 9.0 & 19.3 & 15.6 & 26.5 & 38.3 & 53.0 & 17.1 & 28.0 \\
\hline $\begin{array}{ll}\text { Bank } & \text { in } \\
10 \mathrm{~km} & \\
\end{array}$ & 12.7 & 18.5 & 21.3 & 23.5 & 26.2 & 29.4 & 32.8 & 37.5 & 50.6 & 60.3 & 30.9 & 36.4 \\
\hline $\begin{array}{l}\text { Feeder road } \\
\text { in } 1 \mathrm{~km}\end{array}$ & 83.9 & 70.6 & 86.1 & 79.4 & 89.2 & 81.8 & 91.9 & 85.3 & 95.1 & 90.8 & 89.8 & 82.6 \\
\hline $\begin{array}{l}\mathrm{H} \quad \mathrm{a} \quad \mathrm{s} \\
\text { electricity }\end{array}$ & 6.0 & 6.3 & 9.8 & 11.5 & 14.0 & 17.0 & 23.1 & 25.8 & 46.1 & 54.7 & 22.3 & 26.0 \\
\hline
\end{tabular}




\begin{tabular}{|c|c|c|c|c|c|c|c|c|c|c|c|c|}
\hline & \multicolumn{2}{|c|}{ Quintile 1 } & \multicolumn{2}{|c|}{ Quintile 2} & \multicolumn{2}{|c|}{ Quintile 3} & \multicolumn{2}{|c|}{ Quintile 4} & \multicolumn{2}{|c|}{ Quintile 5} & \multicolumn{2}{|c|}{ All } \\
\hline & $\begin{array}{l}\text { Implemen } \\
\text { ted }\end{array}$ & Needs & $\begin{array}{l}\text { Implemen } \\
\text { ted }\end{array}$ & Needs & $\begin{array}{l}\text { Implemen } \\
\text { ted }\end{array}$ & Needs & $\begin{array}{l}\text { Implemen } \\
\text { ted }\end{array}$ & Needs & $\begin{array}{l}\text { Implemen } \\
\text { ted }\end{array}$ & Needs & $\begin{array}{l}\text { Implemen } \\
\text { ted }\end{array}$ & Needs \\
\hline Uganda & & & & & & & & & & & & \\
\hline Water provision & 41.5 & 63.1 & 41.1 & 69.6 & 45.8 & 75.0 & 46.1 & 78.7 & 53.8 & 80.7 & 46.4 & 74.9 \\
\hline $\begin{array}{l}\text { Infrastructure } \\
\text { (roads, markets, } \\
\text { bridges) }\end{array}$ & 28.3 & 83.9 & 36.0 & 89.0 & 37.5 & 89.4 & 39.7 & 88.6 & 39.6 & 88.0 & 36.7 & 88.1 \\
\hline $\begin{array}{l}\text { Improving } \\
\text { transport }\end{array}$ & 20.8 & 84.8 & 26.2 & 96.1 & 28.7 & 95.4 & 32.8 & 93.6 & 30.4 & 93.2 & 28.2 & 93.2 \\
\hline Desk making & 34.9 & 87.5 & 40.5 & 90.9 & 38.7 & 91.9 & 37.8 & 93.0 & 37.3 & 96.3 & 37.8 & 92.4 \\
\hline $\begin{array}{l}\text { School } \\
\text { construction }\end{array}$ & 14.5 & 71.7 & 15.8 & 80.8 & 19.8 & 86.4 & 19.9 & 84.4 & 21.8 & 88.7 & 18.8 & 83.9 \\
\hline $\begin{array}{l}\text { Classroom } \\
\text { construction }\end{array}$ & 49.1 & 82.4 & 55.1 & 89.2 & 51.5 & 90.1 & 47.3 & 91.7 & 43.4 & 94.6 & 48.7 & 90.0 \\
\hline $\begin{array}{l}\text { Other school } \\
\text { related }\end{array}$ & 48.9 & 91.2 & 55.1 & 92.9 & 51.9 & 94.4 & 47.4 & 93.8 & 45.6 & 96.0 & 49.4 & 93.8 \\
\hline Health related & 44.3 & 75.2 & 44.3 & 86.0 & 43.8 & 90.3 & 46.3 & 86.5 & 42.8 & 87.6 & 44.3 & 85.5 \\
\hline Sensitization & 56.5 & 68.1 & 52.8 & 81.2 & 55.6 & 82.6 & 59.9 & 85.0 & 63.2 & 84.0 & 58.1 & 81.0 \\
\hline $\begin{array}{l}\text { Demonstration } \\
\text { garden }\end{array}$ & 12.7 & 79.4 & 13.0 & 89.4 & 15.3 & 91.8 & 12.1 & 93.9 & 11.3 & 93.6 & 12.7 & 90.2 \\
\hline $\begin{array}{l}\text { Livestock } \\
\text { improvement }\end{array}$ & 15.0 & 69.4 & 16.7 & 70.7 & 21.6 & 80.6 & 23.2 & 80.7 & 25.1 & 84.3 & 20.9 & 79.1 \\
\hline Poultry/birds & 5.4 & 80.6 & 7.6 & 78.0 & 10.4 & 87.1 & 13.3 & 85.4 & 20.6 & 87.3 & 12.4 & 85.3 \\
\hline Vaccination & 84.1 & 94.7 & 84.4 & 97.7 & 83.7 & 97.4 & 81.2 & 96.1 & 72.4 & 91.7 & 80.4 & 95.4 \\
\hline $\begin{array}{l}\text { Improved } \\
\text { varieties/new } \\
\text { crops }\end{array}$ & 41.0 & 48.4 & 42.5 & 58.2 & 44.9 & 61.6 & 42.0 & 65.4 & 32.2 & 64.7 & 39.9 & 60.2 \\
\hline $\begin{array}{l}\text { Improved } \\
\text { agricultural } \\
\text { techniques }\end{array}$ & 30.5 & 49.2 & 30.7 & 65.4 & 34.5 & 69.7 & 30.7 & 75.8 & 25.3 & 77.3 & 29.9 & 68.5 \\
\hline Environmental & 21.3 & 60.5 & 24.4 & 59.6 & 23.8 & 69.5 & 26.2 & 77.2 & 24.2 & 68.4 & 24.1 & 67.9 \\
\hline
\end{tabular}


Table A 4.1: The business environment in Uganda

\begin{tabular}{|c|c|c|c|}
\hline \multicolumn{4}{|c|}{ \% of firms evaluating constraint as "major" or "very severe" } \\
\hline Item & General & Exporter & Non-Exporter \\
\hline Cost of Financing & 60.3 & 62.5 & 60.2 \\
\hline Tax rates & 48.3 & 48.9 & 48.4 \\
\hline Macroeconomic instability & 45.4 & 64.3 & 41.7 \\
\hline Access to Financing & 45.0 & 37.2 & 46.6 \\
\hline Electricity & 44.5 & 52.4 & 42.9 \\
\hline Corruption & 38.2 & 56.4 & 35.0 \\
\hline Tax administration & 36.1 & 42.9 & 35.1 \\
\hline $\begin{array}{l}\text { Anti-competitive or } \\
\text { informal practices }\end{array}$ & 31.1 . & 41.5 & 29.4 \\
\hline $\begin{array}{l}\text { Skills and Education of } \\
\text { Available Workers }\end{array}$ & 30.8 & 36.6 & 30.0 \\
\hline $\begin{array}{l}\text { Regulatory Policy } \\
\text { Uncertainty }\end{array}$ & 27.6 & 42.9 & 24.6 \\
\hline $\begin{array}{l}\text { Customs and Trade } \\
\text { Regulations }\end{array}$ & 27.4 & 33.3 & 26.3 \\
\hline Crime, theft and disorder & 26.8 & 36.4 & 25.3 \\
\hline Transportation & 22.9 & 36.4 & 20.2 \\
\hline Access to Land & 17.4 & 17.1 & 17.4 \\
\hline Labour Regulations & 10.8 & 14.6 & 10.1 \\
\hline $\begin{array}{l}\text { Business Licensing and Operating } \\
\text { permits }\end{array}$ & 10.1 & 8.9 & 10.4 \\
\hline Telecommunications & 5.2 & 7.0 & 4.5 \\
\hline
\end{tabular}


Table A 4.2: Delays in procedures and constraints to business ${ }^{5}$

\begin{tabular}{|c|c|}
\hline Procedure & Delays \\
\hline Utilities & $\begin{array}{l}\text { Takes } 1-2 \text { months to get an electricity connection; water } \\
\text { connections are slow: no formal procedure for self-financing } \\
\text { connections }\end{array}$ \\
\hline Registration & $\begin{array}{l}\text { Foreign businesses have to register with three agencies. Business } \\
\text { registry and city council are slow. UIA takes } 3-5 \text { days. Times are } \\
\text { longer than in Europe or North America though faster than in } \\
\text { most African countries. }\end{array}$ \\
\hline Tax appeals & Process formal and slow. \\
\hline Duty drawback & $\begin{array}{l}\text { Should take } 7 \text { days but can take months because of manual } \\
\text { administration. Businesses report that it has become slower. }\end{array}$ \\
\hline VAT refunds & $\begin{array}{l}\text { Businesses report that it has become slower. URA reports period } \\
10-26 \text { days, almost always within the } 30 \text { days stipulated. }\end{array}$ \\
\hline $\begin{array}{l}\text { Imports border } \\
\text { clearance }\end{array}$ & 6 days \\
\hline $\begin{array}{l}\text { Imports veterinary./ } \\
\text { health inspection }\end{array}$ & 5 days \\
\hline $\begin{array}{l}\text { Imports customs } \\
\text { clearance }\end{array}$ & 9 days \\
\hline Land purchase & Sometimes a very slow process \\
\hline $\begin{array}{l}\text { Export border } \\
\text { clearance }\end{array}$ & 6 days \\
\hline $\begin{array}{l}\text { Exports veterinary/ } \\
\text { health clearance }\end{array}$ & 3 days \\
\hline $\begin{array}{l}\text { Exports - customs } \\
\text { clearance }\end{array}$ & 4 days \\
\hline
\end{tabular}


Table A 4.5: Forms of land con icts in registered and unregistered land

\begin{tabular}{|c|c|c|c|c|c|c|c|c|c|c|}
\hline \multirow{4}{*}{$\begin{array}{l}\text { Type of con icts occurring on } \\
\text { Land where rights are defined } \\
\text { and registered vs. unregistered } \\
\text { Interests in Land }\end{array}$} & \multicolumn{4}{|c|}{ Titled land $n=48$} & \multicolumn{4}{|c|}{ Customary $\mathrm{N}=332$} & & \\
\hline & \multicolumn{4}{|c|}{ Sex Of HH Head } & \multicolumn{4}{|c|}{ Sex Of HH Head } & \multicolumn{2}{|c|}{ Total } \\
\hline & \multicolumn{2}{|c|}{ Female } & \multicolumn{2}{|c|}{ Male } & \multicolumn{2}{|c|}{ Female } & \multicolumn{2}{|c|}{ Male } & \multirow{2}{*}{$\mathbf{n}$} & \multirow{2}{*}{$\%$} \\
\hline & $\mathbf{n}$ & $\%$ & $\mathbf{n}$ & $\%$ & $\mathbf{n}$ & $\%$ & $\mathbf{n}$ & $\%$ & & \\
\hline Inheritance & 1 & 8 & 3 & 8 & 18 & 23 & 23 & 9 & 45 & 12 \\
\hline User Rights & 1 & 8 & 4 & 11 & 16 & 21 & 43 & 17 & 64 & 17 \\
\hline Encroachment & 4 & 30 & 13 & 37 & 26 & 33 & 57 & 22 & 100 & 26 \\
\hline Exceeding boundaries & 4 & 30 & 9 & 26 & 10 & 13 & 90 & 35 & 113 & 30 \\
\hline Trespass & 1 & 8 & 2 & 6 & 1 & 1 & 15 & 6 & 19 & 5 \\
\hline Others* & 2 & 16 & 4 & 11 & 7 & 9 & 26 & 10 & 39 & 10 \\
\hline Total & 13 & 100 & 35 & 100 & 78 & 100 & 254 & 100 & 380 & 100 \\
\hline
\end{tabular}

** Districts of Mbale, Luweero, Lira, Kibaale and Mbarara

* Compensation/resettlement/land sales/ Government Gazetted land

Source: MISR/ EPRC, 2003 (forthcoming) 
Table A 4.6: Household perceptions of benefits of systematic demarcation in pilot areas

\begin{tabular}{|l|c|c|c|c|c|c|c|c|}
\hline \multirow{2}{*}{$\begin{array}{l}\text { Household Perceptions of the Benefits of } \\
\text { Systematic Demarcation }\end{array}$} & \multicolumn{9}{|c|}{ Study District } & \multicolumn{2}{c|}{ Total } \\
\cline { 2 - 9 } & \multicolumn{2}{|c|}{ Masaka } & \multicolumn{2}{|c|}{ Ntungamo } & \multicolumn{2}{|c|}{ Soroti } & \multicolumn{2}{c|}{} \\
\cline { 2 - 10 } & $\mathbf{n}$ & $\%$ & $\mathbf{n}$ & $\%$ & $\mathbf{n}$ & $\%$ & $\mathbf{n}$ & $\%$ \\
\hline $\begin{array}{l}\text { Security of tenure / attain a title/ get } \\
\text { empowered }\end{array}$ & 18 & 24.3 & 28 & 23.0 & 20 & 28.2 & 66 & 24.7 \\
\hline Protection of female spouses & 2 & 2.7 & 8 & 6.6 & 1 & 1.4 & 11 & 4.1 \\
\hline No more evictions/ have say on my land & 15 & 20.3 & 8 & 6.6 & 12 & 16.9 & 35 & 13.1 \\
\hline Assured collateral & 9 & 12.2 & 15 & 12.3 & 3 & 4.2 & 27 & 10.1 \\
\hline Can plan what to do with my land & 5 & 6.8 & 4 & 3.3 & 1 & 1.4 & 10 & 3.7 \\
\hline Reduced land con icts & 12 & 16.2 & 26 & 21.3 & 14 & 19.7 & 52 & 19.5 \\
\hline $\begin{array}{l}\text { Not sure (More sensitization needed, } \\
\text { program may not be free and fair) }\end{array}$ & 13 & 17.6 & 33 & 27.0 & 20 & 28.2 & 66 & 24.7 \\
\hline Totals & 74 & 100.0 & 122 & 100.0 & 71 & 100.0 & 267 & 100.0 \\
\hline
\end{tabular}

Source: Ministry of Water, Lands and Environment

\section{Chart A 4.1: The potential effect of global warming on coffee production in Uganda}

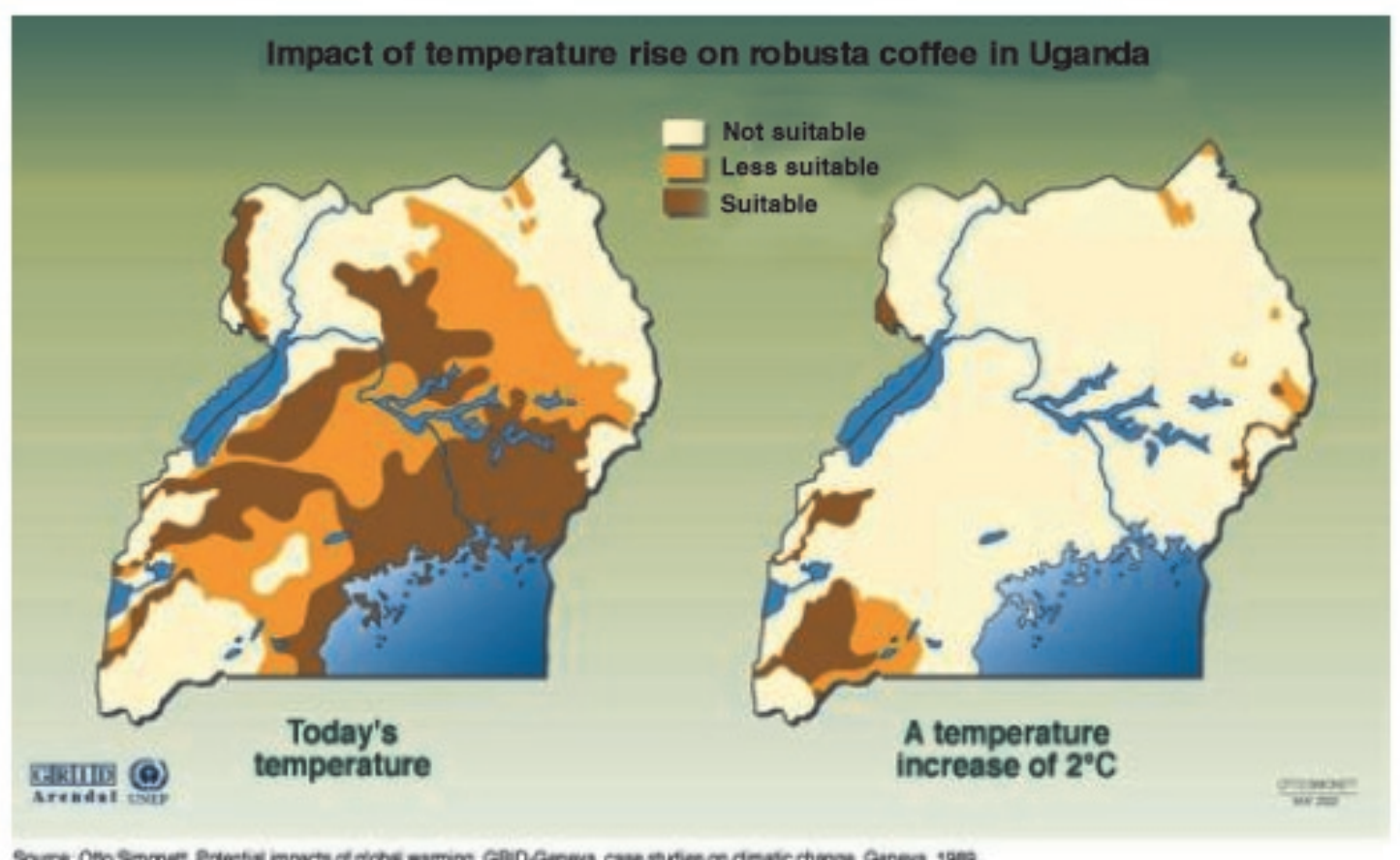




\begin{tabular}{|l|c|c|c|c|}
\hline \multirow{2}{*}{ Table A 4.7: Improvement in the condition of roads 1988-2003 } \\
\hline & \multicolumn{2}{|c|}{1988} & \multicolumn{2}{c|}{2003} \\
\cline { 2 - 5 } & Good/Fair & Poor/Bad & Good/Fair & Poor/Bad \\
\hline National roads & $6 \%$ & $94 \%$ & $75 \%$ & $25 \%$ \\
\hline Urban roads & $5 \%$ & $95 \%$ & $30 \%$ & $70 \%$ \\
\hline District roads & $15 \%$ & $85 \%$ & $67 \%$ & $33 \%$ \\
\hline Community access roads & $0 \%$ & $100 \%$ & $10 \%$ & $90 \%$ \\
\hline
\end{tabular}

Source: MoWHC FY2003/04

\begin{tabular}{|c|c|c|}
\hline Year & Nature of disaster & Impacts \\
\hline 1966 & Tooro earthquake & $\begin{array}{l}157 \text { people died, } 1,320 \text { people injured, } 67,000 \text { huts } \\
\text { and houses damaged. }\end{array}$ \\
\hline 1981-1986 & Civil strife & 500,000 displaced \\
\hline $1993 / 4$ & Drought and famine & $\begin{array}{l}\text { Over } 1.8 \mathrm{~m} \text { people affected and falling into poverty, } \\
\text { inadequate pasture and water for livestock in } 16 \\
\text { districts }\end{array}$ \\
\hline 1994 & $\begin{array}{l}\text { Earthquake in Kabarole, Bundibugyo, } \\
\text { Kasese districts }\end{array}$ & $\begin{array}{l}50,000 \text { people affected and losses of } 70 \text { billion } \\
\text { shillings worth in } 1994 \text { prices }\end{array}$ \\
\hline 1994 & Kisomoro earthquake & $\begin{array}{l}8 \text { people dead, damage and destruction worth } 6 \\
\text { billion Uganda Shillings }\end{array}$ \\
\hline 1997-1999 & El Nino rains & $\begin{array}{l}35 \text { people buried by landslides in Mbale, } 18 \text { dead } \\
\text { elsewhere, over } 2000 \text { people in need of relocation. } \\
\text { Roads, bridges and homes worth over } 30 \text { billion } \\
\text { shillings were destroyed. }\end{array}$ \\
\hline 1999 & Drought and famine & $\begin{array}{l}3.5 \mathrm{~m} \text { people affected and a large number of livestock } \\
\text { in } 28 \text { districts }\end{array}$ \\
\hline $1986-2003$ & $\begin{array}{l}\text { Northern con ict in Acholi, Lango and } \\
\text { Teso regions }\end{array}$ & $\begin{array}{l}\text { Over } 1 \mathrm{~m} \text { people displaced, over } 200,000 \text { refugees; an } \\
\text { average US } \$ 100 \text { million is lost each year }\end{array}$ \\
\hline Annually & Drought, oods, landslides, hailstorms & Destroy an average of 800,000 hectares of crop \\
\hline
\end{tabular}




\begin{tabular}{|c|c|c|c|}
\hline \multicolumn{4}{|c|}{ Table A 6.1: Death rates in prisons } \\
\hline YEAR & $\begin{array}{c}\text { POPULATION } \\
\text { TURNOVER }\end{array}$ & $\begin{array}{c}\text { NUMBER OF } \\
\text { REPORTED } \\
\text { DEATHS }\end{array}$ & $\begin{array}{l}\text { CRUDE DEATH RATE } \\
\text { PER } 1000 \text { HELD } \\
\text { INMATES }\end{array}$ \\
\hline 1993 & 28,757 & 378 & 13.1 \\
\hline 1994 & 31,813 & 439 & 13.7 \\
\hline 1995 & 33,954 & 391 & 11.5 \\
\hline 1996 & 21,674 & 286 & 13.1 \\
\hline 1997 & 36,271 & 289 & 7.9 \\
\hline 1998 & 42,141 & 321 & 9.9 \\
\hline 1999 & 34,857 & 276 & 7.9 \\
\hline 2000 & 46,954 & 185 & 3.4 \\
\hline 2001 & 46,091 & 301 & 6.5 \\
\hline 2002 & 47,490 & 285 & 6.0 \\
\hline
\end{tabular}



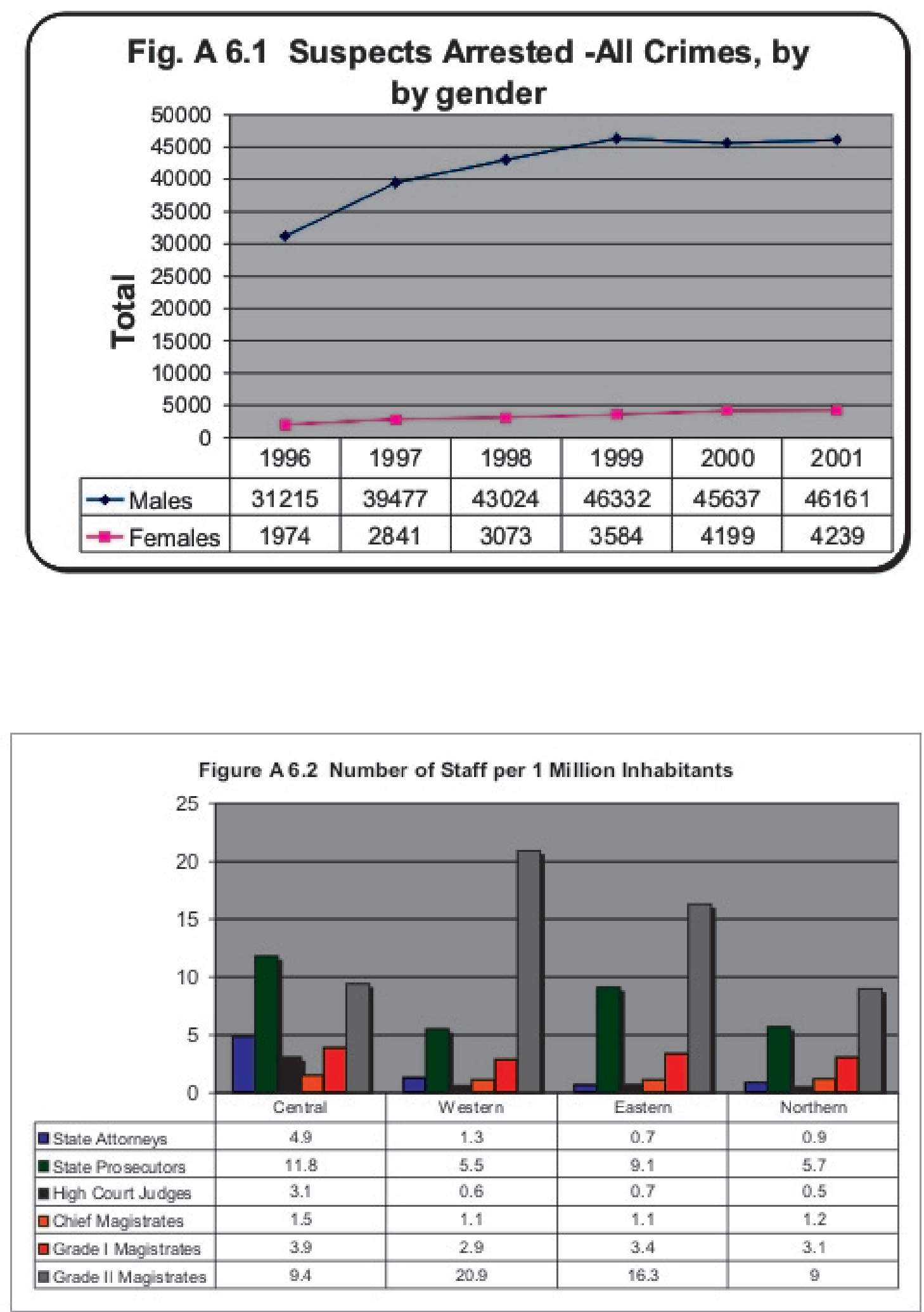
Table A 6.2: Transparency International Corruption Perception Index for Uganda 1998-2003

\begin{tabular}{|c|c|c|}
\hline Year & Ranking from the top & $\begin{array}{c}\text { Ranking from the } \\
\text { bottom }\end{array}$ \\
\hline 1998 & $73 / 85$ & 8 \\
\hline 1999 & $87 / 99$ & 12 \\
\hline 2000 & $80 / 90$ & 3 \\
\hline 2001 & $889 / 91$ & 9 \\
\hline 2002 & $93 / 102$ & 17 \\
\hline 2003 & $113 / 133$ & 10 \\
\hline
\end{tabular}

Table A 6.3: Reported Percentage Levels of Bribery in Selected Institutions

\begin{tabular}{|l|c|c|}
\hline Institution & 1998 & 2003 \\
\hline primary school & & 8 \\
\hline Education department & & 19 \\
\hline Traffic police & & 34 \\
\hline LC1 & & 16 \\
\hline LC3 & & 9 \\
\hline Agricultural department & & 8 \\
\hline Veterinary department & & 35 \\
\hline Water department & & 15 \\
\hline Local Defence Unit & & 28 \\
\hline Police & 63 & 46 \\
\hline URA & 40 & 31 \\
\hline Magistrates' courts & 50 & 29 \\
\hline Health units & 28 & 24 \\
\hline Local Government & 30 & 16 \\
\hline
\end{tabular}


Table A 6.4: Institutional respondents' ranking of integrity of various institutions ${ }^{6}$

\begin{tabular}{|c|c|c|c|}
\hline & Most honest & Honest & $\begin{array}{c}\text { Least } \\
\text { honest }\end{array}$ \\
\hline Traffic police & 5 & 12 & 83 \\
\hline Tender boards & 4 & 17 & 79 \\
\hline Electoral commission & 4 & 18 & 78 \\
\hline URA & 5 & 17 & 77 \\
\hline MOD & 8 & 18 & 74 \\
\hline Privatisation unit & 9 & 24 & 67 \\
\hline Police excluding traffic & 10 & 24 & 67 \\
\hline Immigration department & 17 & 23 & 60 \\
\hline Courts & 18 & 28 & 54 \\
\hline $\mathrm{NSSF}$ & 20 & 26 & 54 \\
\hline District councils & 17 & 36 & 47 \\
\hline State house/President's office & 31 & 23 & 45 \\
\hline $\mathrm{MOH}$ & 22 & 37 & 41 \\
\hline DPP & 29 & 30 & 40 \\
\hline IGG & 28 & 33 & 39 \\
\hline MOPS & 29 & 35 & 37 \\
\hline Parliament & 31 & 34 & 35 \\
\hline Local administration & 23 & 42 & 34 \\
\hline LC3 & 27 & 39 & 34 \\
\hline MOWHC & 27 & 44 & 29 \\
\hline LC1 & 35 & 37 & 27 \\
\hline MOEd & 29 & 44 & 27 \\
\hline MFPED & 29 & 45 & 26 \\
\hline MAAIF & 34 & 41 & 25 \\
\hline MGLSD & 33 & 45 & 21 \\
\hline Prisons & 48 & 31 & 20 \\
\hline MOFA & 42 & 20 & 18 \\
\hline Central bank & 63 & 26 & 11 \\
\hline NWSC & 60 & 29 & 11 \\
\hline DEI & 59 & 31 & 11 \\
\hline Post Office & 57 & 31 & 10 \\
\hline
\end{tabular}


Table A 6.5: Investigations carried out by the IG from the years 2001 and 2002

\begin{tabular}{|l|c|c|c|c|}
\hline & Jan-Jun 2001 & July-Dec 2001 & Jan 02-June 02 & Jul-Dec 02 \\
\hline Complaints load & 3,179 & 2,942 & 2,870 & 3,384 \\
\hline $\begin{array}{l}\text { Investigated } \\
\text { completed }\end{array}$ & 1,288 & 1,002 & 1,104 & 1,003 \\
\hline
\end{tabular}

Table A 7.1: Enrolment numbers by grade level, 1998-2002

\begin{tabular}{|c|c|c|c|c|c|c|c|c|}
\hline & & P1 & P2 & P3 & P4 & P5 & P6 & P7 \\
\hline \multirow[t]{3}{*}{1998} & Male & 848,973 & 671,945 & 455,744 & 376,226 & 293,697 & 239,590 & 175,547 \\
\hline & Female & 806,153 & 640,648 & 407,404 & 327,937 & 251,454 & 188,974 & 122,093 \\
\hline & Total & $1,655,126$ & $1,312,593$ & 863,148 & 704,163 & 545,151 & 428,564 & 297,460 \\
\hline \multirow[t]{3}{*}{1999} & Male & 813,991 & 630,235 & 584,412 & 428,974 & 352,445 & 282,599 & 209,232 \\
\hline & Female & 796,017 & 575,112 & 543,804 & 384,346 & 302,506 & 231,957 & 152,609 \\
\hline & Total & $1,610,008$ & $1,205,347$ & $1,128,216$ & 813,320 & 654,951 & 514,556 & 361,841 \\
\hline \multirow[t]{3}{*}{2000} & Male & 828,345 & 589,184 & 572,070 & 495,954 & 381,107 & 308,451 & 220,443 \\
\hline & Female & 809,306 & 568,363 & 553,215 & 466,908 & 342,025 & 260,492 & 163,960 \\
\hline & Total & $1,637,651$ & $1,157,547$ & $1,125,285$ & 962,052 & 723,132 & 568,943 & 384,403 \\
\hline \multirow[t]{3}{*}{2001} & Male & 855,571 & 586,537 & 569,712 & 515,412 & 429,142 & 332,320 & 239,341 \\
\hline & Female & 849,195 & 571,445 & 559,058 & 503,950 & 403,713 & 296,857 & 188,663 \\
\hline & Total & $1,704,766$ & $1,157,982$ & $1,128,770$ & $1,019,362$ & 832,855 & 629,177 & 428,004 \\
\hline \multirow[t]{3}{*}{2002} & Male & 920,053 & 606,611 & 582,406 & 535,935 & 460,098 & 363,918 & 252,114 \\
\hline & Female & 927,127 & 597,372 & 577,465 & 534,184 & 450,592 & 338,283 & 207,995 \\
\hline & Total & $1,847,180$ & $1,203,983$ & $1,159,871$ & $1,070,119$ & 910,690 & 702,201 & 460,109 \\
\hline \multirow[t]{3}{*}{$2003 *$} & Male & 960,342 & 626,755 & 595,916 & 548,729 & 483,218 & 391,311 & 265,115 \\
\hline & Female & 954,011 & 617,690 & 582,602 & 540,850 & 474,953 & 369,151 & 220,409 \\
\hline & Total & $1,914,893$ & $1,244,801$ & $\mathbf{1 , 1 7 8 , 8 9 0}$ & 1,089,884 & 954,458 & 760,685 & 485,703 \\
\hline
\end{tabular}


Table A 7.2: Enrolment in public sector BTVET institutions 1999/2000 $-2003 / 2004$

\begin{tabular}{|l|l|l|l|l|l|l|}
\hline Type of Institution & $\mathbf{1 9 9 9 / 2 0 0 0}$ & $\mathbf{2 0 0 0 / 2 0 0 1}$ & $\mathbf{2 0 0 1 / 2 0 0 2}$ & $\mathbf{2 0 0 2 / 2 0 0 3}$ & $\mathbf{2 0 0 3 / 2 0 0 4}$ & Total \\
\hline Colleges of Commerce & 2,169 & 2,320 & 2,984 & 3,420 & 3,596 & 14,489 \\
\hline Technical Colleges, & 1,652 & 1,789 & 1,922 & 1,980 & 2,136 & 9,479 \\
\hline Technical Institutes & 9,188 & 9,690 & 10,215 & 10,694 & 11,292 & 51,079 \\
\hline Technical Schools & 6,984 & 6,902 & 7,218 & 7,123 & 7,264 & 35,491 \\
\hline Health Training Institutions & 2,301 & 2,412 & 2,386 & 2,599 & 2,811 & 12,509 \\
\hline Community Polytechnics & & & & 1,800 & 1,800 & 1,800 \\
\hline Agric. Colleges and others & 912 & 1,120 & 1,317 & 1,580 & 1,613 & 6,542 \\
\hline Total & $\mathbf{2 3 , 2 0 6}$ & $\mathbf{2 4 , 2 3 3}$ & $\mathbf{2 6 , 0 4 2}$ & $\mathbf{2 8 , 7 8 2}$ & $\mathbf{2 8 , 7 1 2}$ & $\mathbf{1 3 0 , 9 7 5}$ \\
\hline
\end{tabular}

Table A 7.3: Summary of PEAP Matrix Macro Indicators

\begin{tabular}{|l|c|c|c|}
\hline \multicolumn{1}{|c|}{ Indicator } & $\mathbf{2 0 0 2 / 0 3}$ & $\mathbf{2 0 0 7 / 0 8}$ & $\mathbf{2 0 1 3 / 1 4}$ \\
\hline Fiscal Deficit(\%GDP) & $11.3 \%$ & $<8 \%$ & $6.5 \%$ \\
\hline Domestic Revenues (\%GDP) & $12.6 \%$ & $>13.5 \%$ & $15.8 \%$ \\
\hline Govt Expenditures (\%GDP) & $23.9 \%$ & $<21.5 \%$ & $22.5 \%$ \\
\hline In ation (\%) & $2.4 \%$ & $<5 \%$ & $<5 \%$ \\
\hline Private Sector Credit (\%GDP) & $7.1 \%$ & $>10 \%$ & $17.5 \%$ \\
\hline Savings (\%GDP) & $6.6 \%$ & $>10 \%$ & $13.6 \%$ \\
\hline NPV External Debt (\% Exports) & $305 \%$ & $<240 \%$ & $187 \%$ \\
\hline Reserves (months of imports) & 6.2 & $>5.0$ & 5.0 \\
\hline Private Investment (\%GDP) & $17 \%$ & $>19 \%$ & $22.4 \%$ \\
\hline Total Exports (\%GDP) & $12.1 \%$ & $>14 \%$ & $15.4 \%$ \\
\hline
\end{tabular}




\section{Endnotes}

Chap1

${ }^{1}$ Deepening the understanding of poverty, second report of the Uganda Participatory Poverty Assessment Process, 2003

\section{Chap 2}

${ }^{1}$ Major sources of information include: the 20003 National Household Survey, the Poverty Status Reports of 2001, 2002 and 2003, the second report of UPPAP in 2003, the Census, Integrity surveys, and other research, including publications by the Economic Policy Research Centre and by the International Food Policy Research Institute

${ }^{2}$ The Gini coefficient measures inequality and takes the values 0 if everyone has the same income and 1 if one household has all the income. Generally, Gini coefficients are lower for expenditures than for incomes. Gini coefficients in African economies are mostly quite high by international standards, and a Gini coefficient of .39 for expenditures would put Uganda in the relatively high-inequality group even among African economies.

${ }^{3}$ Simon Appleton, Poverty reduction during growth: the case of Uganda, 1992-2000, 2001, and S. Appleton and S. Sswanyana, Preliminary explanations for the worsening of poverty 1999-2003, Information paper for UBOS/MFPED, 2003. The sample for 1999/2000 and 2002/3 excludes Kitgum, Gulu, Pader, Bundibugyo and Kasese. Data by occupation are available only for the years shown.

${ }^{4}$ Source as for Table 2.1

5 See McGee, Rosemary. 2000. “Analysis of Participatory Poverty Assessment (PPA) and Household Survey Findings on Poverty Trends in Uganda." Institute of Development Studies, Sussex (UK) and Department for International Development, DFID (UK).

${ }^{6}$ UBOS, , Uganda National Household Survey 2002/3, Report on the socio-economic survey

${ }^{7}$ J. Okidi, Trends in Ugandan household assets during the 1990s, EPRC, draft,2004

${ }^{8}$ UBOS, Uganda National Household Survey 2002/3, Report on the socio-economic survey

${ }^{9}$ There is a difficulty in interpreting this as evidence of increasing inequality; it is also possible that these data simply re ect the fact that households which accumulate assets end up richer than others. To demonstrate increasing inequality, one would want to compare asset accumulation of households at various wealth levels at the beginning (rather than at the end) of the period. However, the magnitude of the shift suggests that there is a real increase in inequality.

${ }^{10}$ Appleton and Ssewanyanya op.cit.

${ }^{11}$ The rate and sectoral pattern of GDP growth is discussed in more detail in the next chapter.

${ }^{12}$ A possible explanation is that consumption in the 1997 survey was somewhat underestimated.

${ }^{13}$ Price calculations from Appleton and Ssewanyanya, op.cit.

${ }^{14}$ A recent study suggests that having a non-crop enterprise increases consumption by about $7 \%$,

${ }^{15} \mathrm{~K}$. Bird and A.

16

${ }^{17}$ K. Bird and , op.cit.

${ }^{18} \mathrm{~J}$. Okidi, op.cit.

${ }^{19}$ In some cases, such as travel to work and collection of water, urban households may face higher financial costs that are not fully re ected in the CPI

${ }^{20}$ D. Lawson, Gender Analysis of the Ugandan National Household Surveys (1992 - 2003), paper for the PEAP revision process

${ }^{21}$ Women have limited rights to consent on the disposal of certain land assets, a presumptive share of $25 \%$ of their deceased husbands' land, and usually no rights to a share of the household's assets in the event of divorce (though they retain land they own in their own right).

${ }^{22}$ UBOS, Uganda National Household Survey 2002/3, report on the Labour Force Survey

${ }^{23}$ Gender analysis of the Uganda National Household Surveys, 1992-2003, D. Lawson, October 2003

${ }^{24}$ Deepening the understanding of poverty, second participatory poverty assessment report, Uganda participatory poverty assessment process, MFPED, December 2002 
${ }^{25}$ It is not known whether this is a cause or effect of divorce.

${ }^{26}$ Lawson, op.cit

${ }^{27}$ S. Ssewanyana, J. Okidi, D. Angemi and V. Barungi, Understanding the determinants of income inequality in Uganda, EPRC background paper for the PEAP, draft, 2004

${ }^{28}$ P. Mijumbi and J. Okidi, Analysis of poor and vulnerable groups in Uganda, EPRC Occasional Paper no. 16, 2001, and K. Deininger and P. Mpuga, Child labour and schooling: how vulnerable are the orphans ? Evidence from Uganda, World bank mimeo., 2003

${ }^{29}$ See Mijumbi and Okidi, op.cit., and S. Appleton and J. Mackinnon, Poverty in Uganda: characteristics, causes and constraints, EPRC research bulletin 1996, for contrasting results.

${ }^{30}$ Mijumbi and Okidi, op.cit.

${ }^{31}$ S. Appleton and S. Ssewanyana, Information paper on changes in poverty in Uganda 1999/2000 - 2002/3, paper commissioned by MFPED

${ }^{32}$ S. Ssewanyana, J. Okidi, D. Angemi and V. Barungi, Understanding the determinants of income inequality in Uganda, background paper for PEAP, EPRC 2004. For other studies using the same data, see ....; for more evidence on the pattern of incomes, see F. Ellis and G. Bahiigwa, .... Data are sensitive to definitions used but the overall patterns are clear.

${ }^{33}$ Appleton and Ssewanyana, op.cit.

${ }^{34}$ Bennell et al.

${ }^{35}$ More discussion of employment and underemployment is provided in ch. 3.

${ }^{36}$ This definition re ects standard international nomenclature. However, there is a limited conceptual basis to the distinction.

${ }^{37}$ Labour Force Survey, UBOS

${ }^{38} 73 \%$ sell to local consumers or passers-by, $11 \%$ to local markets, and $13 \%$ to local traders (who may sell further afield) (UNHS 2003)

${ }^{39}$ The most in uential research study has been the India Poverty Project at the World Bank. Findings from the project are on the World Bank website: publications include G. Datt and M. Ravallion, "Why have some Indian states done better than others at reducing rural poverty ?" Economica vol. 65 no.257 pp.17-38 (1998) and M. Ravalion and G. Datt "How important to India's poor is the sectoral composition of economic growth ?" World Bank Economic Review vol. 10 pp.1-26 (1996)

${ }^{40}$ Bevan et al., op.cit. The benchmark per capita income level is $\$ 2800$ in purchasing power parity terms, which would be reached by Uganda after 20 years of growth at $4 \%$ per capita.

${ }^{41}$ In other words, incomes of all groups increase by the same proportion.

Costs of improved service delivery

Page 226

Para 1 sentence 2

'The largest cost items in this set of are curative health (especially AIDS drugs and the costs of delivering them), preventive health, agricultural advisory services, and secondary education..'

Inter-sectoral issues and local Government exibility

$2^{\text {nd }}$ para $2^{\text {nd }}$ sentence add HIV

'Examples include gender, HIV, vulnerable...'

${ }^{43}$ See Snyder,op.cit.

\section{Chap 3}

${ }^{1}$ Discussion Paper on Economic Growth, Investment and Export Promotion; Bevan, Okidi, Adam \& Muhumuza 2003

${ }^{2}$ These data use all household members of working age whereas the figures in Table 2.4 refer to household heads. Household heads are mostly male and therefore less likely than other household members to be employed in agriculture; hence the share in agriculture is higher in Table 2.4

${ }^{3}$ The role of environment in increasing growth and reducing poverty in Uganda; Technical Report Draft 1 , Yaron et al, October 2003

${ }^{4}$ The 2000/01 Demographic Health Survey by UBOS implies that on average Ugandan women give birth to almost two more children than they desire in their lifetime, owing to lack of access to family planning.

${ }^{5}$ Kasekende and Atingi-Ego, 1999 and Henstridge and Kasekende, 2002. 
${ }^{6}$ The overall fiscal deficit excluding grants is defined as domestic revenues (taxes and non tax revenues) minus total expenditure. The data pertains to Central Government revenues and expenditures only, including Central Government transfers to local authorities.

${ }^{7}$ Long Term Expenditure Framework, Macroeconomic Policy Department, Ministry of Finance, Planning and Economic Development, March 2004.

${ }^{8}$ Underlying in ation excludes food crop prices, which tend to be much more volatile than non food crop prices.

${ }^{10}$ Net Government borrowing is defined as the change in commercial bank loans to Government, including loans in the form of Government securities, minus the change in Government deposits.

${ }^{11}$ Modelling the Equilibrium Real Effective Exchange Rate of the Ugandan Shilling, Ronald MacDonald, March 2004

${ }^{12}$ External debt repayments include the repayment of IMF debt, which although not recorded in the Government budget must still be funded from resources in the BOU. Domestic debt repayments are excluded because domestic debt consists of short term Government securities and it should be possible to roll over these securities as they mature.

${ }^{13}$ World Bank Foreign Investment Advisory Service (FIAS) Study on Administrative Barriers to Investment in Uganda, June 2003

${ }^{14}$ Economic Growth in Uganda: A summary of the post-con ict experience and future prospects; D. Dunn, IMF 2002

15 Comparative advantage depends on the endowment of resources such as land, labour and capital. Competitive advantage also re ects actions induced by export strategy (private or public sector) that have created sector-specific knowledge or other sector-specific advantages over other competitors.

${ }^{16}$ According to the World Bank, unskilled workers in India and China earn \$40 a month, as compared to $\$ 57$ per month in Uganda

17 Although some specific commodities, such as coffee, are subject to a small producer levy to fund development activities in the sector

${ }^{18}$ Discussion Paper on Economic Growth, Investment and Export Promotion; Bevan, Okidi, Adam \& Muhumuza 2003

\section{Chap 4}

${ }^{1}$ National Household Survey 2003

${ }^{2}$ UBOS National Household Survey 2003, Report on the labour force survey.

${ }^{3}$ See the various studies conducted under IFPRI's SCRIP project and by EPRC for recent information on agriculture in Uganda.

${ }^{4}$ Harmsworth, J. (1991), "The impact of the tobacco industry on rural development and farming systems in Arua, Uganda" in Haswell, M. and D.Hunt, eds., Rural households in emerging societies: technology and change in sub-Saharan Africa, Berg, Oxford

${ }^{5}$ A. Madanda, A gender assessment of factors that affect household food security in Bunghoko county - Mbale district, Makerere University Women Studies Department MA thesis, cited in M. Snyder, Women in African economies: from burning sun to boardroom, Fountain Press 2000

${ }^{6}$ Udry, C. 1996. Gender, Agricultural Production, and the Theory of the Household. Journal of Political Economy 104: 1010-1046.

${ }^{7}$ Fan et al.. Public Expenditure, Growth and Poverty Reduction in Rural Uganda, Shenggen Fan, Xiaobo Zhang, and Neetha Rao , International Food Policy Research Institute, 2003

${ }^{8}$ Agricultural productivity constraints in Uganda: implications for investment, Rosetti Nabbumba8 and Godfrey Bahiigwa, IFPRI report, 2003

${ }^{9}$ SCRIP reports

${ }^{10}$ F.Elllis and G.Bahiigwa, 'Rural livelihoods and poverty reduction in Uganda', World Development 2003

${ }^{11}$ See G. Bahiigwa, F. Ellis, O-H.Fjeldstad, V.Iversen, Uganda rural taxation study, EPRC/ODG/CMI Institute, 2004 
${ }^{12}$ The role of environment in increasing growth and reducing poverty in Uganda, Gil Yaron and Yakobo Moyini with David Wasike, Maxwell Kabi and Mildred Barungi, report for DFID, October 2003. The estimate values soil nutrients at replacement cost rather than marginal impact on productivity; the effect on productivity is likely to be smaller than the replacement cost, but may well still be very significant. Oter forms of environmental degradation are small in value relative to these two.

13 The effects of soil nutrient depletion on soil fertility are not known; further research is being undertaken to estimate the size of this effect.

${ }^{14}$ UPPAP 2

${ }^{15}$ See various studies by Centre for Research and "Lessons from Uganda on strategies to fight poverty", J. Mackinnon and R. Reinikka, World Bank Policy Research Working Paper 2440, 1999

${ }^{16}$ Incidence and impact of land con ict in Uganda, Klaus Deininger1and Raffaella Castagnini,mimeo. World Bank, 2002

${ }^{17}$ See CBR and Mackinnon/Reinikka, op.cit.

${ }^{18}$ FIAS report

${ }^{19}$ See Klasen,op.cit.

${ }^{20}$ LSSP, Analysis of the Economic Rationale; 2002 pg. v

21

${ }^{22}$ UBOS survey data

${ }^{23}$ Information provided by Department of Fisheries Resources (DFR).

${ }^{24}$ See Budget Speech by Minister Gerald M. Ssendaula, June 2003.

${ }^{25}$ UPPAP 2

${ }^{26}$ NEMA, 2001. pg 41

${ }^{27}$ Wetlands Sector Strategic Plan, 2001.

${ }^{28}$ NEMA, 2001.

29

${ }^{30}$ Beintema, S. and C. Tizikara, Uganda: Agricultural science and technology indicators, ASTI Country Brief no.1, IFPRI/ISNAR/NARO,. October 2002

${ }^{31}$ Ssewanyana et al., op.cit. The returns are found in the range of 8-11\% in three different surveys, in 1992 , 1999 and 2003, and are statistically significant in each case. This would give absolute returns of the order of $\$ 150$ a year. The cost of connection per household is estimated at about $\$ 1,345$, of which a third is to be borne by the public sector, which implies a rate of return rather above $10 \%$; however, poverty benefits are experienced by non-connected households as well, so that the overall return is likely to be much higher. A caveat is that the presence of electricity may be determined by income levels as well as determining it.

32 The cost of a connection over household are about

${ }^{33}$ Collier and Pradhan ( ) report 39\% return to post-war road projects, but this would not necessarily apply to future roads.

Chap 5

${ }^{1}$ MFPED Discussion Paper 5, 2002; UPPAP reports, 2002; Ian Leggett, 2001; Lartin, M, 2002.

2 Uganda's Defence Review: Summary of Key Findings and Proposed Strategy for Defence Transformation. Ministry of Defence, Uganda, 2003.

3 The Amnesty Commission Report 2000-2003; Amnesty Commission, 2003. Implementation of the Amnesty Act 2000: Achievements, Challenges and Future Plans, Kampala.

${ }^{5}$ Ministry of Defence Policy Statement for 2003/04.

${ }^{6}$ This of course will need to be done in a way compatible with the mandate and procedures of UNHCR or other agencies working with refugees.

Chap 6

${ }^{12}$ See Terms of Reference of the CRC for details

${ }^{3}$ Insiders and outsiders: varying perceptions of democracy and governance in Uganda, Uganda round 2 
Afro barometer survey report, January 2003

${ }^{4}$ These challenges are brought out in the CSO PEAP Revision Steering Committee/Liaison Office (2003) In Search of Consensus on a New Development Path: A Synthesis of Civil Society Views into the 2003 PEAP Revision Process, CSO PEAP Revision Steering Committee/Liaison Office, Kampala

${ }^{5}$ Deepening the understanding of poverty, second UPPAP report

${ }^{6}$ Prisons Data and Criminal Justice Baseline Survey p. 71 Most prisons were built in 1930s - 1950s

${ }^{7}$ Criminal Justice Baseline Survey (May 2002)

${ }^{8}$ Data on crime can be collected both from household surveys and from administrative records. While the administrative records are more precise in the type of crime, they depend on victims' choice whether to report; hence a higher crime rate may re ect more crime or more reporting.

${ }^{9}$ Study on sexual offences by the Uganda Law Reform Commission, 2000, and Baseline Survey on fulltime street children, FOCA (1996)

${ }^{10}$ Save the Children, 'The Silent Majority: Child Poverty in Uganda' compiled by Sophie Witter, 2002

11 The JLOS institutions include; Ministry of Justice and Constitutional Affairs, Ministry of Internal Affairs, The Judiciary, The Uganda Prison Services, The Uganda Police Force, The Directorate of Public Prosecution, The Judicial Service Commission, The Uganda Law Reform Commission, Ministry of Gender Labor and Social Development, Probation Services, Ministry of Local Government, Local Council Courts

${ }^{12}$ Preliminary results from the police census indicate that the actual strength may be as low as 12,000 when deceased, abandoned and 'ghost' staff' are removed.

${ }^{13}$ Sudharshan Ramaswamy, 'Rule of Law and Access to Justice: Perspectives from UNDP Experience' Seminar on the Rule of Law, European Initiative for Democracy and Human Rights, July 2003, p.5

${ }^{14}$ Commercial Justice Baseline Survey, Law and Development Partnership \& Steadman Research Services, November 2001

${ }^{15}$ Second National Integrity Survey, K2-Consult for the Inspector-General of Government

${ }^{16}$ The sample over represents urban areas, so the figure may be overstated.

${ }^{17}$ LGFC, Report of regional workshops on best practices in mobilising and generating local revenues, February 2003

${ }^{18}$ G. Bahiigwa, F. Ellis, O-H.Fjeldstad, V.Iversen, Uganda rural taxation study, EPRC/ODG/CMI Institute, 2004

19 ibid.

${ }^{20}$ Price Waterhouse Coopers, Study of cost efficiency and effectiveness in human resources deployment in social sectors, for the Ministry of Public Service, 2003

${ }^{21}$ World Development Report 2004, table 1.2

${ }^{22}$ In all but one case, the wages alone were much higher than the pay received by economists in the public service. The commissions were ULRC, ULGFC, UAC, UEC, UHRC and UIC. 23

${ }^{24}$ Uganda currently has14,850 regular officers (though the actual strength may be closer to 12,000), 4,500 special Police constables and 6,560 local administration police in addition to LDUs who in some cases play policing roles. A population size of 25.8 million is assumed.

\section{Chap 7}

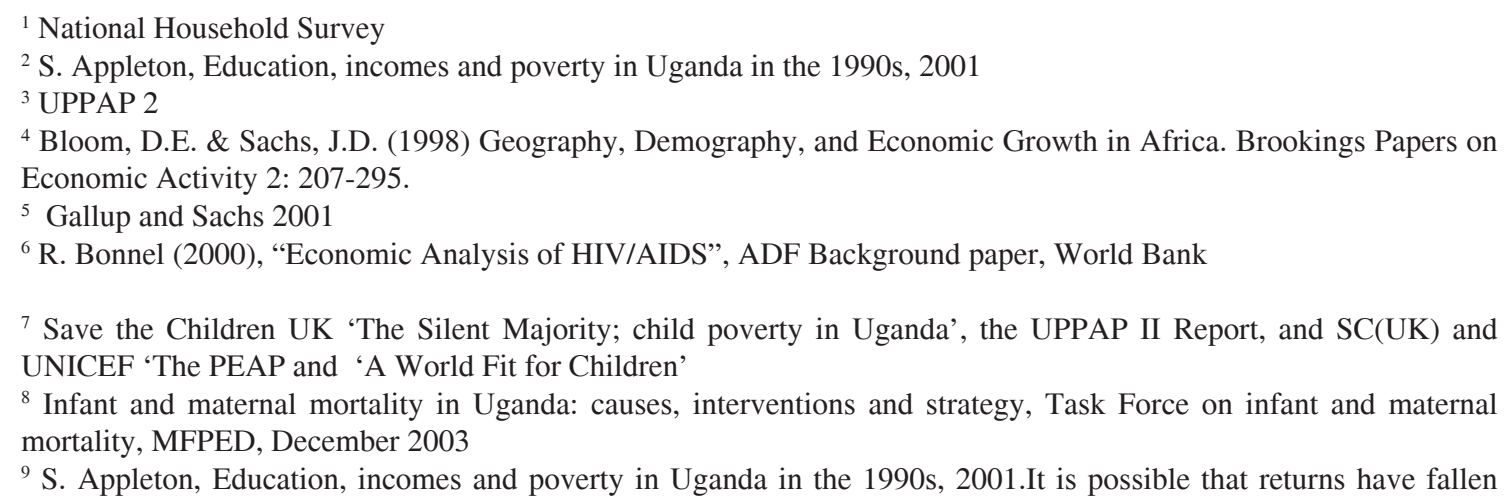


during the early 2000s in line with the general fall in incomes among poorer households.

${ }^{10}$ UDHS 2000

11 The net enrolment rate for primary education is the proportion of children of school going age who are actually attending school. The gross enrolment rate is the ratio between the number of children (of whatever age) in school and the number of children of the relevant age. GER is by definition higher than NER for the same level of education, and GER can be over $100 \%$ whereas NER cannot. In some cases an NER above $100 \%$ may indicate that some children from outside the region are attending school.

12 Socio-economic survey 2003, UBOS

${ }^{13}$ Exercise books, pens, uniforms, top-up for teachers' salaries, building funds, lunch fees, coaching fees, registration fees monthly test fees.

${ }^{14}$ See PEAP 2001-3 Volume 1 Table 6.1

15 TVET Draft Policy Document, p.7

16

${ }^{17}$ M.Mayanja, ...

18 Burden of Disease Study in Uganda (Ministry of Health 1995)

${ }^{19}$ S. Ssewanyana, Nabyonga O.J.,Kasirye I., and D.Lawson, Demand for health care services in Uganda: implications for poverty reduction, EPRC mimeo., January 2004.

${ }^{20}$ National Household Survey, 2003

${ }^{21}$ Including district lower level health units, district health management, district hospitals and Private not-for Profit hospitals and lower level units

${ }^{22}$ See K. Deininger and P. Mpuga, Has abolition of heath user fees improved the welfare of vulnerable groups ? Evidence from Uganda, World Bank mimeo., November 2003, and S. Ssewanyana, Nabyonga O.J.,Kasirye I., and D.Lawson, Demand for health care services in Uganda: implications for poverty reduction, EPRC mimeo., January 2004

${ }^{23}$ Ssewanyana et al.

${ }^{24}$ Ssewanyana et al.

${ }^{25}$ Water for production and water resource management are discussed in Chapter 4.

${ }^{26}$ International and local evidence suggest that information play a key complementary role.

27 UPPAP 2000

${ }^{28}$ UDHS

${ }^{29}$ Malmberg-Calvo,

${ }^{30}$ Data analysis UNHS 1999, Maxwell Stamp (2003)

${ }^{31}$ Labour inspections were considered above in Chapter 5.

${ }^{32}$ UBOS, UNHS 2002/03

${ }^{33}$ National Union of Disabled Persons in Uganda (2003): Participation of Organizations and Partners for Persons with Disabilities

${ }^{34}$ See J.Hammer, ....

${ }^{35}$ Blocks of input costs have been identified as due to the complex nature of health services and the fact that current services are so far from optimal quality levels it is not feasible to calculate output costs at this stage.

\section{Chap 7}

${ }^{1}$ The data in table 8.1 are final expenditures; i.e. they only include expenditures on goods and non factor services provided free or at subsidised cost by Government to the public. This is the definition of public expenditures in the national income accounts in which GDP is classified by expenditure. Public expenditure in the national income accounts differs from total Government expenditure in the fiscal accounts because the former omits transfer payments to the private sector and interest payments, which are not classified as final public expenditures. Also the national income accounts include some components of public investment which are in the Public Investment Plan but are not part of the Central Government budget because they are undertaken by parastatals or other public sector agencies. Consequently, total Government spending in the fiscal data is usually higher than final public expenditure in the national income accounts. In the national income accounts, public investment is defined as investment in fixed assets only, hence some expenditure items which are included in the Government's development budget are classified in the national income accounts as Government consumption.

2 The PAF share is calculated as the share of PAF in Government expenditure not including donor projects.

${ }^{3}$ Three major loans for road projects with a combined value of \$120 million were contracted in 1999/2000 and 2000/01 from the IDA, NDF and ADF. By the end of 2002/03, only $\$ 40$ million, or one third of the contracted loans, had actually been disbursed. 
${ }^{4}$ The rate of return is technically defined as that discount rate for which discounted costs equal discounted benefits. An alternative approach is to estimate the Net Present Value, the amount by which benefits exceed costs for a given discount rate.

${ }^{5}$ Sometimes these are adjusted for disability (DALYs) or quality (QALYs). These methodologies generally value children's lives more highly than adults, because they have longer to live; one caveat is that this does not take into account the harm done to the whole family when an adult dies.

${ }^{6}$ Public Expenditure, Growth and Poverty Reduction in Rural Uganda, Shenggen Fan, Xiaobo Zhang, and Neetha Rao, International Food Policy Research Institute, draft mimeo. There are some potential caveats: the statistical significance of the coefficients is tested only at the $10 \%$ level: the returns to future projects may be different from the average returns to existing projects (particularly for roads) they have to proxy research and extension by spending on extension alone, but nonetheless observe that Uganda's expenditure on agricultural research is exceptionally low even by regional and even more by international standards: and the benefits of health and education do not come only in the form of incomes.

${ }^{7}$ S.Sewanyana et al, op.cit., and D.Deininger and J. Okidi, op.cit.

${ }^{8}$ A complication is that delaying the rehabilitation of a road may allow further deterioration before the road is repaired.

${ }^{9}$ A more detailed explanation of how the ceilings are derived can be found in the LTEF.

${ }^{10}$ See Williamson, Tim and Canagarajah, Sudharshan (2003), "Is there a place for Virtual Poverty Funds in Pro-Poor Public Spending Reform? Lessons from Uganda's PAF” Development Policy Review Volume 21: 4 .

11 The donor funded project expenditure ceiling will be based on the projected disbursements rather than commitments. This arises out of the fact that, given the various procedures and conditions that trigger disbursements, commitments made between donors and Government do not necessarily result in disbursement, and hence disbursements are usually lower than commitments.

${ }^{12}$ Other agencies are not included in these figures. The data on the development budget re ect commitments included in the approved estimates; actual disbursements may be lower.

13 These aid projections do not include emergency humanitarian aid for refugees, internally displaced persons, etc.

\section{Chap 9}

${ }^{1}$ Uganda Info will be the system to support M\&E activities at the national level, while LOGICS will support the activities of local governments.

${ }^{2}$ See G. Bahiigwa, Uganda's Poverty Eradication Agenda: Measuring up to the Millennium Development Goals (MDGs), prepared for UNDP and MFPED, 2002, and Uganda's Progress in Attaining the PEAP Targets - in the Context of the Millennium Development Goals, MFPED background paper for the Consultative Group Meeting, May 2003: and Millennium Development Goals and corresponding PEAP targets at a glance, NGO Forum, information lea et, 2004

\section{Chap 10}

${ }^{1}$ Source: Deininger and Okidi op.cit.(2001), using the IHS and the NHS.

${ }^{2}$ Labour Force Survey, UBOS

${ }^{3}$ Analysis by EPRC in collaboration with the World Bank

${ }^{4}$ Analysis by EPRC in collaboration with the World Bank

${ }^{5}$ See Uganda: Administrative barriers to investment: update, Foreign Investment Advisory Service, World Bank 2003

${ }^{6}$ ibid. 